FHWA/IN/JTRP-2008/17

Final Report

TIRE SHRED BACKFILL IN MECHANICALLY STABILIZED EARTH WALL APPLICATIONS

\author{
Umashankar Balunaini \\ Sungmin Yoon \\ Monica Prezzi \\ Rodrigo Salgado
}

August 2009 
Final Report

FHWA/IN/JTRP- 2857

\title{
Tire Shred Backfill in Mechanically Stabilized Earth Wall Applications
}

\author{
By \\ Umashankar Balunaini \\ Graduate Research Assistant \\ Sungmin Yoon \\ Graduate Research Assistant \\ Monica Prezzi \\ Associate Professor \\ and \\ Rodrigo Salgado \\ Professor \\ School of Civil Engineering \\ Purdue University \\ Joint Transportation Research Program \\ Project No. C-36-50AA \\ File No. 6-19-26 \\ SPR-2857 \\ Prepared in Cooperation with the \\ Indiana Department of Transportation and \\ The U.S. Department of Transportation \\ Federal Highway Administration
}

The contents of this report reflect the views of the authors who are responsible for the facts and the accuracy of the data presented herein. The contents do not necessarily reflect the official views or policies of the Federal Highway Administration and the Indiana Department of Transportation. This report does not constitute a standard, specification or regulation.

Purdue University

West Lafayette, Indiana

August 2009 
TECHNICAL REPORT STANDARD TITLE PAGE

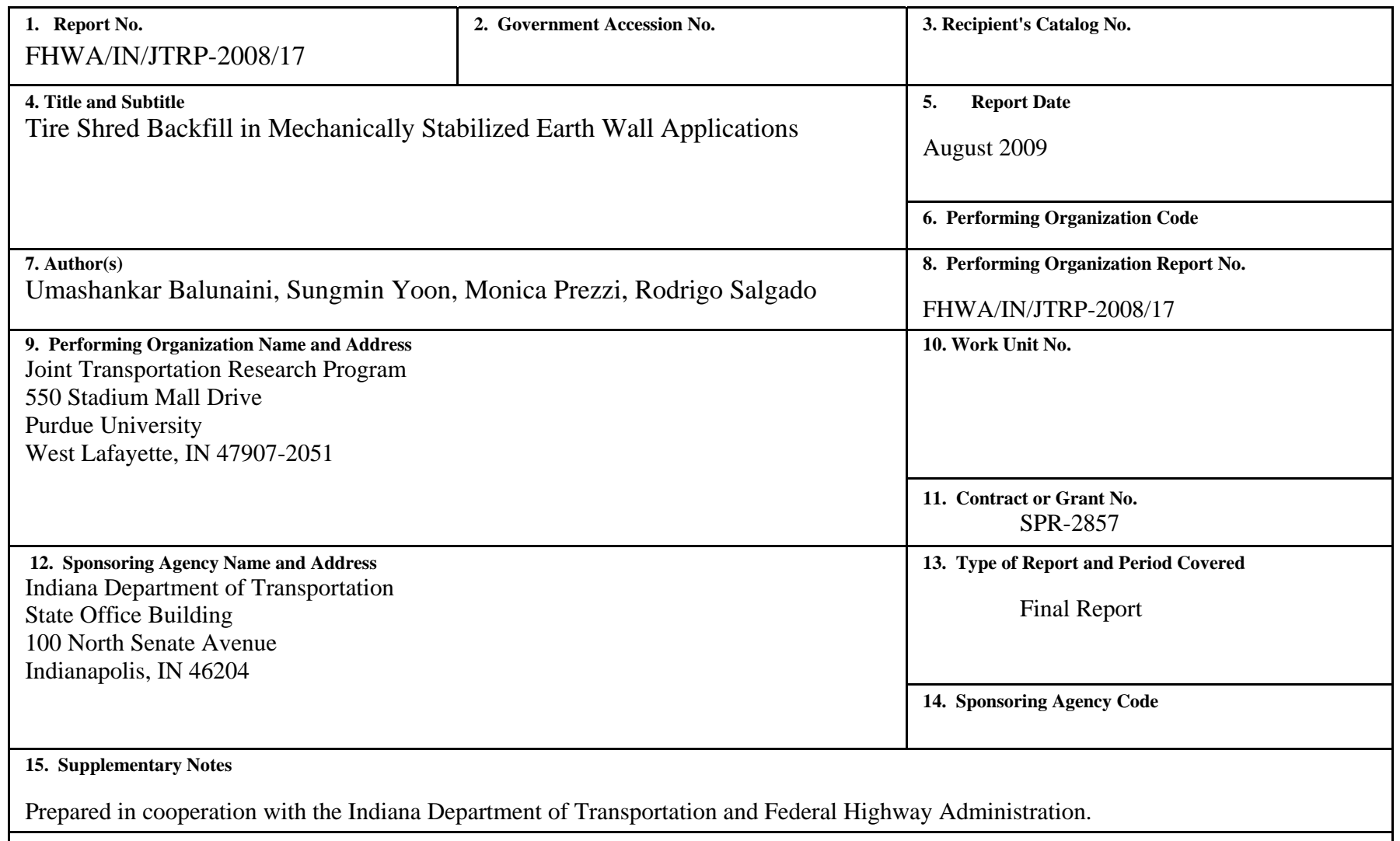

\section{Abstract}

Tire shred-soil mixture backfill for use in mechanically stabilized earth (MSE) walls has several advantages over traditional backfill materials: 1) good drainage, 2) high shear strength, 3) low compacted unit weight and 4) low lateral pressure exerted on retaining structures. This work presents the results of laboratory tests performed on tire shred-sand mixtures focusing on determining the properties required for their use as backfill in MSE wall applications. Three sizes of tire shreds are considered: tire chips with $9.5 \mathrm{~mm}$ in nominal size, and tire shreds with 50-to-100-mm and 100-to-200-mm in length. The optimal mix proportions of tire shred-sand mixtures for enhanced mechanical response of the composite material are provided. Segregation of the materials in the tire shred-sand mixtures was investigated for various mix proportions. The effects of tire shred size, and tire shred-sand mixing ratio on the interaction between geogrids/ ribbed-metal strips and the mixtures are evaluated based on a series of laboratory pullout tests. Results indicate that the optimal mix proportion of tire shreds and sand is 25/75 and 30/70 (tire shred/sand) by weight, equivalent to approximately 40/60 and 50/50 (tire shred/sand) by volume for tire shreds with 50-100 mm and 100-200mm in length, respectively. This optimum mix proportion also ensures negligible segregation of the components of the mixture in the composite material. For all three shredded tire sizes considered, the pullout capacity of a geogrid embedded in the tire shred-sand mixtures prepared at the optimum mixing ratio is larger than that obtained for pure tire shreds. The pullout capacity of geogrid placed in samples prepared at optimum tire shred-sand mixing ratio is found to be higher for tire chip-sand mixtures than for tire shred-sand mixtures. This is mainly due to the crossing of the geogrid by the tire chips, which generates passive resistance during pullout. The size of tire shred has a negligible effect on the pullout response of ribbed-strip embedded in mixtures. Large-scale direct tests evaluated the shear strength properties of samples prepared at optimum tire chip-sand and tire shred (50 to $100 \mathrm{~mm}$ in size)-sand mixing ratios.

\section{Key Words}

Tires; Backfill; Waste material; Compaction; Optimum mixing ratio; Pull-out resistance; Geogrid, Ribbed-metal strip, Shear strength.

\section{Distribution Statement}

No restrictions. This document is available to the public through the National Technical Information Service, Springfield, VA 22161
19. Security Classif. (of this report)

Unclassified

\author{
20. Security Classif. (of this page)
}

Unclassified

\begin{tabular}{|c|c}
\hline 21. No. of Pages & 22. Price \\
169 &
\end{tabular}




\section{TABLE OF CONTENTS}

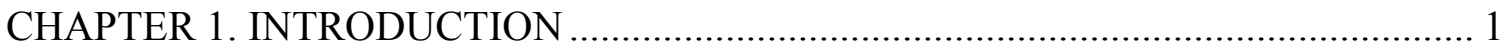

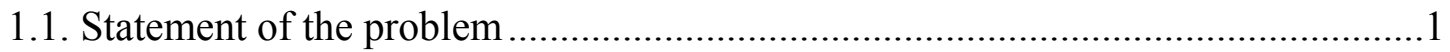

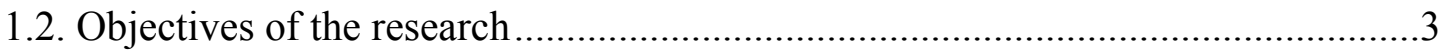

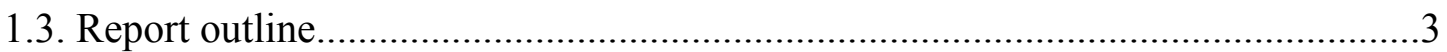

CHAPTER 2. ENGINEERING PROPERTIES OF TIRE SHREDS …..........................4

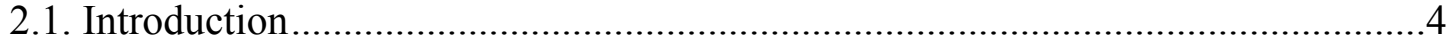

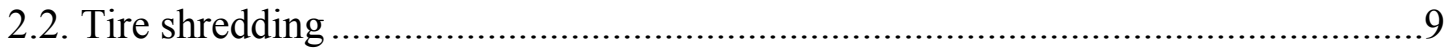

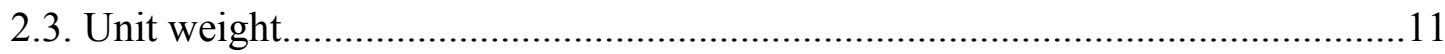

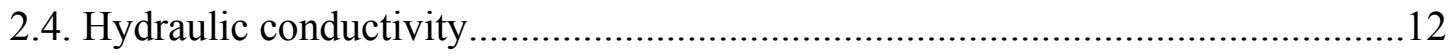

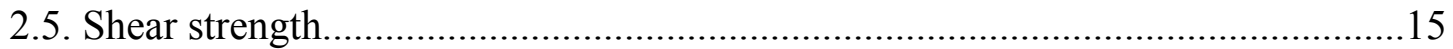

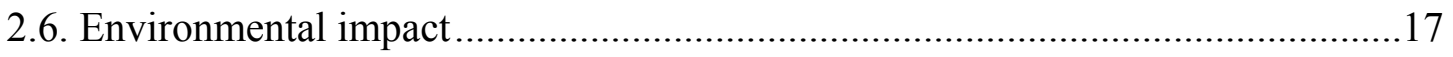

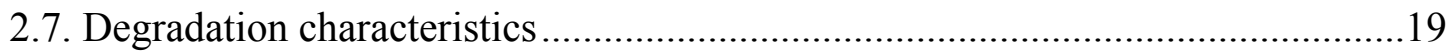

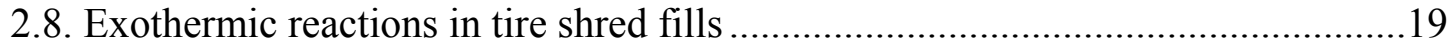

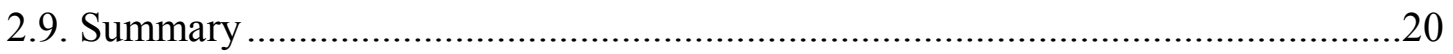

CHAPTER 3. OPTIMUM SIZE OF TIRE SHREDS AND TIRE SHRED-SAND

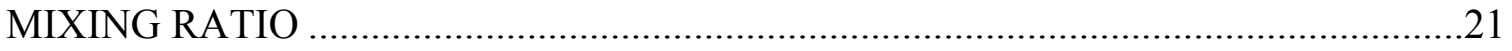

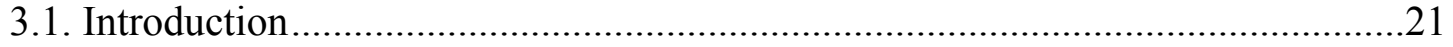

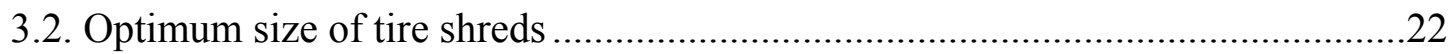

3.3. Overall void ratio in mixtures with particles of different sizes ..........................23

3.4. Optimum mixing ratio of compacted tire shred-sand mixtures ..........................25

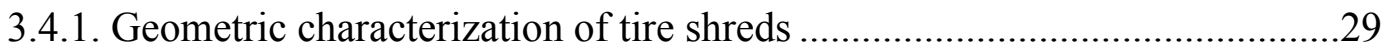

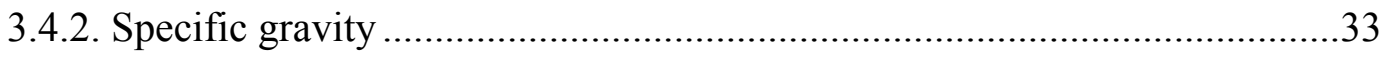

3.4.3. Optimum mixing ratio determination of shredded tires and sand mixture ...37

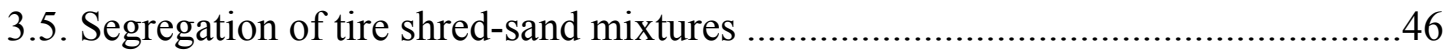

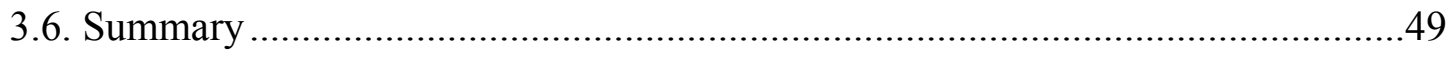

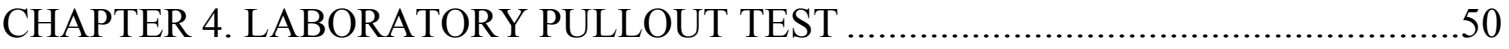

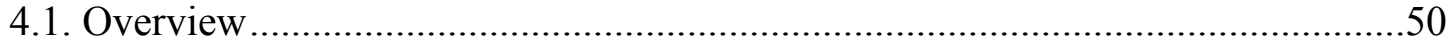

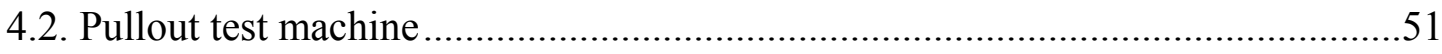

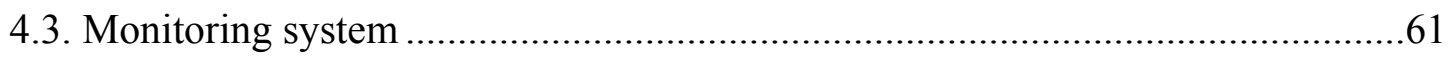

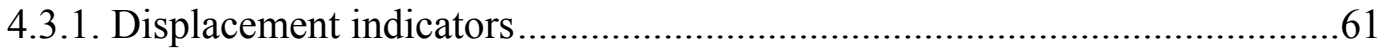


4.3.2. Load cell and pressure transducer.........................................................62

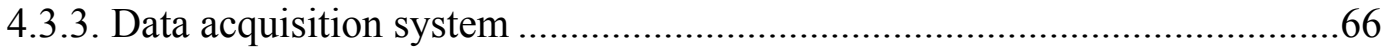

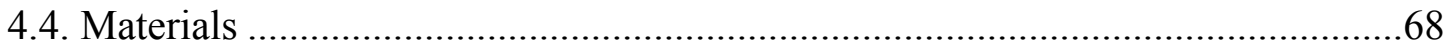

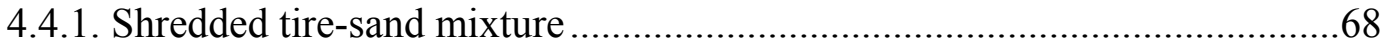

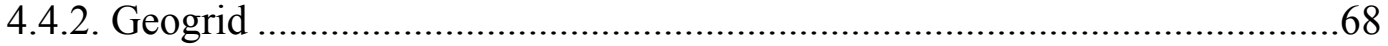

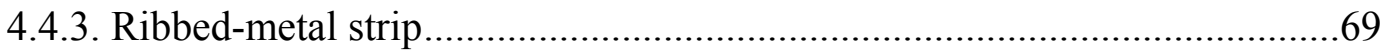

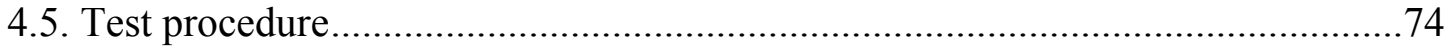

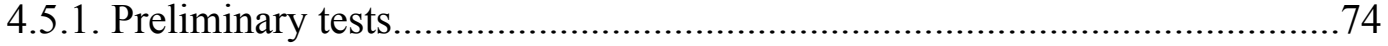

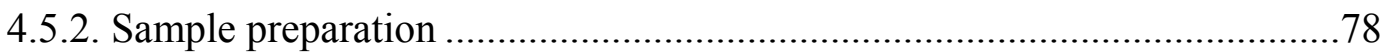

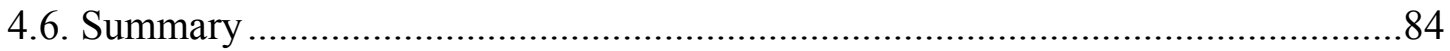

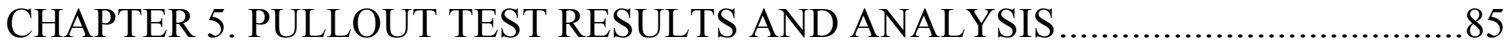

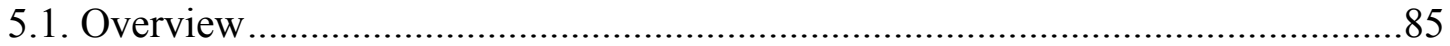

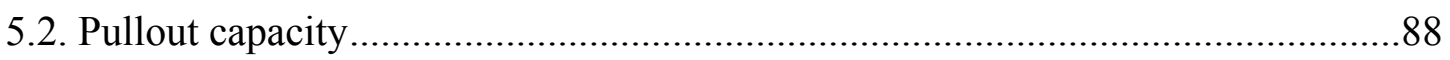

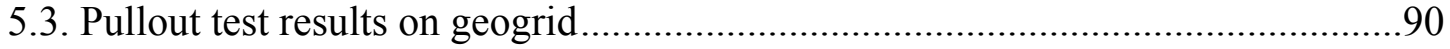

5.3.1. Effect of tire shred-sand mixing ratio ................................................... 90

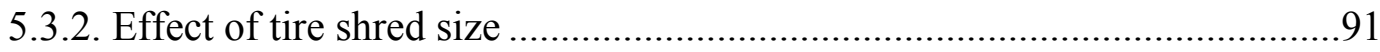

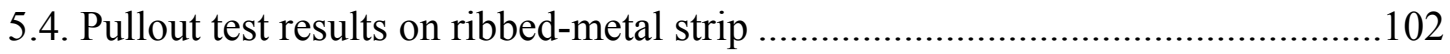

5.4.1. Effect of tire shred-sand mixing ratio ....................................................102

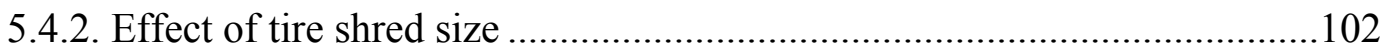

5.5. Progressive load transfer behavior for geogrids ..........................................112

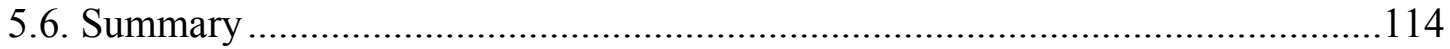

CHAPTER 6. LARGE-SCALE DIRECT SHEAR TESTING .....................................116

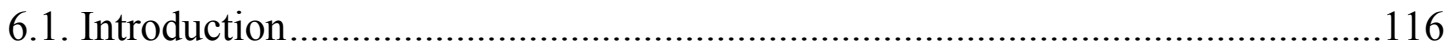

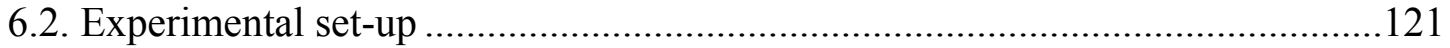

6.2.1. Main components of the large-scale ds box...........................................121

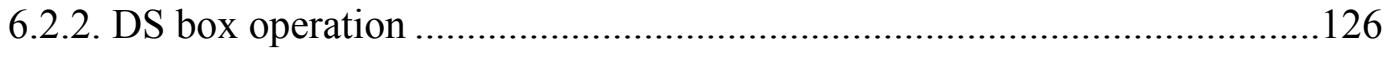

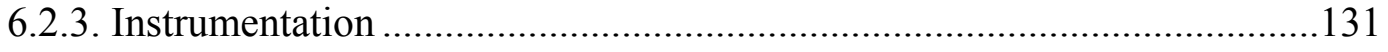

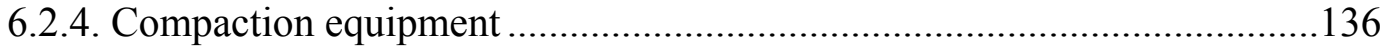

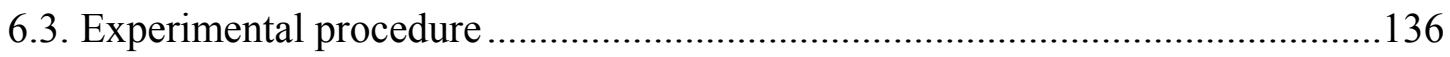

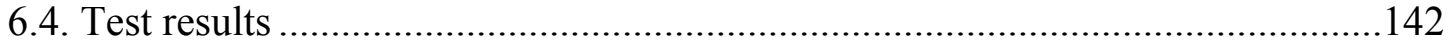

6.4.1. DS tests performed on $50-100 \mathrm{~mm}$ tire shred-sand mixtures.................143 
6.4.2. DS tests performed on $9.5 \mathrm{~mm}$ tire chip-sand mixtures. .144

6.4.3. Shear strength envelopes for $50-100 \mathrm{~mm}$ tire shred-sand and 9.5 mm tire chip-sand mixtures .......................................................... 145

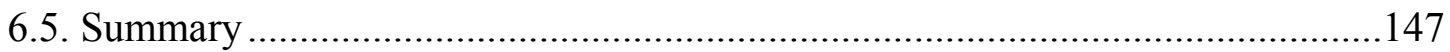

CHAPTER 7. CONCLUSIONS AND RECOMMENDATIONS ................................148

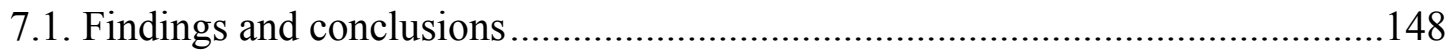

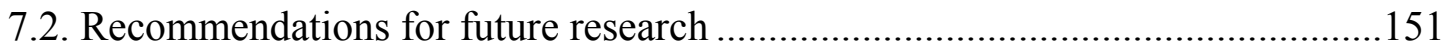

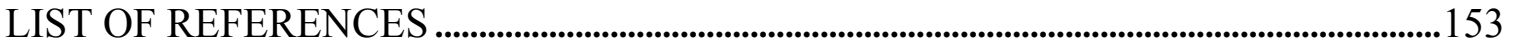




\section{LIST OF TABLES}

Table

Page

Table 2-1 Unit weight and cost of various lightweight fill materials. ..............................8

Table 2-2 Dry unit weight of different types of compacted tire shreds..........................13

Table 2-3 Hydraulic conductivity of different types of tire shreds and tire shred-sand mixtures

Table 2-4 Shear strength of different types of tire shreds.............................................. 16

Table 2-5 Chemical composition of scrap tires (Moo-Young et al. 2001) .......................18

Table 3-1 Prices of shredded rubber according to size (California Integrated Waste Management Board 2001).......................................................................22

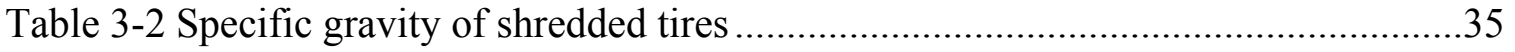

Table 3-3 Summary of compaction tests results.........................................................45

Table 4-1 Optimum mixing ratios of different sizes of shredded tires.

Table 4-2 Maximum dry unit weight of tire shred-sand mixtures with various tire shred sizes and prepared with different mixing ratios....................................... 70

Table 4-3 Properties of the geogrid studied (UX 1500 MSE, Tensar) ............................71

Table 4-4 Dry unit weight and degree of compaction of the samples tested at a

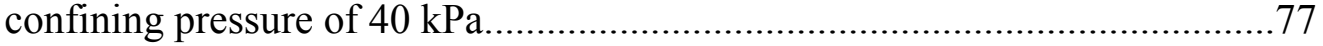

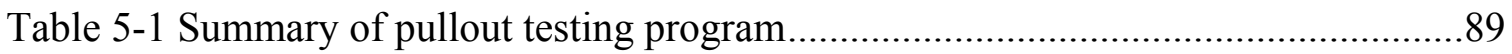

Table 5-2 Summary of geogrid pullout capacities at a confining pressure of $\quad 40 \mathrm{kPa} .101$

Table 5-3 Summary of pullout capacities of ribbed-metal strip at a confining pressure of $40 \mathrm{kPa}$.

Table 6-1 Details of TX equipment and materials used in previous studies

Table 6-2 Main Components of the DS machine......

Table 6-3 Optimum mixing ratios and maximum dry densities of the tire shred-sand mixtures used in DS tests.....

Table 6-4 Overview of test cases considered for DS tests.

Table 6-5 c- shear strength fitting parameters for the range of confining stresses considered 


\section{LIST OF FIGURES}

Figure 2-1 Generation and recycling of scrap tires in the US (Rubber Manufacture Association 2006).

Figure 2-2 Consumption of scrap tires for various markets in the US in 2005 (Rubber Manufacture Association 2006) .7

Figure 2-3 Main shredding operation

Figure 3-1 Schematic diagram illustrating minimum void ratio arrangements of binary packing of particles (after Lade et al. 1998). .24

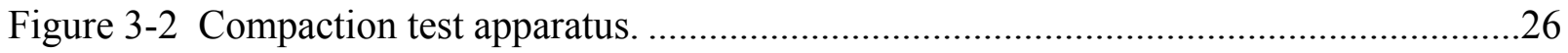

Figure 3-3 Typical pieces of shredded tires................................................................28

Figure 3-4 Geometry of tire shred (after Drescher et al. 1999) ...........................................30

Figure 3-5 Geometry of tire shreds (50-100 $\mathrm{mm}$ in length) ..............................................

Figure 3-6 Geometry of tire shreds (100-200 mm in length) ..........................................32

Figure 3-7 Apparatus used for determination of the specific gravity of tire shreds...............36

Figure 3-8 Dry unit weight of shredded tires and Ottawa sand mixtures with different shredded tire contents.

Figure 3-9 Total void ratios of compacted shredded tire-sand mixtures as a function of the shredded tire content by weight.

Figure 3-10 Relationship between weight ratios and volume ratios of shredded tires present in the mixtures.

Figure 3-11 Segregation of shredded tire-sand mixtures .48

Figure 4-1 Reinforcement types used in this study: geogrid and ribbed-metal strip ...............51

Figure 4-2 Pullout testing machine. .54

Figure 4-3 Schematic diagram of the cross section of the pullout box. .55

Figure 4-4 Schematic of the geogrid pullout clamping detail............................................56

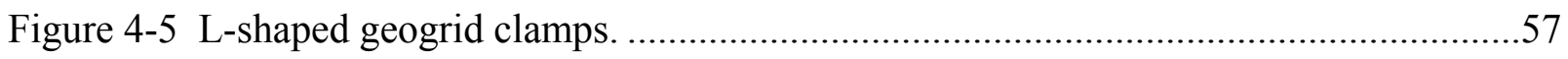

Figure 4-6 Schematic layout showing the geogrid placed in tire shred-sand mixture chamber.. .58

Figure 4-7 Schematic diagram of the cross section of the pullout box. 59 
Figure 4-8 Schematic layout showing the metal strip placed in tire shred-sand mixture chamber. .60

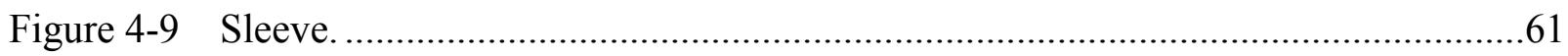

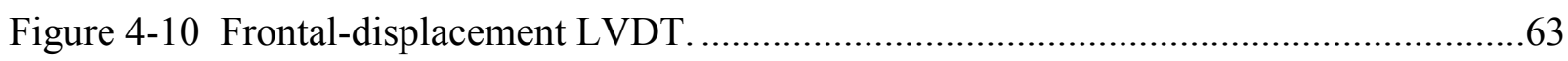

Figure 4-11 Nodal-displacement monitoring system........................................................64

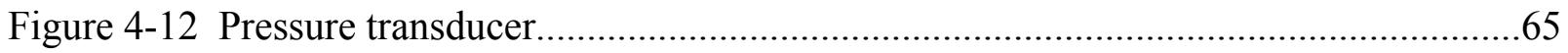

Figure 4-13 Load cell connected between the clamping system and transversal bar (top

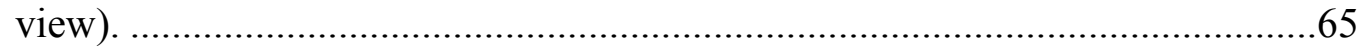

Figure 4-14 Schematic diagram of the data acquisition system. ......................................67

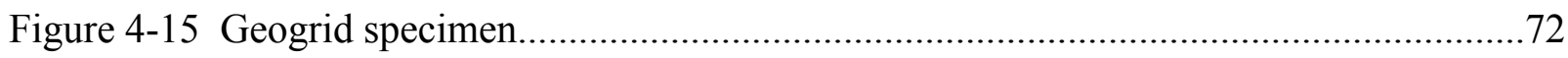

Figure 4-16 Cross-section of a ribbed-metal strip specimen .........................................73

Figure 4-17 Filter, regulator and lubricator mounted on the wall.......................................76

Figure 4-18 An impact piston-type compactor bolted to a steel plate (Compactor Model: 50-2LS-EM, manufactured by VIBCO) ...........................................76

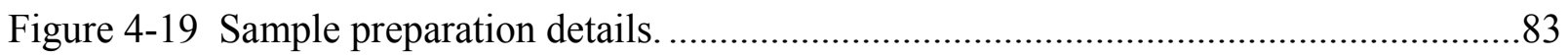

Figure 5-1 Mechanisms involved in geogrid pullout resistance ........................................87

Figure 5-2 Frictional and passive resistances developed along the length of ribbed-

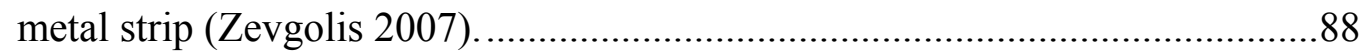

Figure 5-3 Pullout load versus frontal displacement for samples prepared with various mixing ratios by weight of tire chips $(9.5 \mathrm{~mm}$ nominal size) and sand and subjected to a confining pressure of $40 \mathrm{kPa}$. . .93

Figure 5-4 Pullout load versus frontal displacement for samples prepared with various mixing ratios by weight of tire shreds (50 to $100 \mathrm{~mm}$ in length) and sand and subjected to a confining pressure of $40 \mathrm{kPa}$.

Figure 5-5 Pullout load versus frontal displacement for samples prepared with various mixing ratios by weight of tire shreds (100 to $200 \mathrm{~mm}$ in length) and sand and subjected to a confining pressure of $40 \mathrm{kPa}$. . .95

Figure 5-6 Pullout capacity versus tire shred-sand mixing ratio for various sizes of shredded tires and subjected to a confining pressure of $40 \mathrm{kPa}$ .96 
Figure 5-7 Pullout load versus frontal displacement for various tire shred sizes at a tire shred-sand mixing ratio of $12 \%$ by weight and subjected to a confining pressure of $40 \mathrm{kPa}$.

Figure 5-8 Pullout load versus frontal displacement for various tire shred sizes at a tire shred-sand mixing ratio of $25 \%$ by weight and subjected to a confining pressure of $40 \mathrm{kPa}$.

Figure 5-9 Pullout load versus frontal displacement for various tire shred sizes at a tire shred-sand mixing ratio of $100 \%$ by weight and subjected to a confining pressure of $40 \mathrm{kPa}$.

Figure 5-10 Pullout capacity versus average size of shredded tire for various tire shred-sand mixing ratios by weight and subjected to a confining pressure of $40 \mathrm{kPa}$.

Figure 5-11 Pullout load versus frontal displacement for samples prepared with various mixing ratios by weight of tire chips $(9.5 \mathrm{~mm}$ nominal size) and sand and subjected to a confining pressure of $40 \mathrm{kPa}$. 103

Figure 5-12 Pullout load versus frontal displacement for samples prepared with various mixing ratios by weight of tire shreds (50 to $100 \mathrm{~mm}$ in length) and sand and subjected to a confining pressure of $40 \mathrm{kPa}$ 104

Figure 5-13 Pullout load versus frontal displacement for samples prepared with various mixing ratios by weight of tire shreds (100 to $200 \mathrm{~mm}$ in length) and sand and subjected to a confining pressure of $40 \mathrm{kPa}$. 105

Figure 5-14 Pullout capacity versus tire shred-sand mixing ratio for various sizes of shredded tires and subjected to a confining pressure of $40 \mathrm{kPa}$. 106

Figure 5-15 Pullout load versus frontal displacement for various tire shred sizes at a tire shred-sand mixing ratio of $12 \%$ by weight and subjected to a confining pressure of $40 \mathrm{kPa}$.

Figure 5-16 Pullout load versus frontal displacement for various tire shred sizes at a tire shred-sand mixing ratio of $25 \%$ by weight and subjected to a confining pressure of $40 \mathrm{kPa}$. 
Figure 5-17 Pullout load versus frontal displacement for various tire shred sizes at a tire shred-sand mixing ratio of $100 \%$ by weight and subjected to a confining pressure of $40 \mathrm{kPa}$.

Figure 5-18 Pullout capacity versus average size of shredded tire for various tire shredsand mixing ratios by weight.

Figure 5-19 Nodal displacement versus frontal displacement (Ottawa sand).

Figure 6-1 Schematic of a typical DS apparatus.

Figure 6-2 Schematic of large-scale DS box. 120

Figure 6-3 Isometric view of the DS box. 124

Figure 6-4 Front view of the DS box.

Figure 6-5 Components of control panel.

Figure 6-6 The lateral speed detector programmed to show the lateral speed of the lower box in $\mathrm{mm} / \mathrm{minute}$.

Figure 6-7 The arrow direction imprinted on the high-torque gear box indicating the shearing direction of the lower box.

Figure 6-8 Setting the desired pressure in the hydraulic system switch located in the control panel.

Figure 6-9 Load cell in position. 132

Figure 6-10 Lateral LVDT in position. 133

Figure 6-11 Vertical LVDT in position. 134

Figure 6-12 A thin smooth sheet attached to the side walls of the DS box.

Figure 6-13 Compaction of a layer of tire shred-sand mixture

Figure 6-14 Placement of the cover plate on top of the sample.

Figure 6-15 Shear stress - lateral displacement response for $50-100 \mathrm{~mm}$ tire shredsand mixtures prepared at a tire shred-sand mixing ratio of $25 \%$ by weight .

Figure 6-16 Shear stress - lateral displacement response for $9.5 \mathrm{~mm}$ tire chip-sand mixtures prepared at a tire shred-sand mixing ratio of $25 \%$ by weight.

Figure 6-17 Shear strength envelopes for tire shred-sand and tire chip-sand mixtures prepared at a tire shred-sand mixing ratio of $25 \%$ by weight. 


\section{ACKNOWLEDGEMENTS}

This research was funded with the support of the Indiana Department of Transportation through the Joint Transportation Research Program at Purdue University. The authors would like to thank the agency for support. Thanks are due to Nayyar Zia for his valuable suggestions during this work. The authors are thankful as well for the support of the

Study Advisory Committee throughout the duration of the project. 


\section{CHAPTER 1. INTRODUCTION}

\subsection{Statement of the Problem}

According to Dickson et al. (2001), there are more than 500 million tires (5.5 million metric tons) stockpiled across the United States, and 270 million (3 million metric tons) more are generated each year. About $30 \%$ of these tires are disposed in landfills, and thousands of tires are left in empty yards and even dumped illegally. In the state of Indiana, approximately 5 million waste tires $(56,000$ metric tons) are generated each year, and there are 40 stockpiles containing millions of tires in different counties (Kaya 1992). Similar disposal problems also exist worldwide. For example, in England and Wales, there are about 38 stockpiles with nearly 14 million tires $(0.16$ million metric tons) stored in them (Hird et al. 2002). Therefore, it is essential to find beneficial ways of recycling and/or reusing tires.

In civil engineering applications, tires are often used after they have been shredded to small pieces. Tire shreds have various shapes and sizes, typically varying between 50 and $300 \mathrm{~mm}$ (ASTM D 6270-98). The steel belting is sometimes removed during processing of the tire shreds. The market for use of scrap tires in civil engineering applications increased steadily in the last decade. Approximately 12 million scrap tires (0.13 million metric tons) were used in civil engineering applications in 1995, and 15 million (0.17 million metric tons), in 1996. These applications include 
leachate collection systems, landfill cover, artificial reefs, clean fill for road embankments, roadbed support, and similar projects (Liu et al. 2000).

Tire shreds have been used as a lightweight fill material in many embankments and retaining structures in various states of the US, including Colorado, Indiana, Maine, Minnesota, Oregon, Vermont, Washington and Wisconsin, and outside the USA (Bosscher et al. 1992; Humphrey 1996; Humphrey et al. 2000; Dickson et al. 2001; Moo-Young et al. 2001; Khan and Shalaby 2002; Zornberg et al. 2004). Seven states (North Carolina, Oregon, Minnesota, Washington, Colorado, Indiana, and New York) have provisions for the use of tire shreds (Moo-Young et al. 2001). Although recent studies show that tire shred-soil mixtures have lower compressibility and higher shear strength and thus perform better than only tire shreds, limited field studies of structures using tire shred-soil mixture as fill material were reported in literature.

The engineering behavior of the tire shred-soil mixture depends on both the tire shred size and the tire shred-sand mixing ratio. The optimum mixing ratio of tire shreds and sand should be determined based on the tire shred size. However, there are no guidelines available to determine the mixing ratio based on the specific characteristics of tire shreds.

The main goal of this research is to evaluate the mechanical behavior of tire shred-sand mixtures for use as fill materials in embankment construction or backfill materials in MSE construction. In this report, we present the results of laboratory tests (compaction tests, pullout tests and large-scale direct shear tests) performed on several different tire shred-sand mixtures tested under various test conditions. In addition, we 
present the results of field tests performed to assess the performance of local projects constructed using different tire shred-sand mixtures.

\subsection{Objectives of the Research}

The main objectives of this research are:

1. Perform compaction tests and develop guidelines to determine the optimum tire shred-sand mixing ratio.

2. Evaluate the mechanical properties of tire shred and tire shreds-sand mixtures (different tire shred sizes and tire shred-sand mixing ratios were considered).

3. Assess the interaction of geogrid and ribbed-metal strip embedded in tire shredsand mixtures with different tire shred sizes and tire shred-sand mixing ratios.

4. Assess the shear strength properties of tire shred-sand mixtures.

\subsection{Report Outline}

This report consists of eight chapters:

Chapter 1: Introduction.

Chapter 2: Engineering properties of tire shreds and tire shred-sand mixtures.

Chapter 3: Optimum tire shred-sand mixing ratio based on laboratory test results.

Chapter 4: Laboratory pullout test equipment and procedure.

Chapter 5: Results of laboratory pullout tests.

Chapter 6: Large-scale direct shear testing.

Chapter 7: Conclusions and recommendations. 


\section{CHAPTER 2. ENGINEERING PROPERTIES OF TIRE SHREDS}

\subsection{Introduction}

The generation and recycling of scrap tires has increased over the years in the US. Figure 2-1 shows the trends in generation and recycling of scrap tires from 1990 to 2005. In 2005 , more than $87 \%$ of scrap tires produced in the US was recycled (Rubber Manufacturers Association 2006). Figure 2-2 shows the percentages of scrap tires recycled in various applications in 2005. Civil engineering applications form one of the biggest markets for the recycling of scrap tires. One of the most important characteristics of tire shreds is that they are a lightweight material. When roads are constructed across weak and compressible soils, stability and settlement considerations are critical. Various lightweight materials have been used in the construction of fills in order to reduce the weight of highway structures over these soils. Table 2-1 shows the unit weight and approximate cost of tire shreds with the corresponding values of other widely used lightweight materials (Holtz 1989; Elias et al. 1998; ASTM D 6270-98). The cost of tire shreds varies from $\$ 5$ to $\$ 50$ per cubic meter ( 1 cubic meter is approximately 0.45 ton), depending on the quality of the tire shreds (personal communication with tire shredding companies in the State of Indiana: C.C.E. Inc., Elk Distributing Inc., and Tire Recyclers of America, LLC 2002). Tire shreds are relatively inexpensive when compared with the cost of other lightweight fill materials. One advantage of using tire shreds either as a 
lightweight fill material in embankments or as retaining wall backfills is that tire shreds are not biodegradable and thus are more durable than conventional lightweight fill materials. Since tire shreds are lightweight, smaller horizontal stresses are induced behind a retaining wall constructed with a mixture of soil and tire shreds as the backfill material, compared with a retaining wall having only soil as the backfill material. Also, tire shredsand mixtures have relatively high shear strength. Due to these properties, the width of a retaining wall can be reduced and savings obtained. In addition, tire shreds are freedraining materials, and thus do not contribute to excessive pore pressure generation that can cause stability problems during loading of the backfill material. Based on the results of a full-scale field test, Humphrey and Eaton (1993) indicated that the use of tire shreds could also reduce the depth of frost penetration and be a cost effective solution when an insulation layer is necessary for a given application. However, there are some concerns regarding the possibility of internal combustion of fills constructed with tire shreds exclusively, as observed in Washington and Colorado (Humphrey 1996), and of groundwater contamination. 


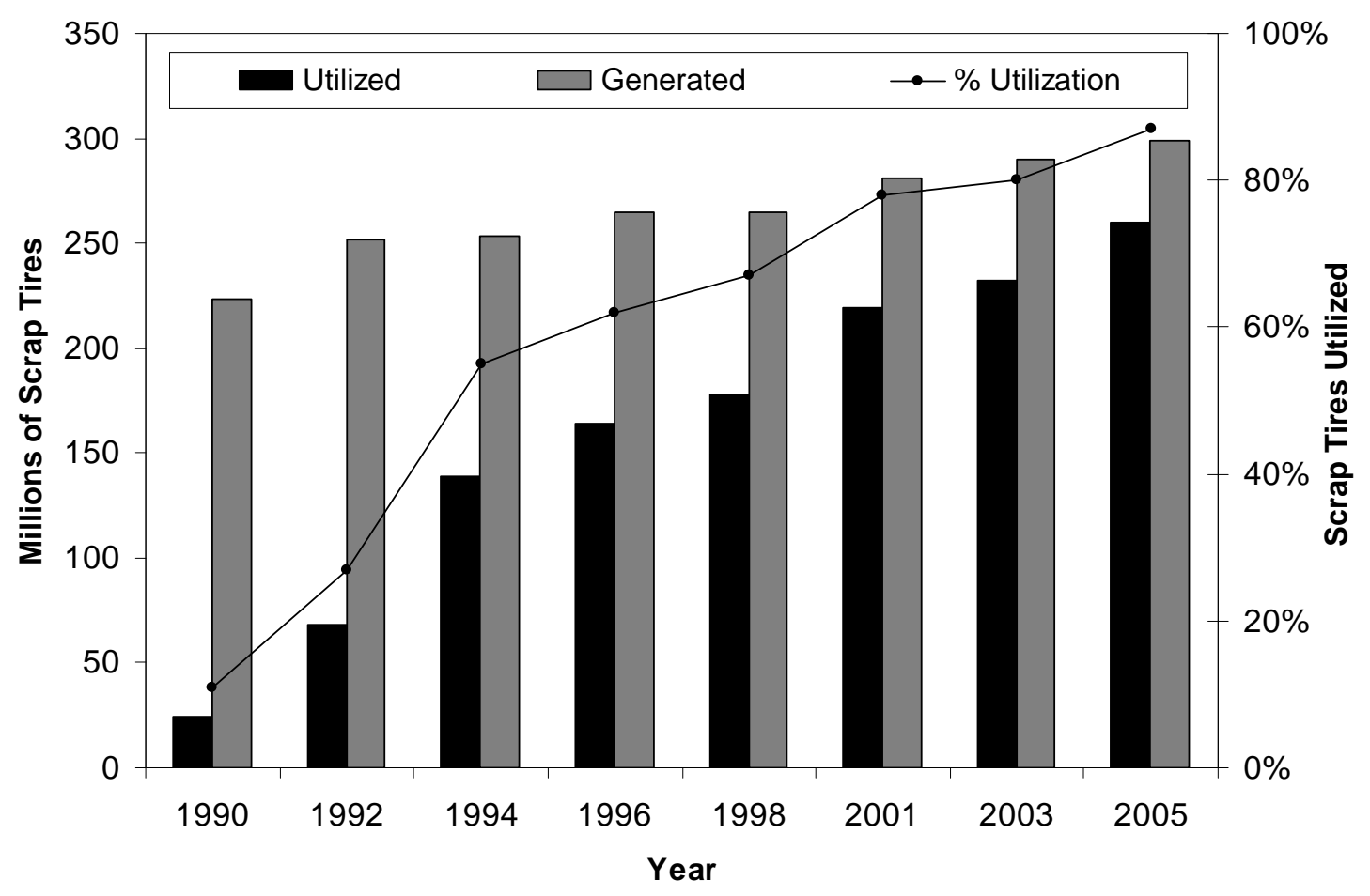

Figure 2-1 Generation and recycling of scrap tires in the US (Rubber Manufacture Association 2006). 


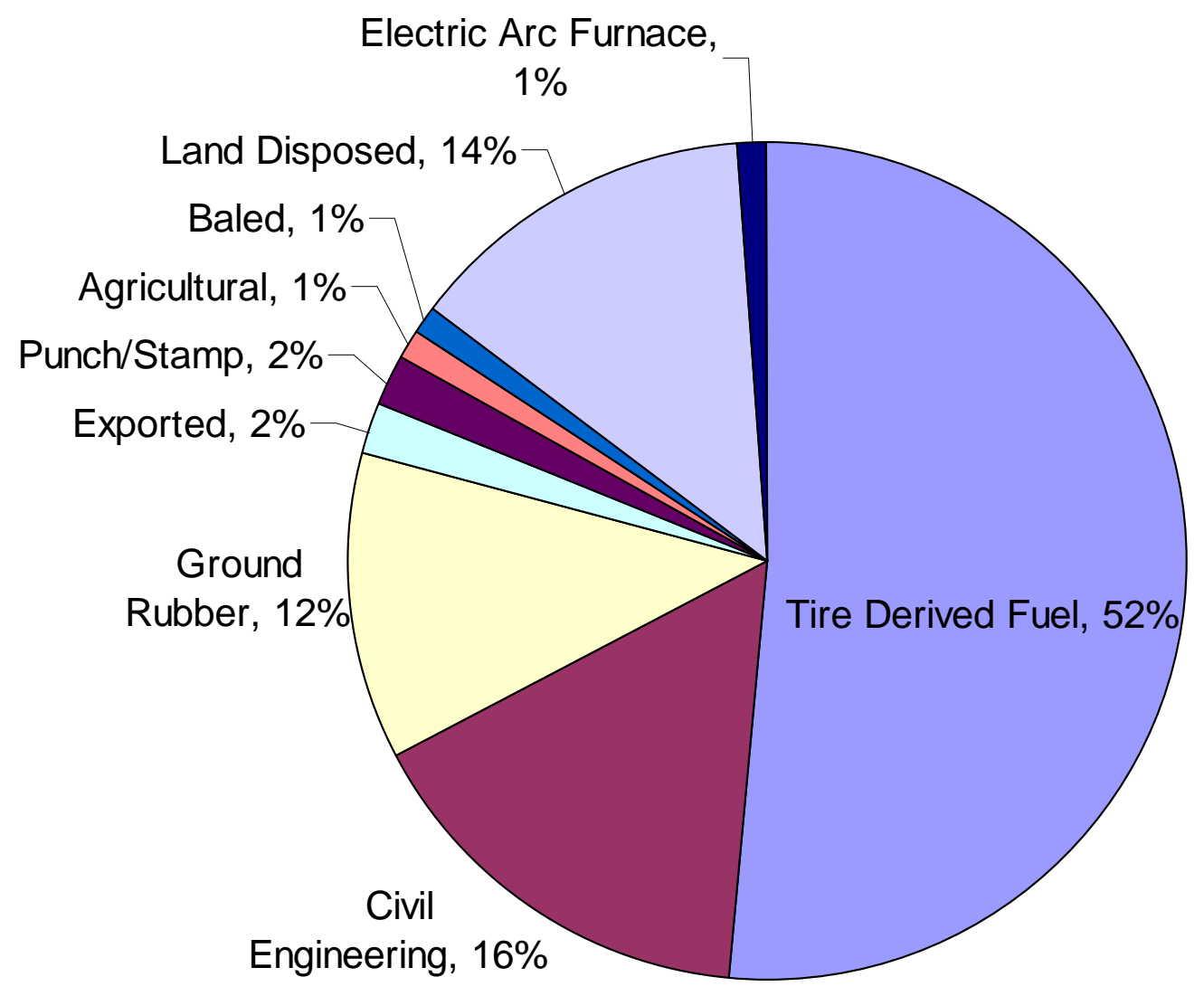

Figure 2-2 Consumption of scrap tires for various markets in the US in 2005 (Rubber Manufacture Association 2006). 
Table 2-1 Unit weight and cost of various lightweight fill materials.

\begin{tabular}{ccc}
\hline Lightweight Material & Unit Weight $\left(\mathrm{kN} / \mathrm{m}^{3}\right)$ & Approximate Cost $\left(\$ / \mathrm{m}^{3}\right)$ \\
\hline Shredded Tires & $5.5-6.4$ & $20-30$ \\
Geofoam (EPS) & $0.2-1$ & $35-65$ \\
Wood Fiber / Sawdust & $8-10$ & $12-20$ \\
Expanded Shale and Clay & $3-10$ & $40-55$ \\
Fly Ash & $10-14$ & $15-21$ \\
\hline
\end{tabular}




\subsection{Tire Shredding}

In civil engineering applications, tires can either be used as whole tires or in shredded form. Shredded tires offer several advantages in comparison with whole tires (e.g. lower compressibility and ease of handling). The steps involved in a typical shredding process are as follows (Moo-Young et al. 2001):

1. Primary shredding: whole or parts of tires from cars, trucks and off-road vehicles are inspected and cleaned to minimize mud, rocks and oils. They are then transported to the shredder using a conveyor as shown in Figure 2-3a. The tires are then shredded to a size that is acceptable for the main shredder.

2. Main shredding: the tires are torn apart between tooth rotor and stator tools as shown in Figure 2-3b. The shredding blades should be maintained in a good working condition by welding and grinding operations. Blunt blades may produce tire shreds with a larger aspect ratio (length-to-width ratio). At the end of the main shredding process, most steel wires present in the tire shreds are removed.

3. Vibratory screening: after completion of the main shredding process, the shredded tires are conveyed to a vibrating sieve (Figure 2-3c). The oversized tire shreds are conveyed back to the shredder. If additional grinding is required to produce finer shreds, the shredded tires can be conveyed to a special shredding equipment. 


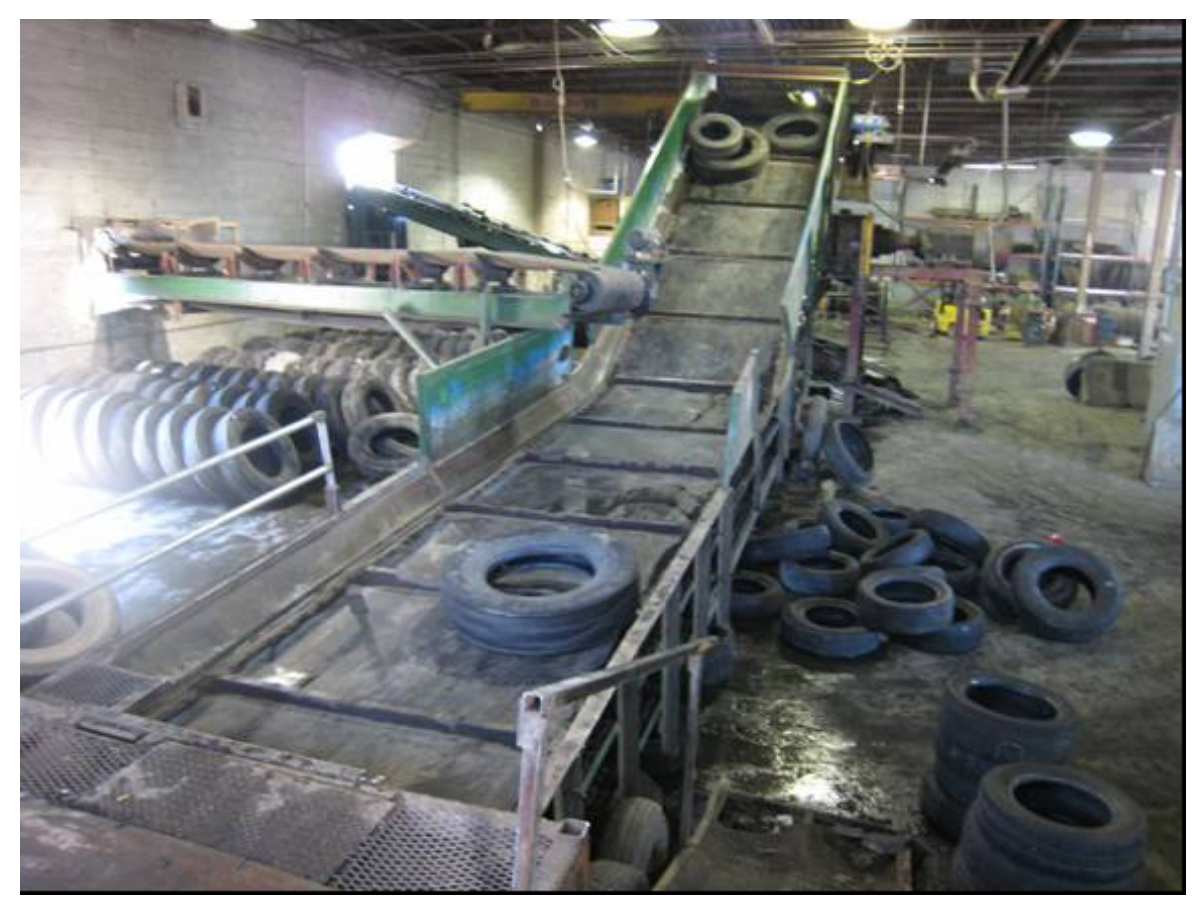

(a)

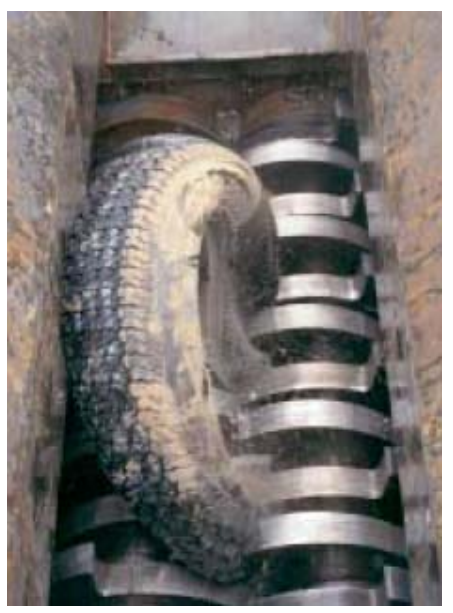

(b)

Figure 2-3 Main Shredding Operation: (a) Conveyor used to transport tires to shredder (Courtesy of Elk Distributing, Inc., Elkhart, IN), (b) Tooth rotor and stator tools, (c) Tire shredding process (Shred-tech $<$ www.shred-tech.com $>2006)$. 


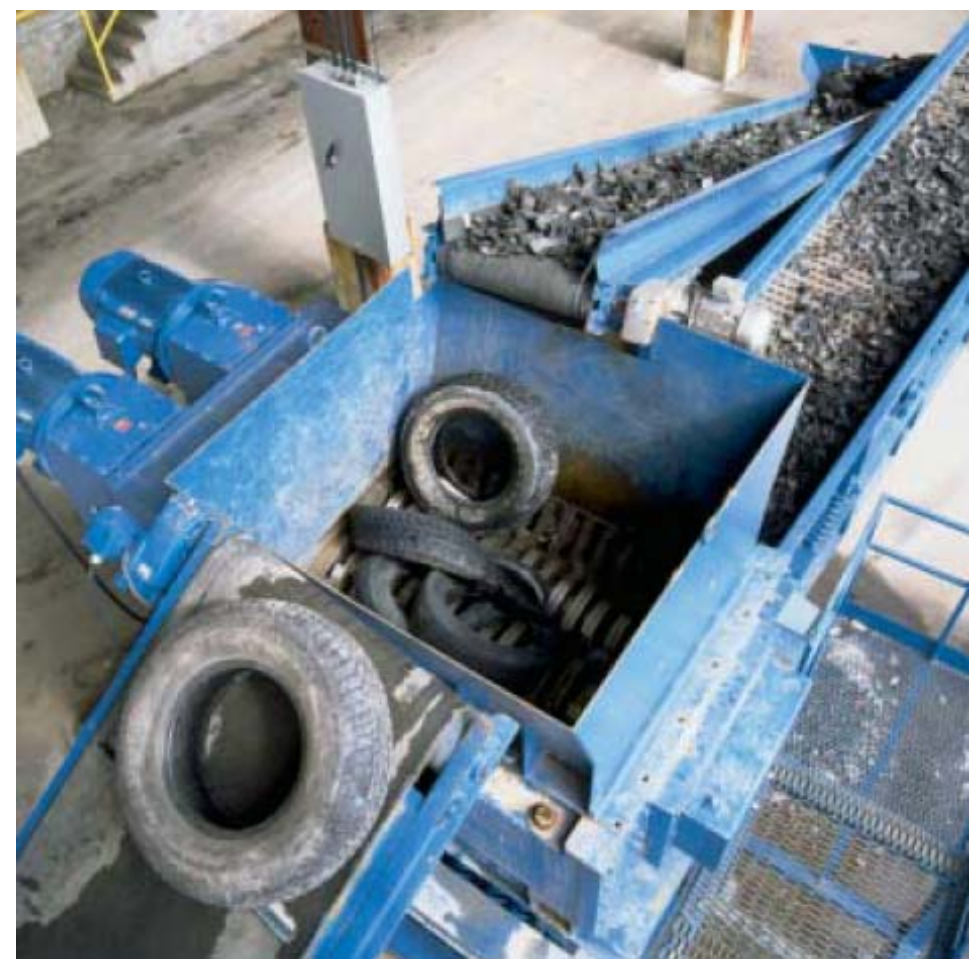

(c)

\subsection{Unit Weight}

Tire shreds are a lightweight material. The unit weight of different types of compacted tire shreds, as reported in the literature, ranges from $2.4 \mathrm{kN} / \mathrm{m}^{3}$ to $7.0 \mathrm{kN} / \mathrm{m}^{3}$, as shown in Table 2-2 (Humphrey and Manion 1992; Ahmed 1993; Ahmed and Lovell 1993; Humphrey et al. 1993; Reddy and Marella 2001). These values are approximately $10 \%$ to $40 \%$ of the unit weight of typical soils. The effect of the compaction energy on the unit weight of tire shred-soil mixtures is only important for tire shred-soil mixtures with tire shred contents less than $20 \%$ by weight. The influence of the compaction energy 
decreases as the tire shred content of the mixture increases (Ahmed 1993). Even though the maximum dry unit weight of tire shred-soil mixtures increases as the tire shred-soil ratio decreases, tire shred-soil mixtures are still considered lightweight when compared with conventional fill materials.

\subsection{Hydraulic Conductivity}

The drainage characteristics of fill materials have significant influence on the stability of embankments or retaining structures under saturated conditions. Fill materials with low hydraulic conductivity under a saturated condition may induce slope failures due to the generation of excessive pore pressures. As shown in Table 2-3, compacted tire shreds and tire shred-sand mixtures have high hydraulic conductivity, values ranging from $1.8 \times 10^{-3} \mathrm{~cm} / \mathrm{s}(16 \%$ shredded tire by weight) to $15.4 \mathrm{~cm} / \mathrm{s}(100 \%$ shredded tires $)$; these values are greater than (or equal to) those of typical sand or coarse gravel (Hall 1990; Humphrey et al. 1992; Ahmed 1993; Humphrey and Sandford 1993; Zimmerman 1997; Reddy and Marella 2001). 
Table 2-2 Dry unit weight of different types of compacted tire shreds.

\begin{tabular}{|c|c|c|c|}
\hline Reference & $\begin{array}{l}\text { Tire shred } \\
\text { size }(\mathrm{cm})\end{array}$ & $\begin{array}{l}\text { Dry unit } \\
\text { weight } \\
\left(\mathrm{kN} / \mathrm{m}^{3}\right)\end{array}$ & Compaction type \\
\hline Ahmed 1993, & $1.3-2.5$ & 4.90 & ASTM D 4253 \\
\hline \multirow{9}{*}{$\begin{array}{l}\text { Ahmed and Lovell } \\
\qquad 1993\end{array}$} & 1.3 & 4.67 & ASTM D 4253 \\
\hline & $1.3-5.1$ & 6.07 & $50 \%$ Standard \\
\hline & $1.3-2.5$ & 6.29 & $50 \%$ Standard \\
\hline & $1.0-5.1$ & 6.29 & Standard \\
\hline & $1.3-3.8$ & 6.38 & Standard \\
\hline & $1.3-2.5$ & 6.45 & Standard \\
\hline & 2.3 & 6.26 & Standard \\
\hline & $1.27-5.1$ & 6.56 & Modified \\
\hline & $1.3-2.5$ & 6.71 & Modified \\
\hline \multirow{2}{*}{$\begin{array}{l}\text { Humphrey et al. } \\
\text { 1992; }\end{array}$} & $0.2-7.6$ & 6.13 & $60 \%$ Standard \\
\hline & $0.2-5.1$ & 6.29 & $60 \%$ Standard \\
\hline \multicolumn{4}{|l|}{ Humphrey and } \\
\hline Sandford 1993 & $0.2-2.5$ & 2.4 & $60 \%$ Standard \\
\hline \multirow[t]{2}{*}{ Tweedie et al. 1998} & 3.8 & 6.96 & Full scale field test \\
\hline & 7.6 & 6.78 & Full scale field test \\
\hline
\end{tabular}


Table 2-3 Hydraulic conductivity of different types of tire shreds and tire shred-sand mixtures.

\begin{tabular}{|c|c|c|c|}
\hline Reference & $\begin{array}{l}\text { Tire shred } \\
\text { size }(\mathrm{cm})\end{array}$ & $\begin{array}{l}\text { Hydraulic } \\
\text { conductivity } \\
(\mathrm{cm} / \mathrm{s})\end{array}$ & Test condition \\
\hline & $1-5.1$ & 7.7 & Void ratio, $\mathrm{e}=0.925$ \\
\hline & $1-5.1$ & 2.1 & $\mathrm{e}=0.488$ \\
\hline $\begin{array}{c}\text { Humphrey et al. } \\
1992 ;\end{array}$ & $1.9-7.6$ & 15.4 & $\mathrm{e}=1.114$ \\
\hline \multirow{4}{*}{$\begin{array}{l}\text { Humphrey and } \\
\text { Sandford } 1993\end{array}$} & $1.9-7.6$ & 4.8 & $\mathrm{e}=0.583$ \\
\hline & $1-3.8$ & 6.9 & $\mathrm{e}=0.833$ \\
\hline & $1-3.8$ & 1.5 & $\mathrm{e}=0.414$ \\
\hline & $20.3-40.6$ & 9.0 & $e=2.77$ \\
\hline \multirow[t]{3}{*}{ Zimmerman 1997} & $20.3-40.6$ & 3.2 & $e=1.53$ \\
\hline & $20.3-40.6$ & 1.8 & $e=0.78$ \\
\hline & $1.3-3.8$ & 7.6 & $e=0.693$ \\
\hline \multirow{3}{*}{$\begin{array}{l}\text { Lawrence et. al. } \\
1998\end{array}$} & $1.3-3.8$ & 1.5 & $\mathrm{e}=0.328$ \\
\hline & $1.3-7.6$ & 16.3 & $e=0.857$ \\
\hline & $1.3-7.6$ & 5.6 & $\mathrm{e}=0.546$ \\
\hline \multirow{3}{*}{$\begin{array}{c}\text { Ahmed } 1993 \\
\text { ASTM D6270 } 1998\end{array}$} & 2.5 & $1.8 \times 10^{-3}$ & $\begin{array}{c}\text { Mix with Ottawa sand, } \\
15.5 \% \text { of tire shred by } \\
\text { weight }\end{array}$ \\
\hline & 2.5 & $3.5 \times 10^{-3}$ & $\begin{array}{c}\text { Mix with Ottawa sand, } \\
30.1 \% \text { of tire shred by } \\
\text { weight }\end{array}$ \\
\hline & 2.5 & $8.7 \times 10^{-3}$ & $\begin{array}{c}\text { Mix with Ottawa sand, } \\
37.7 \% \text { of tire shred by } \\
\text { weight }\end{array}$ \\
\hline
\end{tabular}




\subsection{Shear Strength}

The shear strength of a tire shred-soil mixture is affected mainly by the confining stresses, the tire shred-soil ratio and the density of the mixture as shown in Table 2-4 (Ahmed and Lovell 1993; Humphrey et al. 1993; Bernal et al. 1996; Masad et al. 1996; Wu et al. 1997; Reddy and Marella 2001). In mixtures of tire shreds and sand, the tire shreds have a reinforcing effect (Edil and Bosscher 1992; Ahmed 1993; Foose 1993; Bernal et al. 1996). Ahmed (1993) conducted triaxial tests on tire shred-soil mixtures (tire shred size $=25 \mathrm{~mm}$ ) with various mixing ratios. A tire shred-soil mixture ratio of approximately 40:60 by dry weight (65:35 by volume) was reported to produce maximum shear strength values at low to medium confining stresses. Although the mixing ratio that produces the maximum shear strength varies depending on the size of the tire shreds, the mixture ratio mentioned above can be used as a reference in the selection of the tire shred-soil mixture ratio to be used in the construction of embankments. Small size tire chips $(12 \mathrm{~mm}-50 \mathrm{~mm})$ are usually equidimensional and larger size tire shreds $(50 \mathrm{~mm}-305 \mathrm{~mm})$ are elongated and flat; their shape has an influence on the stress-strain behavior of the mixtures (ASTM D 6270-98: Standard practice for use of scrap tires in civil engineering application). 
Table 2-4 Shear strength of different types of tire shreds.

\begin{tabular}{|c|c|c|c|c|}
\hline Reference & $\begin{array}{l}\text { Tire shred size } \\
(\mathrm{cm})\end{array}$ & $\mathrm{c}\left(\mathrm{kN} / \mathrm{m}^{2}\right)$ & $\phi\left(^{\circ}\right)$ & Test condition \\
\hline \multirow{4}{*}{$\begin{array}{l}\text { Ahmed and } \\
\text { Lovell } 1993\end{array}$} & 1.3 & 35.8 & 20.5 & $\begin{array}{c}\text { Standard compaction } \& \\
\text { value measured at } 20 \% \\
\text { strain }\end{array}$ \\
\hline & 2.5 & 39.2 & 24.6 & $\begin{array}{c}\text { Modified compaction } \& \\
\text { value measured at } 20 \% \\
\text { strain }\end{array}$ \\
\hline & 2.5 & 33.2 & 25.3 & $\begin{array}{l}\text { Standard compaction \& } \\
\text { value measured at } 20 \% \\
\text { strain }\end{array}$ \\
\hline & 2.5 & 37.3 & 22.6 & $\begin{array}{c}50 \% \text { standard } \\
\text { compaction \& value } \\
\text { measured at } 20 \% \text { strain }\end{array}$ \\
\hline \multirow{3}{*}{$\begin{array}{c}\text { Humphery et al. } \\
1993\end{array}$} & $<3.8$ & 8.6 & 25 & \multirow{3}{*}{$\begin{array}{c}\text { Normal stress: 19.2- } \\
71.8\left(\mathrm{kN} / \mathrm{m}^{2}\right)\end{array}$} \\
\hline & $<5.1$ & $4.3-7.7$ & $21-26$ & \\
\hline & $<7.6$ & 11.5 & 19 & \\
\hline $\begin{array}{c}\text { Bernal et al. } \\
1996\end{array}$ & 5.1 & 0 & $17-35$ & $\begin{array}{c}17^{\circ} \text { at } 5 \% \text { strain } 35^{\circ} \text { at } \\
20 \% \text { strain }\end{array}$ \\
\hline \multirow{3}{*}{$\begin{array}{c}\text { Masad et al. } \\
1996\end{array}$} & \multirow{3}{*}{0.46} & 70.0 & 6 & $10 \%$ strain \\
\hline & & 71.0 & 11 & $15 \%$ strain \\
\hline & & 82.0 & 15 & $20 \%$ strain \\
\hline \multirow{4}{*}{ Wu et al. 1997} & $<0.2$ & 0 & 45 & \multirow{4}{*}{$\begin{array}{c}\text { Triaxial tests under } \\
\text { confining stress of } 34.5- \\
55.0 \mathrm{kN} / \mathrm{m}^{2}\end{array}$} \\
\hline & $<0.9$ & 0 & $47-60$ & \\
\hline & $<1.9$ & 0 & 54 & \\
\hline & $<3.8$ & 0 & 57 & \\
\hline
\end{tabular}




\subsection{Environmental Impact}

Tires are made of natural and synthetic rubber that contains: a) organic substances (carbon black, polymers, oil, paraffin, and volatile organic compounds), and b) inorganic substances (pigments, fabrics, bead or belt materials, aluminum, barium, chromium, iron, lead, manganese, sulfur, and zinc). Table 2-5 shows the chemical composition of scrap tires (Moo-Young et al. 2001). Various laboratory leaching tests have been conducted by many researchers on shredded tire samples to evaluate the potential environmental problems that they can cause (Minnesota Pollution Control Agency 1990; Ealding 1992; Edil and Bosscher 1992). It is reported that the pH level can affect the leaching process. Organic components are found to leach more freely under neutral conditions, while metals leach more freely under acidic conditions (Westerberg and Màcsik 2001). Laboratory leaching tests on shredded tire samples indicate that both the metallic and organic components are well below the EPA's (Environmental Protection Agency) TCLP (Toxicity Characterization Leaching Procedure) and EP (Extraction Procedure) standards, and that tire shreds show little or no likelihood of being a material hazardous to the environment. Also, various studies that were conducted on field test embankments with tire shred as fill material have shown that tire shreds have only a negligible impact on the environment and on the groundwater quality (Minnesota Pollution Control Agency 1990; Bosscher et al. 1992; Humphrey et al. 2000). However, in severe conditions, leaching of metals can occur due to exposure of the metal reinforcements present in the tire shreds (O'Shaughnessy and Garga 2000). Under such conditions, zinc is often used as an indicator to ascertain if leaching has occurred (Collins et al. 1995; Vashisth et al. 1998). 
Table 2-5 Chemical composition of scrap tires (Moo-Young et al. 2001).

\begin{tabular}{|c|c|c|}
\hline Description & $\%$ by weight as received & $\%$ by weight, dry basis \\
\hline \multicolumn{3}{|l|}{ Proximate analysis } \\
\hline Moisture & 0.62 & - \\
\hline Ash & 4.78 & 4.81 \\
\hline Volatile matter & 66.64 & 67.06 \\
\hline Fixed carbon & 27.96 & 28.13 \\
\hline Total & 100 & 100 \\
\hline \multicolumn{3}{|c|}{$\begin{array}{l}\text { Elemental mineral } \\
\text { analysis (Oxide form) }\end{array}$} \\
\hline Zinc & 1.52 & 1.53 \\
\hline Calcium & 0.378 & 0.380 \\
\hline Iron & 0.321 & 0.323 \\
\hline Chlorine & 0.149 & 0.150 \\
\hline Chromium & 0.0097 & 0.0098 \\
\hline Fluoride & 0.0010 & 0.0010 \\
\hline Cadmium & 0.0006 & 0.0006 \\
\hline
\end{tabular}




\subsection{Degradation Characteristics}

Degradation of tire shreds can be due to two types of processes: 1) microbial action, and 2) ultra-violet light exposure. The growth of micro-organisms is inhibited due to the presence of zinc oxide, anti-degradants and vulcanization accelerators. Hence, the attack of micro-organisms on tire shreds has been found to be minimal (Crane et al. 1975). Recent work indicates that the effect of micro-organisms on scrap tires is not well understood and further research into the microbial processes involved is required (HR Wallingford 2005). Carbon black present in tires blocks the damaging ultra-violet component of sunlight. Surface degradation can be prevented when tires are kept away from sunlight, placed underwater or buried underground (Collins et al. 2002). Thus, tires might be considered as non-reactive materials under natural conditions.

\subsection{Exothermic Reactions in Tire Shred Fills}

In 1995, exothermic reactions were experienced in three tire shred fill embankments in Washington (Humphrey 1996). Ignition can occur due to the rise in temperature caused by exothermic reactions. Potential causes of initiation of exothermic reactions are as follows: 1) oxidation of exposed steel wires, 2) oxidation of rubber, and 3) consumption of liquid petroleum products by microbes. Oxidation of exposed steel wires is the primary cause of exothermic reactions (Humphrey 1996). Mixing of tire shreds with soil impedes the oxidation process due to the reduction in the contact area of 
the exposed steel wires to oxygen and the formation of a non-combustible insulating layer that increases the critical ignition temperature (HR Wallingford 2005).

\section{9. $\underline{\text { Summary }}$}

Significant amount of waste tires are generated every year in the US. In 2005, $16 \%$ of the scrap-tire market was devoted for civil engineering applications. Tire shreds offer many advantages in civil engineering applications due to their low unit weight (ranging from $2.4 \mathrm{kN} / \mathrm{m}^{3}$ to $7.0 \mathrm{kN} / \mathrm{m}^{3}$ ), high hydraulic conductivity (ranging from $1.8 \times$ $10^{-3} \mathrm{~cm} / \mathrm{s}$ to $15.4 \mathrm{~cm} / \mathrm{s}$ ), and relatively high shear strength.

Various studies show a negligible impact of tire shreds on the environment and on the groundwater quality, leaching of metals can occur in severe conditions due to exposed metal reinforcement. In this case, zinc can be used as an indicator to ascertain if leaching has taken place.

Exothermic reactions are the main concern when pure tire shreds are used as a fill material. The main cause of exothermic reaction is due to oxidation of exposed metal reinforcement. Mixing of tire shreds with soil forms an insulating layer that inhibits ignition in the fill. 


\section{CHAPTER 3. OPTIMUM SIZE OF TIRE SHREDS AND TIRE SHRED-SAND MIXING RATIO}

\subsection{Introduction}

Tire shreds have been used in geotechnical applications either separately or mixed with soil. Mixing of tire shreds with soil reduces both the compressibility and the combustibility characteristics of tire shred fills. The occurrence of exothermic reactions produced by tire shreds has been a very critical issue for embankments constructed with tire shreds only. The presence of sufficient air within the voids of tire shred fills may have played a role in the ignition process that developed in the incidents where combustion was observed (Humphrey 1996). To prevent self-ignition, isolation of the tire shreds is required. When tire shreds are, on average, floating in a soil matrix, isolation of the tire shreds is practically guaranteed. However, a high tire shred-sand mixing ratio may induce segregation problems. Tire shreds are typically bulky, and the voids created between them are relatively much larger compared with the size of the sand grains. Depending on the compaction method used and the mixing ratio of the tire shred-sand mixture, the sand grains may settle down leaving the upper part of the mixture composed almost entirely of tire shreds.

In this chapter, the optimum mixing ratio for tire shred-sand mixtures is discussed based on the laboratory compaction test. 


\subsection{Optimum Size of Tire Shreds}

Tire shred sizes range typically from $50 \mathrm{~mm}$ to $300 \mathrm{~mm}$. Whole tires or parts of scrap tires are shredded by shredders equipped with knives or blades. Usually, multiple passes through a shredder are required to produce tire shred sizes less than $300 \mathrm{~mm}$ (GeoSyntec Consultants 1998). It is more expensive to produce smaller sizes of tire shreds. Table 3-1 shows the price for shredded tires of various sizes (California Integrated Waste Management Board 2001). For this reason, larger-size tire shreds are more economical when the goal is to use them as construction materials. However, the engineering properties of the tire shred-sand mixtures and the possibility of construction difficulties in the field must also be considered in the process of selection of the size of tire-shreds to be used.

Table 3-1 Prices of shredded rubber according to size (California Integrated Waste Management Board 2001).

\begin{tabular}{cc}
\hline Mesh Size & Cost Price, Free of Board, lbs. \\
\hline 10 Mesh $\left(10\right.$ pieces $/$ in $\left.^{2}\right)$ & $10-18$ cents \\
40 Mesh $\left(40\right.$ pieces $/$ in $\left.^{2}\right)$ & $14-22$ cents \\
80 Mesh $\left(80\right.$ pieces $/$ in $\left.^{2}\right)$ & $25-52$ cents \\
\hline
\end{tabular}




\subsection{Overall Void Ratio in Mixtures with Particles of Different Sizes}

Lade et al. (1998) proposed a theoretical formulation for the void ratio of mixtures composed of particles of two different sizes. Their findings can be used to obtain the void ratio of mixtures composed of tire shreds and sand. Figure 3-1 shows a schematic diagram of the minimum void ratio of binary packing of particles. In Figure 3-1, the minimum void ratio of a material composed entirely of tire shreds or entirely of sand is denoted by $e_{\min , t s}$ and $e_{\min , s}$, respectively. When sand particles are added to the voids of an existing volume of tire shreds, the sand particles fill the voids between the tire shreds, and the minimum void ratio of the mixture $\left(\mathrm{e}_{\min , \operatorname{mix}}\right)$ decreases. This will continue until all the voids between the tire shreds are completely filled with sand particles. When all voids between the tire shreds are filled with sand particles, any further addition of sand will increase both the overall volume of the mixture and consequently its minimum void ratio, as shown in Figure 3-1. From this point on, further addition of sand produces mixtures in which the tire shreds are on average floating in a sand matrix. This explains why, on a plot of $e_{\text {min,mix }}$ vs. sand content, there is a minimum value at a certain value of sand content present in a mixture. This mixing ratio is the minimum mixing ratio ensuring the isolation of the tire shreds in the mixture. This is the optimum mixing ratio that needs to be used for enhanced performance of the material. 


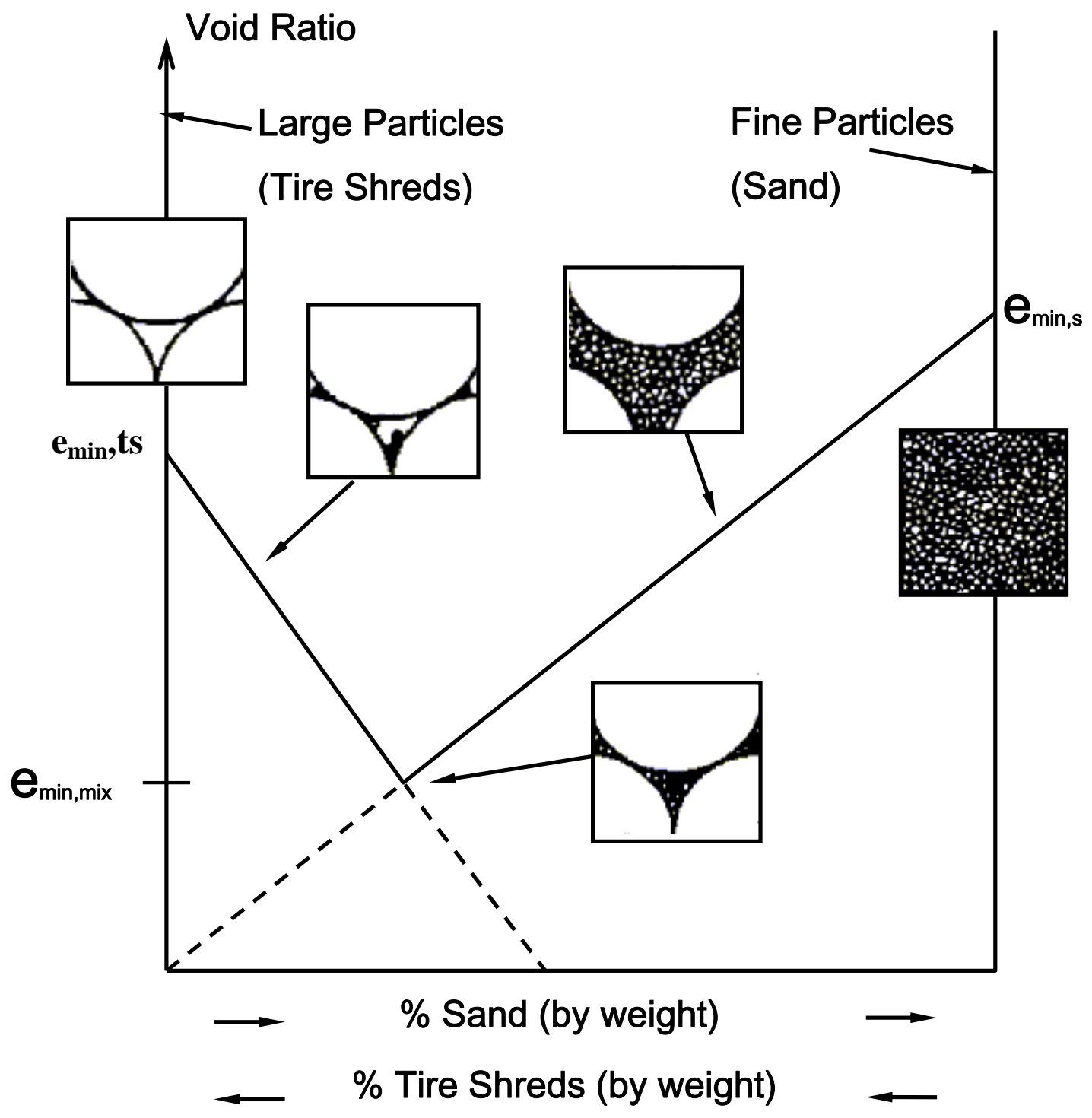

Figure 3-1 Schematic diagram illustrating minimum void ratio arrangements of binary packing of particles (after Lade et al. 1998). 


\subsection{Optimum Mixing Ratio of Compacted Tire Shred-Sand Mixtures}

Laboratory compaction tests were performed to evaluate the optimum mixing ratio of compacted tire shred-sand mixtures using a mold $270-\mathrm{mm}$ in diameter and a specially designed rammer, as shown in Figure 3-2. The mass of the rammer is $9.21 \mathrm{~kg}$, and the drop height is $0.4 \mathrm{~m}$. The mixtures were prepared with shredded tires of various sizes (tire chips $9.5 \mathrm{~mm}$ in nominal size, tire shreds $50-100 \mathrm{~mm}$ in length, and tire shreds $100-200 \mathrm{~mm}$ in length) and Ottawa sand at different mixing ratios. Figure 3-3 shows typical shredded tire pieces. Both tire shreds and Ottawa sand were air-dried and compacted using the Standard Proctor effort $\left(600 \mathrm{kN}-\mathrm{m} / \mathrm{m}^{3}\right)$, as described in ASTM D 698-00a (Standard test methods for laboratory compaction characteristics of soil using standard effort). 


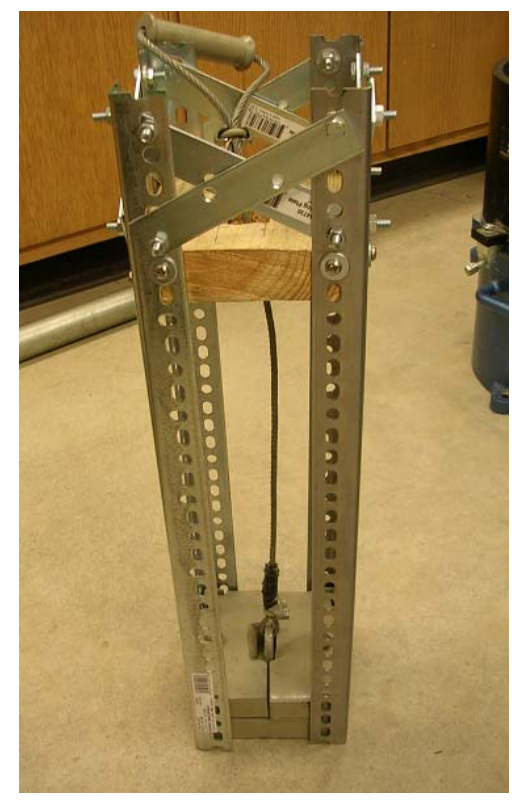

(a) Specially designed rammer

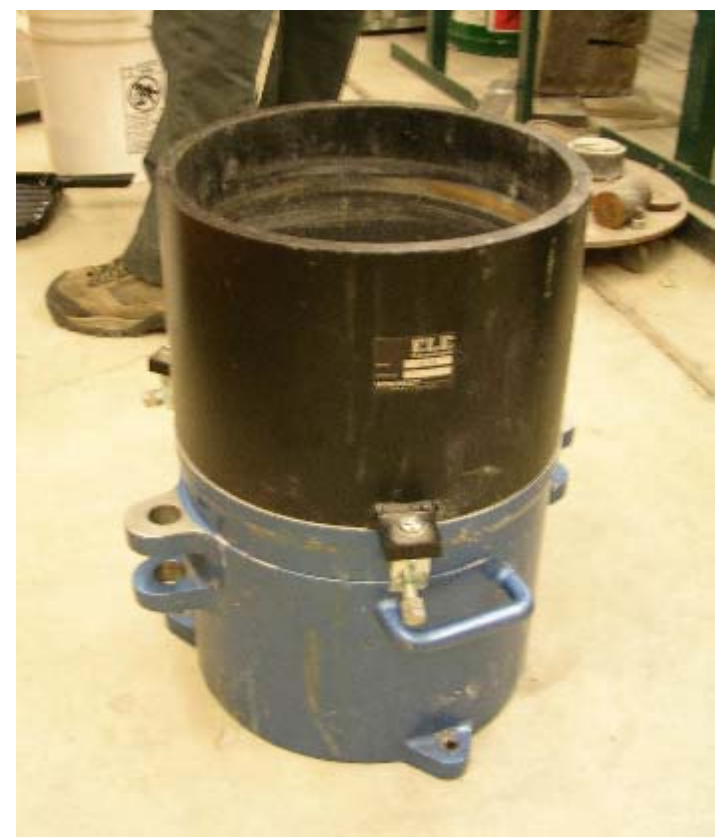

(b) 270-mm-diameter mold with collar

Figure 3-2 Compaction test apparatus. 


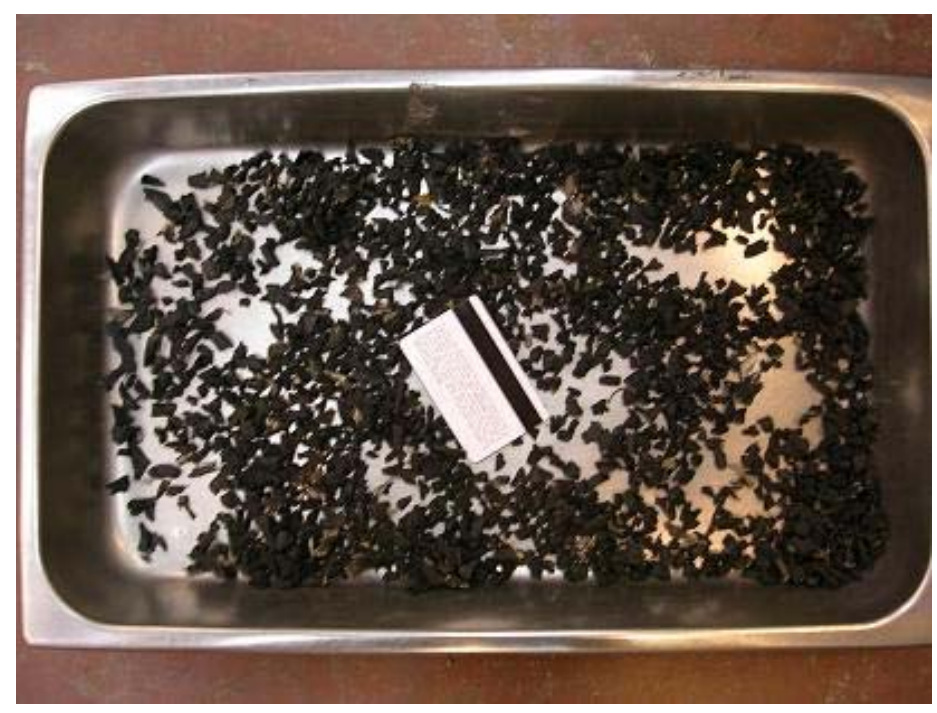

(a) Tire chips $9.5 \mathrm{~mm}$ in nominal size

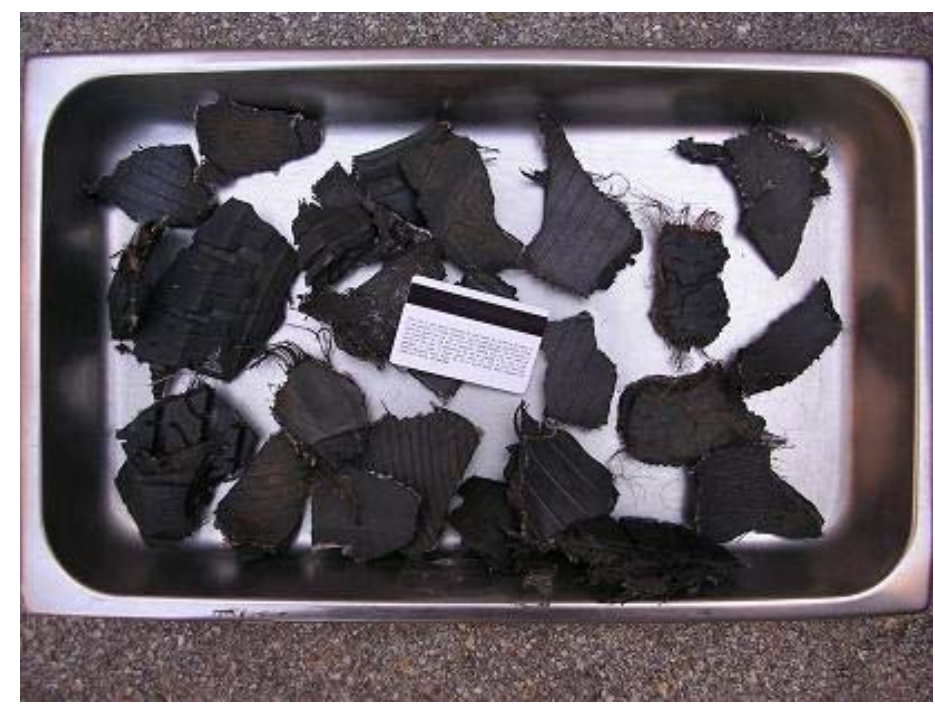

(b) Tire shreds $50-100 \mathrm{~mm}$ in length 


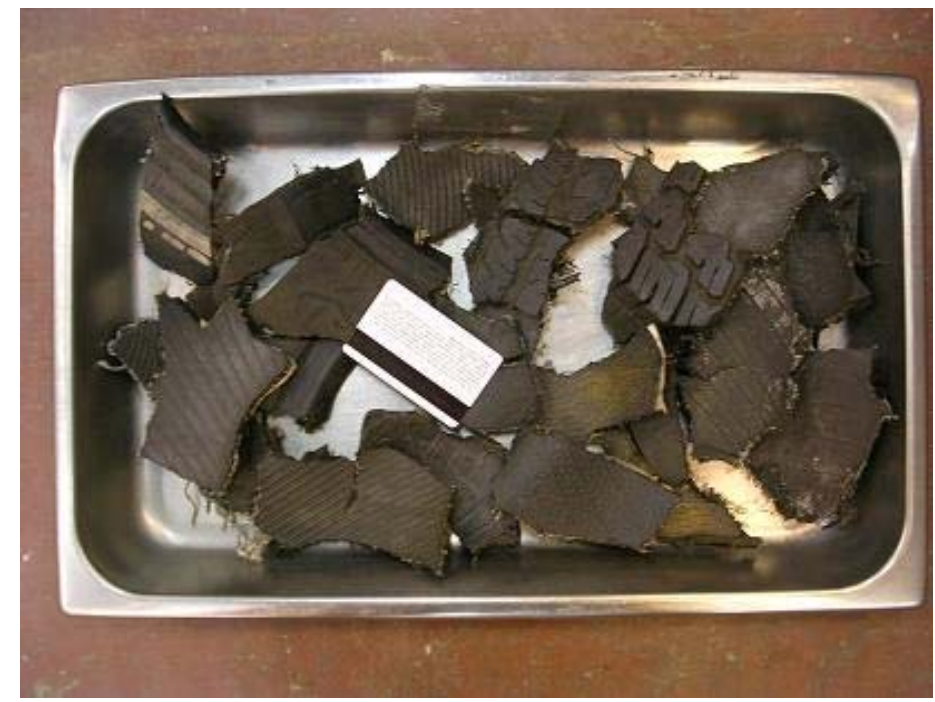

(c) Tire shreds $100-200 \mathrm{~mm}$ in length

Figure 3-3 Typical pieces of shredded tires. 


\subsubsection{Geometric Characterization of Tire Shreds}

Three different sizes of shredded tires were used in the compaction tests (tire chips $9.5 \mathrm{~mm}$ in nominal size, tire shreds $50-100 \mathrm{~mm}$ in length, and tire shreds $100-200$ $\mathrm{mm}$ in length). The shredded tires are produced and supplied by Entech Co. located in White Pigeon, Michigan. For the geometric characterization of the shredded tires, measurements were made using a ruler on randomly selected tire shreds for the two larger size ranges (50-100 mm and 100-200 mm) (see Figure 3-4). Figure 3-5 and Figure 3-6 show the distributions of length and width of tire shreds with lengths ranging from 50$100 \mathrm{~mm}$ and 100-200 mm, respectively. The average lengths, widths, and thicknesses for these two size ranges of 50-100 $\mathrm{mm}$ and $100-200 \mathrm{~mm}$ are $76 \mathrm{~mm}, 49 \mathrm{~mm}$, and $10 \mathrm{~mm}$; and $137 \mathrm{~mm}, 65 \mathrm{~mm}$, and $11 \mathrm{~mm}$, respectively. Typically, the length of the tire shreds is greater than their width, which in turn is greater than their thickness. Thus, tire shreds have a shape that is elongated and flat. An important property indicative of the shape of tire shreds is the aspect ratio, defined as the length-to-width ratio. The average aspect ratios (length/width) are 1.6 and 2.2 for 50-to-100-mm-long tire shreds and 100-to-200mm-long tire shreds, respectively. 


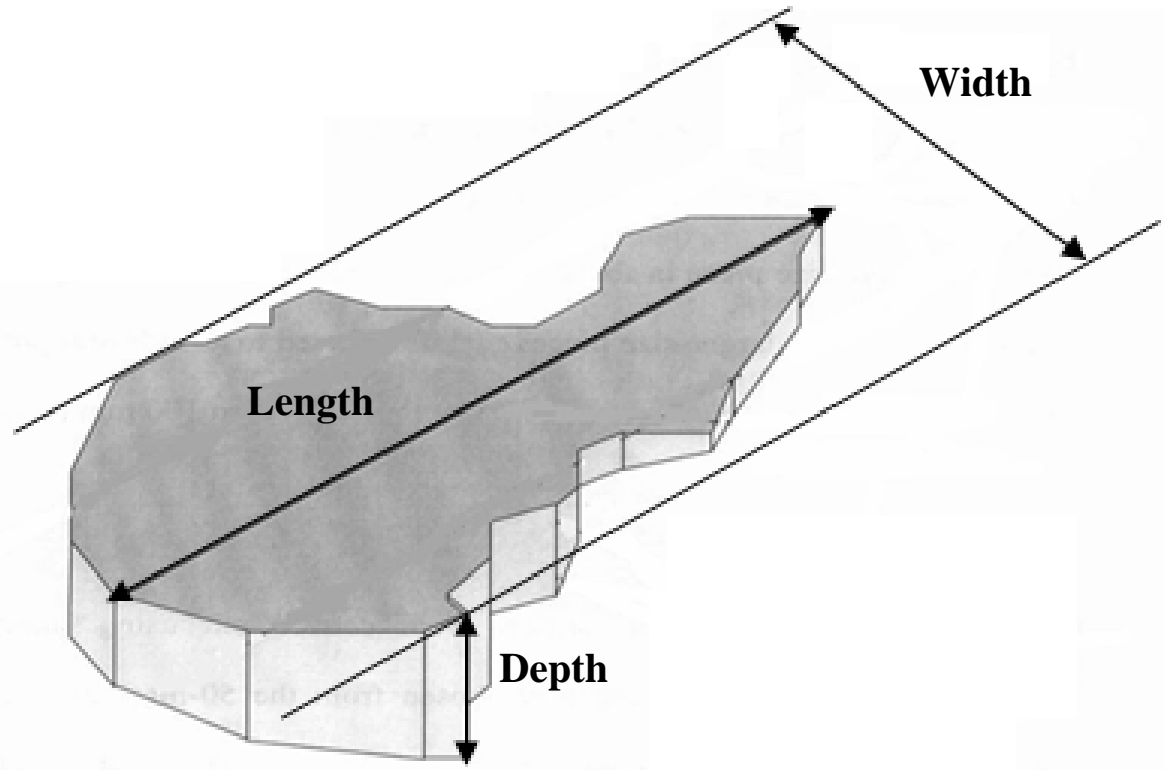

Figure 3-4 Geometry of tire shred (after Drescher et al. 1999). 


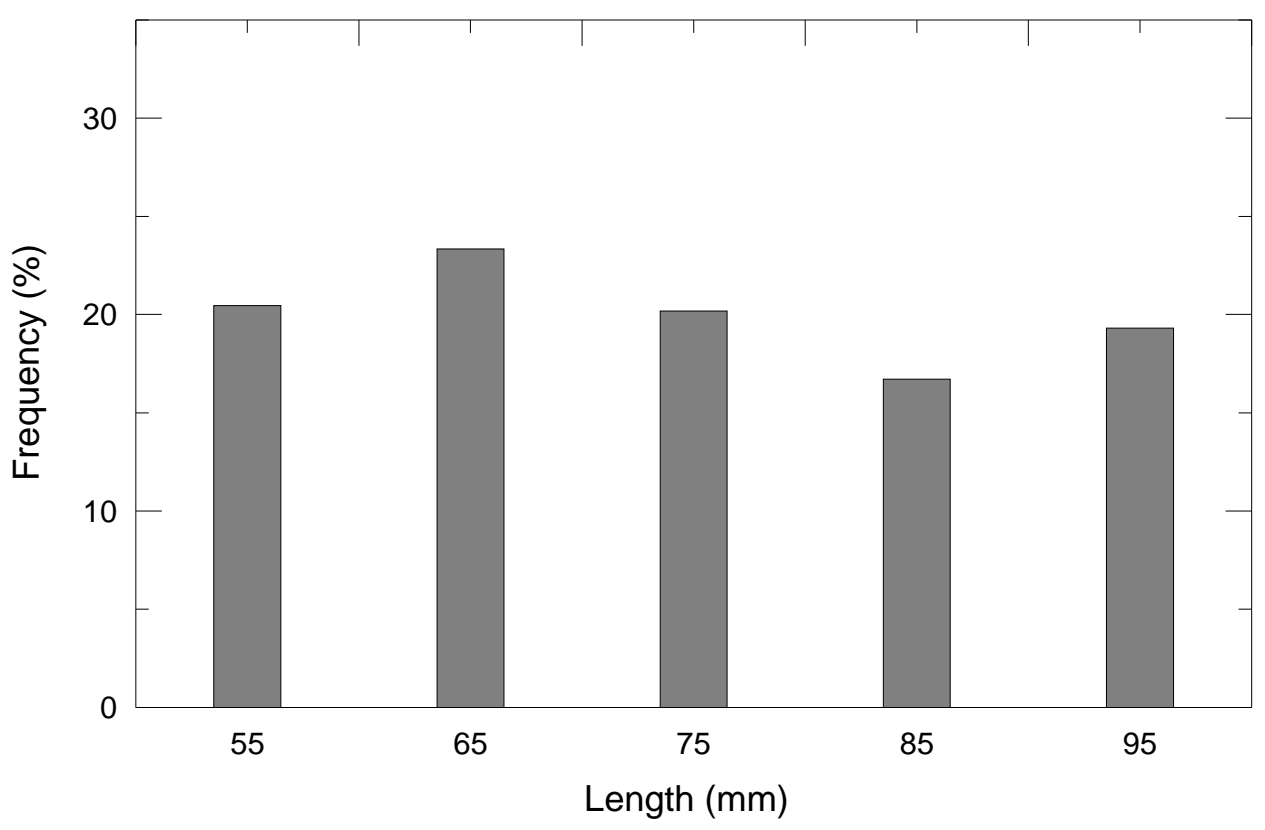

(a) Distribution according to length

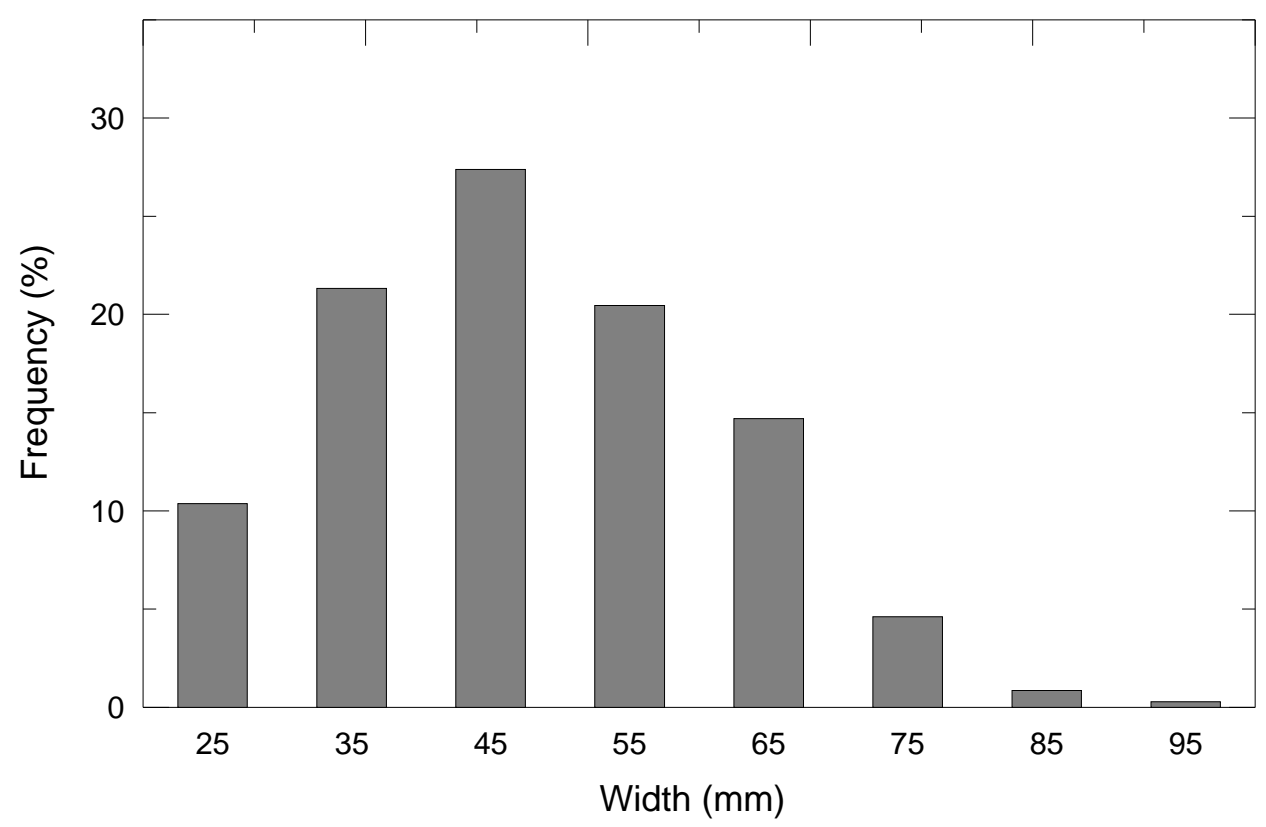

(b) Distribution according to width

Figure 3-5 Geometry of tire shreds (50-100 $\mathrm{mm}$ in length). 


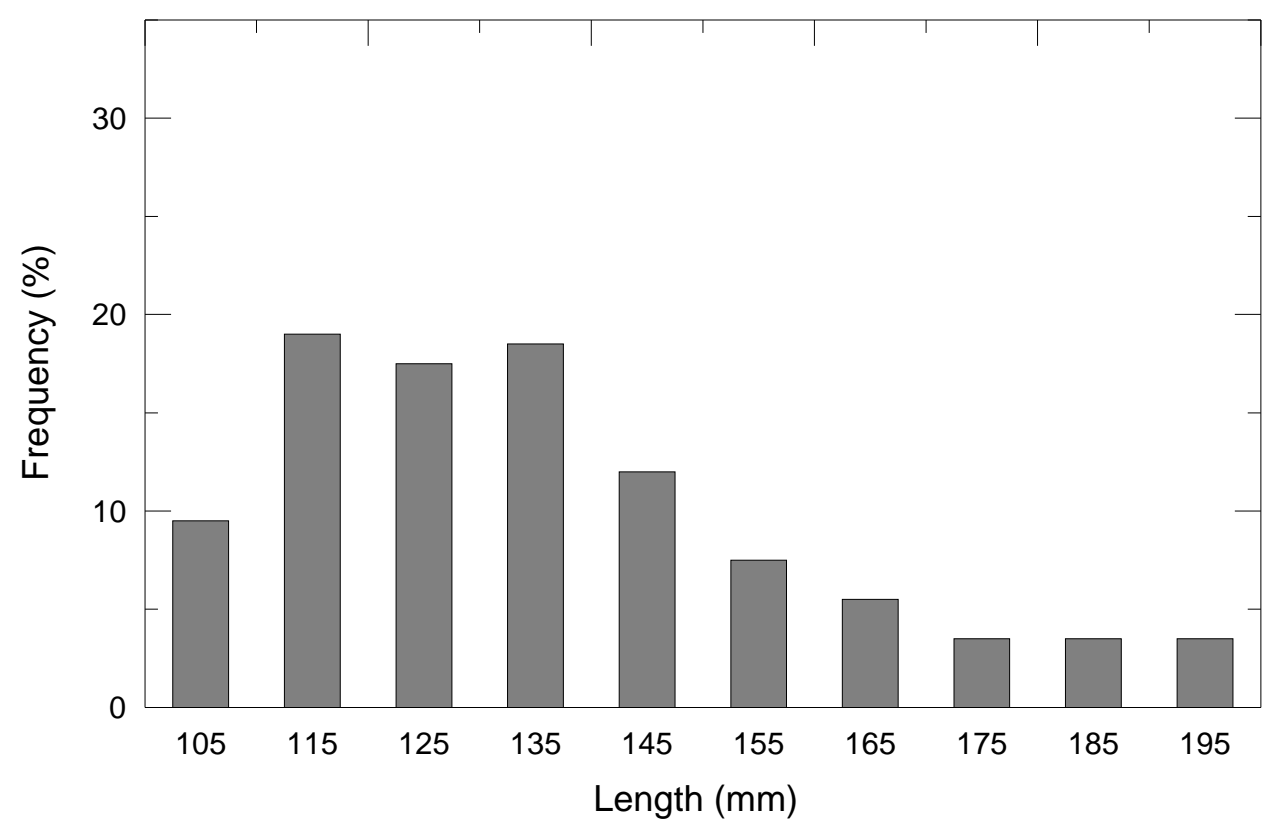

(a) Distribution according to length

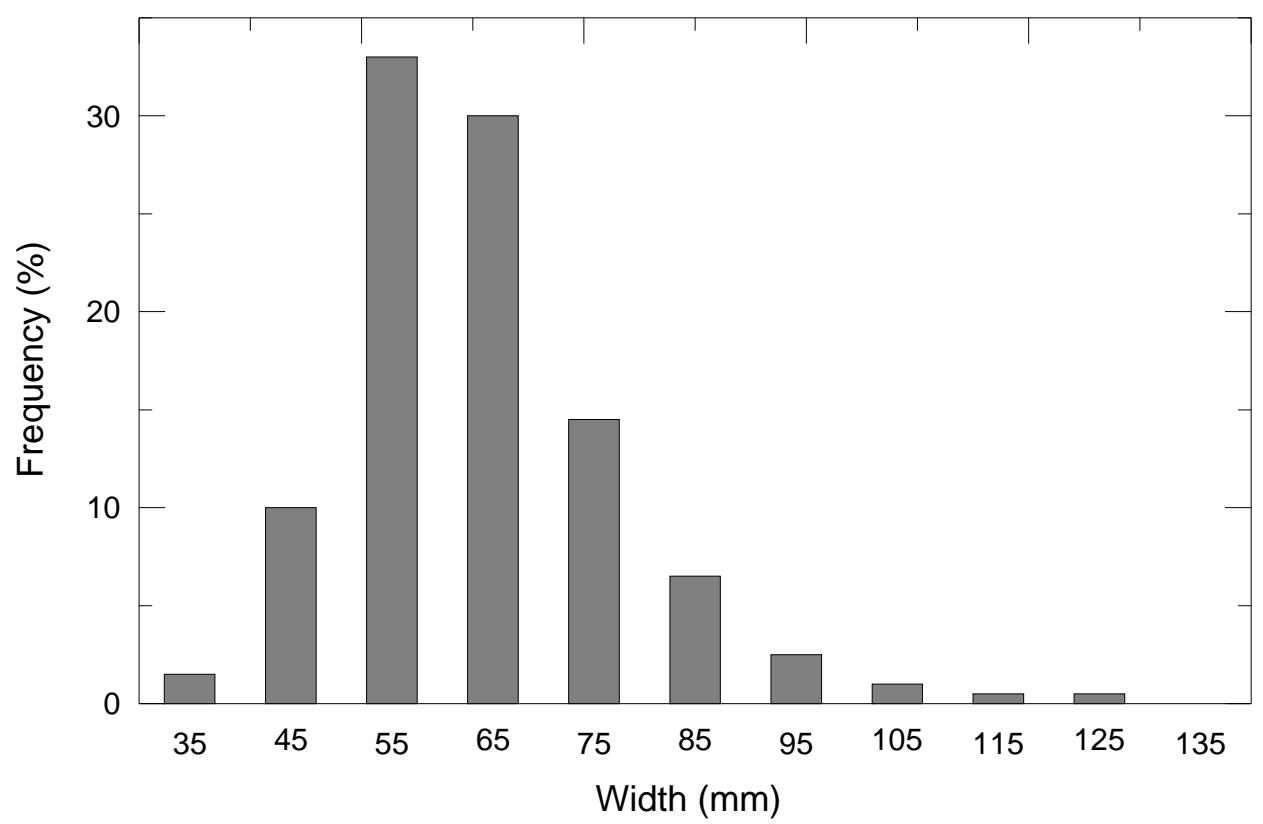

(b) Distribution according to width

Figure 3-6 Geometry of tire shreds (100-200 mm in length). 


\subsubsection{Specific Gravity}

Tire shreds without steel wires are lighter than water, and hence the specific gravity $\mathrm{G}_{\mathrm{S}}$ of tire shreds cannot be determined using conventional test methods, such as the ASTM D 854-02 method (Standard test methods for specific gravity of soil solids by water pycnometer). Ahmed (1993) proposed a simple procedure to measure $\mathrm{G}_{\mathrm{S}}$ of tire chips; a similar method was employed in this experimental program to determine the $\mathrm{G}_{\mathrm{S}}$ of tire shreds. The apparatus consists of: a) a five-gallon bucket of height $0.5 \mathrm{~m}$ with a hole drilled on its side about $0.35 \mathrm{~m}$ above its bottom; b) a screen with opening sizes smaller than the size of the tire shreds; and c) a weight that is used to apply a force on the screen and to facilitate submergence of the tire shreds in water (Figure 3-7).

The test procedure consists of the following steps:

1) determining the total weight of the bucket with water flush with the hole, the screen, and the weight that is placed on top of the screen.

2) submerging the tire shreds wrapped within the screen in the water in the bucket by placing the weight on top of it.

3) determining the weight of the bucket with the submerged tire shreds, the screen, the weight placed on the screen, and the water; note that the volume of water that overflows through the bucket hole is equivalent to the volume of the submerged tire shreds.

The specific gravity of the tire shreds is then determined using the following relation:

$$
G_{S}=\frac{W_{\text {tire }}}{\left(W_{1}-W_{2}+W_{\text {tire }}\right)}
$$


where:

$\mathrm{W}_{\text {tire }}=$ dry weight of tire shreds

$\mathrm{W}_{1}=$ weight of bucket, screen, weight placed on the screen and water

$\mathrm{W}_{2}=$ weight of bucket, submerged tire shreds, screen, weight placed on the screen and water

The specific gravity of tire shreds at a standard temperature of $20^{\circ} \mathrm{C}\left(\mathrm{G}_{\mathrm{S}}\right.$ at $\left.20^{\circ} \mathrm{C}\right)$ is calculated from:

$$
G_{S a t 20^{\circ} \mathrm{C}}=G_{S} \times K
$$

where $\mathrm{K}=$ ratio of the water density at the test temperature to that at the standard temperature of $20^{\circ} \mathrm{C}$.

De-aired water was used in these tests to minimize the possibility of entrapped air. $\mathrm{G}_{\mathrm{S}}$ values determined with equation 3.1 were corrected for the test temperature using equation 3.2. The average $\mathrm{G}_{\mathrm{S}}$ values obtained for the tire shreds are shown in Table 3-2. It is noticed that the specific gravity of the shredded tires is highly dependent on the amount of steel reinforcement present in them.

In addition, the specific gravity of Ottawa sand was determined to be 2.65 , in accordance with the ASTM D 854-02 (Standard test methods for specific gravity of soil solids by water pycnometer). 
Table 3-2 Specific gravity of shredded tires.

\begin{tabular}{cc}
\hline Size of shredded tires & Specific gravity \\
\hline $9.5-\mathrm{mm}$ & 1.04 \\
$50-100 \mathrm{~mm}$ in length & 1.23 \\
$100-200 \mathrm{~mm}$ in length & 1.18 \\
\hline
\end{tabular}




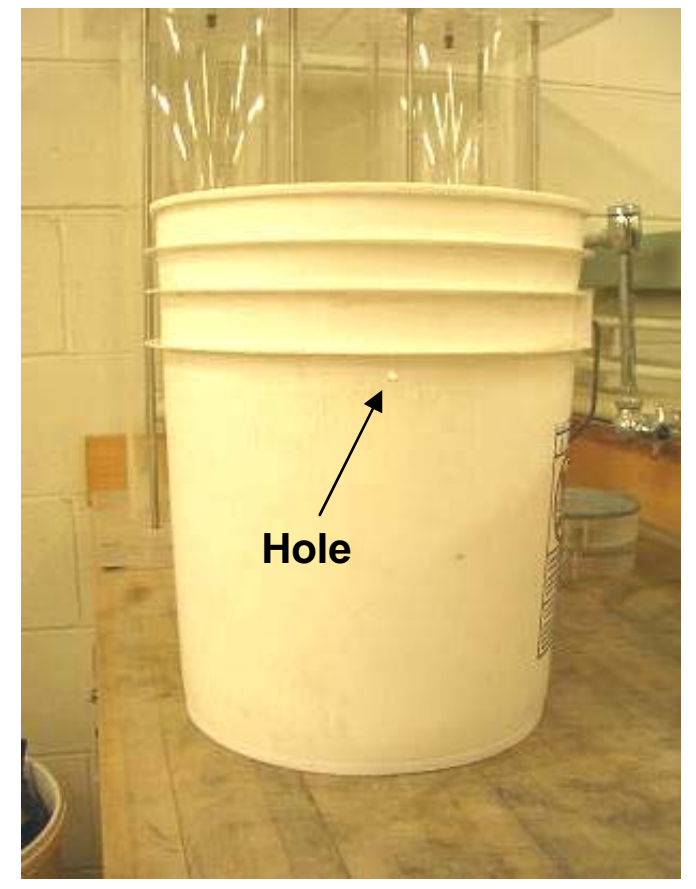

(a) Five-gallon bucket with a hole drilled on its side

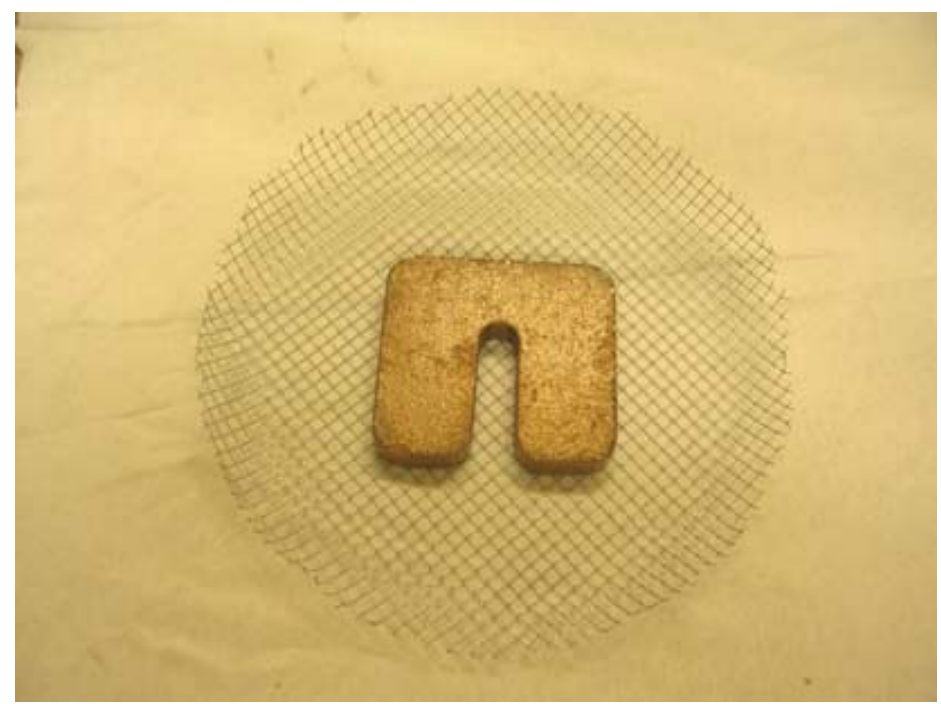

(b) Screen and weight

Figure 3-7 Apparatus used for determination of the specific gravity of tire shreds. 


\subsubsection{Optimum Mixing Ratio Determination of Shredded Tires and Sand Mixture}

As described previously, a series of compaction tests was performed to determine the optimum mixing ratio of the tire shred-sand mixtures considered in this study. The mixtures were prepared at various mixing ratios using shredded tires of three different sizes (tire chips $9.5 \mathrm{~mm}$ in nominal size, tire shreds $50-100 \mathrm{~mm}$ in length, and tire shreds 100-200 $\mathrm{mm}$ in length) and Ottawa sand. Using the standard Proctor compaction effort $\left(600 \mathrm{kN}-\mathrm{m} / \mathrm{m}^{3}\right)$, the air-dried shredded tires and Ottawa sand mixtures were compacted in the mold using a 9.21-kg rammer in three layers with 72,72 and 73 blows, respectively. The compacted unit weight of each mixture was then determined. The sand content of the shredded tire-sand mixtures varied from 0 to $100 \%$ (i.e. from pure sand to pure tire shreds). As shown in Figure 3-8, the compacted unit weight of the mixtures of shredded tires and sand increases linearly with increasing percentages of sand because the specific gravity of the sand is greater than that of the shredded tires.

Using the dry unit weights, the void ratios of the compacted shredded tire-sand mixtures were calculated and plotted as a function of the tire shred content of the mixtures (see Figure 3-9). The compacted mixtures consisting only of tire shreds had void ratios of $0.92,0.95$ and 0.87 for shredded tire sizes of $9.5 \mathrm{~mm}, 50-100 \mathrm{~mm}$ and 100 $200 \mathrm{~mm}$, respectively. As can be seen in Figure 3-9, as the percentage of sand increases, the void ratio of the compacted mixtures decreases up to a point where it reaches a minimum value, as discussed previously, and then it increases again. This occurs at shredded tire contents (by weight) equal to $25 \%$ for tire chips $9.5-\mathrm{mm}$ in nominal size, $25 \%$ for tire shreds $50-100 \mathrm{~mm}$ in length and $30 \%$ for tire shreds $100-200 \mathrm{~mm}$ in length. The void ratios corresponding to these optimum mixing ratios are $0.23,0.21$, and 0.16 , 
respectively. Based on these results, the minimum shredded tire-sand mixing ratios that ensure complete isolation of the shredded tires were determined to be equal to $25 / 75$ for tire shreds $9.5 \mathrm{~mm}$ in nominal size, $25 / 75$ for tire shreds $50-100 \mathrm{~mm}$ in length, and 30/70 for tire shreds $100-200 \mathrm{~mm}$ in length. These weight ratios can be converted to equivalent volume ratios using the weight-volume ratio relations shown in Figure 3-10. The compaction test results are tabulated in Table 3-3.

The optimum mixing ratio, which depends on the shape and size of the tire shreds, can be determined experimentally. Since the shape and size of tire shreds can vary significantly depending on the shredding methods and equipments used, experimental testing was focused only on the tire shreds that were used in the project. In order to estimate the optimum mixing ratio for projects in which mixtures of tire shreds and sandy soils will be used as fill material, the following procedure can be employed:

1) determine the size of the tire shreds and the shredding method;

2) determine the void ratios of compacted mixtures of tire shreds and sand prepared with various mixing ratios;

3) select the mixing ratio corresponding to the minimum void ratio, that is, the minimum mixing ratio that ensures floating of the tire shreds in the soil matrix. 


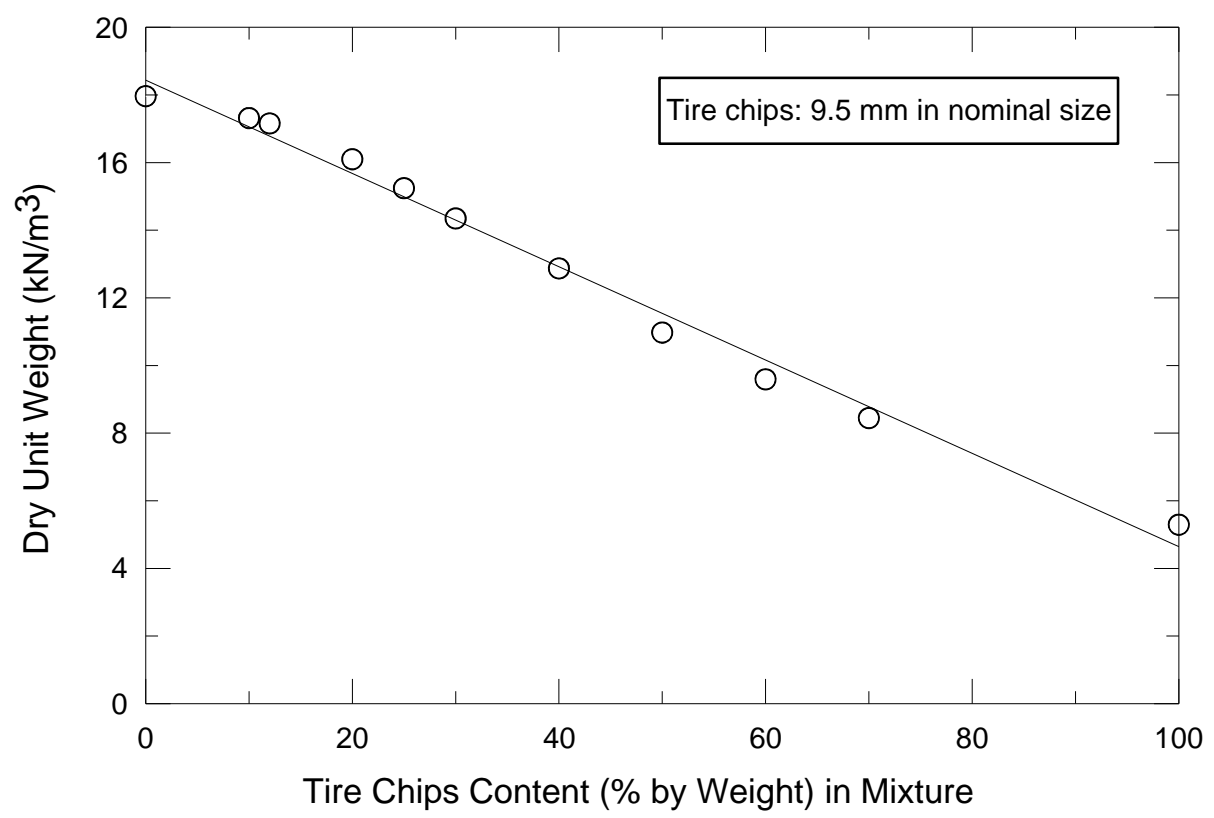

(a) Tire chips (9.5-mm in nominal size)

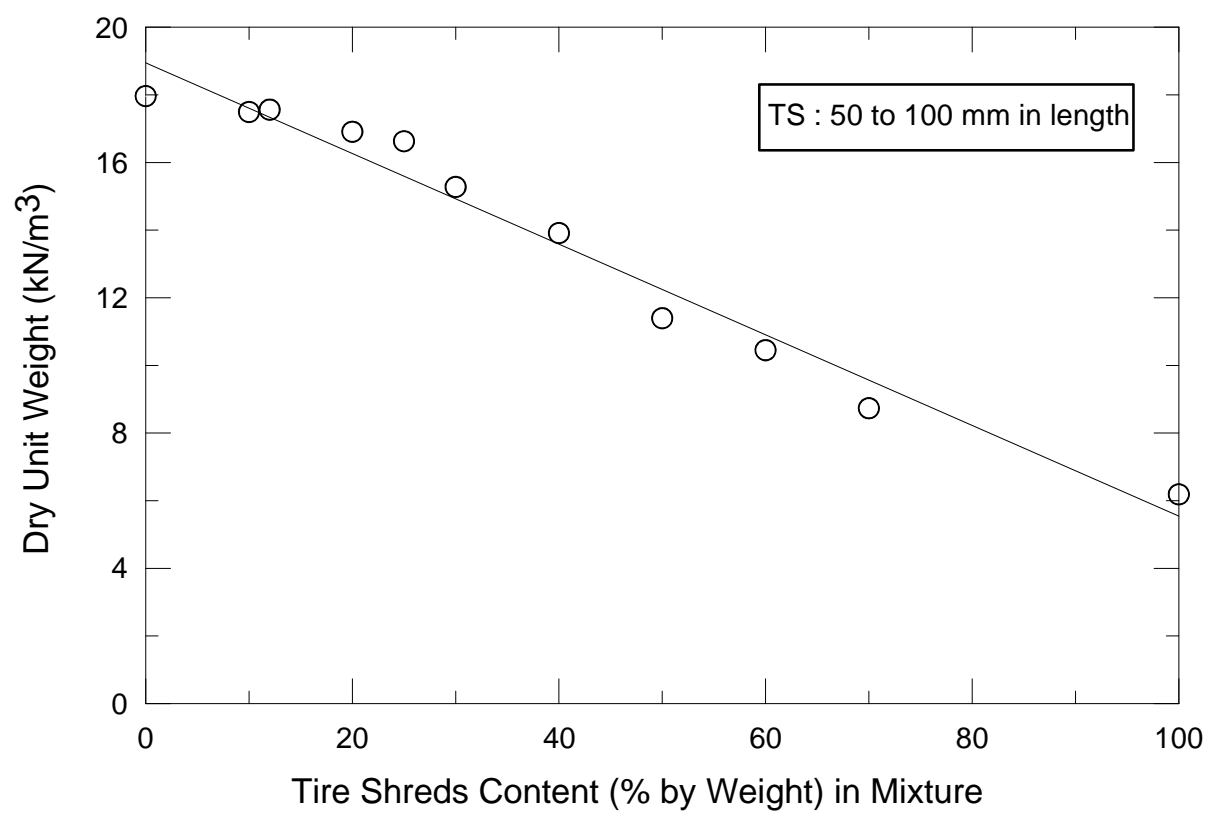

(b) Tire shreds (50-100 $\mathrm{mm}$ in length) 


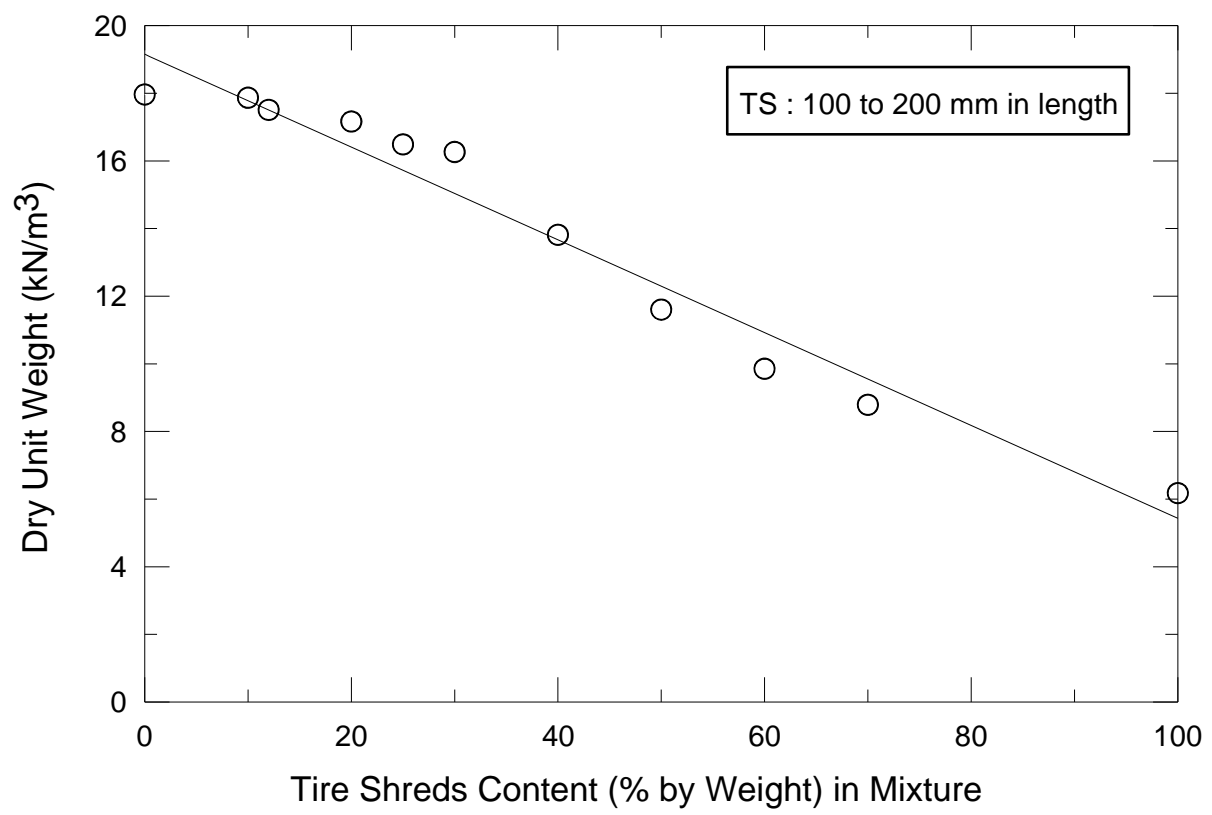

(c) Tire shreds (100-200 $\mathrm{mm}$ in length)

Figure 3-8 Dry unit weight of shredded tires and Ottawa sand mixtures with different shredded tire contents. 


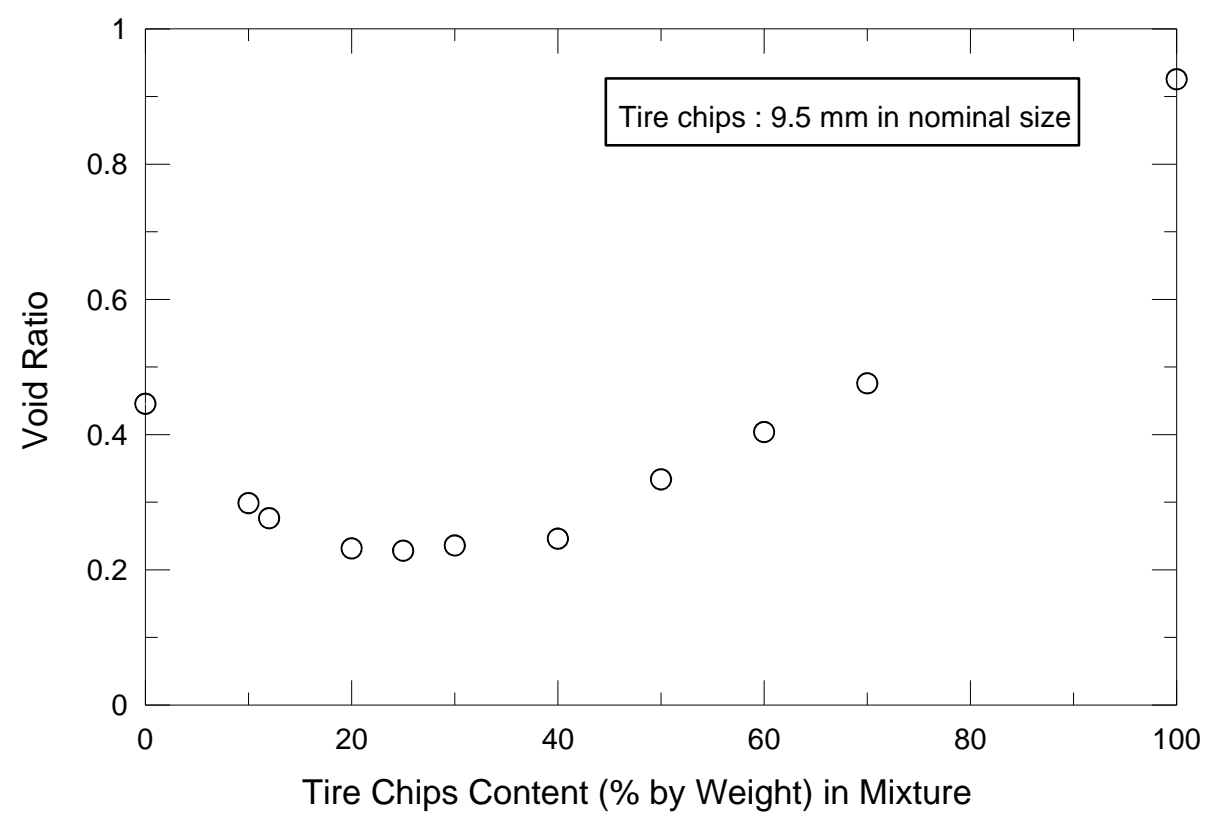

(a) Tire chips ( $9.5 \mathrm{~mm}$ in nominal size)

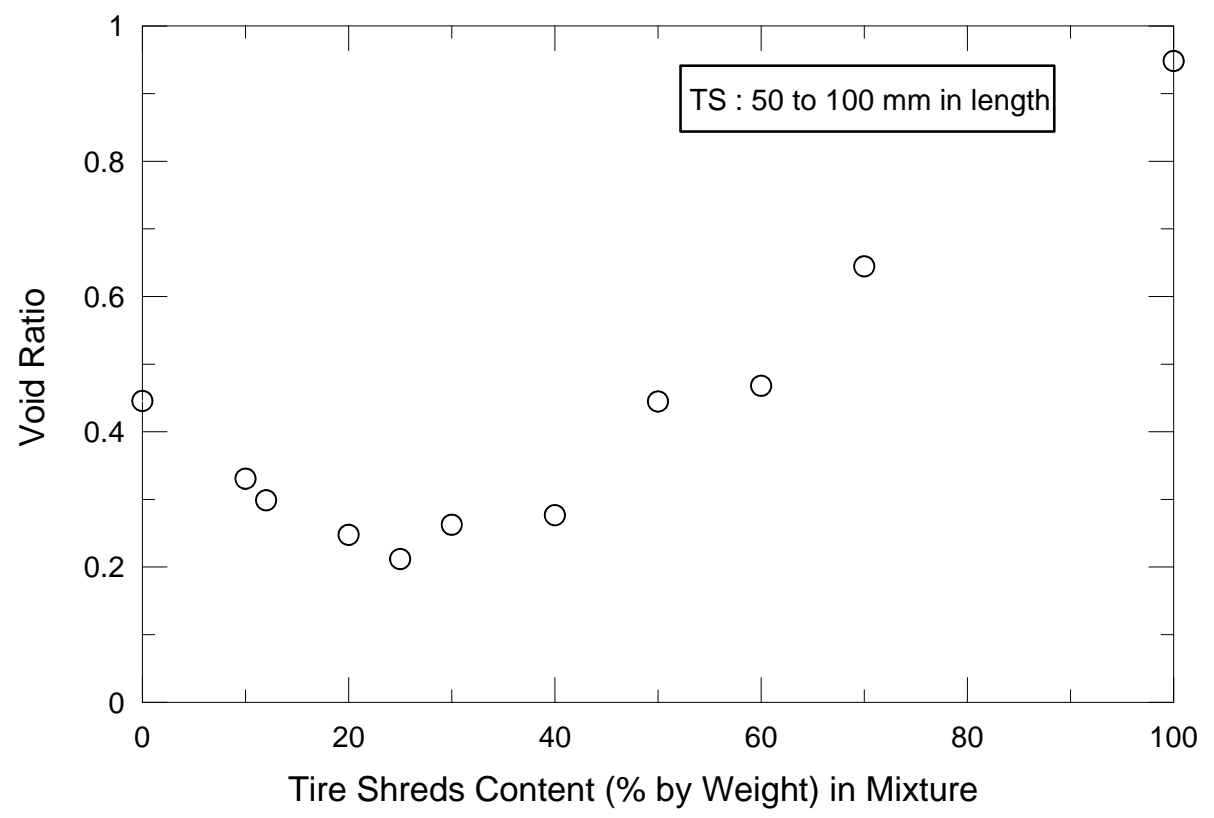

(b) Tire shreds (50-100 $\mathrm{mm}$ in length) 


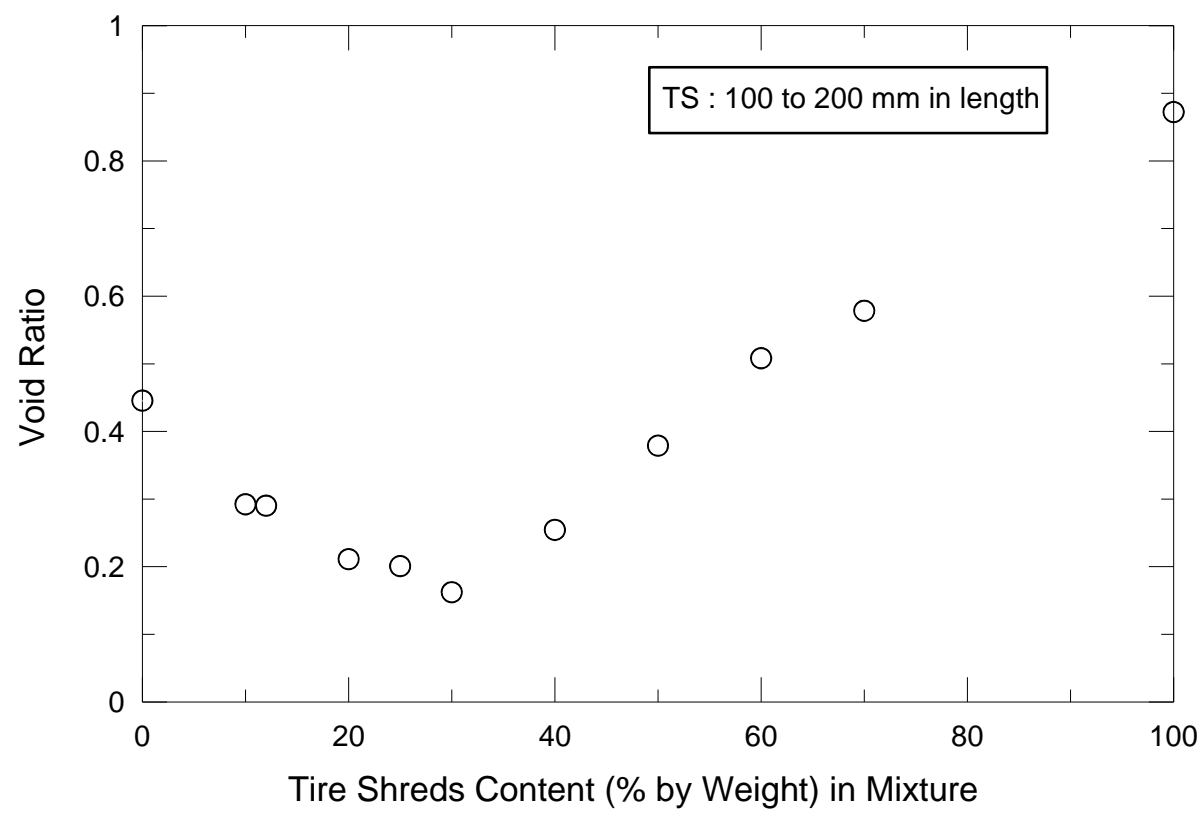

(c) Tire shreds (100-200 $\mathrm{mm}$ in length)

Figure 3-9 Total void ratios of compacted shredded tire-sand mixtures as a function of the shredded tire content by weight. 


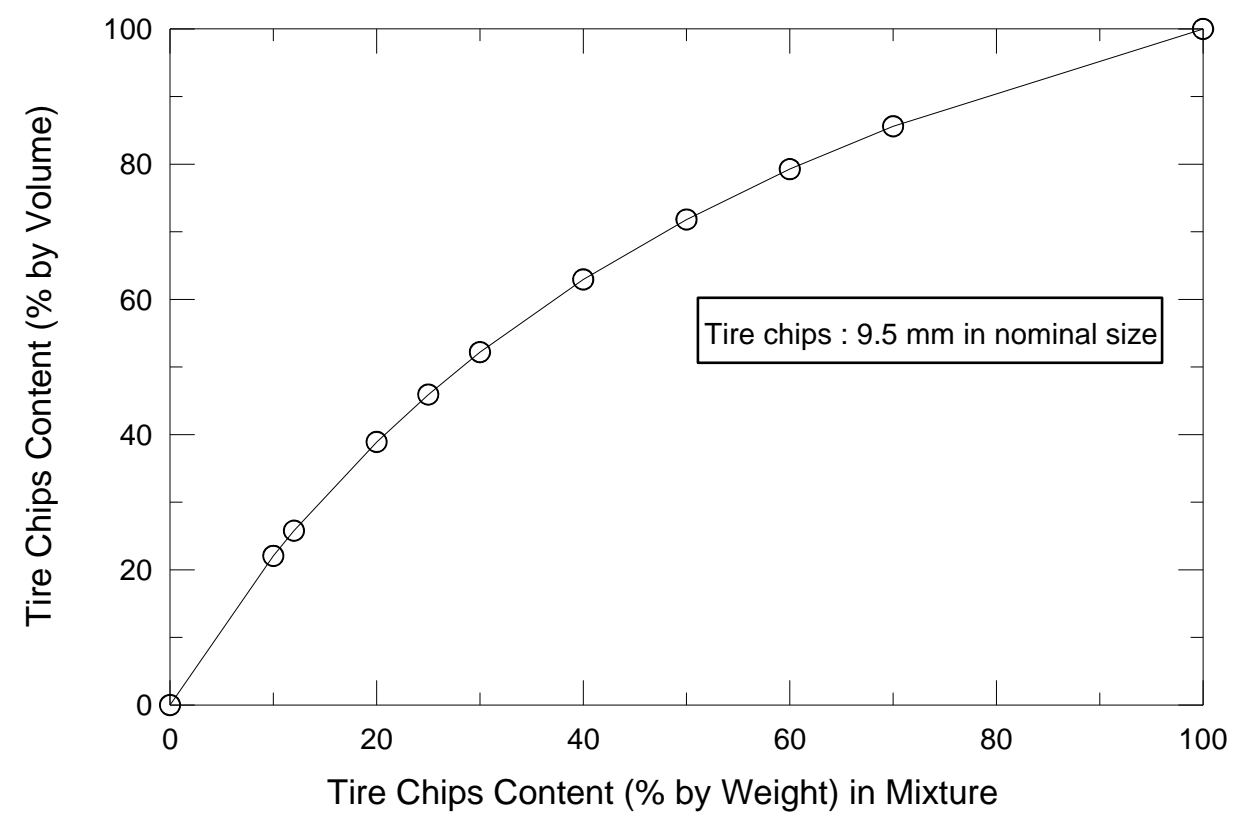

(a) Tire chips (9.5 $\mathrm{mm}$ in nominal size)

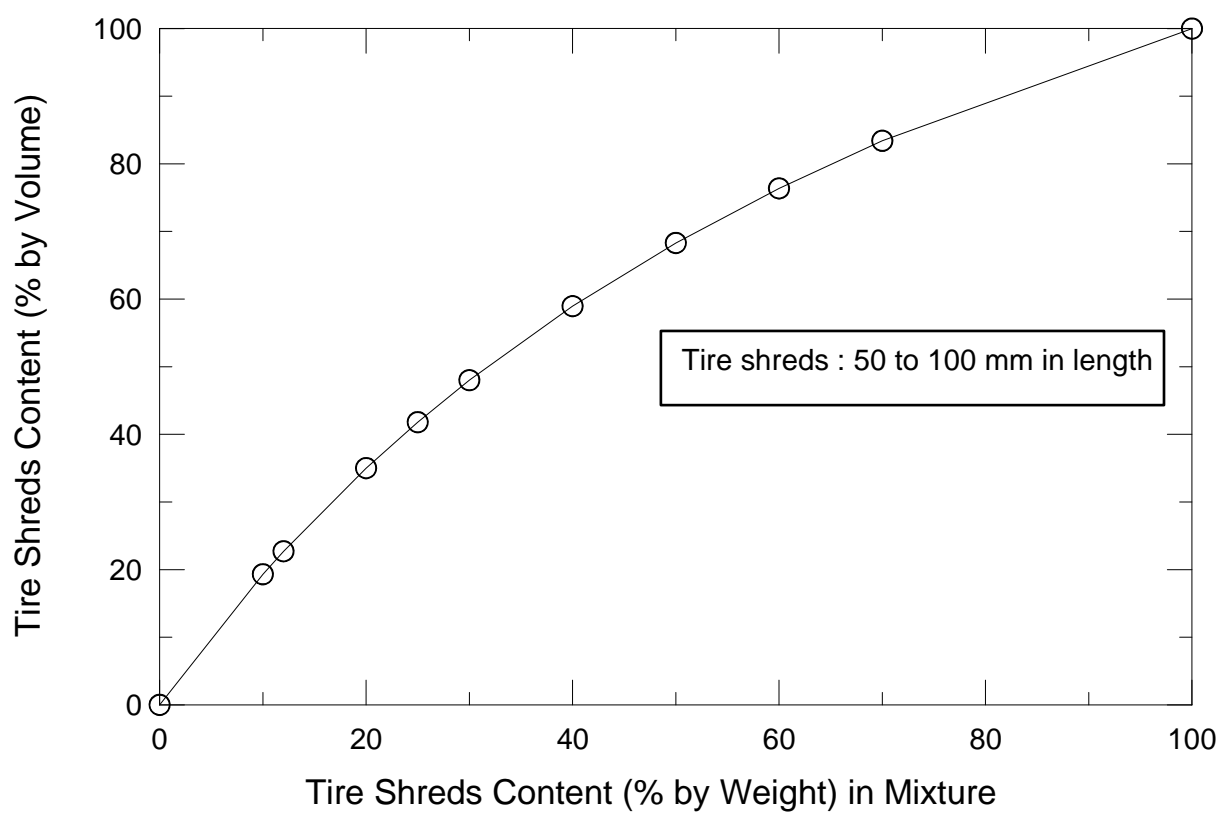

(b) Tire shreds (50-100 $\mathrm{mm}$ in length) 


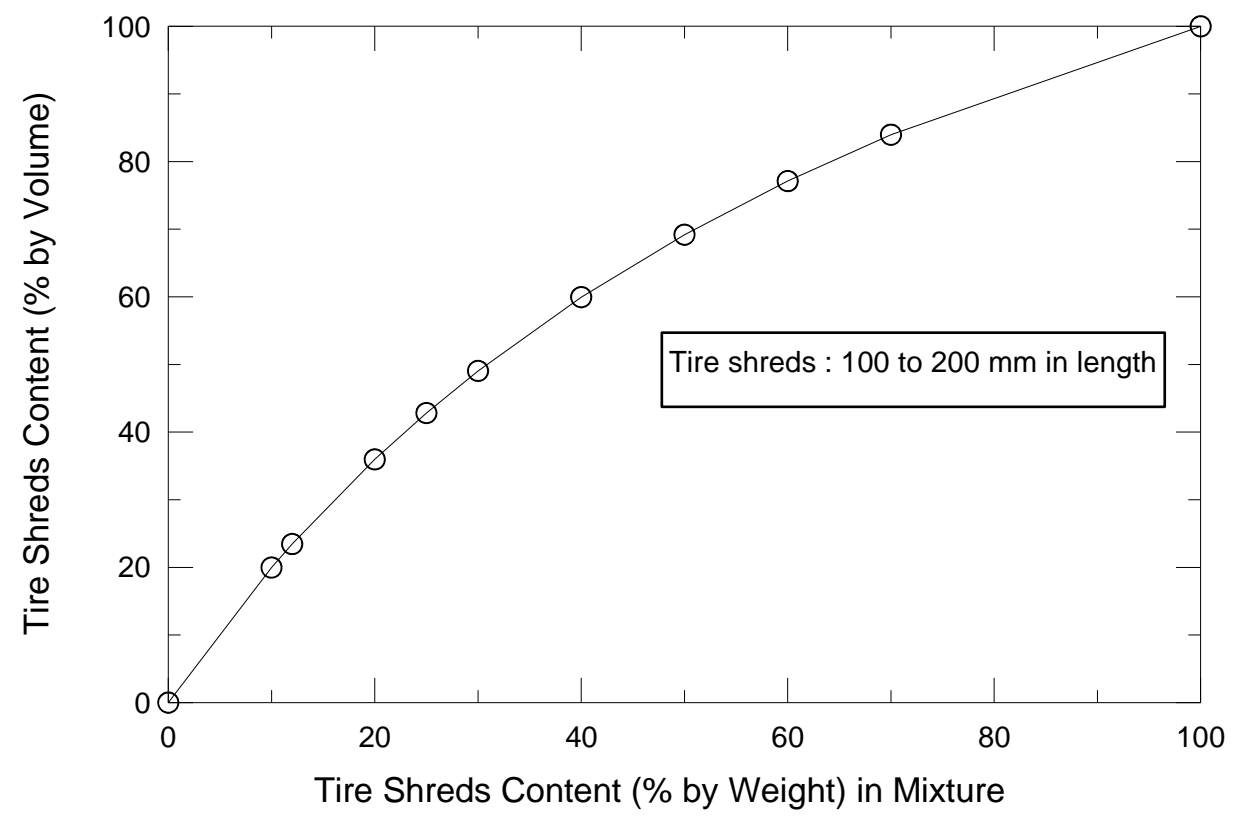

(c) Tire shreds (100-200 $\mathrm{mm}$ in length)

Figure 3-10 Relationship between weight ratios and volume ratios of shredded tires present in the mixtures. 
Table 3-3 Summary of compaction tests results.

\begin{tabular}{ccccccc}
\hline Size of shredded tires & $\begin{array}{c}\gamma_{\mathrm{d} \text {,mixture with }} \\
\text { optimum } \\
\text { mixing ratio } \\
\left(\mathrm{kN} / \mathrm{m}^{3}\right)\end{array}$ & $\mathrm{e}_{\text {min,ts }}$ & $\mathrm{e}_{\text {min,sand }}$ & $\mathrm{e}_{\text {min,mix }}$ & $\begin{array}{c}\text { Optimum mixing ratio } \\
\text { of shredded tires/sand } \\
\text { (by weight) }\end{array}$ & $\begin{array}{c}\text { Optimum mixing ratio } \\
\text { of shredded tires/sand } \\
\text { (by volume) }\end{array}$ \\
\hline $9.5 \mathrm{~mm}$ in nominal size & 15.2 & 0.92 & 0.45 & 0.23 & $25 / 75$ & $46 / 54$ \\
$50-100 \mathrm{~mm}$ in length & 16.6 & 0.95 & 0.45 & 0.21 & $25 / 75$ & $42 / 58$ \\
$100-200 \mathrm{~mm}$ in length & 16.3 & 0.87 & 0.45 & 0.16 & $30 / 70$ & $49 / 51$ \\
\hline
\end{tabular}




\subsection{Segregation of Tire Shred-Sand Mixtures}

Segregation has been one of the main concerns of using tire shred-sand mixtures as fill material. As described in the previous section, tire shred-sand mixtures were prepared with various mixing ratios and compacted in three layers using the standard Proctor compaction energy. Segregation of tire shreds in the compacted samples was evaluated by determining the tire shred-sand ratios at three different layers in these samples. Figure 3-11 shows the result of the segregation tests.

The results show that segregation does not occur for mixtures with high sand contents, as expected. At high tire shred contents, segregation becomes very obvious. This can be explained as follows: the voids between the shredded tires are very large compared with the size of the sand grains, hence, during compaction using an impacttype rammer, the sand grains easily settle down through these voids within the tire shred matrix, particularly in the case of mixtures with high tire shred contents. For the optimum tire shred mixing ratios determined in the previous section, little or no segregation was observed. 


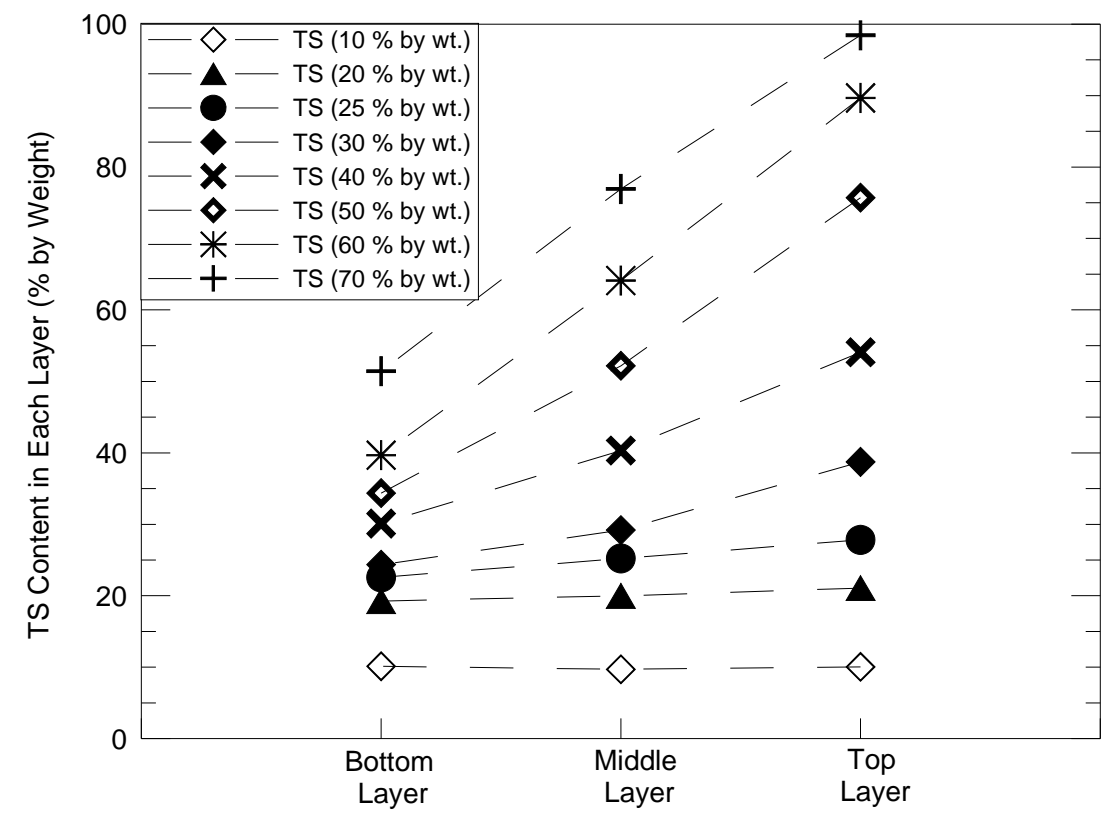

(a) Tire chips (9.5 $\mathrm{mm}$ in nominal size)

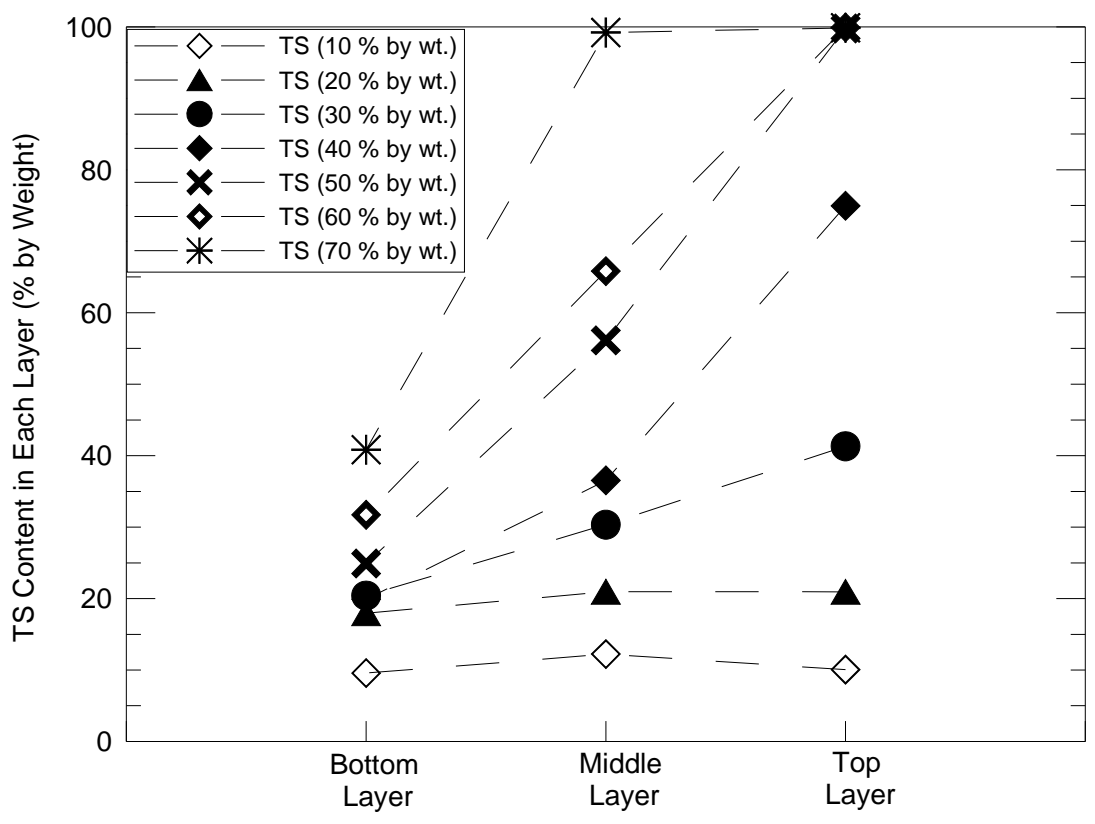

(b) Tire shreds (50-100 mm in length) 


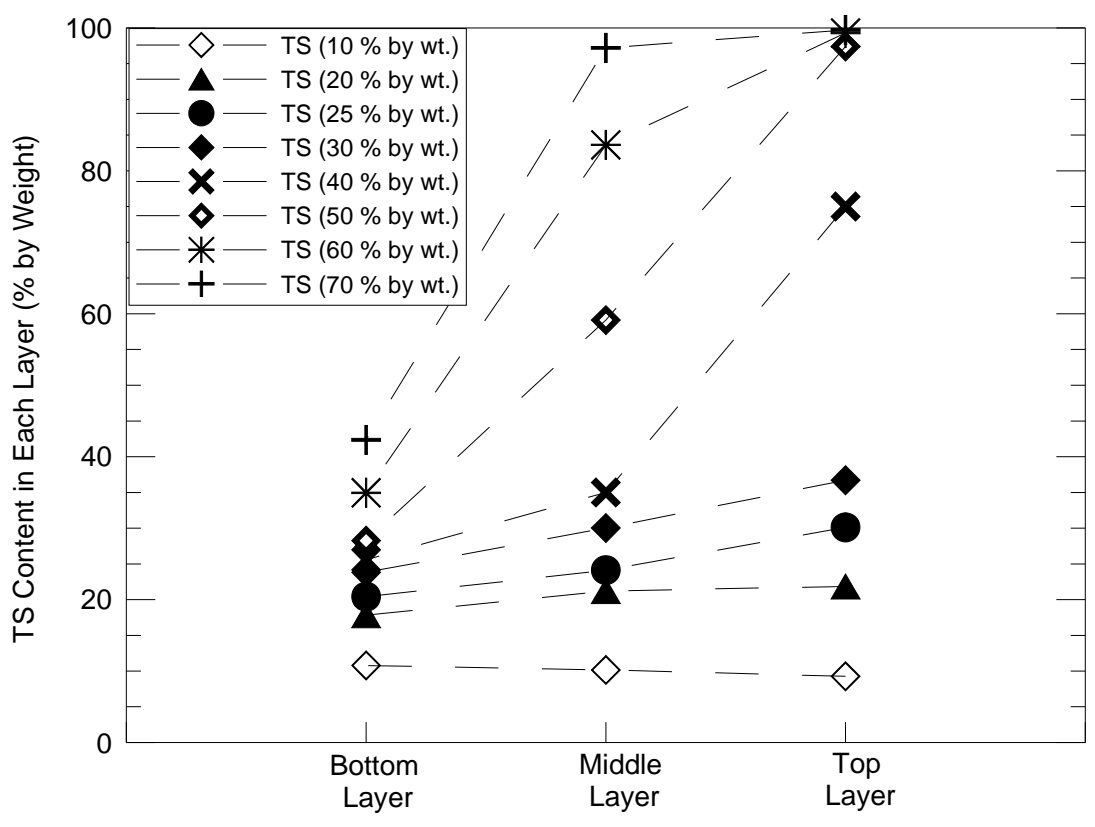

(c) Tire shreds (100-200 $\mathrm{mm}$ in length)

Figure 3-11 Segregation of shredded tire-sand mixtures. 


\subsection{Summary}

To prevent self-ignition, floating of tire shreds in a soil matrix is desired. The minimum mixing ratio that produces such an arrangement can be determined by laboratory compaction tests. The mixing ratio producing a minimum overall void ratio is the minimum mixing ratio leading to this arrangement. To determine the optimum mixing ratios, compaction tests were performed on mixtures of shredded tires (tire chips $9.5 \mathrm{~mm}$ in nominal size, tire shreds $50-100 \mathrm{~mm}$ in length, and tire shreds $100-200 \mathrm{~mm}$ in length) and sand prepared with different mixing ratios. The dry unit weight of the mixtures decreased with increasing contents of shredded tires in the mixtures. As the sand content in the mixtures increased, the overall void ratio of the mixtures decreased, and then increased. The mixing ratio that produced the minimum overall void ratio was defined as the optimum mixing ratio. The optimum mixing ratios (shredded tire/sand) were determined to be $25 / 75,25 / 75$ and $30 / 70$ by weight (46/54, $42 / 58$ and $49 / 51$ by volume) for tire chips $9.5 \mathrm{~mm}$ in nominal size, tire shreds $50-100 \mathrm{~mm}$ in length, and tire shreds $100-200 \mathrm{~mm}$ in length, respectively.

Segregation of the mixtures in samples compacted in the laboratory using impact-type rammer compaction was evaluated in three layers. The test results showed little or no segregation for high sand contents. At the optimum mixing ratio determined using the method proposed, little or no segregation was observed. 


\section{CHAPTER 4. LABORATORY PULLOUT TEST}

\section{1. $\underline{\text { Overview }}$}

The main objective of the pullout testing program was to evaluate the pullout response of two types of reinforcements commonly used in practice - a geogrid and a ribbed-metal strip - placed within the tire shred-sand mixtures for various test conditions. Samples of geogrid and metal strips used in the study are shown in Figure 4-1. The parameters considered for this study were: (1) various tire shreds sizes (tire chips $9.5 \mathrm{~mm}$ nominal size, tire shreds $50-100 \mathrm{~mm}$ in length and tire shreds $100-200 \mathrm{~mm}$ in length), and (2) various tire shred-sand mixing ratios $(0,12,25$ and $100 \%$ of tire shreds in the mixture by weight; the entire range of mixing ratios, from pure sand to pure tire shreds, was investigated). The tests were performed at a confining pressure of $40 \mathrm{kPa}$. While pulling out the geogrid/ribbed-metal strip placed in the tire shred-sand mixture, frontal displacement and the pullout force were monitored using LVDT and a load cell.

This chapter presents the details of the pullout testing apparatus and the sample preparation protocol for the pullout tests performed on geogrid and metal strips with tire shred-sand mixtures. In chapter 5 , the results of the pullout tests are reported and analyzed. 


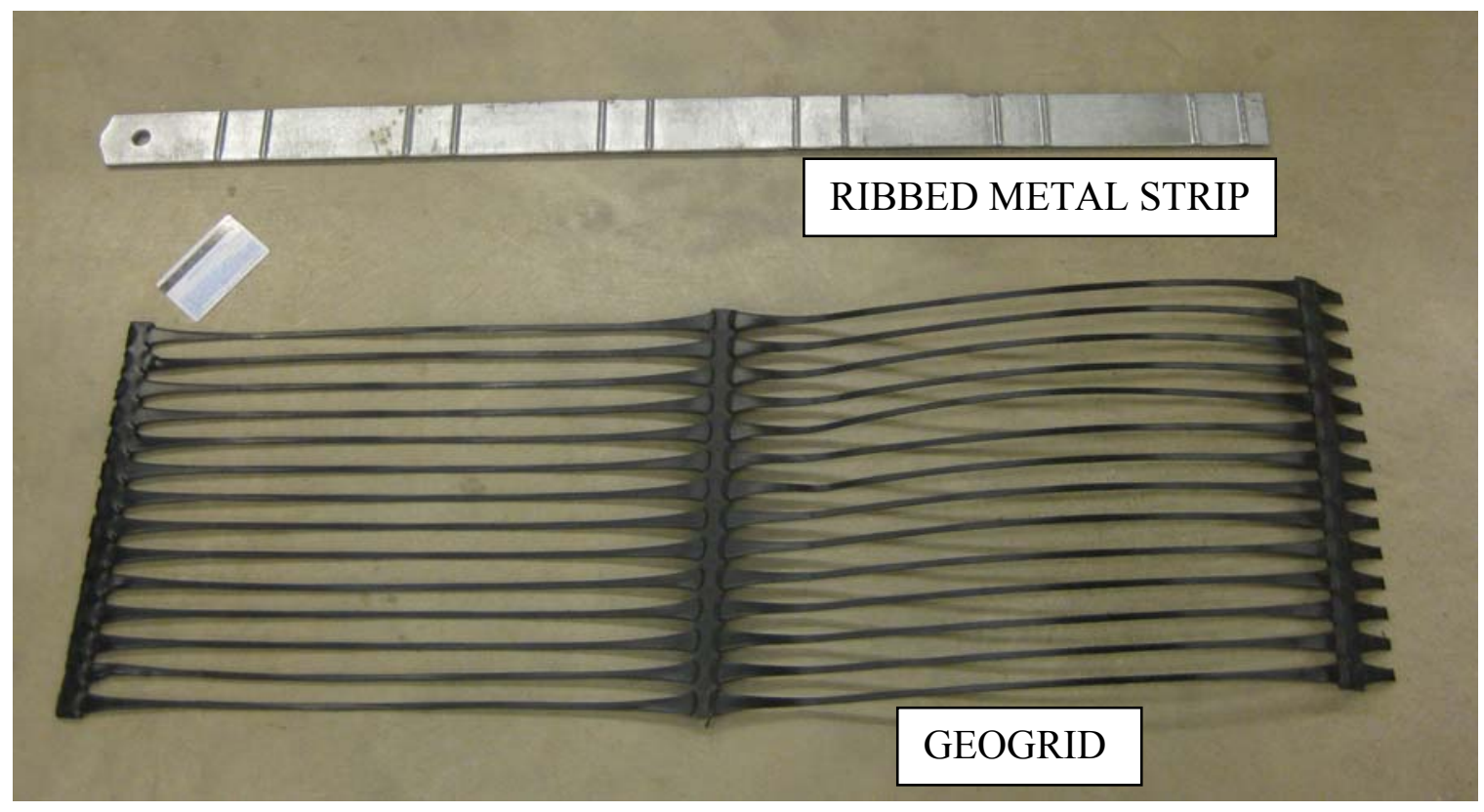

Figure 4-1 Reinforcement types used in this study: geogrid and ribbed-metal strip

\subsection{Pullout Test Machine}

The main components of the pullout testing system are the: (1) pullout box, (2) shearing system, (3) geogrid/ribbed-metal strip clamping system, (4) airbag for application of the confining pressure, (5) monitoring system, and (6) data acquisition system. The pullout testing machine was originally developed by Prof. Fox and built for the determination of the strength of a geosynthetic clay liner (GCL) (Fox et al. 1997). For this research study, the machine was modified to be equipped with a clamping system and a sleeve. Also, the monitoring and data acquisition systems were set up. 
The pullout machine is a free-standing apparatus and essentially consists of two chambers: the tire shred-sand mixture chamber and the load-cell chamber (see Figure 4-2). In order to prepare the sample for testing, the pre-mixed tire shred-sand mixture was placed in four layers within the tire shred-sand mixture chamber and compacted to achieve the desired level of compaction. The inner dimensions of the tire shred-sandmixture chamber are $1.0 \mathrm{~m} \times 0.38 \mathrm{~m} \times 0.47 \mathrm{~m}($ length $\times$ width $\times$ height $)$.

When the confining pressure is applied on top of the sample, friction develops between the sample and the side walls of the pullout box and, as a result, can decrease the normal stress applied on the reinforcement. The pullout capacity of the reinforcement may be overestimated (Farrag et al. 1993). To minimize the sample-side wall friction, smooth-vinyl sheets were glued along the side walls of the pullout box. The pullout load was applied using two stepper motors. This loading system can provide a large pullout rate range, varying from $10 \mathrm{~mm} / \mathrm{min}$ to virtually zero. The motors are connected to double reduction gear boxes that drive the lead screws (diameter of lead screw: $57.1 \mathrm{~mm}$, pitch: $12.7 \mathrm{~mm}$, and gear box ratio: 900/1) during the test. The capacity of each lead screw is $93 \mathrm{kN}$, hence, because there are two screws connected to the gear box, the maximum pullout force that can be applied is $186 \mathrm{kN}$. The pulling out of the reinforcement and the displacement rate are controlled by a computerized system.

Figure 4-3 and Figure 4-4 show, respectively, the schematic cross sections of the pullout box and clamping system when geogrid reinforcement was tested. The clamping system consists of L-shaped upper and lower clamps (Figure 4-5). The geogrid was tightly fastened between the clamps using a screw system to prevent slippage of the geogrid during pullout. The total length of the geogrid used for testing was $0.96 \mathrm{~m}$. Part 
of this length was gripped between the clamps at the front end of the pullout box. The effective embedment length of the geogrid that offered resistance to the applied pullout load was equal to $0.8 \mathrm{~m}$ (Figure 4-6).

A different clamping arrangement was used to clamp the metal strip reinforcement. The ribbed-metal strip was sandwiched between metal wedges and tightly gripped using four bolts to prevent slippage during testing. Figure 4-7 shows the schematic diagram of the cross section of the pullout box for testing of ribbed-metal strip reinforcement. Metal strips of length equal to $1.0 \mathrm{~m}$ were used; a length of about $0.74 \mathrm{~m}$ was embedded in the tire shred-sand mixture. The shear and passive resistances were developed along this embedded length during pullout of the strip (Figure 4-8).

Farrag et al. (1993) reported that the lateral earth pressure developed on the rigid front face of the pullout box during pulling out of the geogrid may cause the pullout capacity of the reinforcement to be overestimated. This potential problem was minimized by using a sleeve, as shown in Figure 4-9, which transfers the point of application of the pullout load beyond the rigid front wall. 


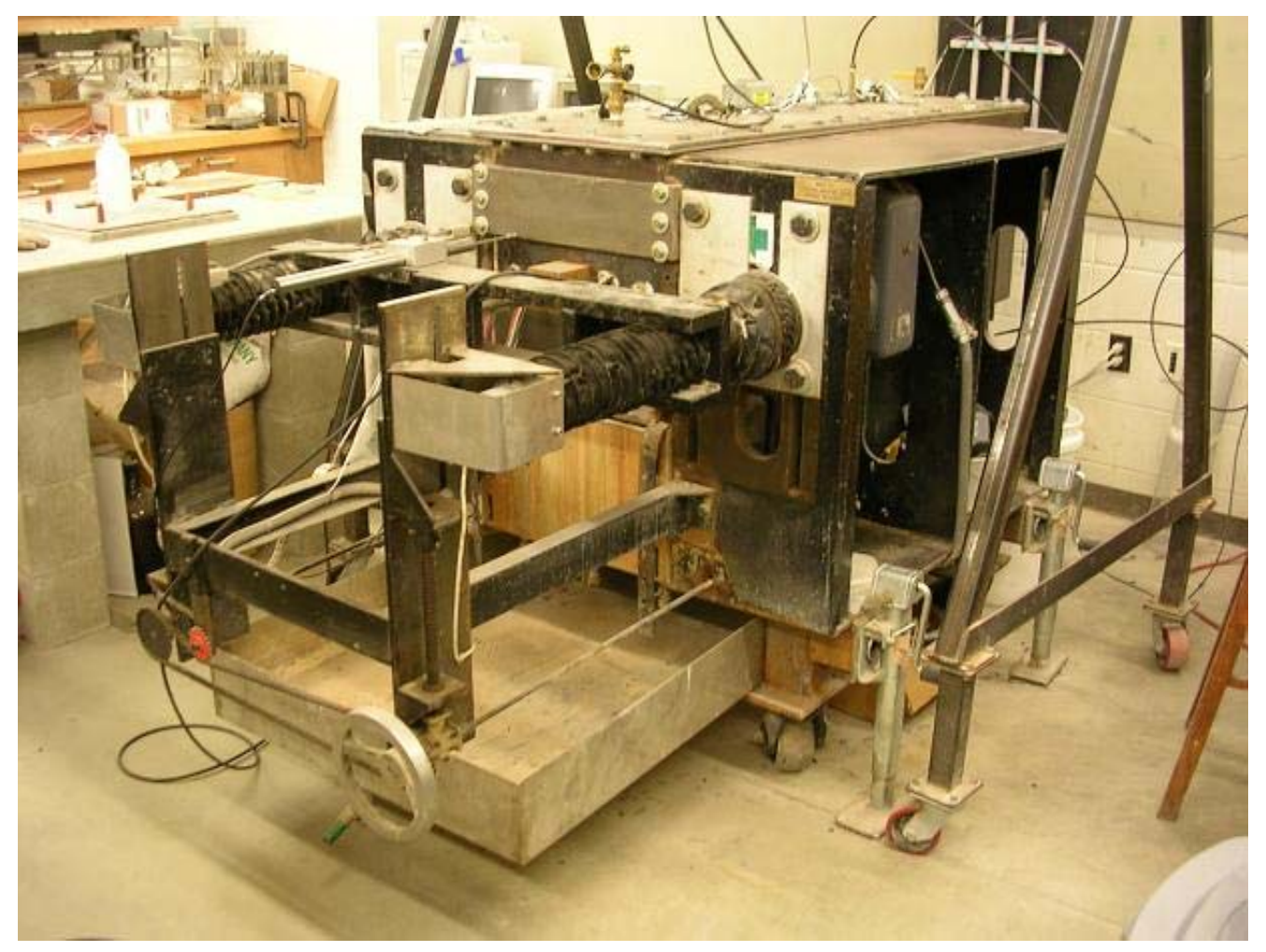

Figure 4-2 Pullout testing machine. 


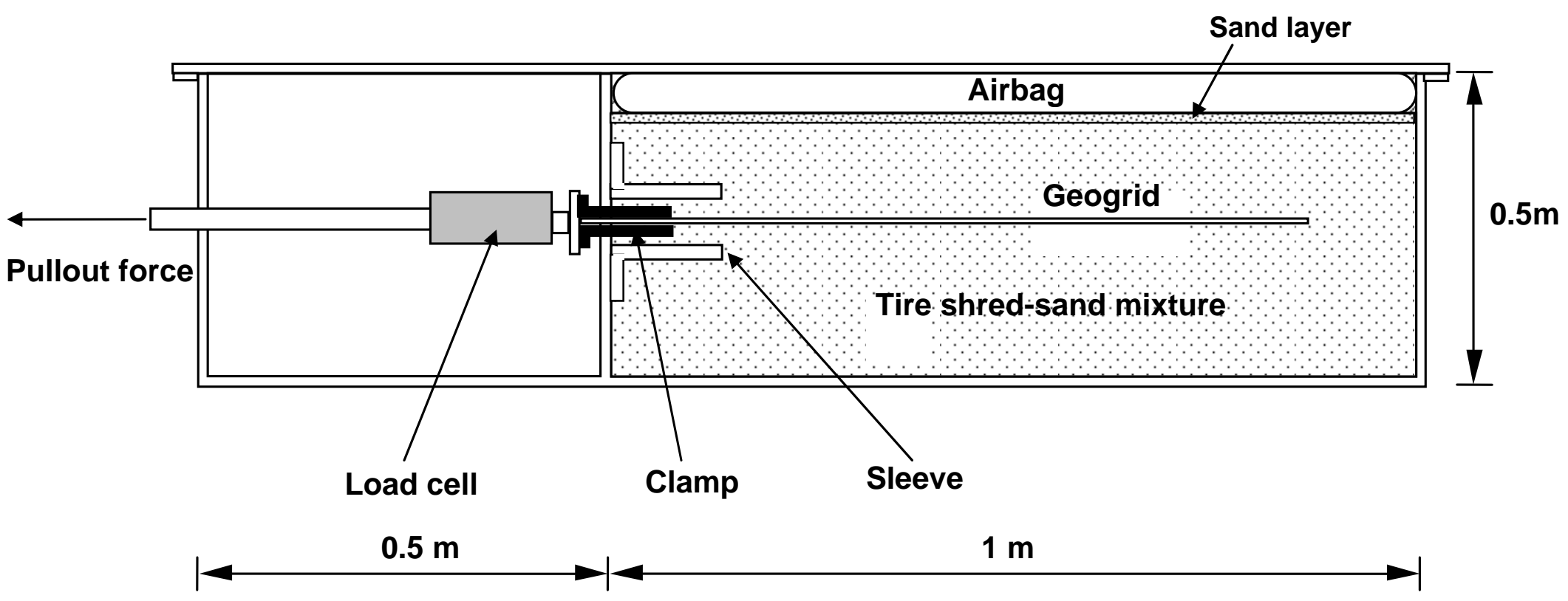

Figure 4-3 Schematic diagram of the cross section of the pullout box. 


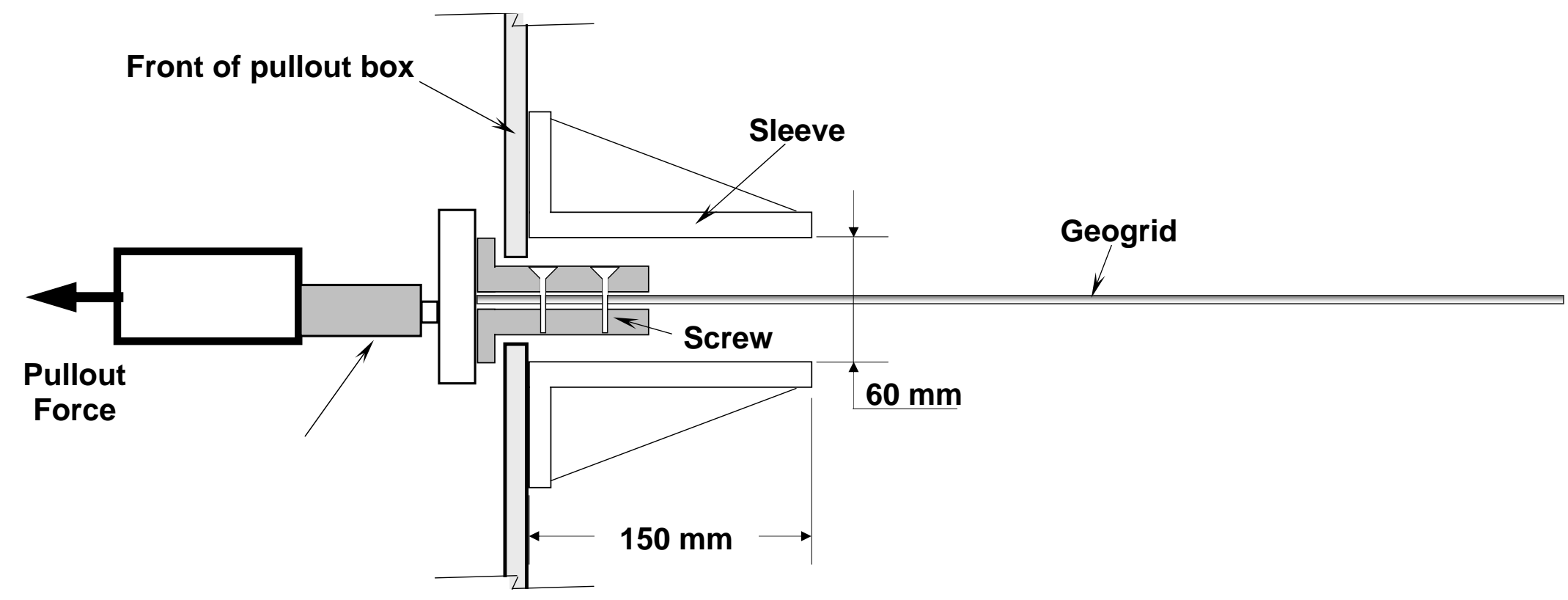

Figure 4-4 Schematic of the geogrid pullout clamping detail. 


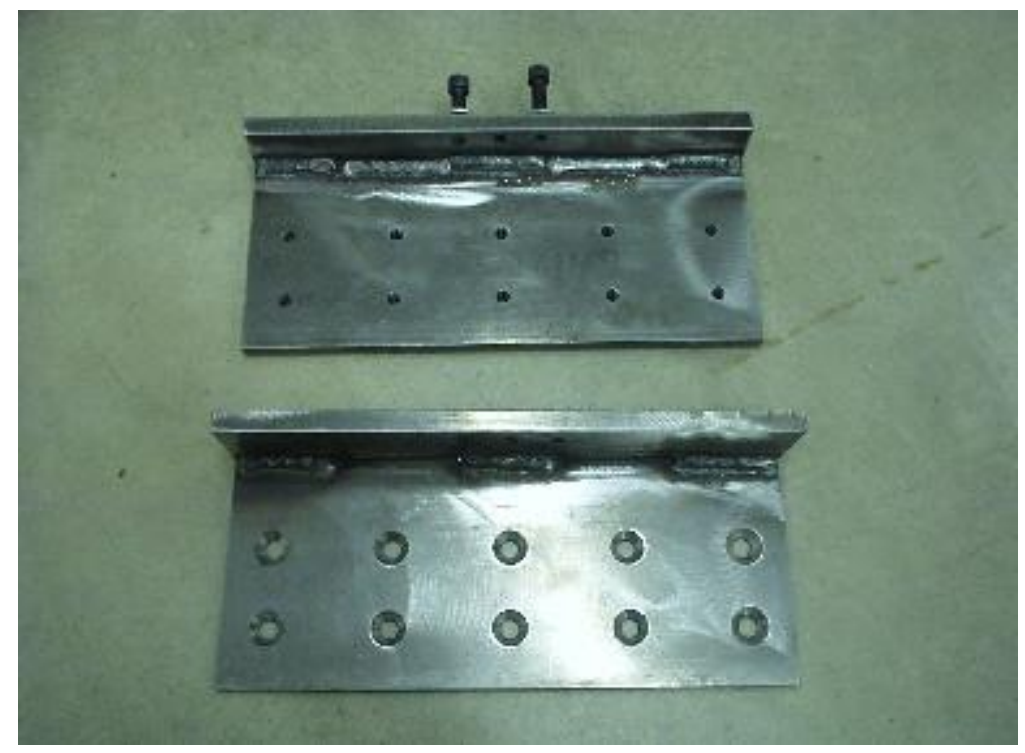

Figure 4-5 L-shaped geogrid clamps. 


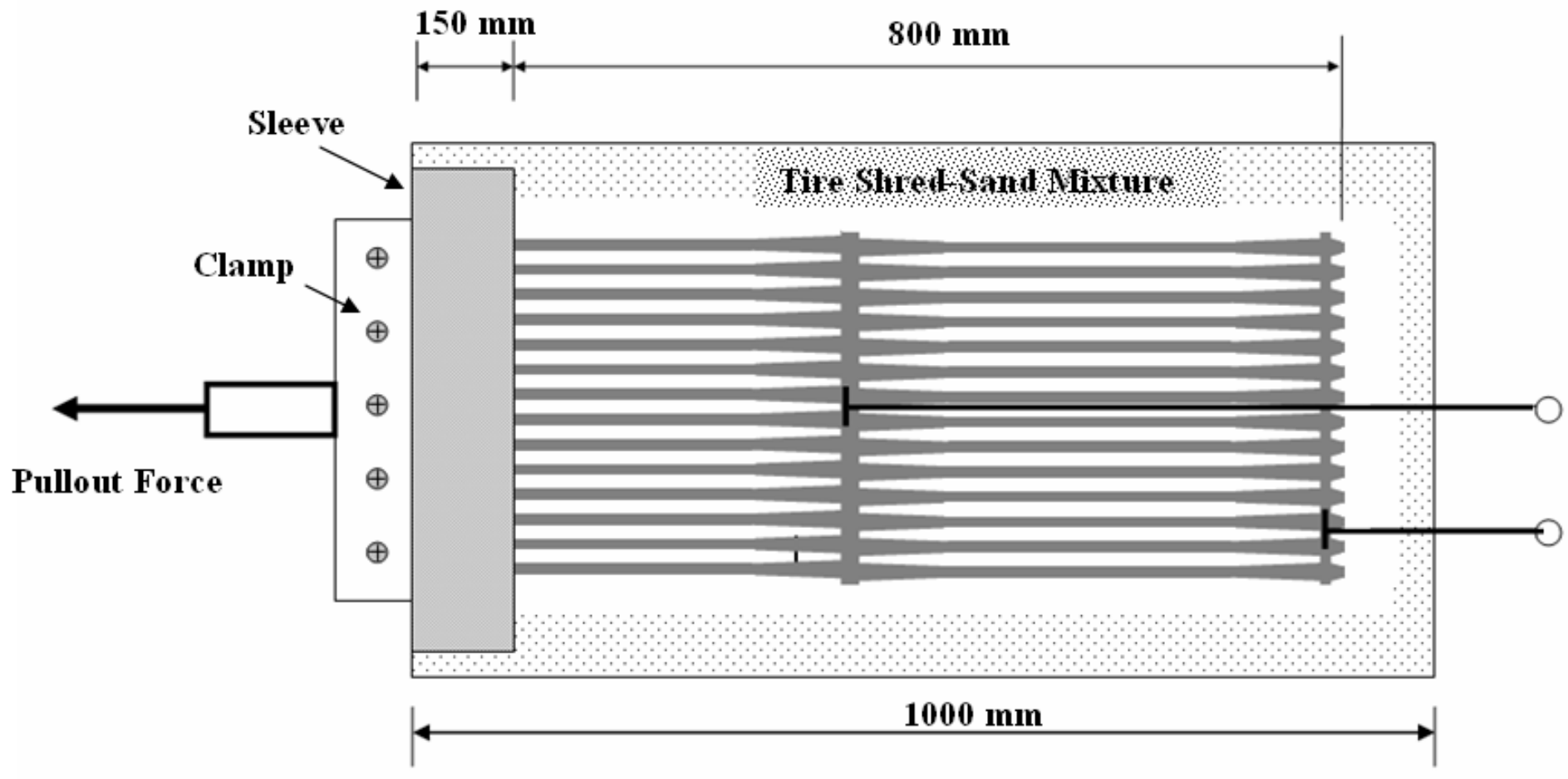

Figure 4-6 Schematic layout showing the geogrid placed in tire shred-sand mixture chamber. 


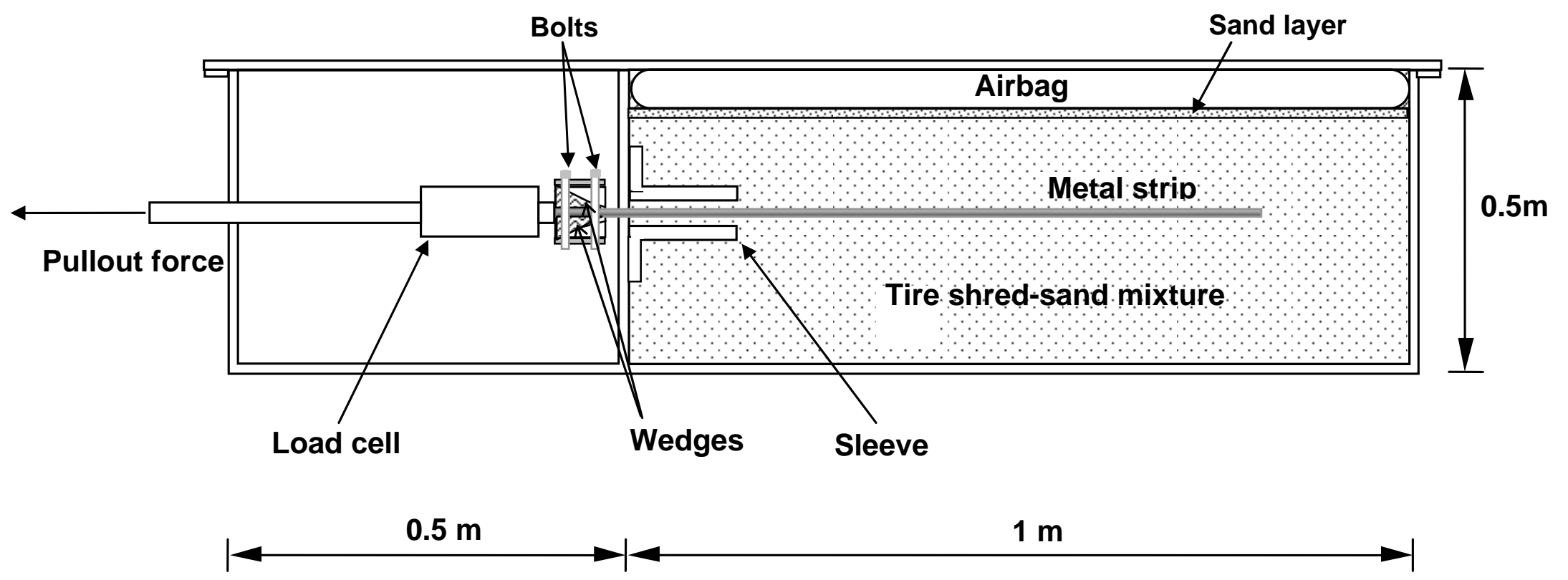

Figure 4-7 Schematic diagram of the cross section of the pullout box. 


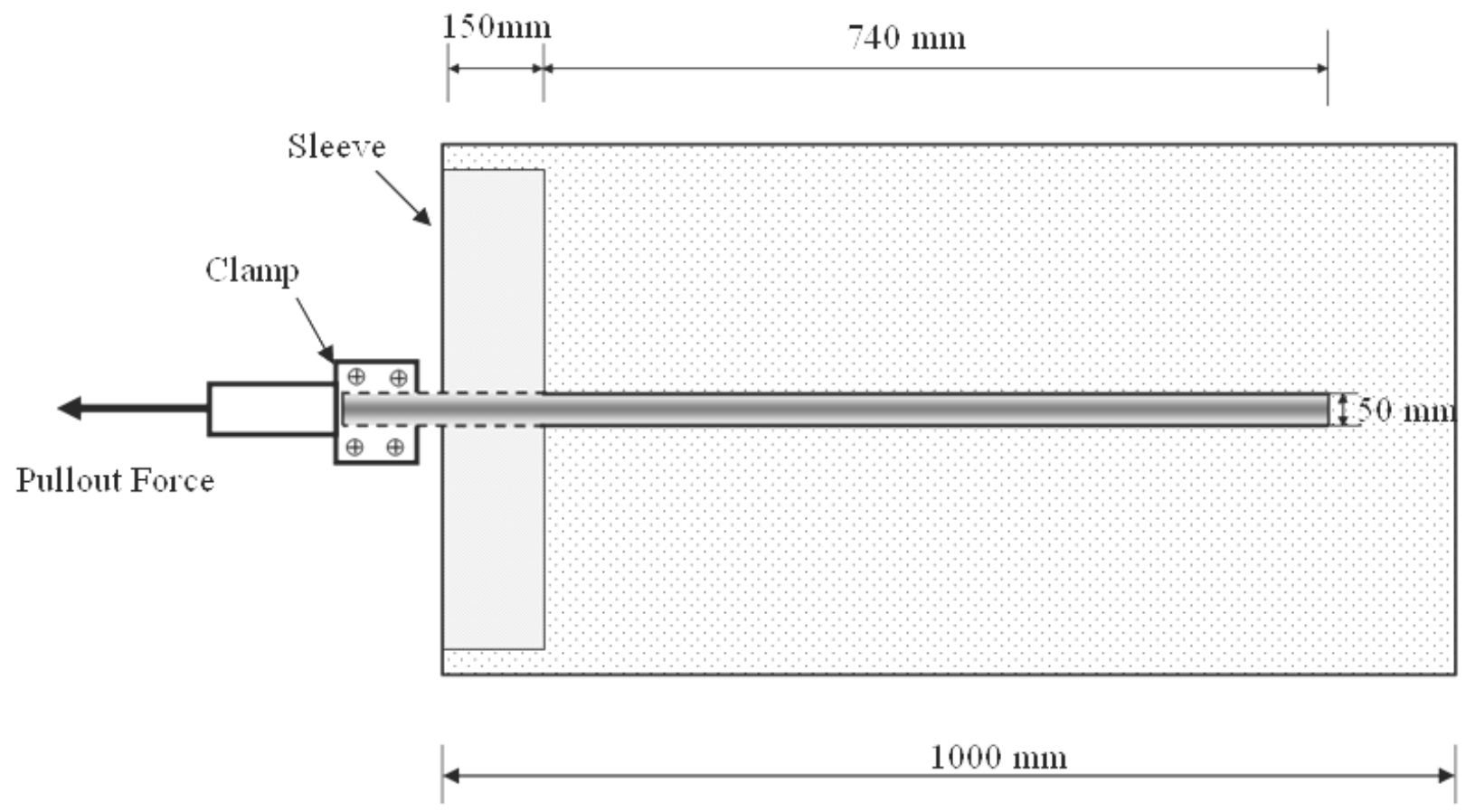

Figure 4-8 Schematic layout showing the metal strip placed in tire shred-sand mixture chamber. 


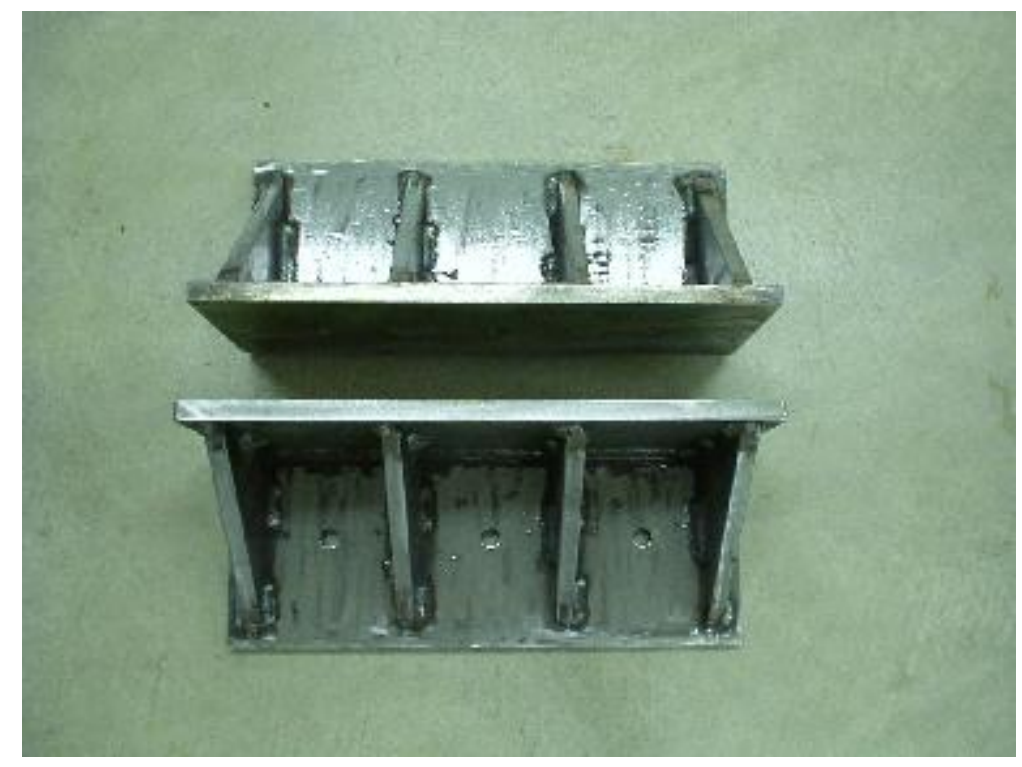

Figure 4-9 Sleeve.

\subsection{Monitoring System}

The monitoring of the frontal and nodal displacements, the pullout force, and the confining pressure was done using LVDTs, a load cell and a pressure transducer, respectively. The LVDTs, load cell and pressure transducer were calibrated before the tests.

\subsubsection{Displacement Indicators}

The frontal and nodal displacements were monitored using LVDTs (model No. LD600-150; manufactured by Omega). The maximum stroke of the LVDTs is $\pm 150 \mathrm{~mm}$. The frontal-displacement LVDT was mounted on the transversal bar that is connected to the lead screws of the pullout box (Figure 4-10). The two nodal-displacement LVDTs 
were mounted on the wall and connected to steel wires attached onto the geogrid (see Figure 4-6 and Figure 4-11).

\subsubsection{Load Cell and Pressure Transducer}

The pullout load was monitored using a load cell connected to the transversal bar that moves together with the lead screws (see Error! Reference source not found.). The load cell is a Universal Tension and Compression-Load cell (Model 3100; manufactured by Houston Scientific International Inc.). The maximum capacity of the load cell is 133 $\mathrm{kN}$.

The confining pressure applied by the airbag on top of the sample was monitored using a pressure transducer (Model AB; manufactured by Data Instruments Inc.). Its capacity is $1379 \mathrm{kPa}$. The air-pressure transducer was attached along the pressure line connecting the air bag during the test. Data acquisition system reads the actual pressure in the line (see Error! Reference source not found.). 


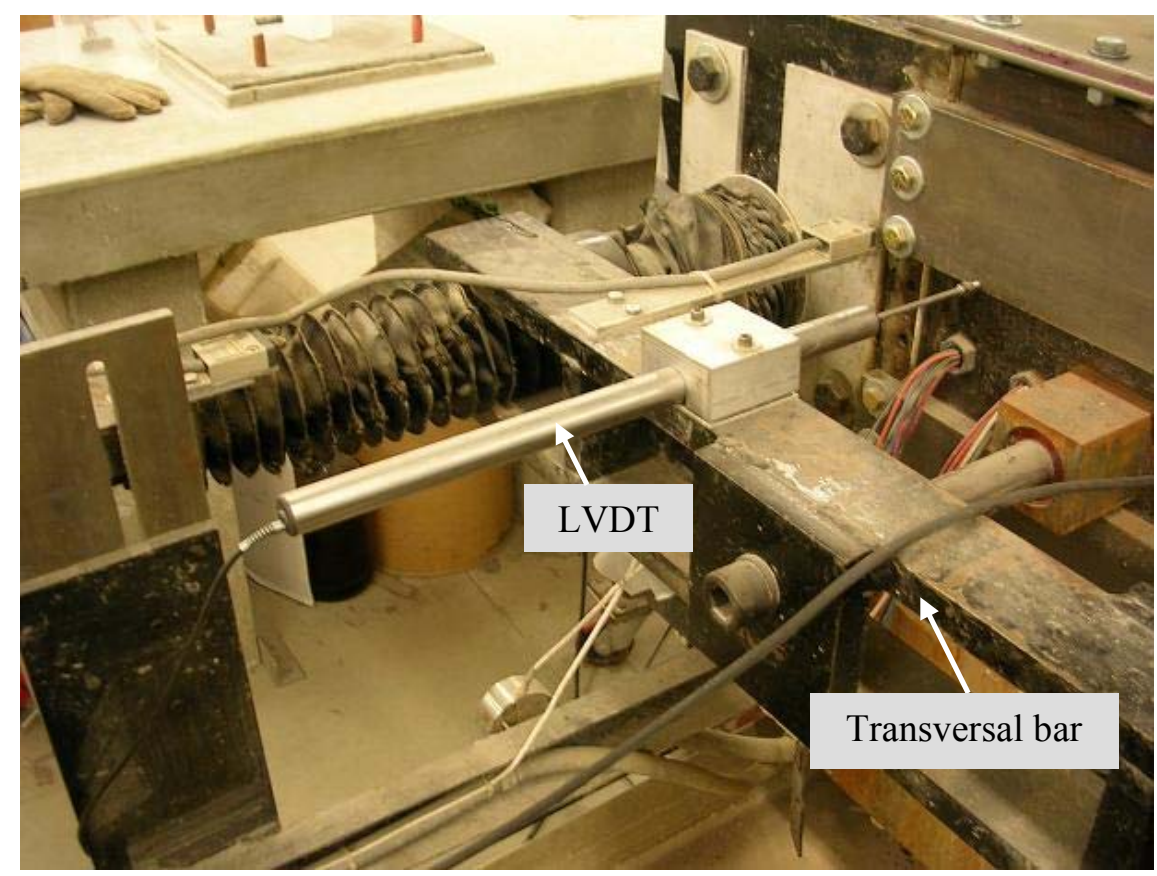

Figure 4-10 Frontal-displacement LVDT. 


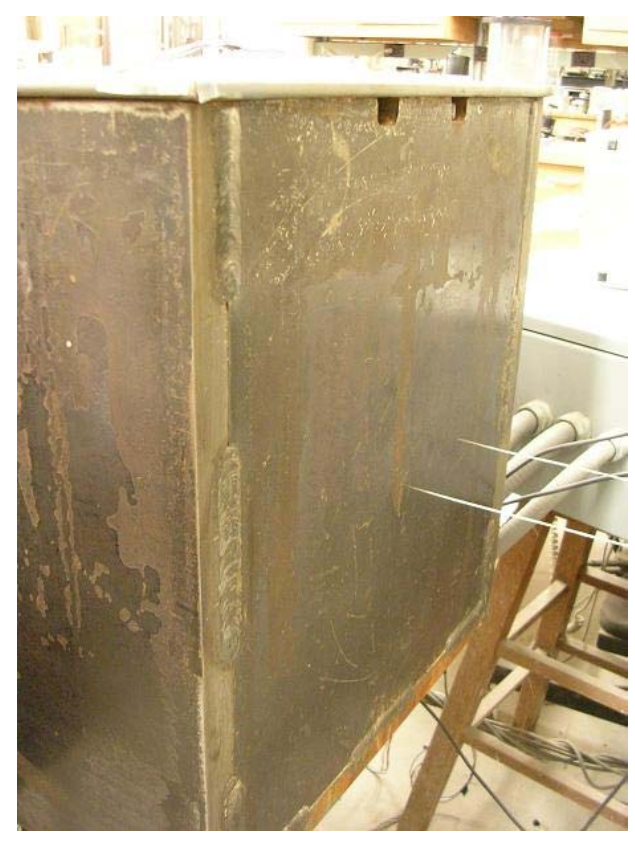

(a) Wires attached to geogrid

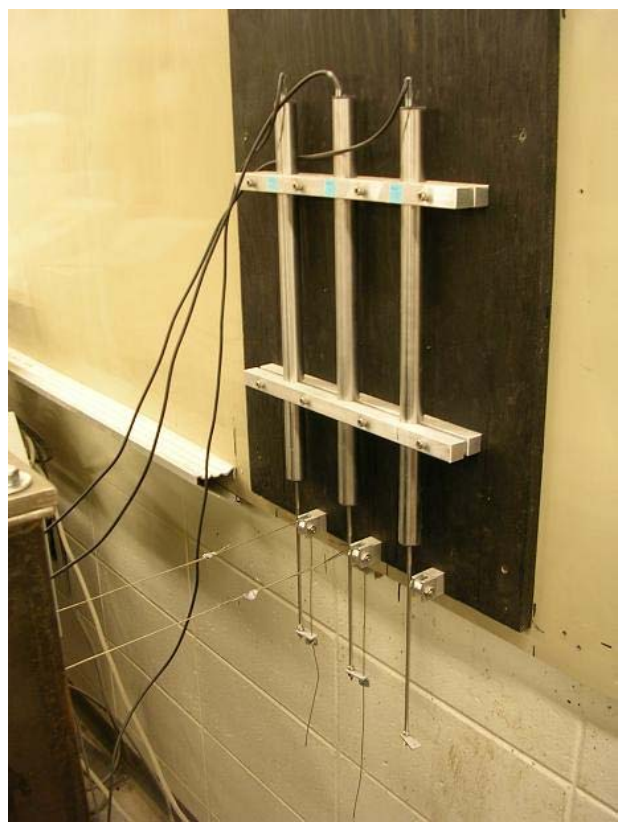

(b) Wall-mounted monitoring system

Figure 4-11 Nodal-displacement monitoring system. 


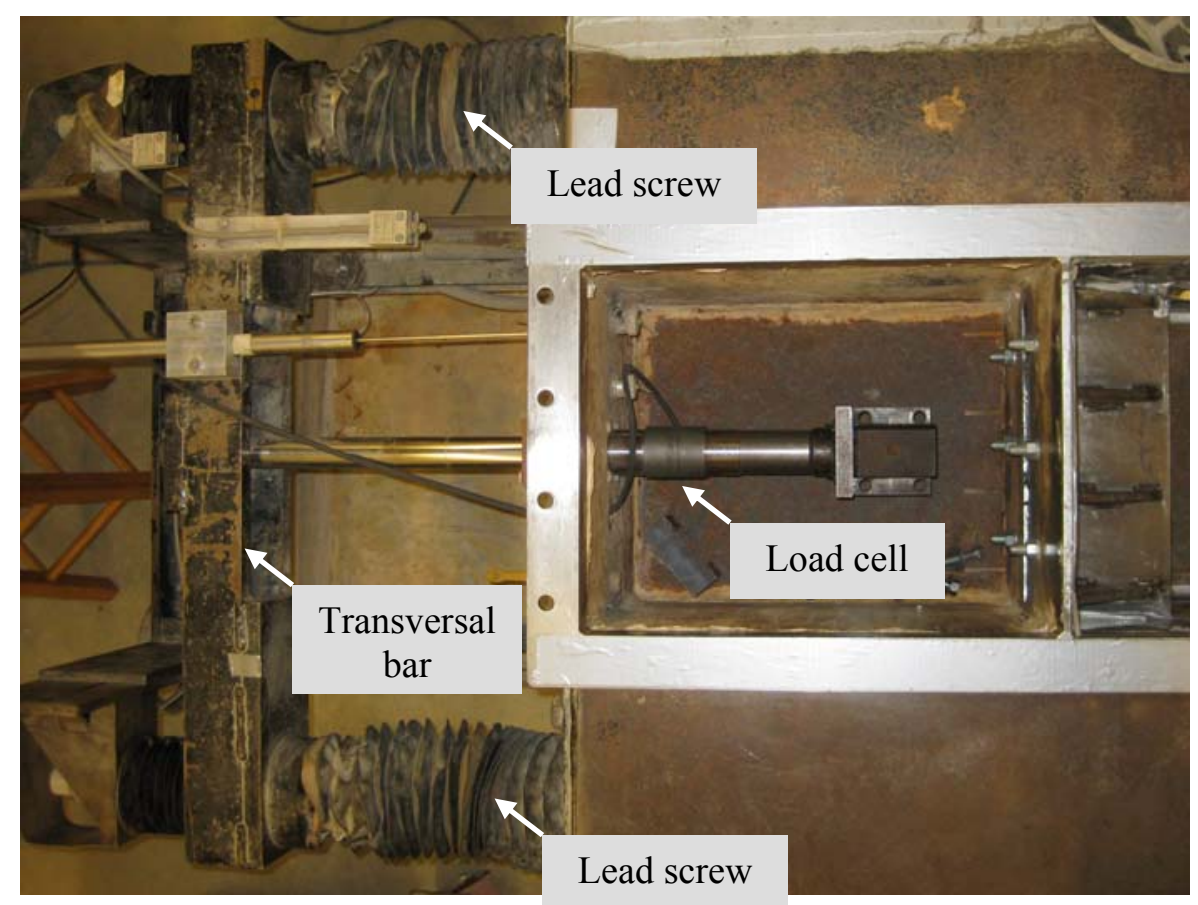

Figure 4-12 Load cell connected between the clamping system and transversal bar (top view).

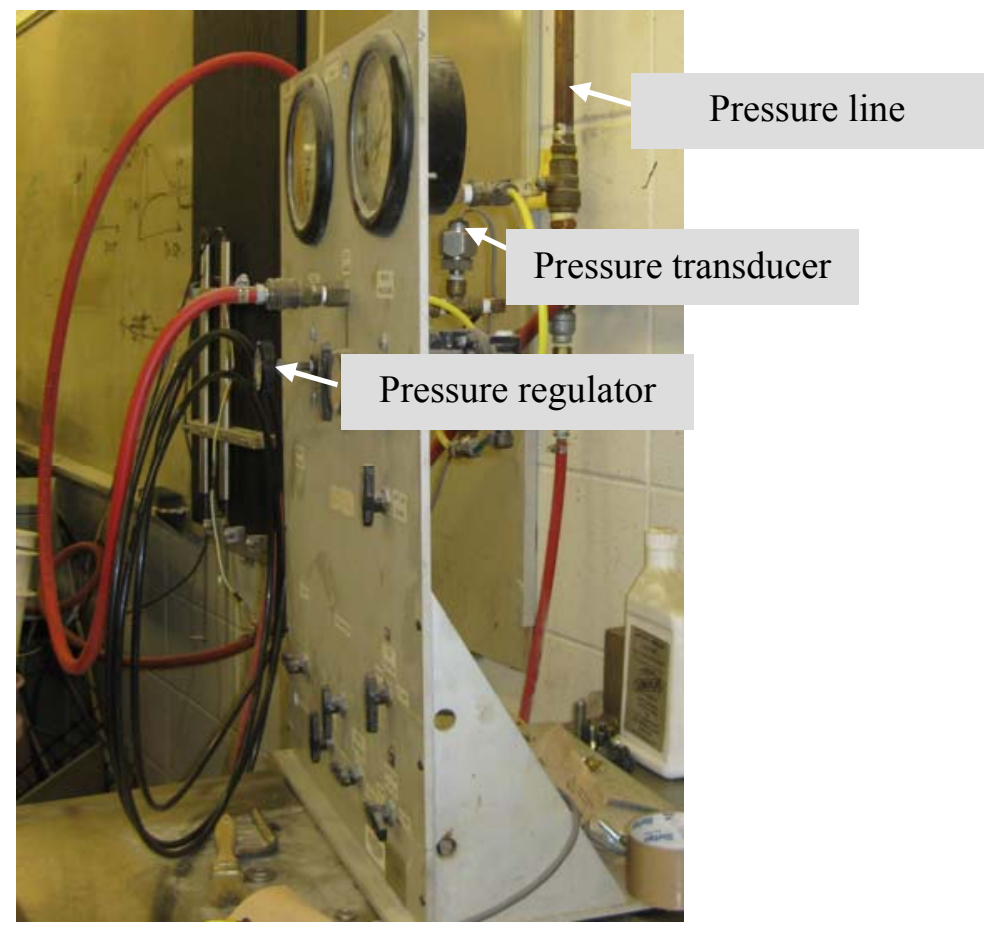

Figure 4-13 Pressure transducer. 


\subsubsection{Data Acquisition System}

Using a computerized data acquisition system and commercial software (LabView 7.1, which is supplied by National Instruments), the electric signals generated by the LVDTs, load cell and pressure transducer were acquired and stored. Figure 4-14 shows the schematic diagram of the data acquisition system used. The system consists basically of the computer with the operating software (LabView 7.1), the terminal block (SCXI-1314), the input module (SCXI-1520), the shielded module enclosure (SCXI 1000) and the DAQ board (PCI 6220) installed in the computer. The electric signals generated in the monitoring sensors are transmitted to the terminal block and the input module. The signals transferred to the input module are conditioned using signal amplification, filtering, electrical isolation and multiplexing. The computer reads and stores the conditioned signals through the DAQ board using the operating software. In addition, this conditioning system is used as an excitation source for the monitoring sensors. The excitations are controlled by the operating software. 


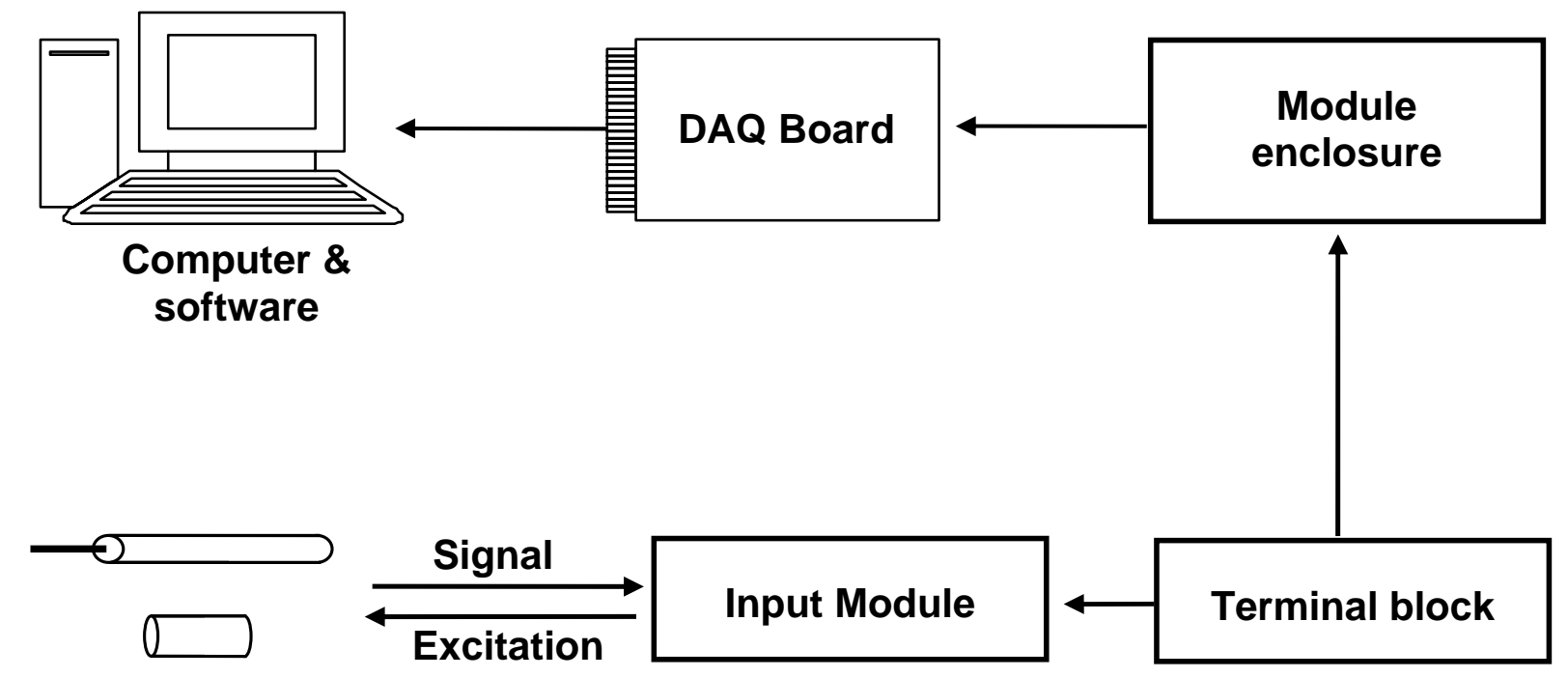

Sensors

Figure 4-14 Schematic diagram of the data acquisition system. 


\subsection{Materials}

\subsubsection{Shredded Tire-Sand Mixture}

The tire shred-sand mixtures were prepared with three different sizes of shredded tires (tire chips $9.5 \mathrm{~mm}$ nominal size, tire shreds $50-100 \mathrm{~mm}$ in length and tire shreds 100-200 mm in length). Geometric and material properties of the shredded tires and Ottawa sand were described in Chapter 3. The optimum mixing ratios for the mixtures studied are shown in Table 4-1 and were decided based on the compaction test results (refer to Chapter 3). The sample mixing ratios used for the pullout tests were equal to 0 , 12,25 and $100 \%$ of shredded tires in the mixture by weight (i.e., from pure sand to pure shredded tires). As discussed in Chapter 3, due to segregation, it is difficult to prepare homogeneous tire shred-sand samples with mixtures containing tire shred contents greater than $25 \%$. Therefore, to study the effect of mixing ratio on the pullout capacity of the reinforcement, two mixing ratios with shredded tire contents of $12 \%$ and $25 \%$ by weight were selected for testing. The dry unit weight of the mixtures compacted using the standard Proctor compaction energy $\left(\gamma_{\mathrm{d} \text {,max-lab }}\right)$ with various shredded tire sizes and mixing ratios is tabulated in Table 4-2. The compaction energy used corresponds to a standard Proctor effort $\left(600 \mathrm{kN}-\mathrm{m} / \mathrm{m}^{3}\right)$.

\subsubsection{Geogrid}

A commercially available uniaxial geogrid made of high-density polyethylene (HDPE) with a tensile strength of $52 \mathrm{kN} / \mathrm{m}$ at $5 \%$ strain was used in the pullout tests (geogrid UX 1500 MSE manufactured by Tensar). The UX 1500 MSE geogrid has a relatively large aperture size; this is the reason it was selected as it allows the large tire 
shreds to penetrate through its openings. The properties of the geogrid are summarized in Table 4-3. The dimensions of the geogrid specimen used for the tests were $1 \mathrm{~m} \times 0.30 \mathrm{~m}$ (length $\times$ width). Figure 4-15 shows one geogrid specimen, which includes three ribs and fourteen strands. When sampling the geogrid from the geogrid roll for each test, specimens were cut from areas away from the edges of the roll due to the presence of defects.

\subsubsection{Ribbed-Metal Strip}

The ribbed-metal strips are manufactured and supplied by The Reinforced Earth Company. The ribbed metal strips are made of mild steel and are $1000 \mathrm{~mm}$ long, $50 \mathrm{~mm}$ wide and $4 \mathrm{~mm}$ thick. The strips, which are galvanized with a zinc coating, have $3 \mathrm{~mm}$ high ribs on the top and bottom surfaces to mobilize passive resistance during pullout. The steel used in the fabrication of the strips is accordance with ASTM A-572 Grade 65 (AASHTO M-223). Figure 4-16 shows the cross-section of a metal strip used in this study.

Table 4-1 Optimum mixing ratios of different sizes of shredded tires.

\begin{tabular}{ccc}
\hline Size of shredded tires & $\begin{array}{c}\text { Optimum mixing ratio } \\
\text { of shredded tires and sand } \\
\text { (by weight) }\end{array}$ & $\begin{array}{c}\text { Optimum mixing ratio } \\
\text { of shredded tires and sand } \\
\text { (by volume) }\end{array}$ \\
\hline $9.5 \mathrm{~mm}$ in nominal size & $25 / 75$ & $46 / 54$ \\
$50-100 \mathrm{~mm}$ in length & $25 / 75$ & $42 / 58$ \\
$100-200 \mathrm{~mm}$ in length & $30 / 70$ & $49 / 51$ \\
\hline
\end{tabular}


Table 4-2 Maximum dry unit weight of tire shred-sand mixtures with various tire shred sizes and prepared with different mixing ratios.

\begin{tabular}{|c|c|c|c|}
\hline $\begin{array}{c}\text { Size of shredded } \\
\text { tires }\end{array}$ & $\begin{array}{c}\text { Shredded } \\
\text { tires/Sand (by } \\
\text { weight) }\end{array}$ & $\begin{array}{c}\text { Shredded } \\
\text { tires/Sand (by } \\
\text { volume) }\end{array}$ & $\begin{array}{l}\gamma_{\mathrm{d}, \text { mixture }} \text { with } \\
\text { optimum mixing } \\
\text { ratio }\left(\mathrm{kN} / \mathrm{m}^{3}\right)\end{array}$ \\
\hline \multirow{4}{*}{$9.5 \mathrm{~mm}$ nominal size } & $0 / 100$ & $0 / 100$ & 18.0 \\
\hline & $12 / 88$ & $26 / 74$ & 17.2 \\
\hline & $25 / 75$ & $46 / 54$ & 15.2 \\
\hline & $100 / 0$ & $100 / 0$ & 5.3 \\
\hline \multirow{4}{*}{$50-100 \mathrm{~mm}$ in length } & $0 / 100$ & $0 / 100$ & 18.0 \\
\hline & $12 / 88$ & $23 / 77$ & 17.6 \\
\hline & $25 / 75$ & $42 / 58$ & 16.6 \\
\hline & $100 / 0$ & $100 / 0$ & 6.2 \\
\hline \multirow{4}{*}{$\begin{array}{l}100-200 \mathrm{~mm} \text { in } \\
\text { length }\end{array}$} & $0 / 100$ & $0 / 100$ & 18.0 \\
\hline & $12 / 88$ & $23 / 77$ & 17.5 \\
\hline & $25 / 75$ & $43 / 57$ & 16.5 \\
\hline & $100 / 0$ & $100 / 0$ & 6.3 \\
\hline
\end{tabular}


Table 4-3 Properties of the geogrid studied (UX 1500 MSE, Tensar).

\begin{tabular}{|c|c|c|}
\hline Property & Unit & $\begin{array}{l}\text { MD (Machine Direction) } \\
\text { Value }\end{array}$ \\
\hline True initial modulus & $\mathrm{kN} / \mathrm{m}$ & 1580 \\
\hline Tensile strength at $5 \%$ strain & $\mathrm{kN} / \mathrm{m}$ & 52 \\
\hline $\begin{array}{l}\text { Long-term allowable load in sands, } \\
\text { silts and clay }\end{array}$ & $\mathrm{kN} / \mathrm{m}$ & 45.2 \\
\hline $\begin{array}{l}\text { Long-term allowable load in well } \\
\text { graded sands }\end{array}$ & $\mathrm{kN} / \mathrm{m}$ & 43.9 \\
\hline $\begin{array}{l}\text { Long-term allowable load in } \\
\text { aggregate }\end{array}$ & $\mathrm{kN} / \mathrm{m}$ & 43.1 \\
\hline Junction strength & $\mathrm{kN} / \mathrm{m}$ & 105 \\
\hline
\end{tabular}




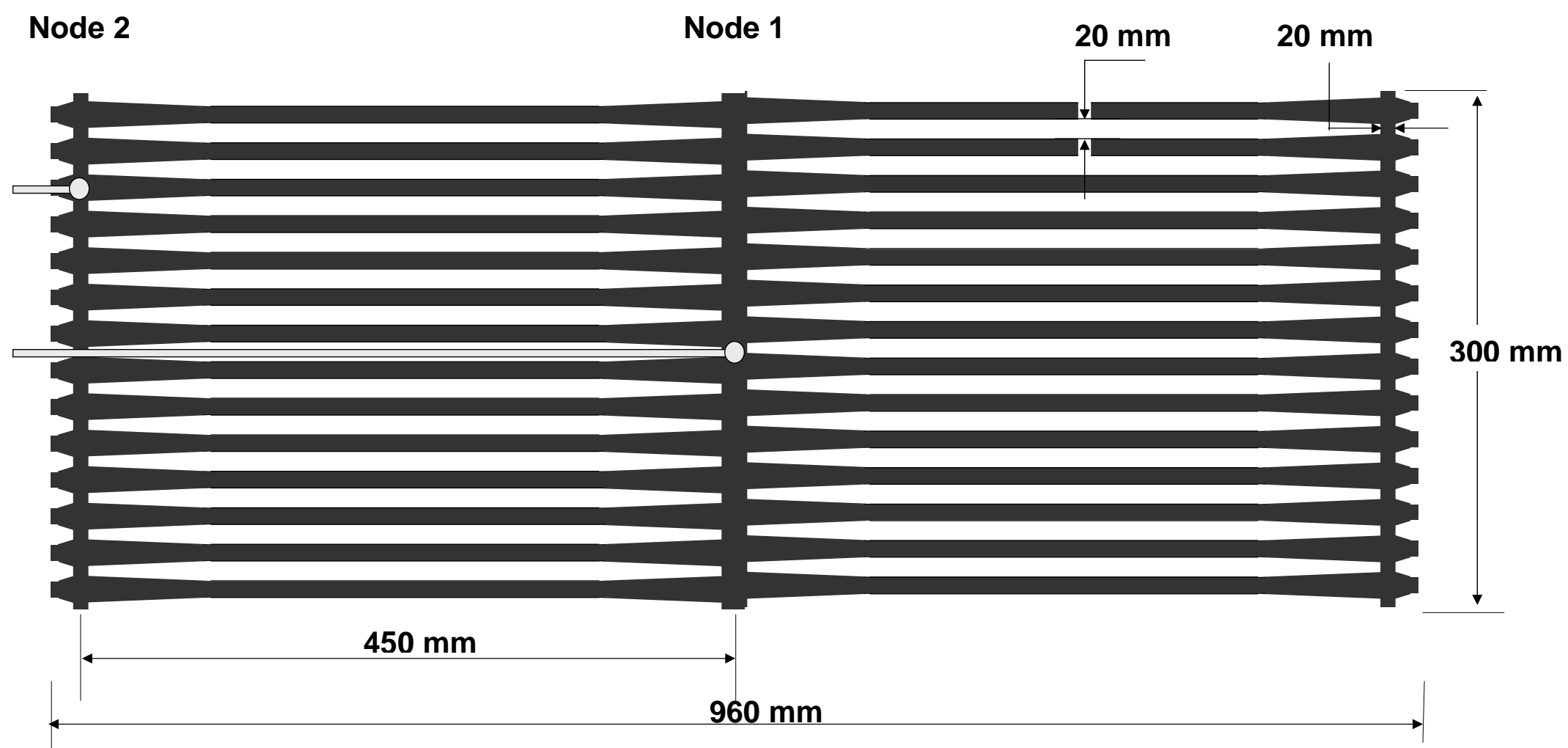

Figure 4-15 Geogrid specimen. 


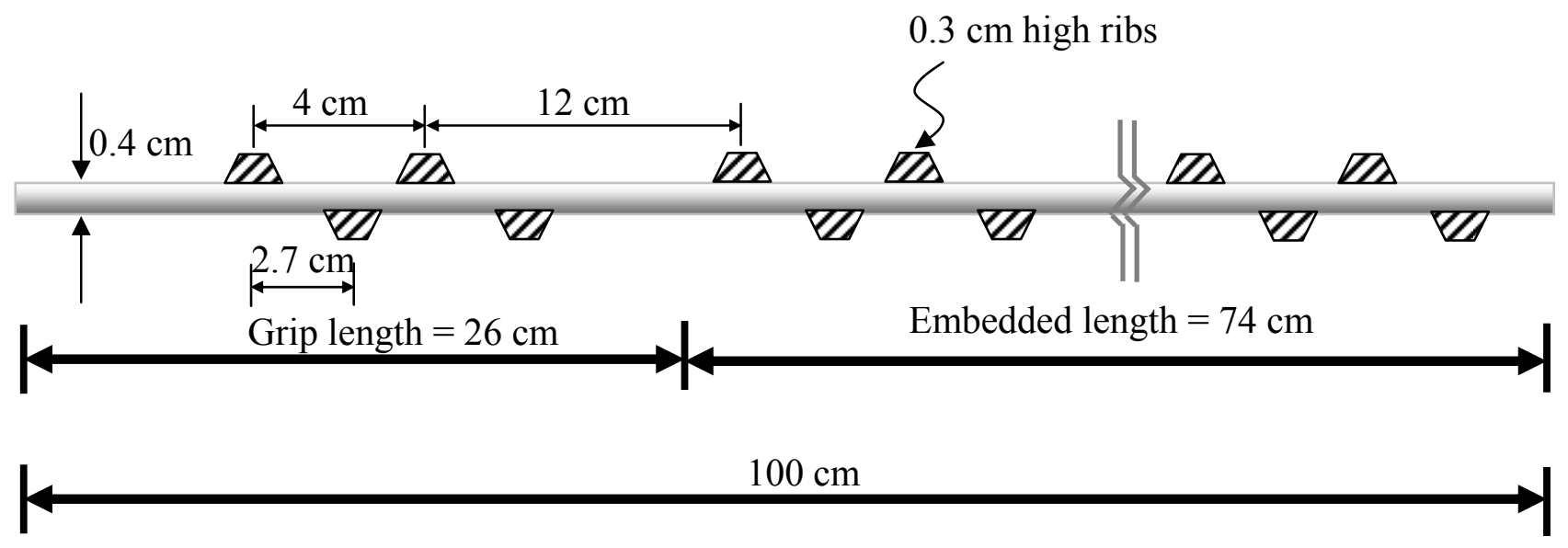

Total number of ribs in the embedded length: 20

Figure 4-16 Cross-section of a ribbed-metal strip specimen 


\subsection{Test Procedure}

\subsubsection{Preliminary Tests}

The compaction method used to compact the pullout samples was selected based on technical concerns related to the type of material being compacted (mixtures of tire shreds and sand) and the size of the sample. Bosscher et al. (1992) reported that segregation of tire shred-sand mixtures can occur when vibratory-type compaction is used. Therefore, the samples in this experimental program were compacted in four layers using a pneumatically operated impact-piston type compactor. This type of compactor imparts a high impact force and, efficiently transfers energy to the sample (this type of compactor is often used to facilitate the flow of dry, granular materials through bins by impact). The compactor is connected to a pressure source by a pressure line. A filter, a regulator system and a lubricator are installed in the pressure line (see Figure 4-17). The regulator system is used to set the desired pressure in the pressure line and, accordingly, vary the impact force applied by the piston to the sample. The lubricator helps the proper functioning of the piston of the compactor. The compactor operates at a maximum operating pressure of $551 \mathrm{kPa}$ (80 psi), 4500 vibrations per minute (VPM), and 0.5 $\mathrm{m}^{3} /$ minute (18 $\mathrm{ft}^{3} /$ minute) discharge of air. The compactor was connected to a square steel plate with dimensions of $35.5 \mathrm{~cm}$ in length $\times 35.5 \mathrm{~cm}$ in width $\times 0.95 \mathrm{~cm}$ in thickness (see Figure 4-18).

Because the samples had to be compacted in the large pullout box, applying an excessive compaction energy could damage the equipment and also demand excessive 
testing effort. Hence, a target relative compaction of $90 \%$ was selected to prepare the samples in the pullout box. Before conducting the full-scale pullout tests, preliminary compaction tests were conducted using a wooden box of dimensions $61 \mathrm{~cm}$ x $58 \mathrm{~cm}$ x 30 $\mathrm{cm}$ (length $\mathrm{x}$ width $\mathrm{x}$ height) to compact the samples. These tests were conducted on tire shred-Ottawa sand mixtures $(0,12,25$ and $100 \%$ by weight of tire shreds) for all the three sizes of shredded tires. Based on these calibration tests, it was concluded that for tire shred contents less than $25 \%$ by weight of the mixture, to achieve compacted densities corresponding to $90 \%$ relative compaction, pressures of $206 \mathrm{kPa}$ (30 psi) needed to be supplied in the pressure line of the compactor to compact the bottom two layers of the sample, while $220 \mathrm{kPa}$ (32 psi) was necessary for the top two layers of the sample. On the other hand, for tire shreds contents equal to or greater than $25 \%$, a higher compaction energy was required to achieve the target relative compaction of $90 \%$, and hence, pressures of $220 \mathrm{kPa}(32 \mathrm{psi}$ ) and $234 \mathrm{kPa}$ (34 psi) were chosen, respectively, for the bottom and top two layers. Each layer was compacted by traversing the compactor along the length of the box for a period of five minutes. The unit weight and degree of compaction achieved for each sample tested are reported in Table 4-4. 


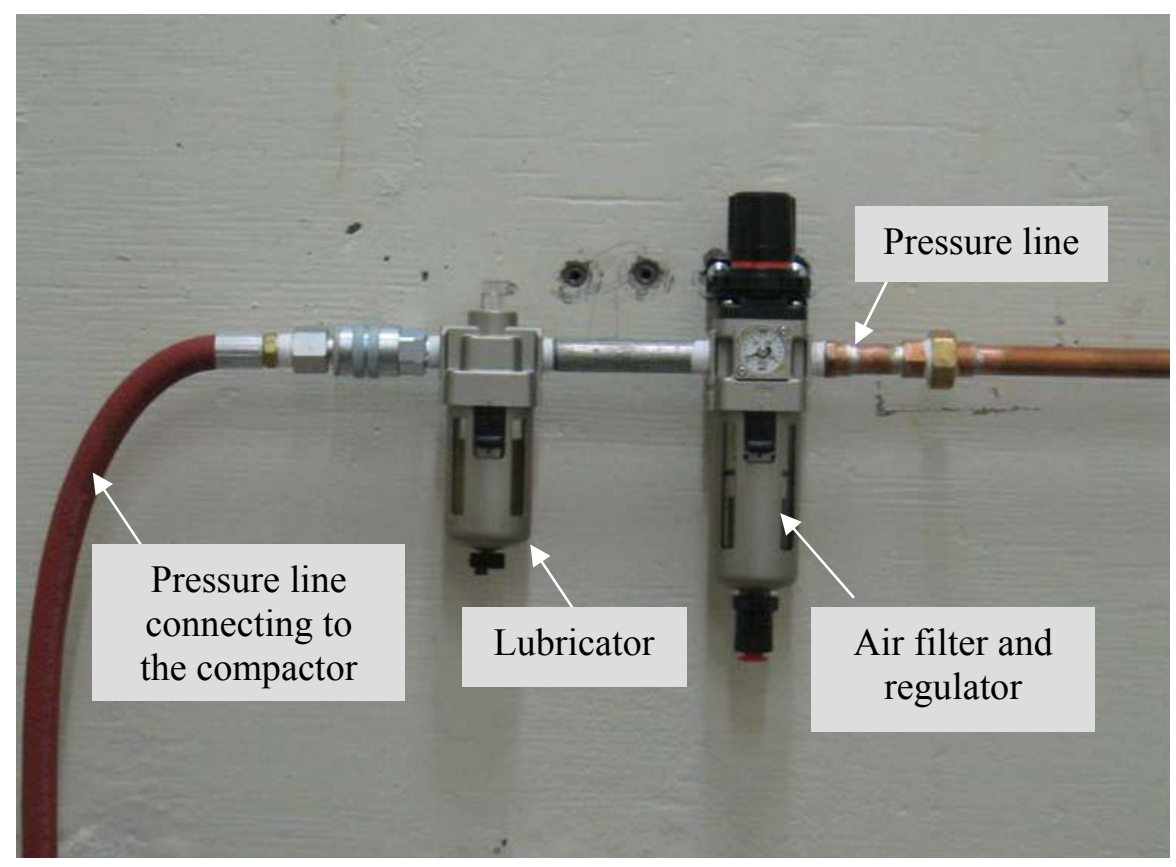

Figure 4-17 Filter, regulator and lubricator mounted on the wall.

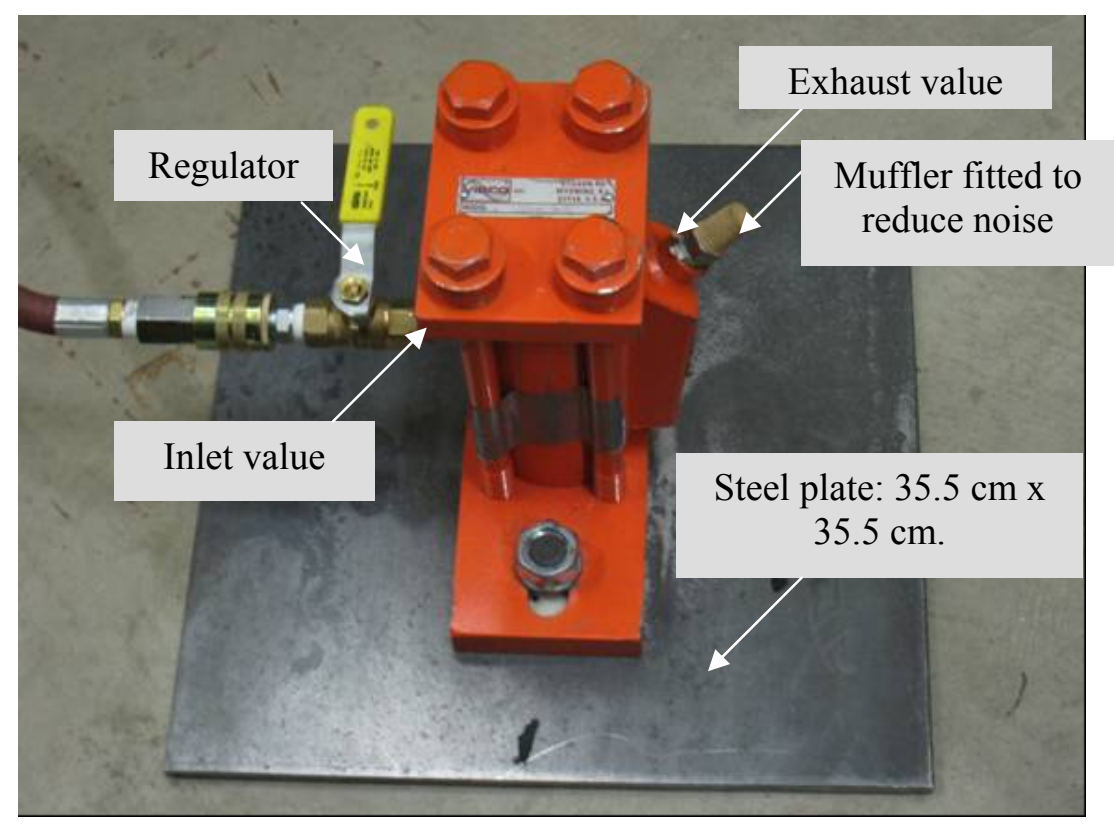

Figure 4-18 An impact piston-type compactor bolted to a steel plate (Compactor Model: 50-2LS-EM, manufactured by VIBCO). 
Table 4-4 Dry unit weight and degree of compaction of the samples tested at a confining pressure of $40 \mathrm{kPa}$.

\begin{tabular}{|c|c|c|c|c|}
\hline $\begin{array}{c}\text { Size of shredded } \\
\text { tires }\end{array}$ & $\begin{array}{l}\text { Shredded } \\
\text { tires/Sand (by } \\
\text { weight) }\end{array}$ & $\begin{array}{c}\text { Shredded } \\
\text { tires/Sand (by } \\
\text { volume) }\end{array}$ & $\begin{array}{l}\text { Dry unit weight } \\
\qquad\left(\mathrm{kN} / \mathrm{m}^{3}\right)\end{array}$ & $\begin{array}{c}\text { Relative } \\
\text { compaction } \\
\text { achieved }(\%)\end{array}$ \\
\hline \multirow{4}{*}{$\begin{array}{c}9.5 \mathrm{~mm} \text { nominal } \\
\text { size }\end{array}$} & $0 / 100$ & $0 / 100$ & 17.5 & 97 \\
\hline & $12 / 88$ & $26 / 74$ & 16.0 & 93 \\
\hline & $25 / 75$ & $46 / 54$ & 14.4 & 95 \\
\hline & $100 / 0$ & $100 / 0$ & 5.1 & 97 \\
\hline \multirow{4}{*}{$\begin{array}{l}50-100 \mathrm{~mm} \text { in } \\
\text { length }\end{array}$} & $0 / 100$ & $0 / 100$ & 17.5 & 97 \\
\hline & $12 / 88$ & $23 / 77$ & 16.2 & 92 \\
\hline & $25 / 75$ & $42 / 58$ & 15.6 & 94 \\
\hline & $100 / 0$ & $100 / 0$ & 5.0 & 80 \\
\hline \multirow{4}{*}{$\begin{array}{l}100-200 \mathrm{~mm} \text { in } \\
\text { length }\end{array}$} & $0 / 100$ & $0 / 100$ & 17.5 & 97 \\
\hline & $12 / 88$ & $23 / 77$ & 16.1 & 92 \\
\hline & $25 / 75$ & $43 / 57$ & 14.2 & 86 \\
\hline & $100 / 0$ & $100 / 0$ & 5.3 & 84 \\
\hline
\end{tabular}




\subsubsection{Sample Preparation}

The sequences of steps involved in the preparation of samples in the pullout box are as follows:

1) The desired quantities of tire shreds and Ottawa sand were first mixed thoroughly in a container. Segregation during mixing was prevented as much as possible. The premixed tire shred-sand mixture was compacted (as explained in the previous section) in the pullout box in four lifts of $10 \mathrm{~cm}$ thick (Figure 4-19a, b).

2) The reinforcement was inserted through the opening between the sleeves and tightly fixed to the clamping system. A PVC foam (used to seal wide gaps) was glued to the opening that remained after gripping of the reinforcement with the appropriate clamps to minimize leakage of sand during compaction of the mixture and pull out of reinforcement during testing (see Figure 4-19c, d).

3) The remaining two layers of tire shred-sand mixture was compacted up to the top of the pullout box to complete the preparation of the sample. To ensure uniform compaction in every layer, the compactor was traversed along the length of the box for five minutes.

4) The density of the compacted mixture was determined from the mass of the mixture used for sample preparation and the volume of the sample (Figure 4-19e). The vertical thickness of the sample was obtained by subtracting the measured depth from the top of 
the box to the top of the sample from the height of the pullout box at ten locations along the periphery and the center line of the pullout box filled with the mixture. These thickness values were averaged and used to calculate the density of the compacted mixture.

5) A thin sand layer was placed on top of the compacted tire shred-sand mixture to prevent any damage to the airbag at the time of inflation of the airbag to the desired confining pressure due to the exposed steel wires of the tire shreds. Then, the flexible rubber airbag was placed on top of the thin sand layer, and a steel plate was bolted on the pullout box. Figure 4-19f shows the flexible rubber airbag. The airbag was inflated against the steel plate.

6) The air pressure was applied through the regulator from a central laboratory airpressure system. The pulling out of the geogrid was performed using two stepper motors. The pullout rate was $1 \mathrm{~mm} / \mathrm{min}$. The pullout force was monitored using a tension load cell. The frontal and nodal displacements and the confining pressure were monitored using LVDTs and a pressure transducer, respectively.

7) The test was stopped and the contents of the box were emptied when the front end of the reinforcement was pulled to a target displacement $(\sim 90 \mathrm{~mm}$ for geogrid and $24 \mathrm{~mm}$ for metal strips). A sieve was used to separate the shredded tire pieces and sand as shown in Figure 4-19g for future reuse. 


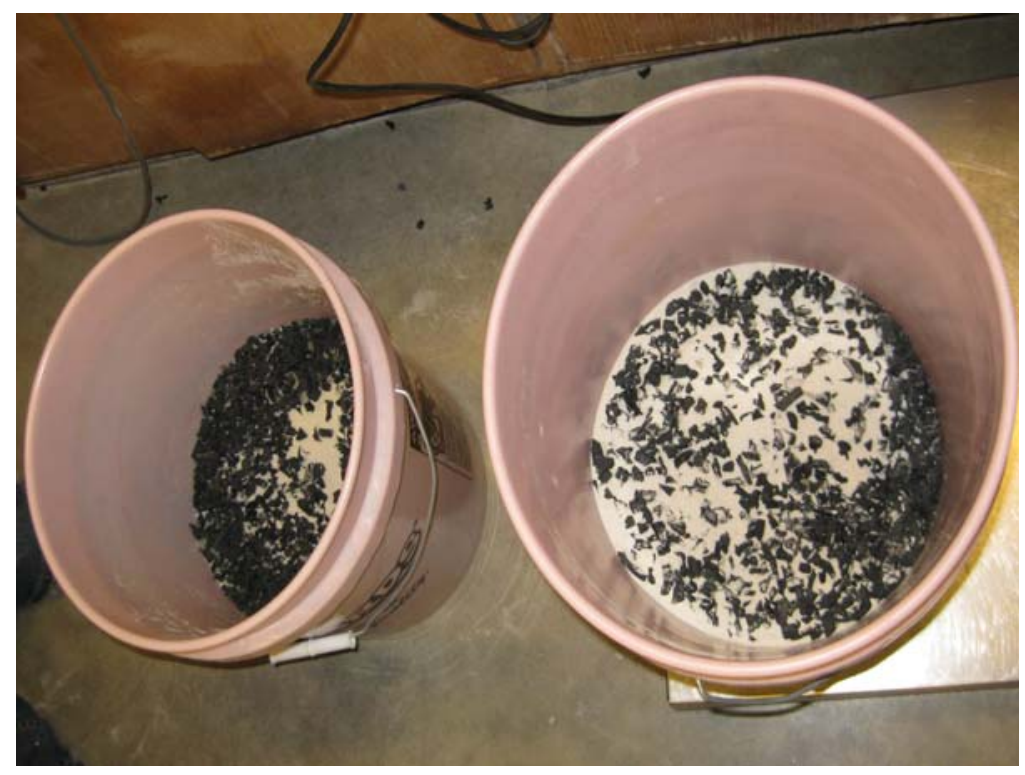

(a)

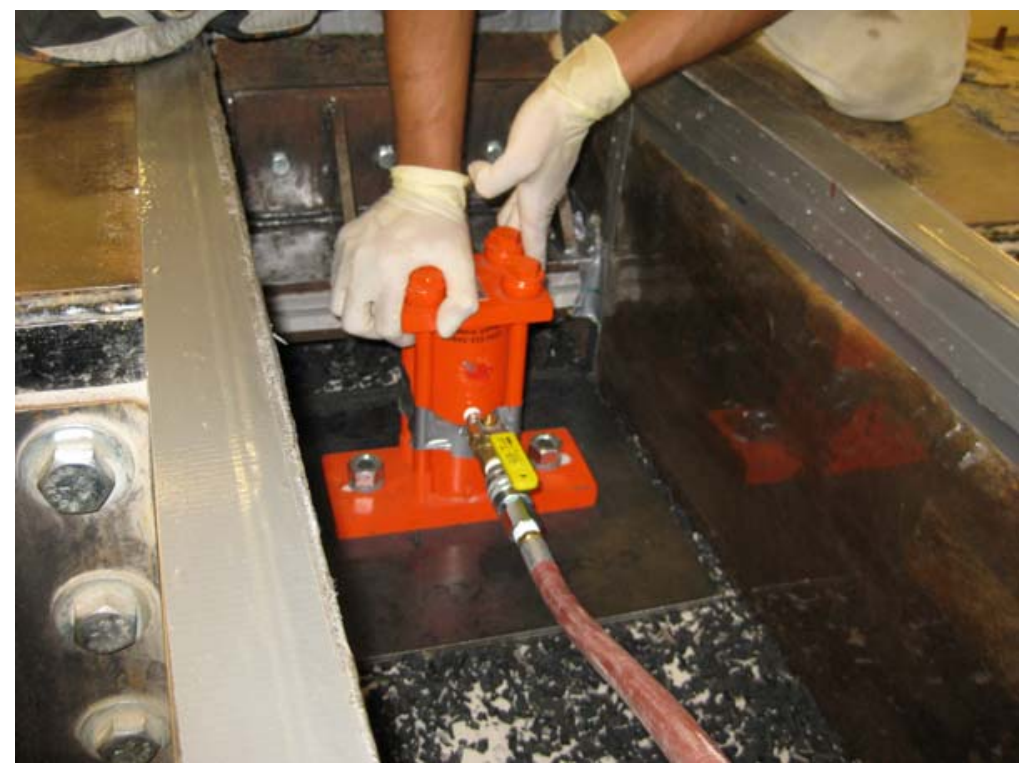

(b) 


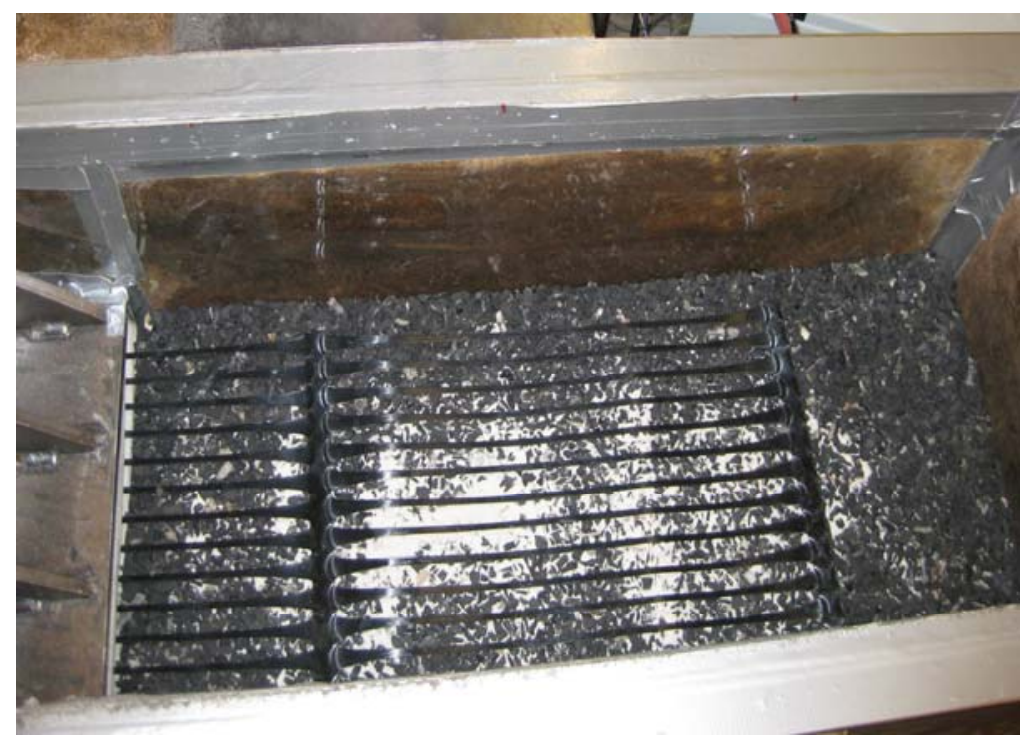

(c)

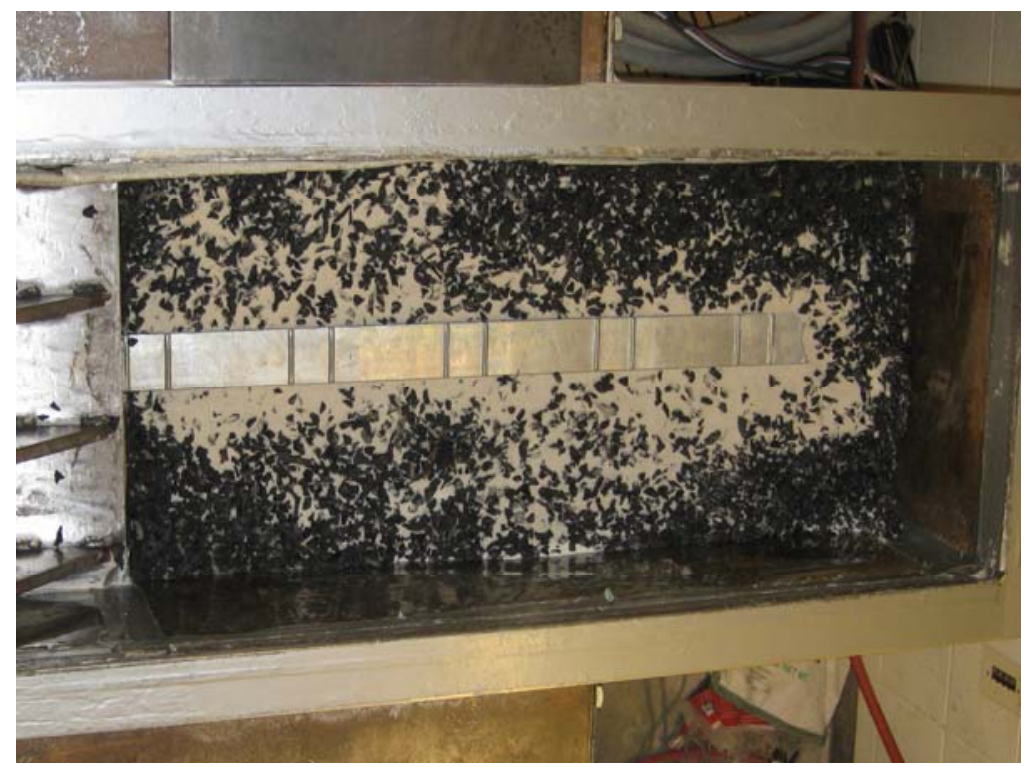

(d) 


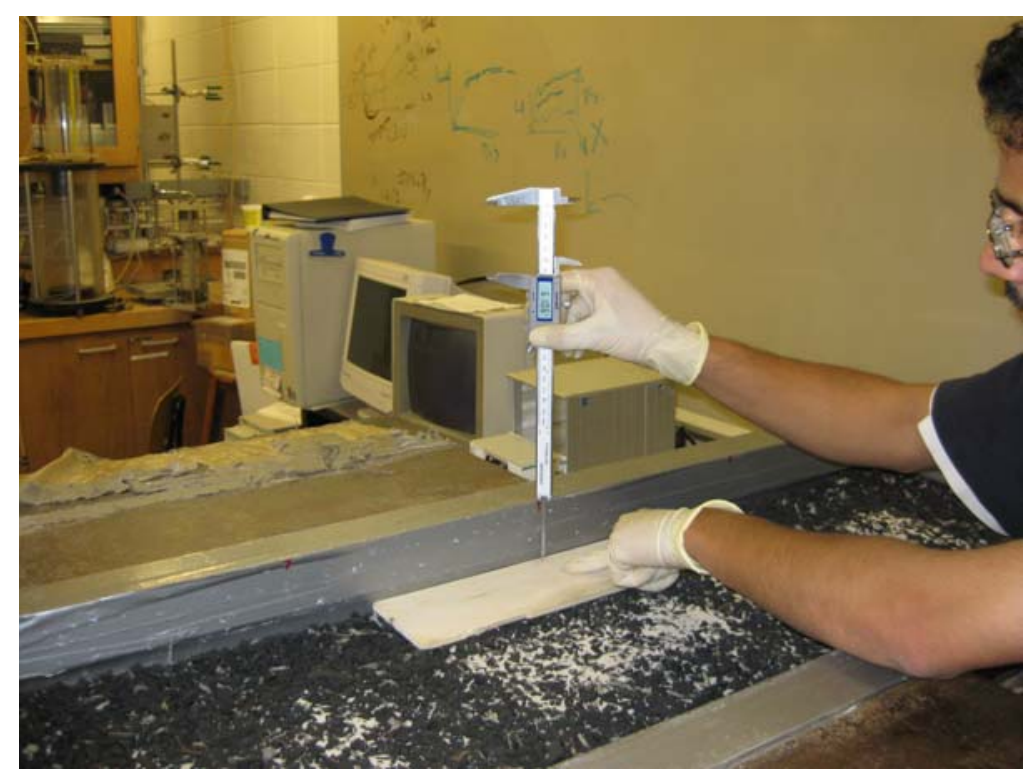

(e)

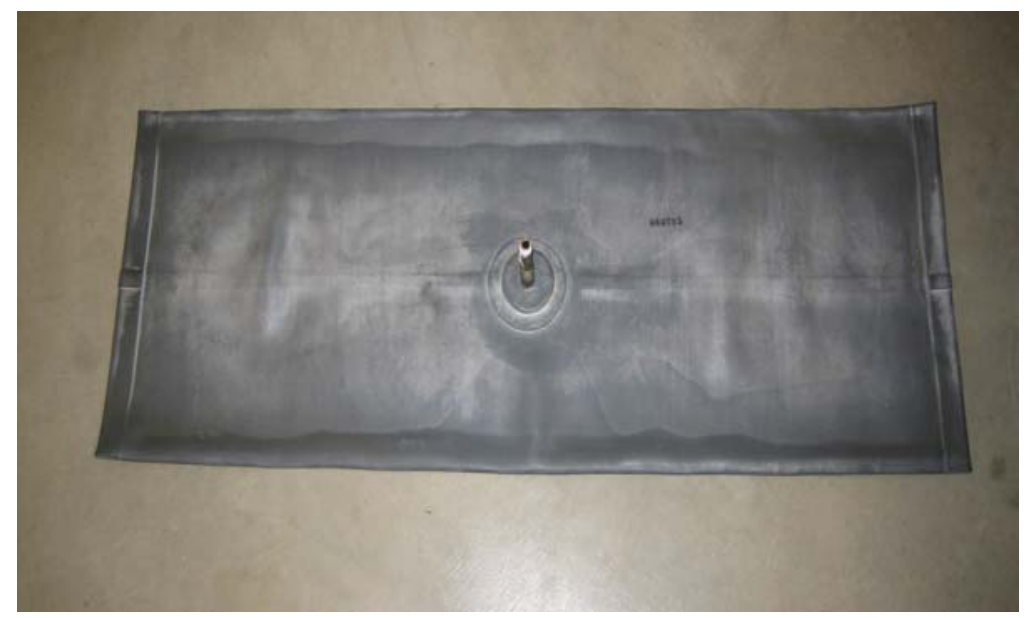

(f) 


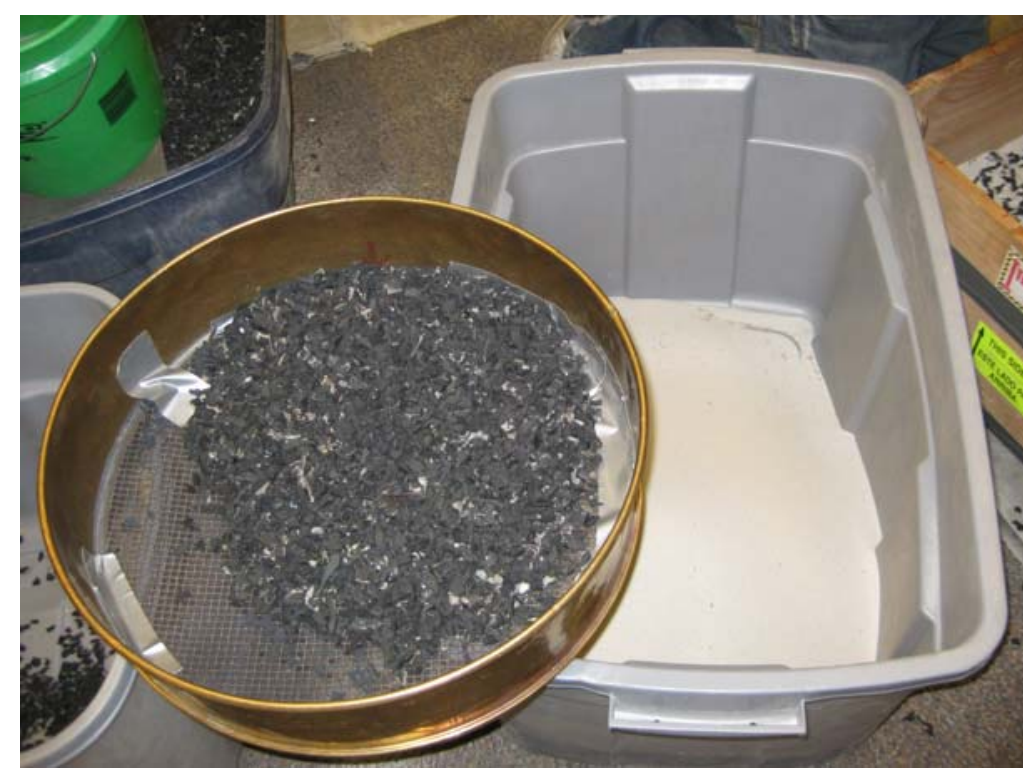

(g)

Figure 4-19 Sample preparation details: (a) pre-mixing of shredded tires and sand, (b) compaction of mixture inside the box, (c)-(d) placement and clamping details of geogrid and metal strip, (e) measurement of depth of final compacted lift, (f) air bag used to apply confining pressure and $(\mathrm{g})$ separation of shredded tires and sand after the end of the test. 


\subsection{Summary}

Large-scale pullout tests were performed to study the interaction of geogrid and ribbed-metal strip placed in tire shred-sand mixtures prepared with various tire shred sizes (tire chips $9.5 \mathrm{~mm}$ nominal size, tire shreds $50-100 \mathrm{~mm}$ in length and tire shreds $100-200 \mathrm{~mm}$ in length), mixing ratios $(0,12,25$ and $100 \%$ of tire shreds in the mixture by weight) and for a confining pressure of $40 \mathrm{kPa}$. The pullout test machine (maximum pullout capacity of $186 \mathrm{kN}$ ) consists of the pullout box, geogrid/metal strip clamping system, loading system, monitoring system, and data acquisition system. The samples were compacted using an impact-type compactor in four 10-cm-thick lifts. For each test, frontal displacements, the pullout force, and the confining pressure were monitored using LVDTs, a load cell and a pressure transducer, respectively. The results of these tests are presented next in Chapter 5. 


\section{CHAPTER 5. PULLOUT TEST RESULTS AND ANALYSIS}

\section{1. $\underline{\text { Overview }}$}

The pullout capacity of a reinforcement is influenced mainly by (1) the characteristics of the reinforcement (extensibility, type, and geometry) and (2) the characteristics of the reinforced fill material (particle shape, grain size distribution and void ratio) and (3) the testing conditions (confining pressure and pullout rate) (Farrag et al. 1993). Two types of reinforcements: geogrid and ribbed-metal strip were considered in this study. In the case of geogrids, the pullout resistance is offered mainly by: a) the passive resistance of the fill within the apertures of the geogrid as shown in Figure 5-1a, and b) the interface frictional resistance developed along transverse and longitudinal ribs due to the relative shear displacement of the geogrid and the fill (see Figure 5-1b). On the other hand, in the case of metallic reinforcements, the pullout resistance is attributed mainly to the interface friction developed due to relative shear displacement between the metallic reinforcement and the fill. For ribbed-metal strips, the fill also offers passive resistance against the ribs on the surface of the metal strip. Figure 5-2 illustrates the development of frictional and passive resistances along the length of ribbed-metal strip reinforcement. 


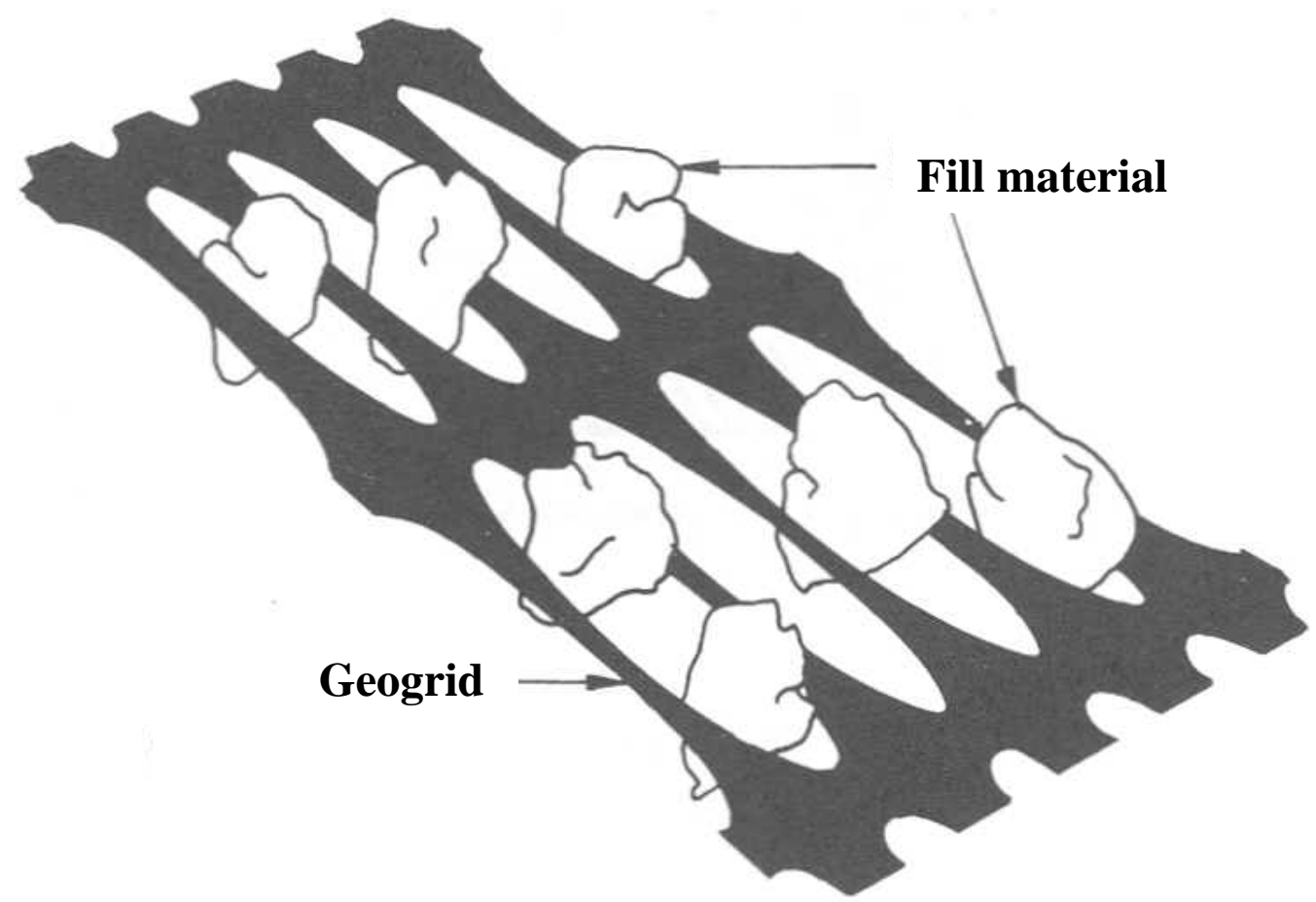

(a) 


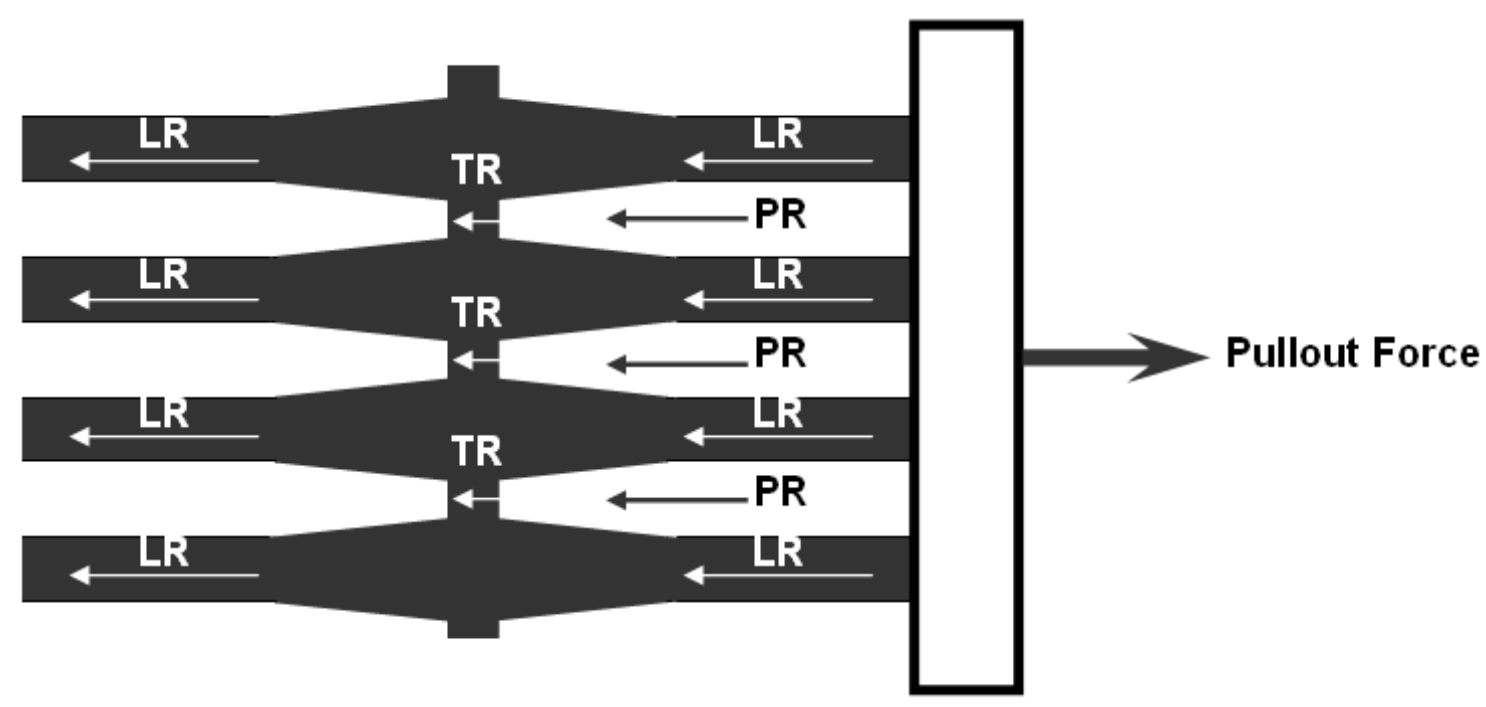

\section{Legend:}

\section{LR $=$ Longitudinal rib resistance \\ TR $=$ Transverse rib resistance \\ $P R=$ Passive resistance}

(b)

Figure 5-1 Mechanisms involved in geogrid pullout resistance: (a) development of passive resistance through interlocking of fill material against the apertures of the geogrid (Shukla and Yin 2006), and (b) schematic of geogrid showing development of frictional and passive resistances. 


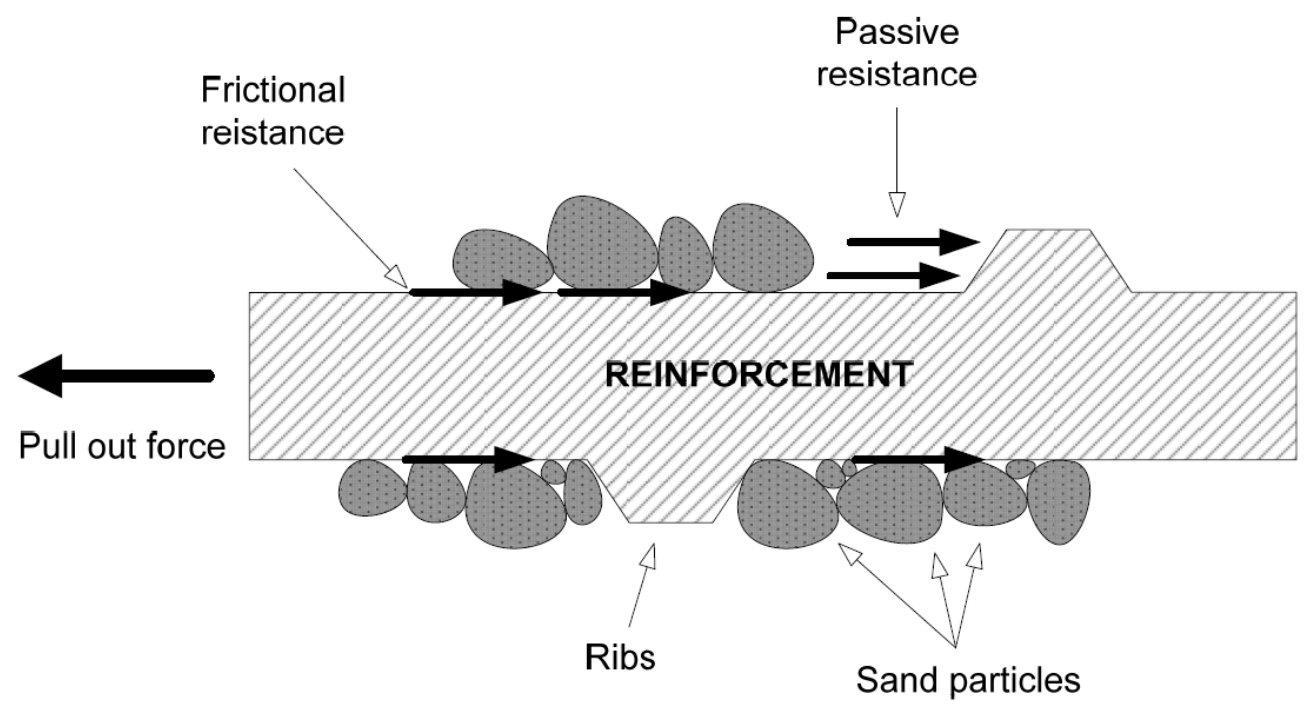

Figure 5-2 Frictional and passive resistances developed along the length of ribbed-metal strip (Zevgolis 2007).

This Chapter presents the results of the pullout tests performed on geogrid and ribbed-metal strip embedded in tire shred-sand mixture samples for various test conditions. Table 5-1 summarizes the test conditions considered for the pullout tests performed in this study. All the tests were performed at a confining pressure of $40 \mathrm{kPa}$. The effects of the size of the tire shreds used in the mixture and the tire shred-sand mixing ratio on the pullout behavior of both geogrid and ribbed-metal strip reinforcements are investigated.

\subsection{Pullout Capacity}

The pullout capacity is defined as the maximum pullout force developed during the pullout test. Based on practical considerations, the pullout force corresponding to a 
geogrid frontal displacement of $80 \mathrm{~mm}$ (10\% of the embedded length of geogrid) is often taken as the pullout capacity (Tatlisoz et al. 1998). For metal-strip reinforcement (inextensible reinforcement), the pullout force corresponding to a maximum displacement of $20 \mathrm{~mm}$ corresponding to the front-end of the reinforcement or the peak pullout force if it occurs within the prescribed $20-\mathrm{mm}$ frontal displacement is taken as the pullout capacity (Elias and Christopher 1997). In next section, the pullout test results for geogrids and ribbed-metal strips are discussed.

Table 5-1 Summary of pullout testing program

\begin{tabular}{|c|c|c|c|c|}
\hline $\begin{array}{c}\text { Size of shredded } \\
\text { tires }\end{array}$ & $\begin{array}{c}\text { Shredded } \\
\text { tires/sand ratio } \\
\text { (by weight) }\end{array}$ & $\begin{array}{c}\text { Shredded } \\
\text { tires/sand ratio } \\
\text { (by volume) }\end{array}$ & $\begin{array}{l}\text { Dry unit weight } \\
\qquad\left(\mathrm{kN} / \mathrm{m}^{3}\right)\end{array}$ & $\begin{array}{c}\text { Relative } \\
\text { compaction } \\
(\%)\end{array}$ \\
\hline Ottawa sand & $0 / 100$ & $0 / 100$ & 17.5 & 97 \\
\hline \multirow{3}{*}{$\begin{array}{l}\quad 9.5 \mathrm{~mm} \\
\text { nominal size }\end{array}$} & $12 / 88$ & $26 / 74$ & 16.0 & 93 \\
\hline & $25 / 75$ & $46 / 54$ & 14.4 & 95 \\
\hline & $100 / 0$ & $100 / 0$ & 5.1 & 97 \\
\hline \multirow{3}{*}{$\begin{array}{l}50-100 \mathrm{~mm} \\
\text { in length }\end{array}$} & $12 / 88$ & $23 / 77$ & 16.2 & 92 \\
\hline & $25 / 75$ & $42 / 58$ & 15.6 & 94 \\
\hline & $100 / 0$ & $100 / 0$ & 5.0 & 80 \\
\hline \multirow{3}{*}{$\begin{array}{l}100-200 \mathrm{~mm} \\
\text { in length }\end{array}$} & $12 / 88$ & $23 / 77$ & 16.1 & 92 \\
\hline & $25 / 75$ & $43 / 57$ & 14.2 & 86 \\
\hline & $100 / 0$ & $100 / 0$ & 5.3 & 84 \\
\hline
\end{tabular}




\subsection{Pullout Test Results on Geogrid}

\subsubsection{Effect of Tire Shred-Sand Mixing Ratio}

Figure 5-3 to Figure 5-5 show the variation of the pullout load per meter of geogrid as a function of its frontal displacement. The geogrid was embedded in tire shred-sand mixtures with various amounts of shredded tires: $0 \%, 12 \%, 25 \%$ and $100 \%$ by weight of shredded tires. The tests were performed for three sizes of shredded tires $9.5 \mathrm{~mm}$ nominal size, 50 to $100 \mathrm{~mm}$ in length, and 100 to $200 \mathrm{~mm}$ in length. The pullout resistance mobilized along the length of the geogrid increases with decreasing tire shred contents. As the tire shred content in the mixture decreases from $100 \%$ to $25 \%$ to $12 \%$ by weight, the pullout response of the geogrid embedded in the sample approaches that for the sample prepared with $100 \%$ sand. Figure 5-6 shows that the pullout capacity of the geogrid embedded in the tire chip-sand mixtures does not vary significantly for mixtures containing $0 \%, 12 \%$, and $25 \%$ of tire chips by weight. For the other tire shredsand mixtures containing shredded tires ranging in size from 50 to $100 \mathrm{~mm}$ and from 100 to $200 \mathrm{~mm}$, the pullout capacity of the geogrid embedded in the mixtures decreases significantly when tire shred contents is increased from 0 to $100 \%$ by weight. 


\subsubsection{Effect of Tire Shred Size}

During sample preparation using mixtures with larger sizes of shredded tires (50 to $100 \mathrm{~mm}$ and 100 to $200 \mathrm{~mm}$ in length), we observed that the tire shreds in the mixture were aligned parallel to the plane containing the geogrid. As result, the contribution of the passive resistance due to the wedging action of the tire shreds within the aperture of the geogrid was minimal.

Figure 5-7 shows that the pullout response of geogrid embedded in mixtures prepared with a mixing ratio of $12 \%$ by weight and tire shreds with sizes of 50 to 100 $\mathrm{mm}$ and 100 to $200 \mathrm{~mm}$ is similar. At low tire shred contents, it is expected that the sand controls the pullout response. For a mixing ratio of $25 \%$, the pullout resistance increases with decreasing tire shred size in the mixture for frontal displacements greater than about $20 \mathrm{~mm}$ (Figure 5-8); the highest pullout capacity was observed for tire chips. This may be attributed to the mobilization of passive resistance by the tire chips wedged in the apertures of the transverse ribs of the geogrid $(9.5 \mathrm{~mm}$ size chips can much more easily wedge against the apertures of the geogrid than the larger size tire shreds). For geogrid embedded in samples prepared with shredded tires only, a slightly higher pullout resistance was observed for the samples containing the larger size tire shreds than for samples prepared with tire chips (see Figure 5-9). This is due to the interlocking effect of the larger shredded pieces in the apertures of the geogrid and to the presence of wires protruding out of them. 
Figure 5-10 shows the variation of the geogrid pullout capacity as a function of the tire shred size used in preparing samples with various tire shred-sand mixing ratios. The pullout capacity of geogrid embedded in only shredded tires is very low, of the order of $30-40 \%$ of the pullout capacity of geogrid embedded in samples prepared with only sand.

Table 5-2 presents the pullout capacities of geogrid for the test cases considered in this study. 


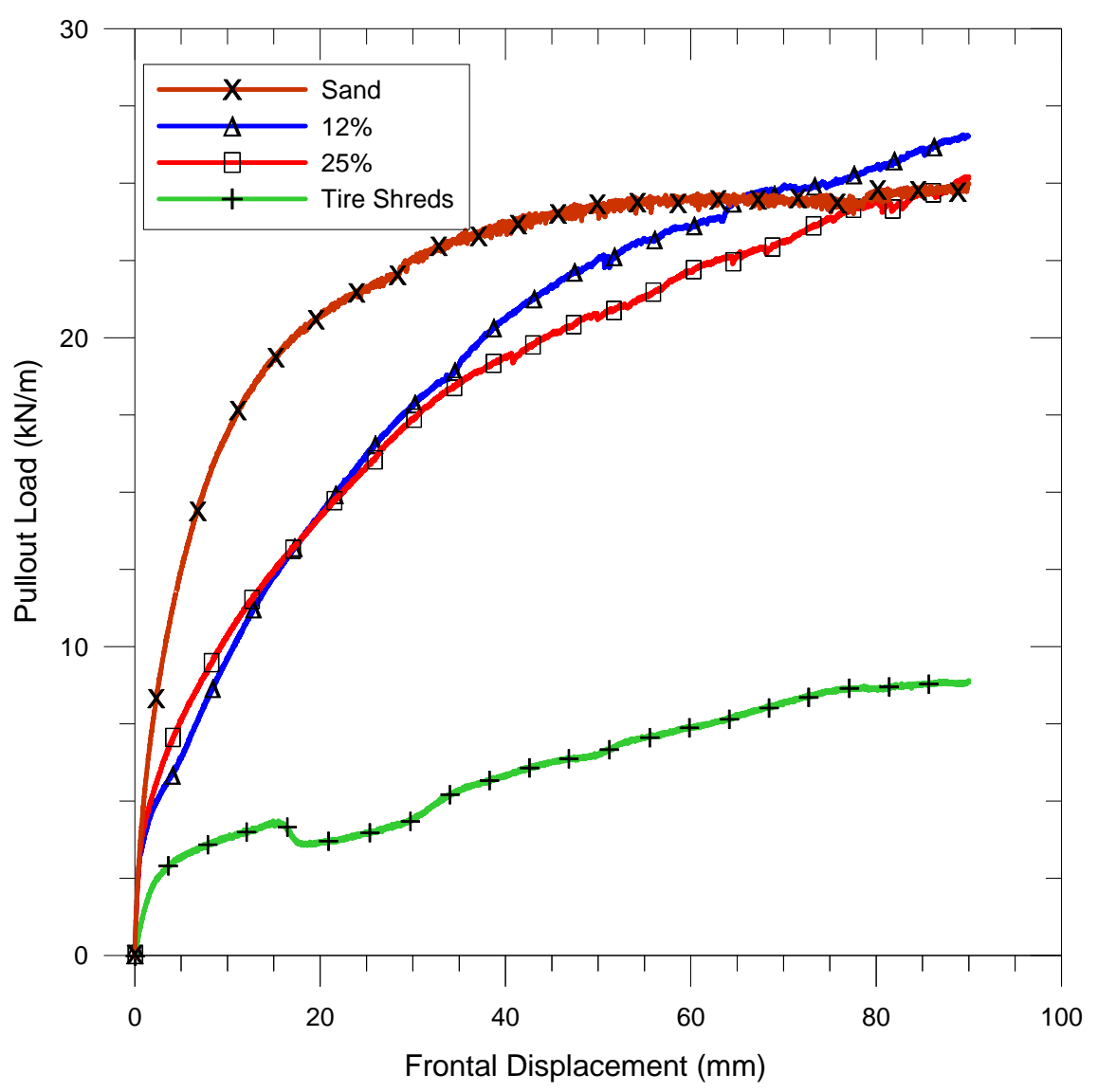

Figure 5-3 Pullout load versus frontal displacement for samples prepared with various mixing ratios by weight of tire chips ( $9.5 \mathrm{~mm}$ nominal size) and sand and subjected to a confining pressure of $40 \mathrm{kPa}$. 


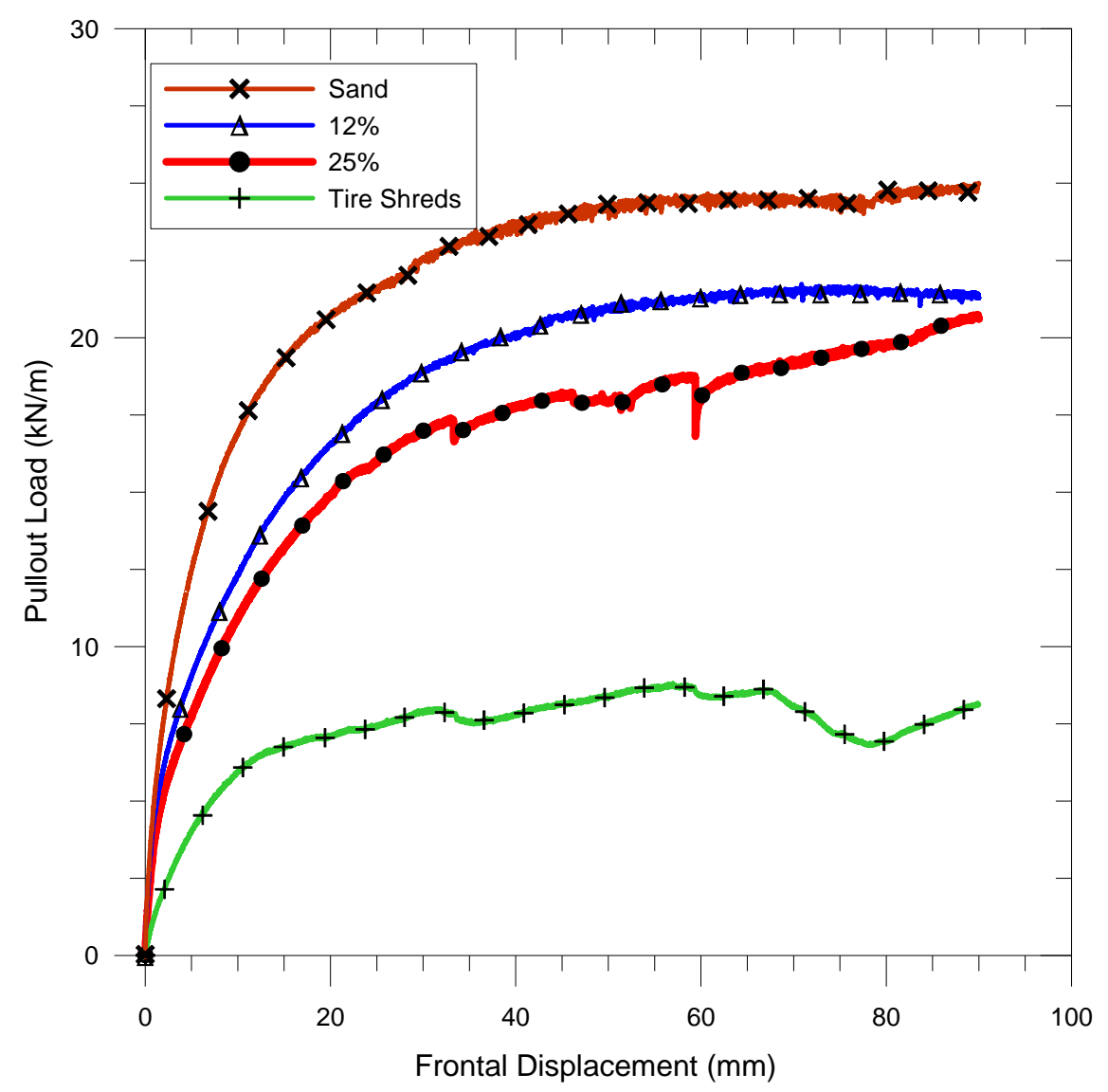

Figure 5-4 Pullout load versus frontal displacement for samples prepared with various mixing ratios by weight of tire shreds (50 to $100 \mathrm{~mm}$ in length) and sand and subjected to a confining pressure of $40 \mathrm{kPa}$. 


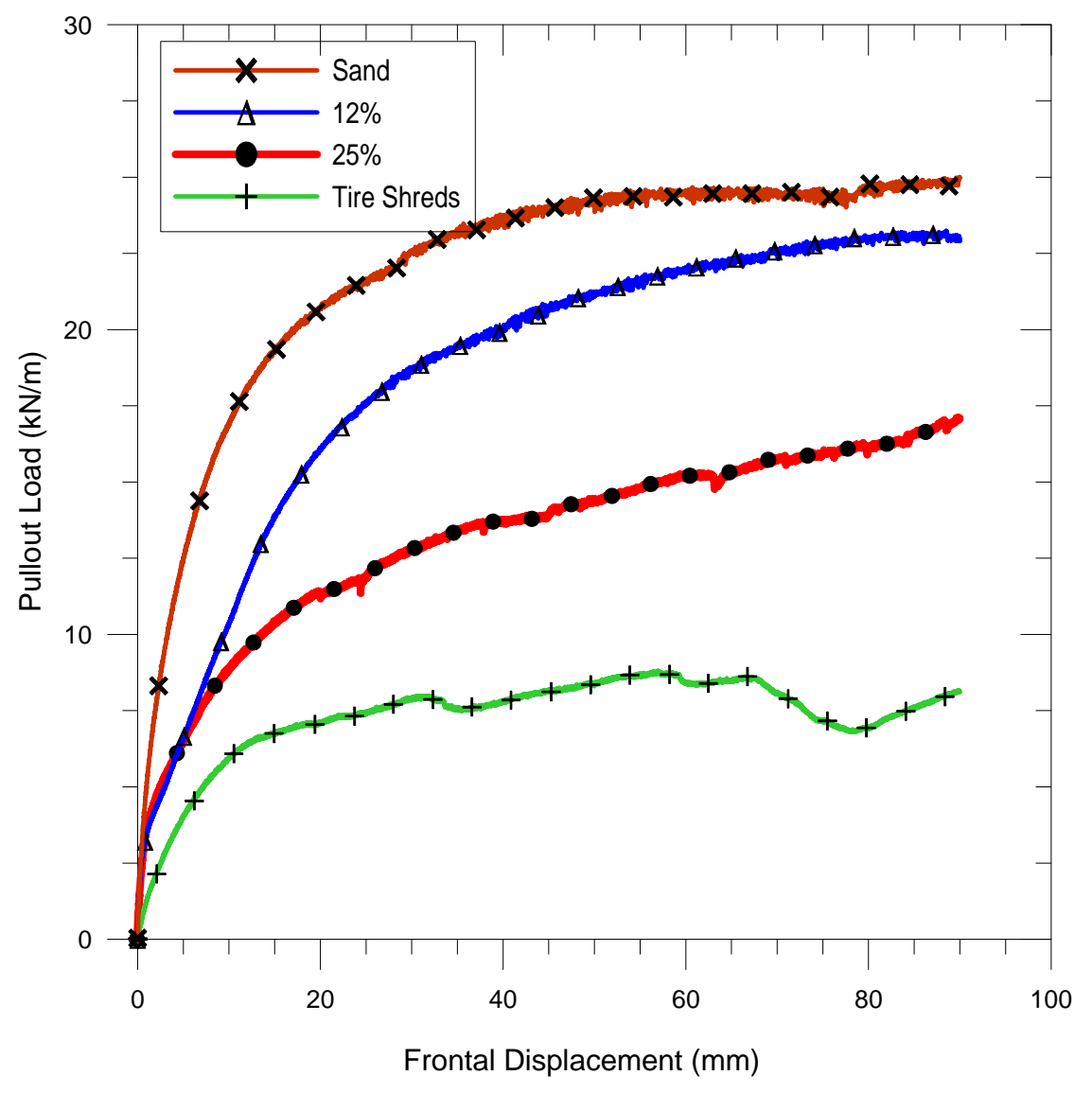

Figure 5-5 Pullout load versus frontal displacement for samples prepared with various mixing ratios by weight of tire shreds (100 to $200 \mathrm{~mm}$ in length) and sand and subjected to a confining pressure of $40 \mathrm{kPa}$. 


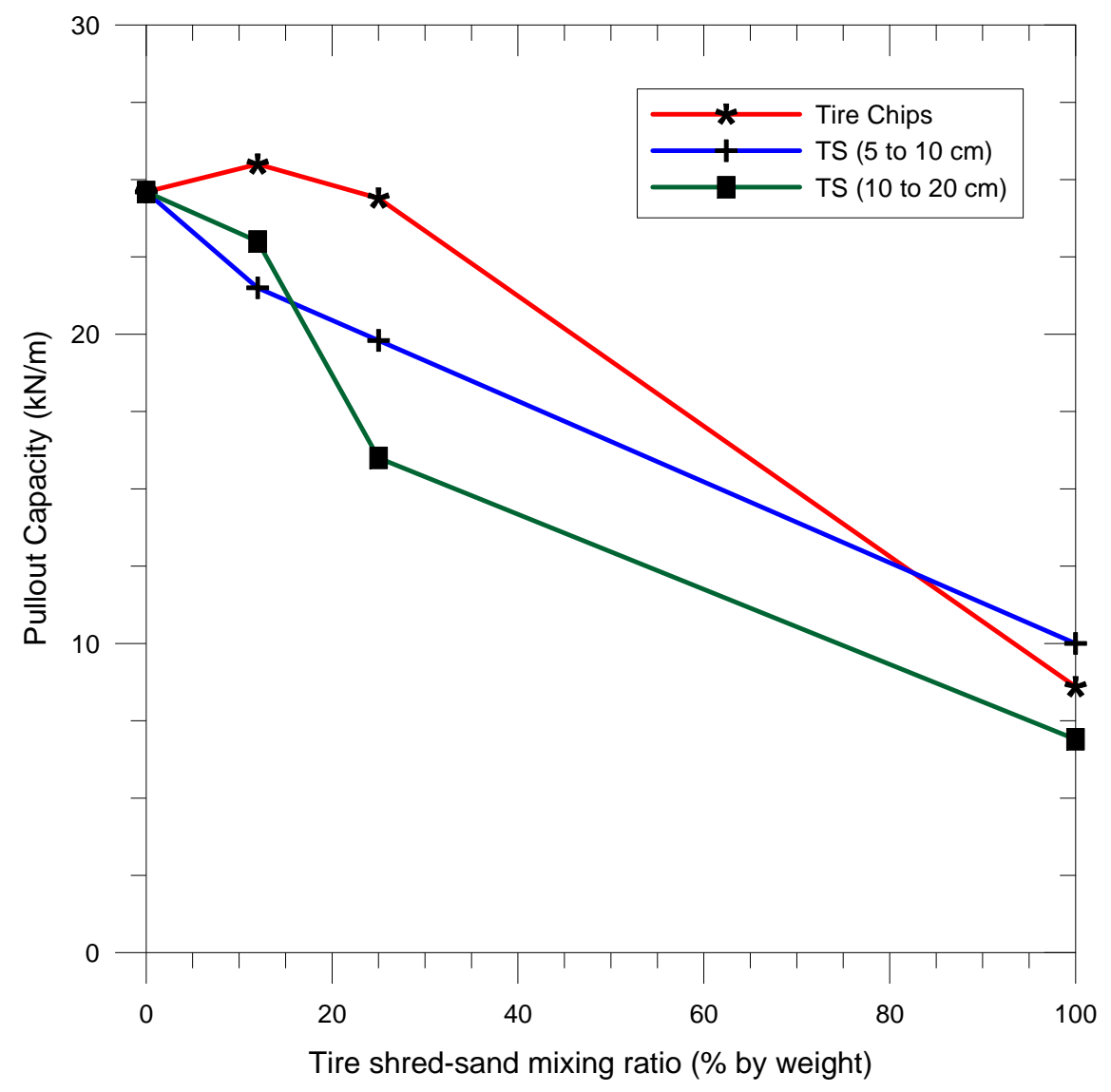

Figure 5-6 Pullout capacity versus tire shred-sand mixing ratio for various sizes of shredded tires and subjected to a confining pressure of $40 \mathrm{kPa}$. 


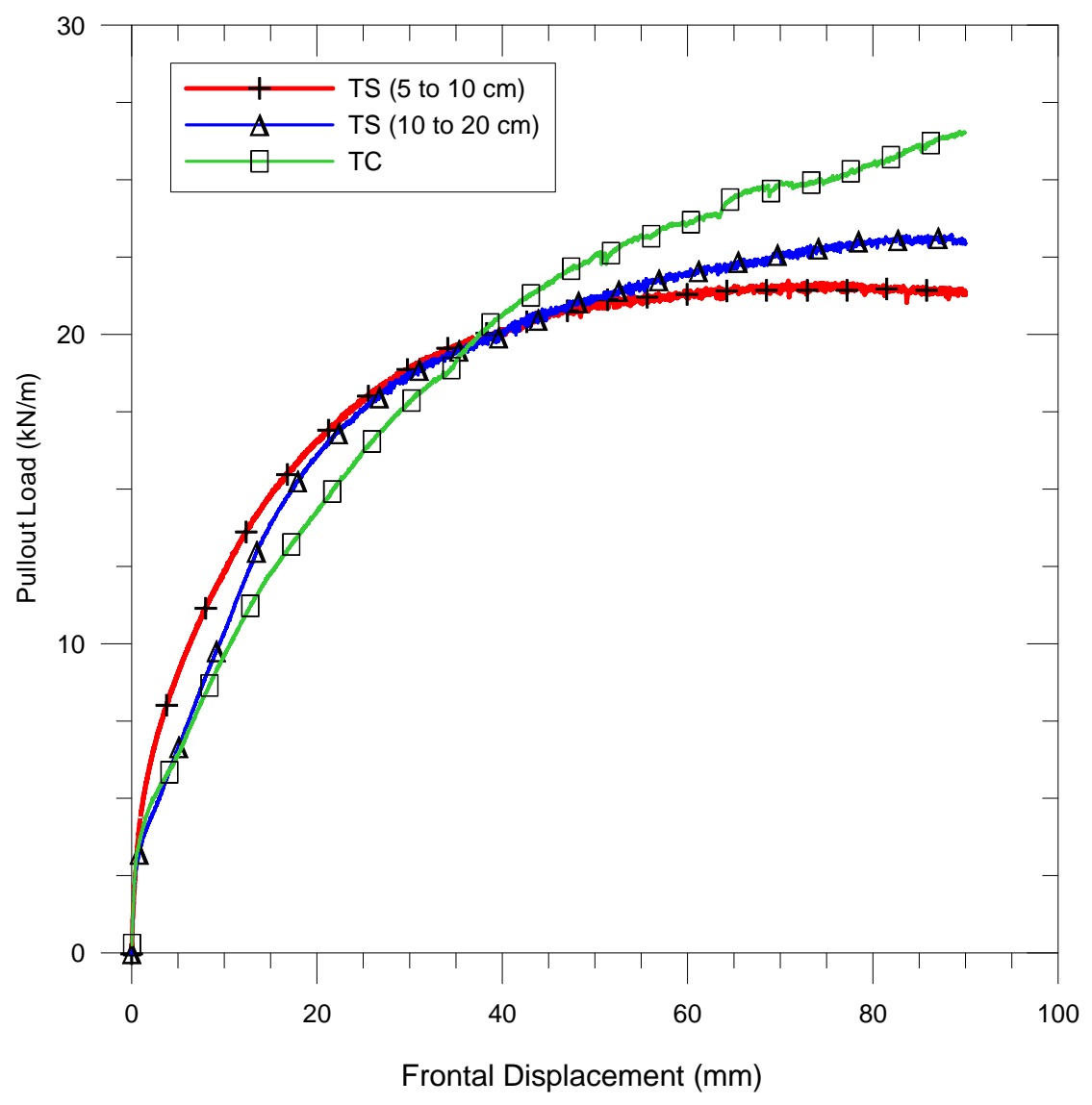

Figure 5-7 Pullout load versus frontal displacement for various tire shred sizes at a tire shred-sand mixing ratio of $12 \%$ by weight and subjected to a confining pressure of 40 $\mathrm{kPa}$. 


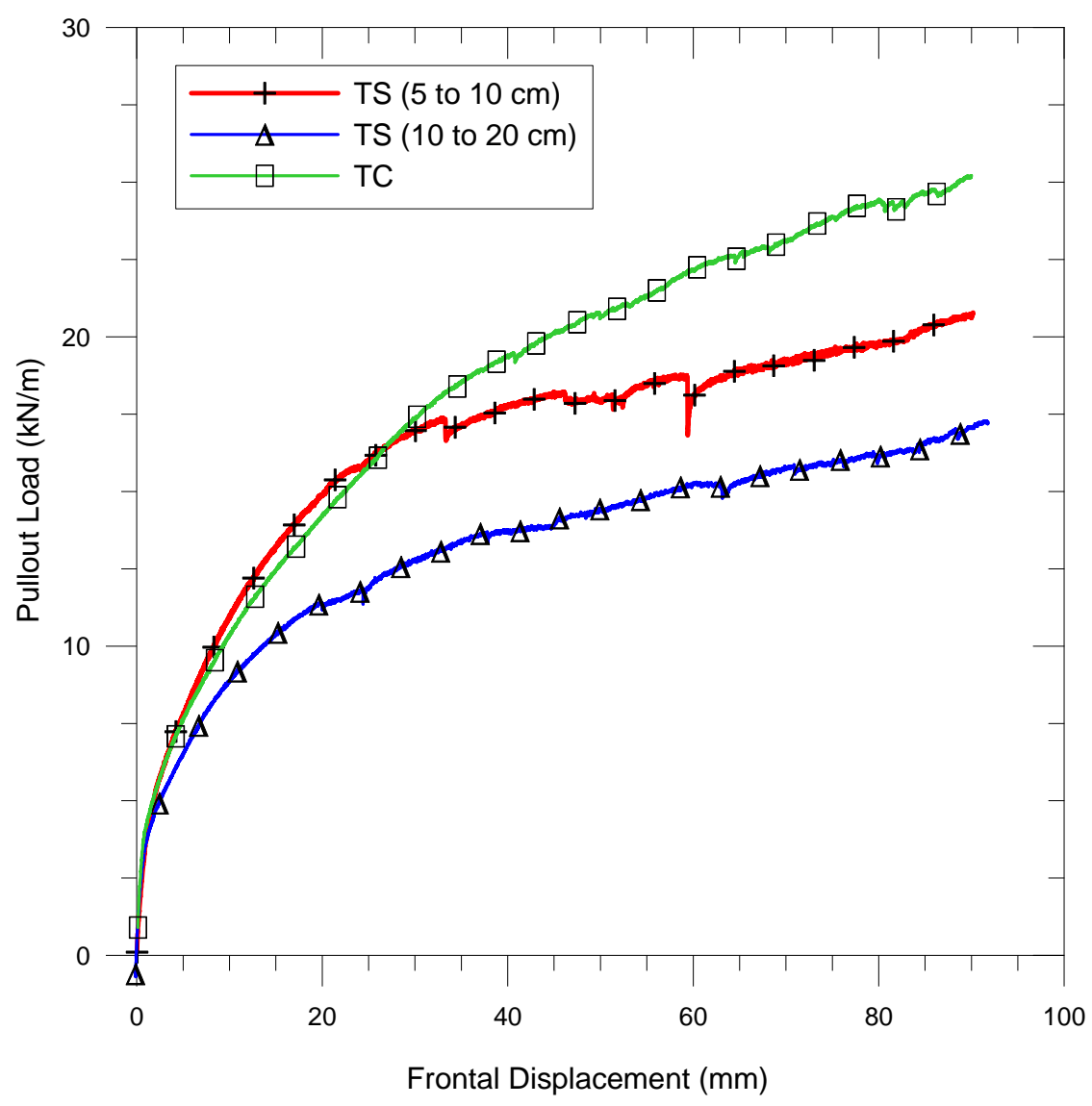

Figure 5-8 Pullout load versus frontal displacement for various tire shred sizes at a tire shred-sand mixing ratio of $25 \%$ by weight and subjected to a confining pressure of 40 $\mathrm{kPa}$. 


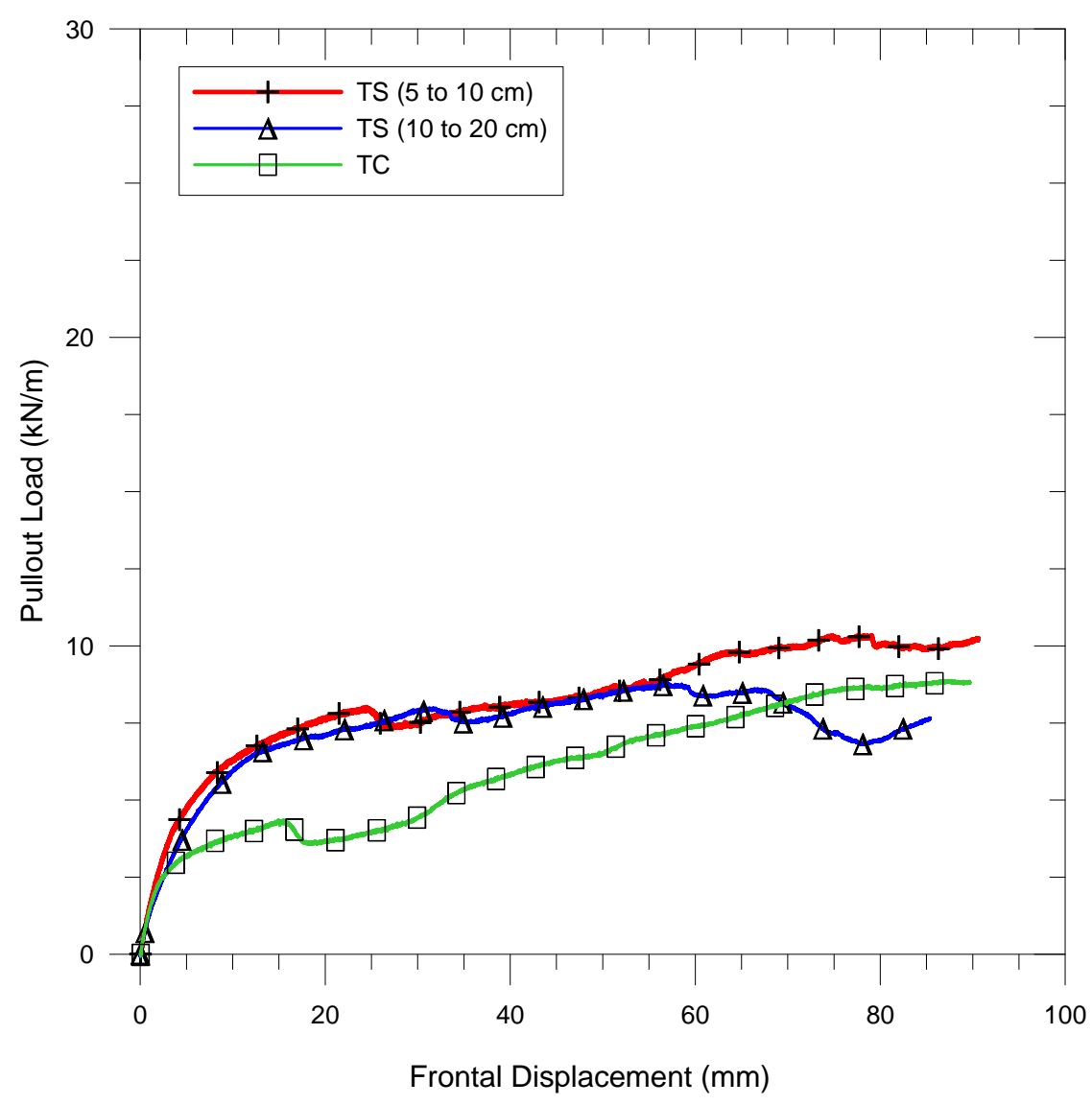

Figure 5-9 Pullout load versus frontal displacement for various tire shred sizes at a tire shred-sand mixing ratio of $100 \%$ by weight and subjected to a confining pressure of 40 $\mathrm{kPa}$. 


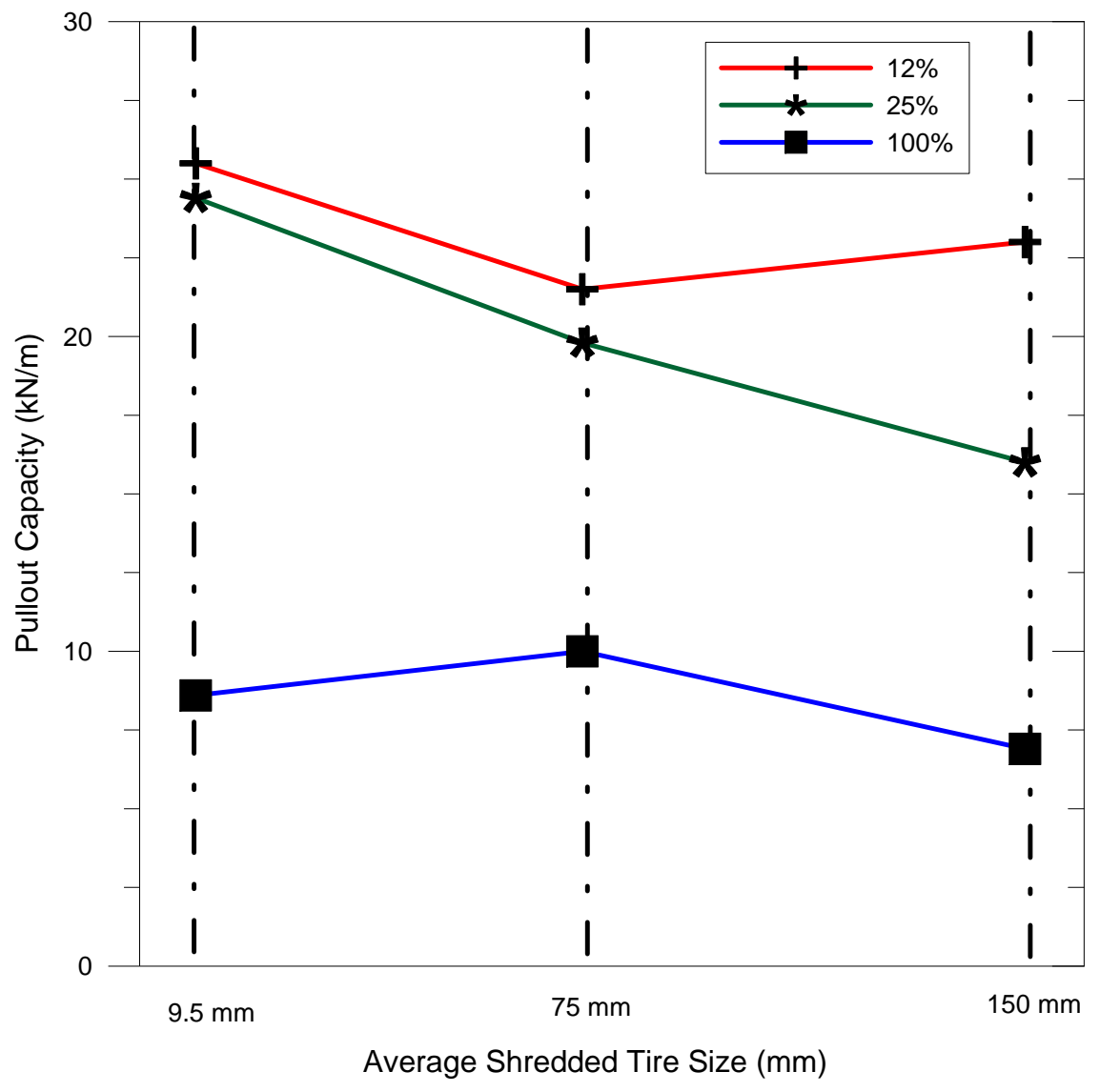

Figure 5-10 Pullout capacity versus average size of shredded tire for various tire shredsand mixing ratios by weight and subjected to a confining pressure of $40 \mathrm{kPa}$. 
Table 5-2 Summary of geogrid pullout capacities at a confining pressure of $40 \mathrm{kPa}$.

\begin{tabular}{|c|c|c|c|}
\hline $\begin{array}{c}\text { Size of shredded } \\
\text { tires }\end{array}$ & $\begin{array}{l}\text { Shredded tires/sand } \\
\text { (by weight) }\end{array}$ & $\begin{array}{l}\text { Shredded tires/sand } \\
\text { (by volume) }\end{array}$ & $\begin{array}{l}\text { Pullout capacity } \\
\qquad(\mathrm{kN} / \mathrm{m})\end{array}$ \\
\hline Sand & $0 / 100$ & $0 / 100$ & 24.6 \\
\hline \multirow{4}{*}{$\begin{array}{c}9.5 \mathrm{~mm} \text { nominal } \\
\text { size }\end{array}$} & $12 / 88$ & $26 / 74$ & 25.5 \\
\hline & $25 / 75$ & $46 / 54$ & 24.4 \\
\hline & $100 / 0$ & $100 / 0$ & 8.6 \\
\hline & $0 / 100$ & $0 / 100$ & 24.6 \\
\hline \multirow{4}{*}{$\begin{array}{l}50-100 \mathrm{~mm} \text { in } \\
\text { length }\end{array}$} & $12 / 88$ & $23 / 77$ & 21.5 \\
\hline & $25 / 75$ & $42 / 58$ & 19.8 \\
\hline & $100 / 0$ & $100 / 0$ & 10.0 \\
\hline & $0 / 100$ & $0 / 100$ & 24.6 \\
\hline \multirow[t]{3}{*}{$\begin{array}{l}100-200 \mathrm{~mm} \text { in } \\
\text { length }\end{array}$} & $12 / 88$ & $23 / 77$ & 23.0 \\
\hline & $25 / 75$ & $43 / 57$ & 16.0 \\
\hline & $100 / 0$ & $100 / 0$ & 6.9 \\
\hline
\end{tabular}




\subsection{Pullout Test Results on Ribbed-Metal Strip}

\subsubsection{Effect of Tire Shred-Sand Mixing ratio}

Ribbed-metal strips embedded in samples prepared with sand only show a peak pullout load of $4.3 \mathrm{kN}$ for a frontal displacement of about $4 \mathrm{~mm}$. On the other hand, for the cases considered in this study, the pullout load versus frontal displacement response of ribbed-metal strip embedded in tire shred-sand mixtures does not show a defined peak, but instead the pullout load increases continuously with increasing frontal displacement (see Figure 5-11 to Figure 5-13). For a given displacement, the pullout load decreases with increasing tire shred content present in the mixture. As the tire shred content in the mixture is reduced from $100 \%$ to $12 \%$ by weight, the ribbed-strip pullout response approaches that of the response of the ribbed-strip embedded in samples prepared with only sand. The presence of tire shreds reduces the passive resistance mobilized at the ribs of the strip. Figure 5-14 shows that the pullout capacity of ribbed-strip decreases significantly with increasing tire shred content. For an increase in tire shred content from $0 \%$ to $100 \%$ in the mixture, the pullout capacity decreases by about $60 \%$ to $70 \%$.

\subsubsection{Effect of Tire Shred Size}

The size of shredded tire has a negligible effect on the pullout response of ribbedmetal strip placed in tire shred-sand mixtures (Figure 5-15 to Figure 5-17). The pullout capacity is significantly lower for ribbed-strips placed in samples prepared with tire shreds only; it is of the order of $25 \%$ to $35 \%$ of the pullout capacity observed for ribbed strip embedded in samples prepared with sand only (see Figure 5-18). Table 5-2 presents the pullout capacities of ribbed-metal strips for the test cases considered in this study. 


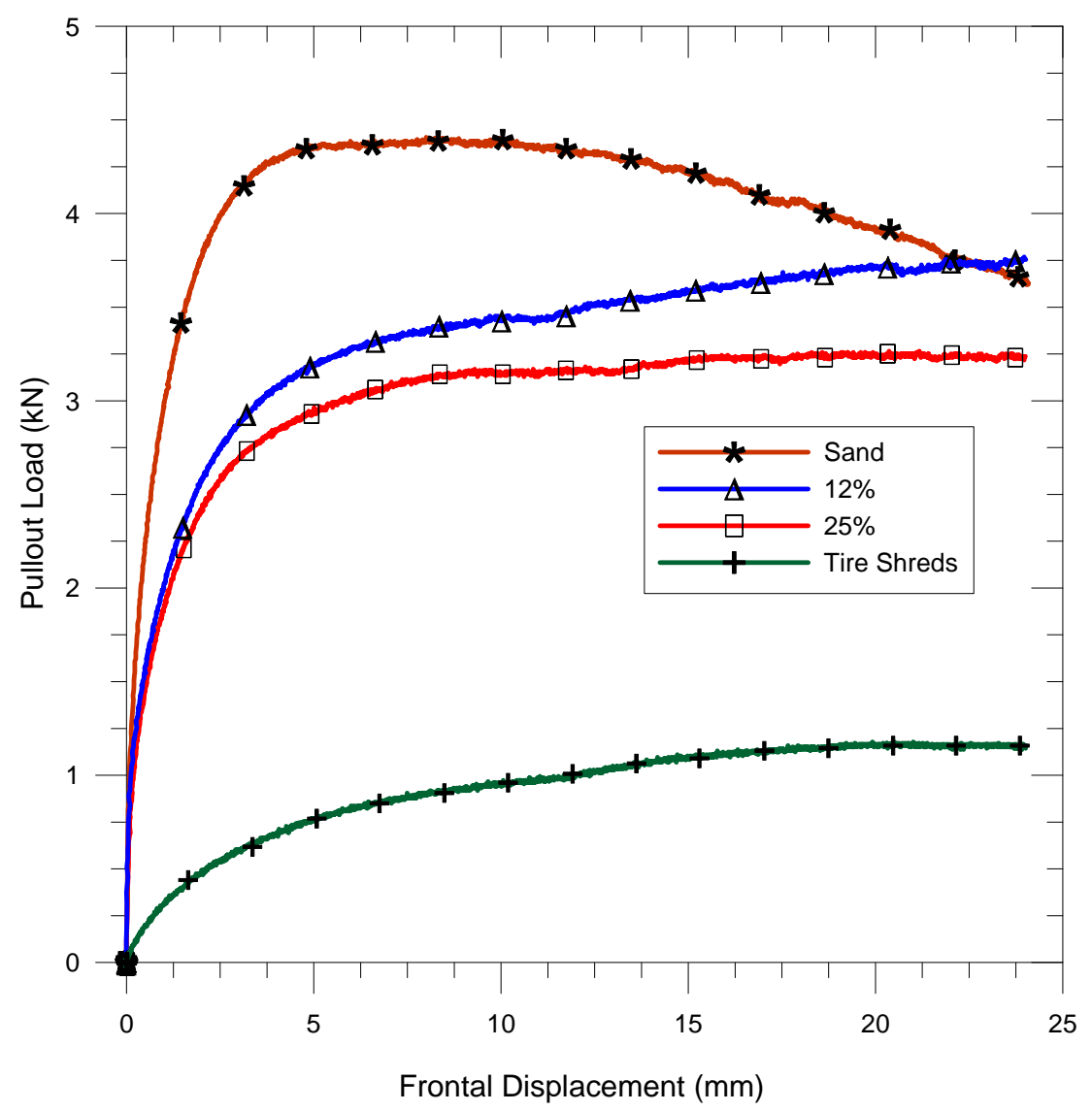

Figure 5-11 Pullout load versus frontal displacement for samples prepared with various mixing ratios by weight of tire chips ( $9.5 \mathrm{~mm}$ nominal size) and sand and subjected to a confining pressure of $40 \mathrm{kPa}$. 


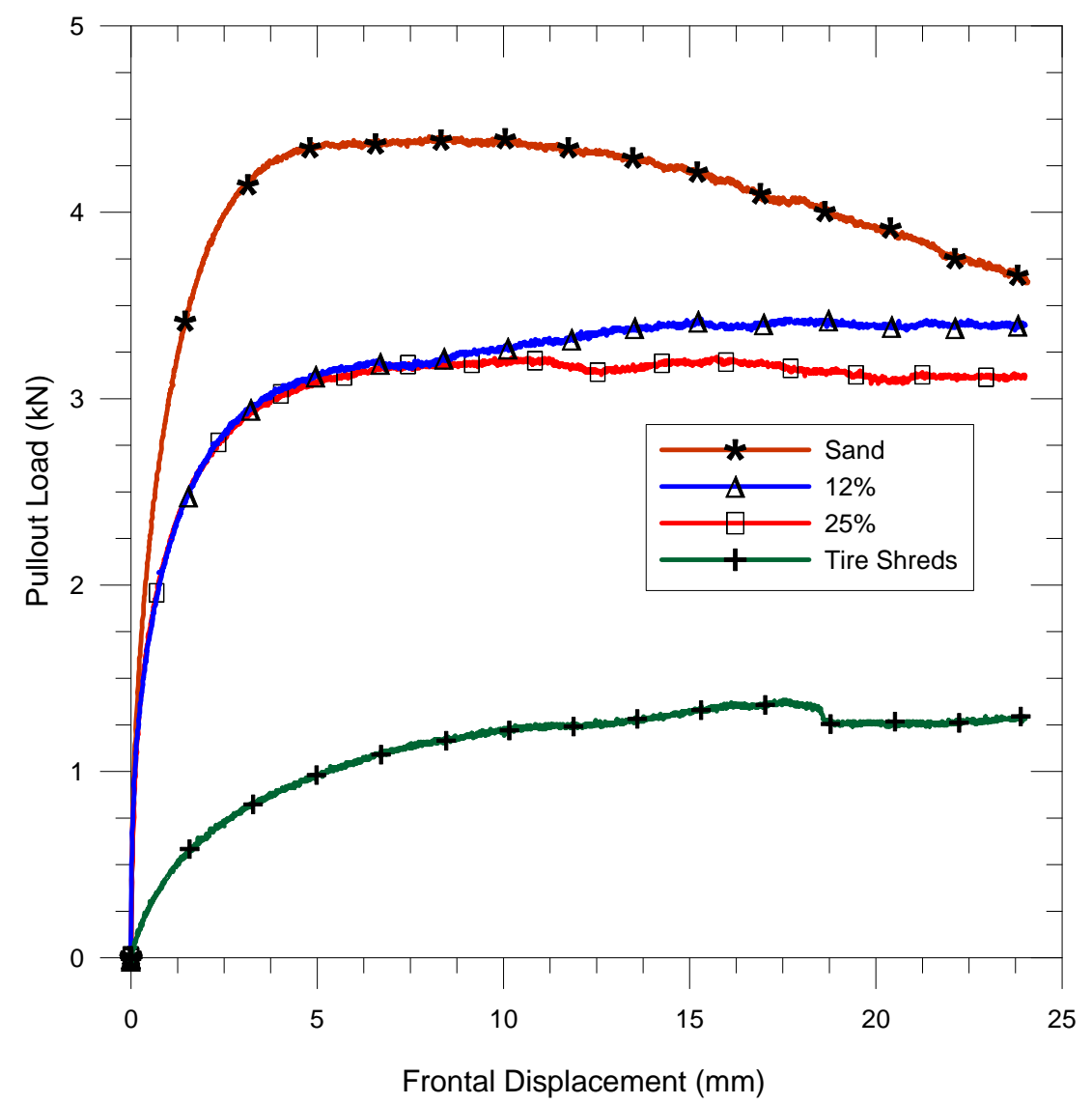

Figure 5-12 Pullout load versus frontal displacement for samples prepared with various mixing ratios by weight of tire shreds (50 to $100 \mathrm{~mm}$ in length) and sand and subjected to a confining pressure of $40 \mathrm{kPa}$. 


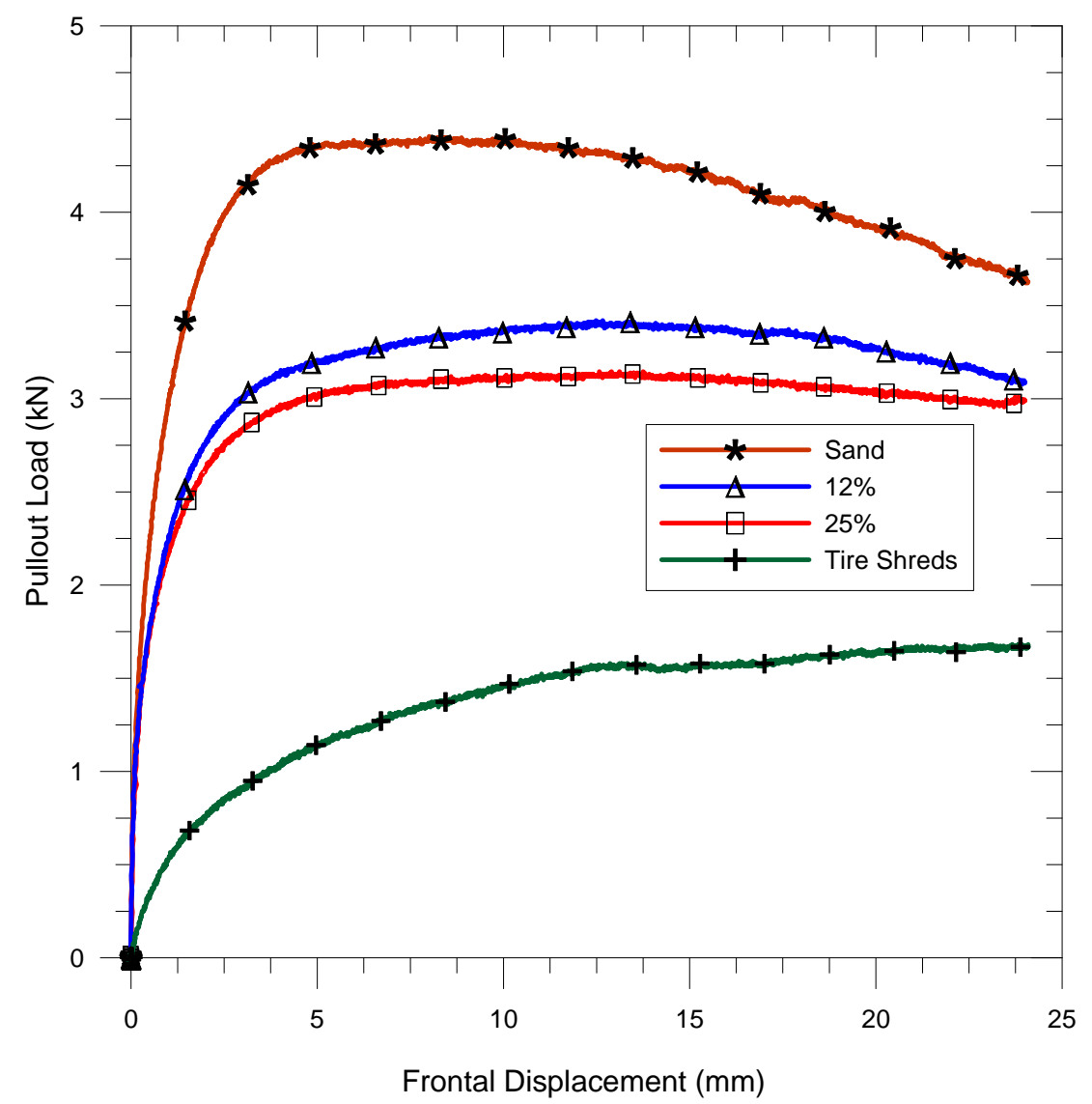

Figure 5-13 Pullout load versus frontal displacement for samples prepared with various mixing ratios by weight of tire shreds (100 to $200 \mathrm{~mm}$ in length) and sand and subjected to a confining pressure of $40 \mathrm{kPa}$. 


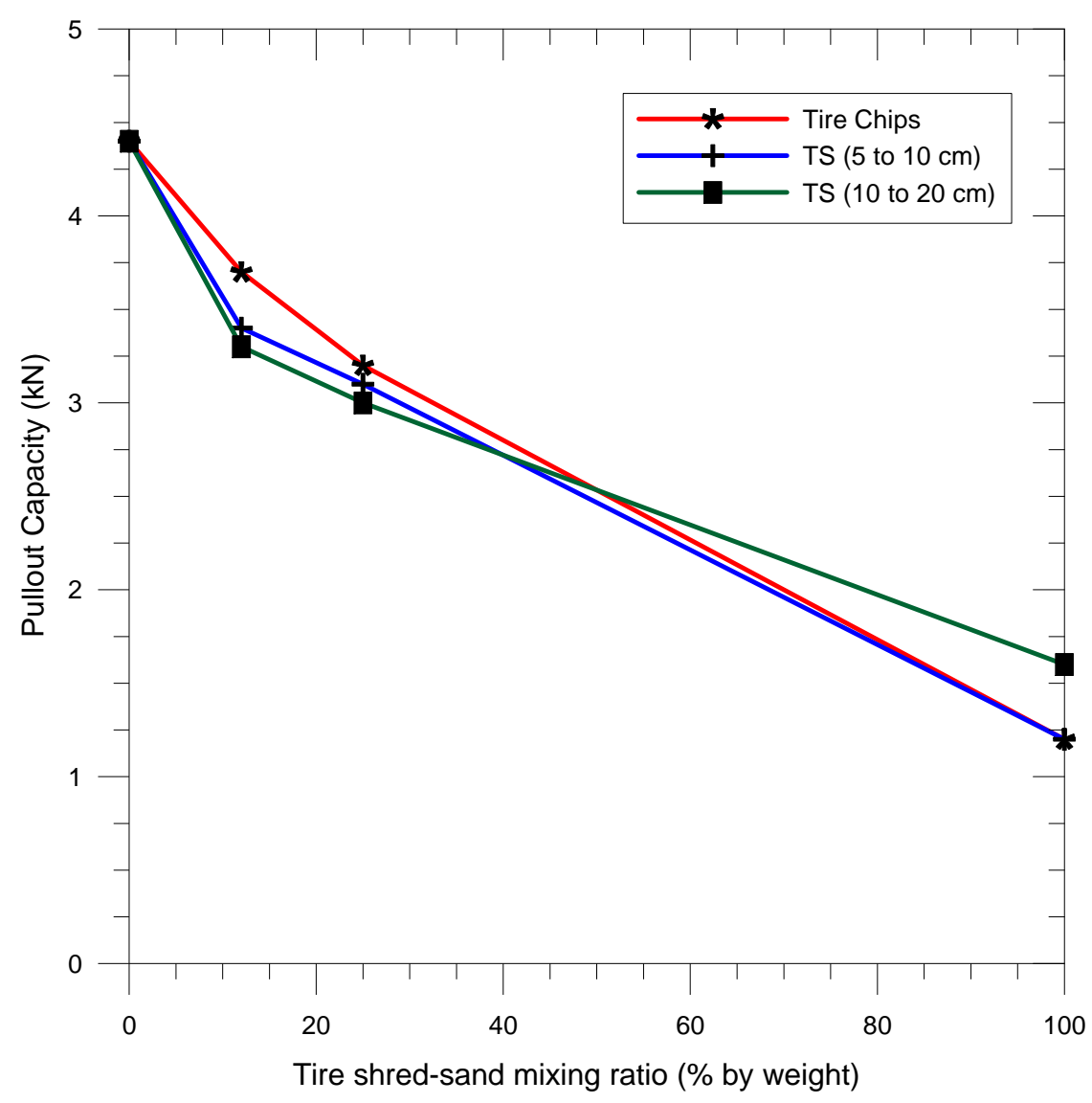

Figure 5-14 Pullout capacity versus tire shred-sand mixing ratio for various sizes of shredded tires and subjected to a confining pressure of $40 \mathrm{kPa}$. 


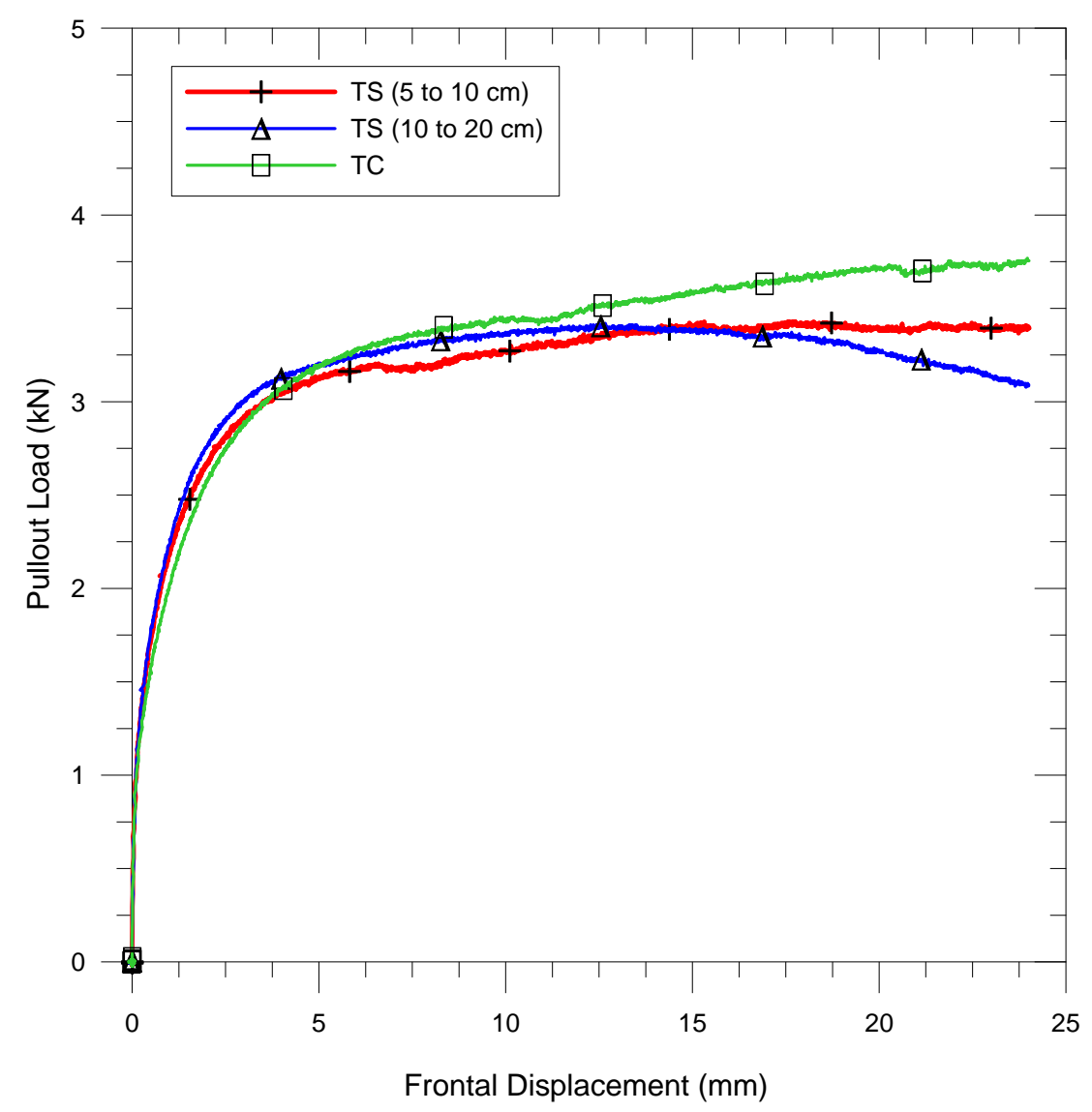

Figure 5-15 Pullout load versus frontal displacement for various tire shred sizes at a tire shred-sand mixing ratio of $12 \%$ by weight and subjected to a confining pressure of 40 $\mathrm{kPa}$. 


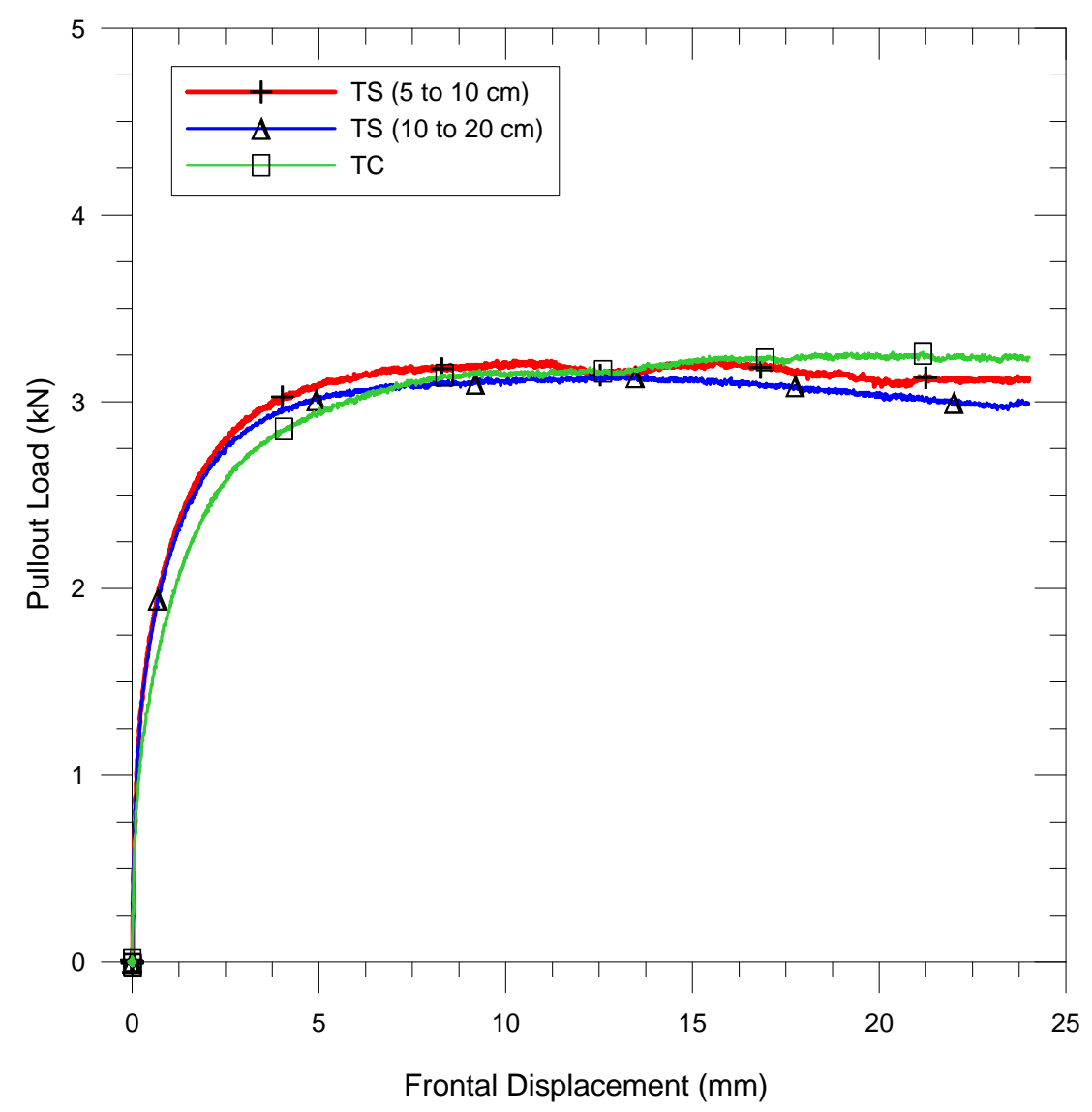

Figure 5-16 Pullout load versus frontal displacement for various tire shred sizes at a tire shred-sand mixing ratio of $25 \%$ by weight and subjected to a confining pressure of 40 $\mathrm{kPa}$. 


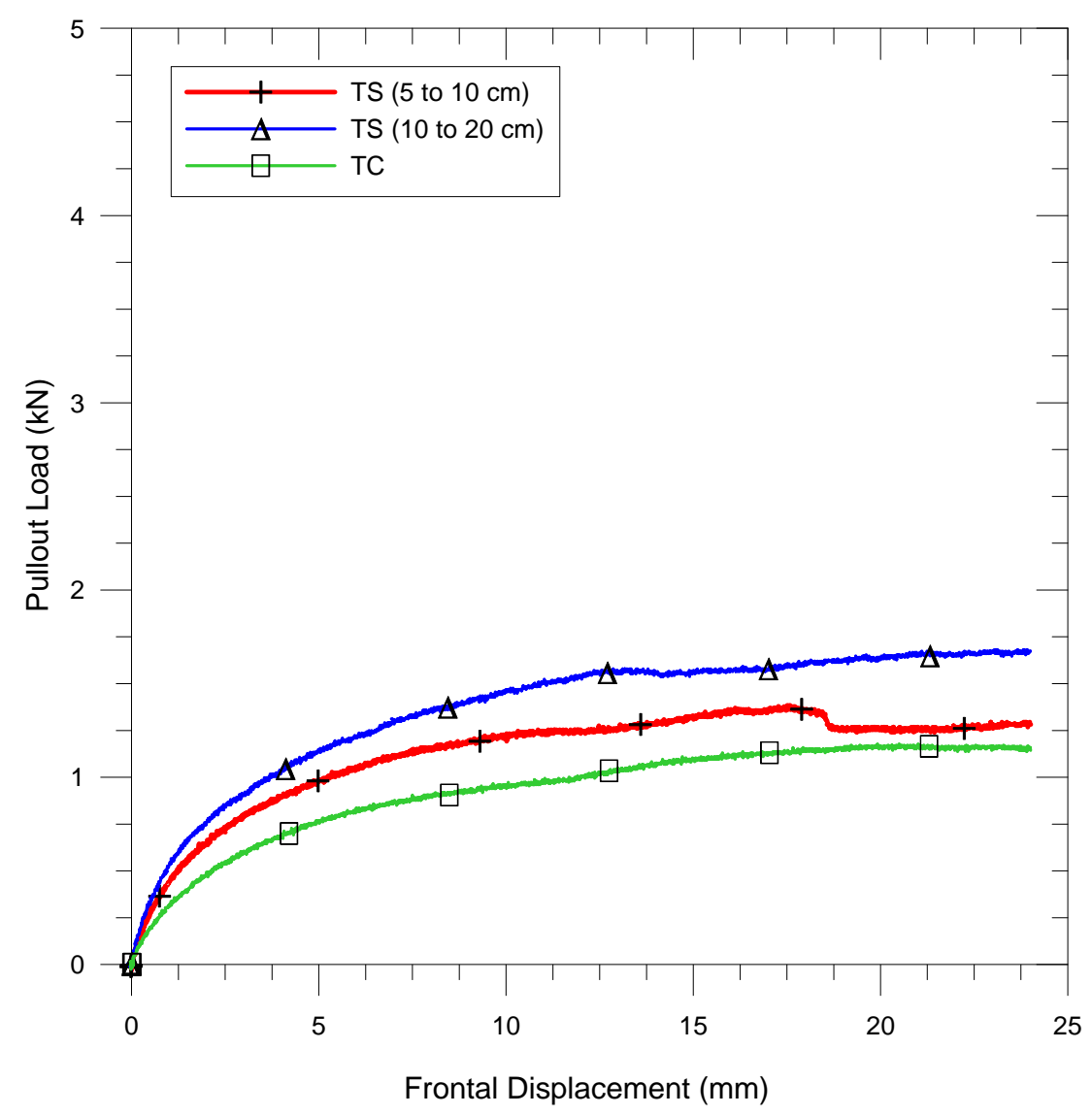

Figure 5-17 Pullout load versus frontal displacement for various tire shred sizes at a tire shred-sand mixing ratio of $100 \%$ by weight and subjected to a confining pressure of 40 $\mathrm{kPa}$. 


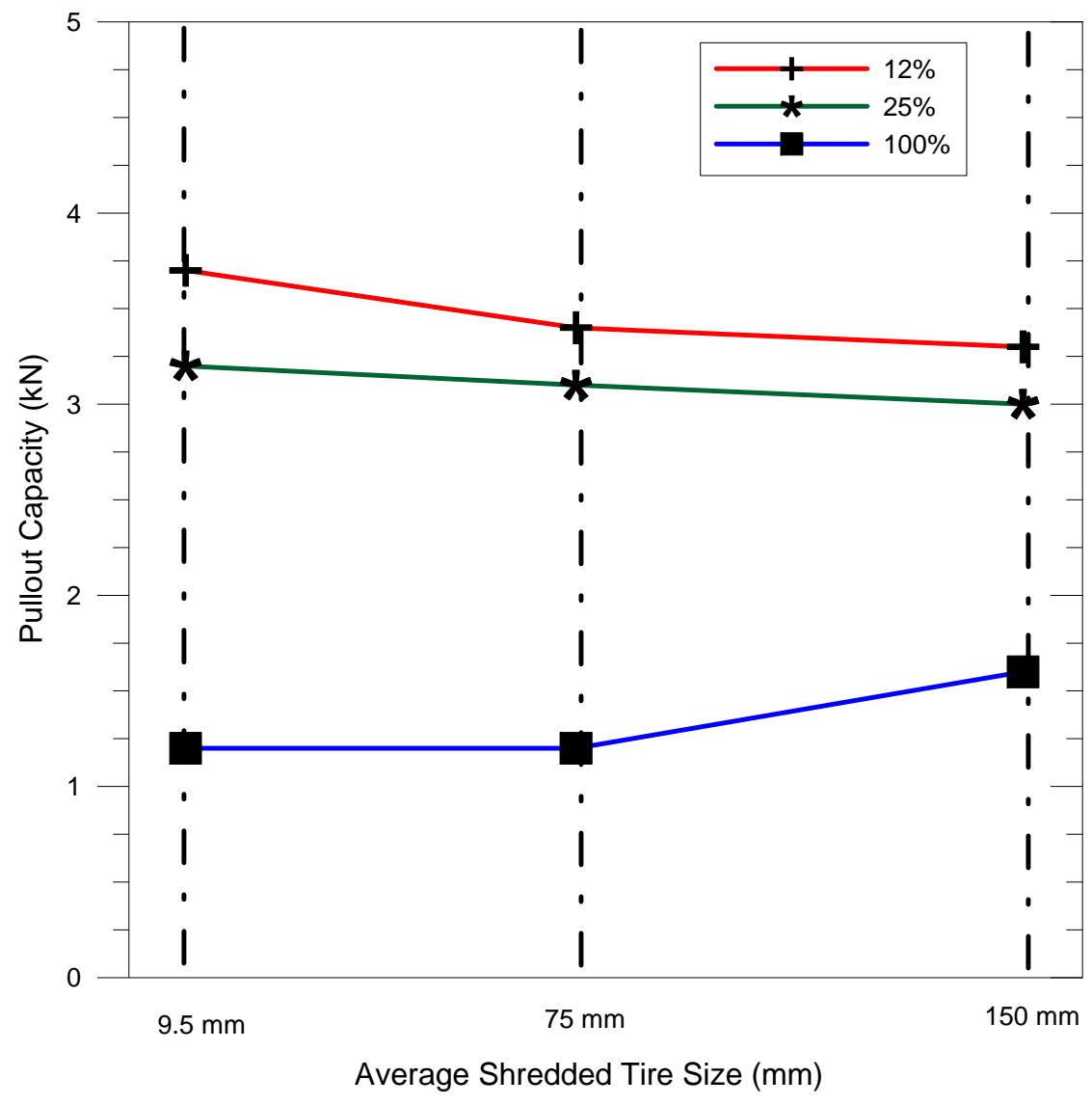

Figure 5-18 Pullout capacity versus average size of shredded tire for various tire shredsand mixing ratios by weight. 
Table 5-3 Summary of pullout capacities of ribbed-metal strip at a confining pressure of $40 \mathrm{kPa}$.

\begin{tabular}{|c|c|c|c|}
\hline Size of shredded tires & $\begin{array}{l}\text { Shredded } \\
\text { tires/Sand (by } \\
\text { weight) }\end{array}$ & $\begin{array}{c}\text { Shredded } \\
\text { tires/Sand (by } \\
\text { volume) }\end{array}$ & $\begin{array}{c}\text { Pullout capacity } \\
(\mathrm{kN})\end{array}$ \\
\hline \multirow{4}{*}{$9.5 \mathrm{~mm}$ nominal size } & $0 / 100$ & $0 / 100$ & 4.4 \\
\hline & $12 / 88$ & $26 / 74$ & 3.7 \\
\hline & $25 / 75$ & $46 / 54$ & 3.2 \\
\hline & $100 / 0$ & $100 / 0$ & 1.2 \\
\hline \multirow{4}{*}{$50-100 \mathrm{~mm}$ in length } & $0 / 100$ & $0 / 100$ & 4.4 \\
\hline & $12 / 88$ & $23 / 77$ & 3.4 \\
\hline & $25 / 75$ & $42 / 58$ & 3.1 \\
\hline & $100 / 0$ & $100 / 0$ & 1.2 \\
\hline \multirow{4}{*}{$100-200 \mathrm{~mm}$ in length } & $0 / 100$ & $0 / 100$ & 4.4 \\
\hline & $12 / 88$ & $23 / 77$ & 3.3 \\
\hline & $25 / 75$ & $43 / 57$ & 3.0 \\
\hline & $100 / 0$ & $100 / 0$ & 1.6 \\
\hline
\end{tabular}




\subsection{Progressive Load Transfer Behavior for Geogrids}

Since the geogrid used in the pullout test is extensible, the strains developed along the geogrid are not uniform. This incremental displacement was evaluated by monitoring nodal displacements. However, as result of the preparation of the samples containing shredded tires, large pieces of tires shreds may have caused bending of the wires (inside the pullout box) that were connected to the LVDTs. Therefore, it was not possible to obtain reasonable values of nodal displacements for samples prepared with tire shredsand mixtures. Figure 5-19 shows the nodal displacements of the geogrid from selected pullout tests performed on samples consisting of sand only. Two nodal displacements (at $0.3 \mathrm{~m}$ and $0.8 \mathrm{~m}$ from the front end of the pullout box) were monitored. As shown in the figure, the nodal displacements decrease with distance from the front end of the pullout box, which means that the strain developed at the front end of the geogrid is higher than that developed at its tail. It is also observed that the nodal displacement decreases with increasing confining pressure because of the apparent increase in geogrid stiffness with confining pressure (Farrag et al. 1993). 


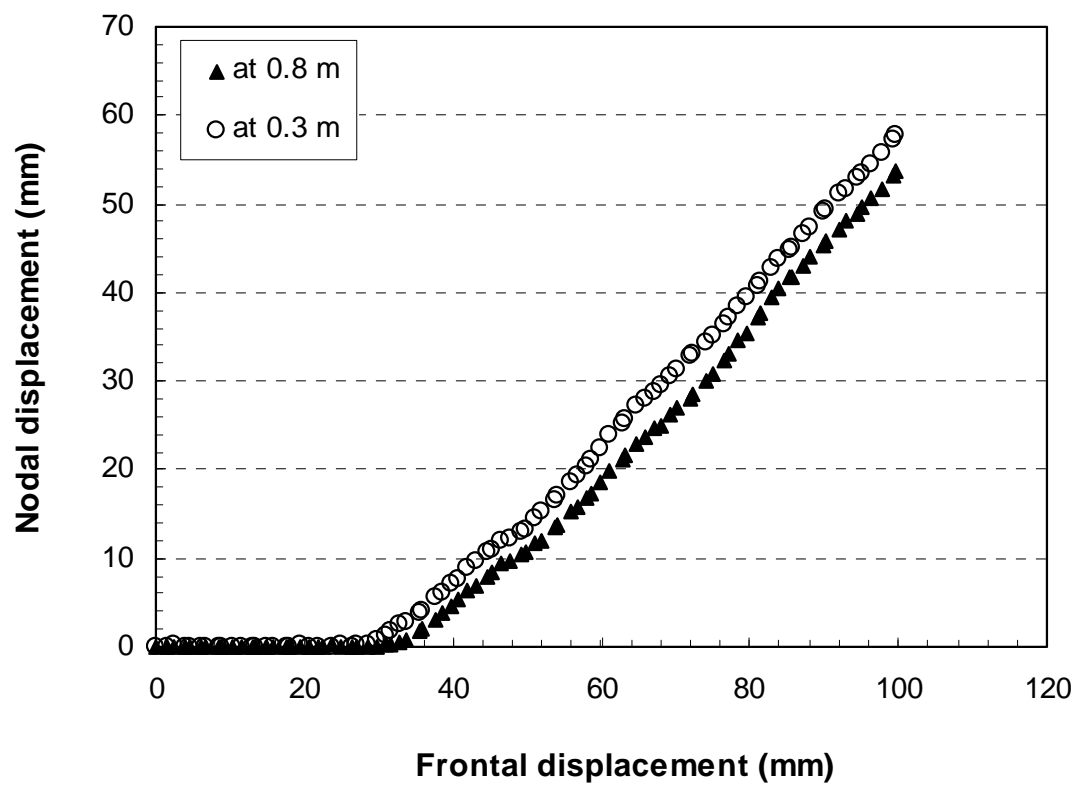

(a) Confining pressure of $40 \mathrm{kPa}$

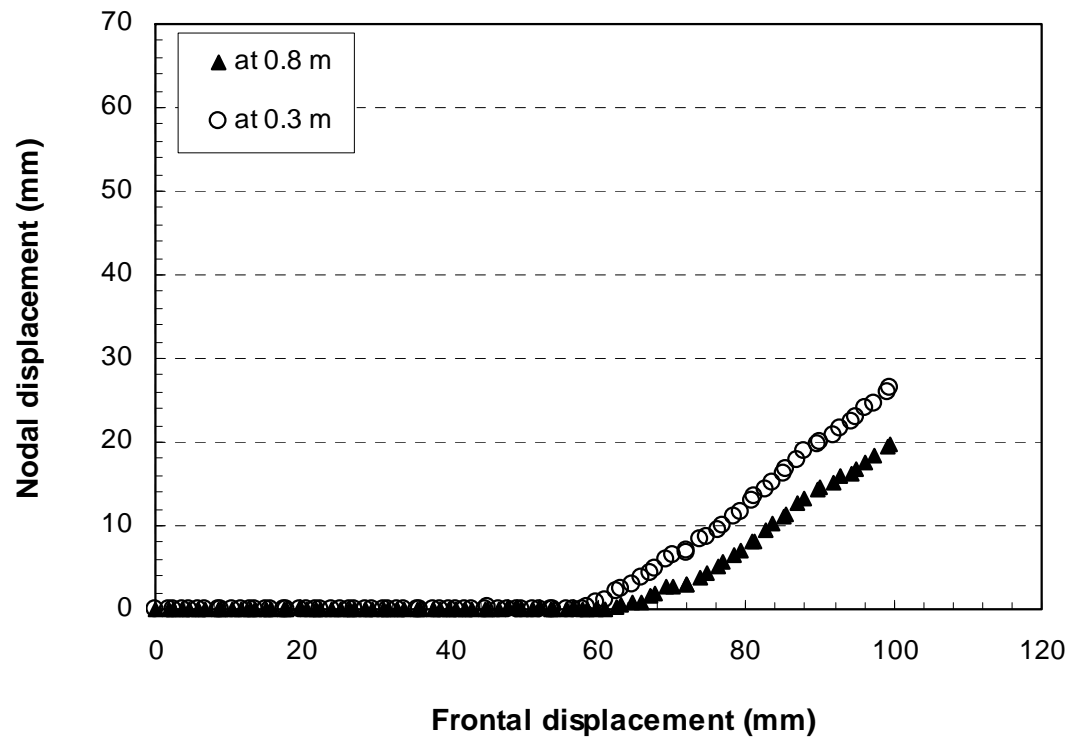

(b) Confining pressure of $80 \mathrm{kPa}$

Figure 5-19 Nodal displacement versus frontal displacement (Ottawa sand). 


\subsection{Summary}

Pullout tests were performed on geogrid and ribbed-metal strip placed in tire shred-sand mixtures with various tire shred sizes and mixing ratios. A confining pressure of $40 \mathrm{kPa}$ was selected. Based on the test results, the following observations were made:

1. The pullout resistance of geogrid and ribbed-metal strip increases with decreasing tire shred-sand ratio in the mixture.

2. The pullout resistance of geogrid placed in samples prepared at optimum tire shred-sand mixing ratio of $25 \%$ by weight is found to be higher for tire chip-sand mixtures than for tire shred-sand mixtures. For the geogrid and confining pressure considered, the pullout capacity of geogrid placed in tire chip-sand mixtures is $30 \%$ higher than that of the tire shred (100-200 mm)-sand mixtures. 9.5-mm-size tire chips can easily wedge against the apertures of the geogrid selected and offer higher passive resistance.

3. The tire shred size has a negligible effect on the pullout capacity of geogrid embedded in tire shred-sand mixtures prepared at tire shred-sand mixing ratios of $12 \%$ and $25 \%$ (by weight).

4. The pullout capacity of geogrid embedded in the sample prepared using only tire shreds is about $30-40 \%$ lower than that measured for geogrid embedded in samples prepared with sand only.

5. The size of shredded tires has a negligible effect on the pullout capacity of ribbedmetal strips. 
6. The pullout capacity of the ribbed-metal strip embedded in samples prepared with tire shreds only is about $65-70 \%$ lower than that measured for ribbed-metal strip embedded in samples prepared with sand only. 


\section{CHAPTER 6. LARGE-SCALE DIRECT SHEAR TESTING}

\subsection{Introduction}

Direct shear (DS) and triaxial (TX) tests are widely used to study the shear strength properties of pure tire shreds and tire shred-soil mixtures. However, conventional TX systems cannot be used to test the large-size tire shreds that are typically used in civil engineering applications because of the boundary effects that appear as a result of the sample size limitation. Several researchers proposed minimum values for the ratio of the diameter of the specimen to the maximum particle size in the sample. Marachi et al. (1972) and Indraratna et al. (1993) proposed minimum sample diameter-particle size ratios of 6 and 8 to 12 , respectively. Conventional TX testing is, hence, usually limited to tire chips with a size of $25 \mathrm{~mm}$ or less (ASTM D 6270-98). Extrapolation of test results to large-size tire shreds can be misleading due to differences in the geometric shapes of tire shreds of different sizes. Tire chips with size less than $25 \mathrm{~mm}$ tend to be cubical, whereas the large-size tire shreds are typically flat and elongated. Also, largesize tire shreds typically contain protruding steel wires that might puncture TX specimen membranes and therefore need to be removed before testing. There are several studies available in the literature on shear strength evaluation of pure tire chips and tire chip-sand mixtures using TX equipment (see Table 6-1). The majority of these studies reported TX test results for mixtures containing small-size tire chips with maximum size less than 50 $\mathrm{mm}$. 
The DS test, which has been in existence for more than 200 years, is simple to perform (Holtz and Kovacs 1981). The test method consists of applying a confining stress on top of the sample and then moving one-half of the DS box in the horizontal direction while the other half is fixed (see Figure 6-1). DS test equipment with a square box of side equal to $300 \mathrm{~mm}$ was developed in the 1940's to test gravel-size particles (Bishop 1948), however, this type of equipment has been widely used to determine the shear strength properties of tire shred and tire shred-sand mixtures.

Foose et al. (1996) reported the results of DS tests performed on samples containing the following tire shred sizes: less than $50 \mathrm{~mm}, 50-100 \mathrm{~mm}$, and 100-150 mm in length (the DS equipment consisted of two top and bottom steel rings $279 \mathrm{~mm}$ of inside diameter and $157 \mathrm{~mm}$ of height). Edil and Bosscher (1994) and Humphrey et al. (1993) used a 305-mm-diameter box to test tire shreds with maximum size equal to 76 mm. Woodward and Blewett (1998) also used a 300-mm-square DS box to test tire shredsand mixtures with two types of shredded tires: granulated rubber (less than $5 \mathrm{~mm}$ in size) and tire chips (less than $30 \mathrm{~mm}$ in length and passing the $3.35-\mathrm{mm}$ sieve).

Youwai (2003) used a slightly larger DS box than the one used by Woodward and Blewett (1998) (the inside dimensions of the box were: $580 \mathrm{~mm}$ in width $\mathrm{x} 930 \mathrm{~mm}$ in length $\times 560 \mathrm{~mm}$ in height) to test tire chips-sand mixtures $(30: 70,40: 60$, and 50:50 tire chip-sand ratios by weight). Youwai (2003) used tire chips that were 5 to $50 \mathrm{~mm}$ in length. Graham et al. (2001) used a large direct shear box with plan dimensions of $0.91 \mathrm{~m}$ x $0.91 \mathrm{~m}$ to estimate the shear strength of large-size tire shreds of $40 \mathrm{~mm}$ to $1.4 \mathrm{~m}$ in length. 
In this study, a large-scale DS apparatus was designed to evaluate the shear strength properties of large-size tire shreds (up to $10 \mathrm{~cm}$ in length) mixed with sand. A schematic representation of the Purdue DS apparatus used in this study is shown in Figure 6-2. This large-scale DS testing equipment can be used not only to obtain the shear strength parameters of composite specimens of tire shreds and sand and but also of other materials composed of large size particles. As per ASTM recommendations, the width of square specimens to be tested in DS systems should be at least 10 times the maximum particle size diameter in order to eliminate the boundary effects (ASTM D 3080- 04). Accordingly, to minimize boundary effects, the DS box was designed such that the inner dimensions of the lower box are $1.2 \mathrm{~m}$ in length $\mathrm{x} 1.0 \mathrm{~m}$ in width $\mathrm{x} 0.47 \mathrm{~m}$ in height, whereas the dimensions of the upper box are: $1.0 \mathrm{~m}$ in length $\mathrm{x} 1.0 \mathrm{~m}$ in width x $0.5 \mathrm{~m}$ in height. During shearing, the lower box is displaced while the upper box remains in place. In this Chapter, we present the results of DS tests performed on tire shred-sand mixtures containing tire shreds with length ranging from 50 to $100 \mathrm{~mm}$. The mixtures were prepared at the optimum mixing ratio of 25/75 (tire shred /Ottawa sand, by weight) and tested in the DS machine. We also evaluated the effect of tire shred size on the shear strength of the mixtures. 
Table 6-1 Details of TX equipment and materials used in previous studies

\begin{tabular}{|c|c|c|c|}
\hline TX specimen details & Test materials used & Mixing ratio & Reference \\
\hline $\begin{array}{l}150 \mathrm{~mm} \text { diameter and } \\
300 \mathrm{~mm} \text { high }\end{array}$ & $\begin{array}{l}\text { Tire Chips of two sizes } \mathbf{1 2} \mathbf{~ m m} \text { and } \mathbf{2 5} \mathbf{~ m m} \\
\text { mixed with Ottawa sand and Crosby Till }\end{array}$ & $\begin{array}{l}0 \text { to } 100 \% \text { by weight } \\
\text { (tire shred: sand/till) }\end{array}$ & Ahmed (1993) \\
\hline $\begin{array}{l}100 \mathrm{~mm} \text { diameter and } \\
200 \mathrm{~mm} \text { high }\end{array}$ & $\begin{array}{l}\text { Five tire chip products in the size range } \mathbf{2} \mathbf{~ m m} \text { to } \\
\mathbf{3 8} \mathbf{~ m m}\end{array}$ & Pure tire chips & Wu et al. (1997) \\
\hline $\begin{array}{l}150 \mathrm{~mm} \text { diameter and } \\
300 \mathrm{~mm} \text { high }\end{array}$ & $\begin{array}{l}\text { Tire chips with }<30 \mathbf{m m} \text { size mixed with } \\
\text { Monterey No. } 30 \text { sand }(\mathrm{SP})\end{array}$ & $\begin{array}{l}\text { 40:60 by weight (tire } \\
\text { shred: sand) }\end{array}$ & Lee et al. (1999) \\
\hline $\begin{array}{l}71.1 \mathrm{~mm} \text { diameter and } \\
149 \mathrm{~mm} \text { high }\end{array}$ & Tire chips size ranging from $\mathbf{2}$ to $\mathbf{1 0} \mathbf{~ m m}$ & Pure tire chips & Yang et al. (2002) \\
\hline $\begin{array}{l}100 \mathrm{~mm} \text { diameter and } \\
200 \mathrm{~mm} \text { high }\end{array}$ & Tire chips with size $<\mathbf{1 6} \mathbf{~ m m}$ (cubical shaped) & $\begin{array}{l}0 \text { to } 100 \% \text { by weight } \\
\text { (tire shred: sand) }\end{array}$ & $\begin{array}{l}\text { Youwai and } \\
\text { Bergado (2003) }\end{array}$ \\
\hline $\begin{array}{l}153 \mathrm{~mm} \text { diameter and } \\
305 \mathrm{~mm} \text { high }\end{array}$ & $\begin{array}{l}\text { Tire shreds of various sizes with maximum size } \\
\text { up to } 102 \mathbf{~ m m}\end{array}$ & $\begin{array}{l}0 \text { to } 100 \% \text { by weight } \\
\text { (tire shred: sand) }\end{array}$ & $\begin{array}{l}\text { Zornberg et al } \\
(2004)\end{array}$ \\
\hline $\begin{array}{l}300 \mathrm{~mm} \text { diameter and } \\
600 \mathrm{~mm} \text { high }\end{array}$ & Tire chips $<\mathbf{5 0} \mathbf{~ m m}$ (flat tire chips) & $\begin{array}{l}\text { 30:70, 40:60, 50:50, and } \\
\text { 100:0 by weight (tire } \\
\text { shred: sand) }\end{array}$ & $\begin{array}{l}\text { Bergado et al } \\
(2005)\end{array}$ \\
\hline
\end{tabular}




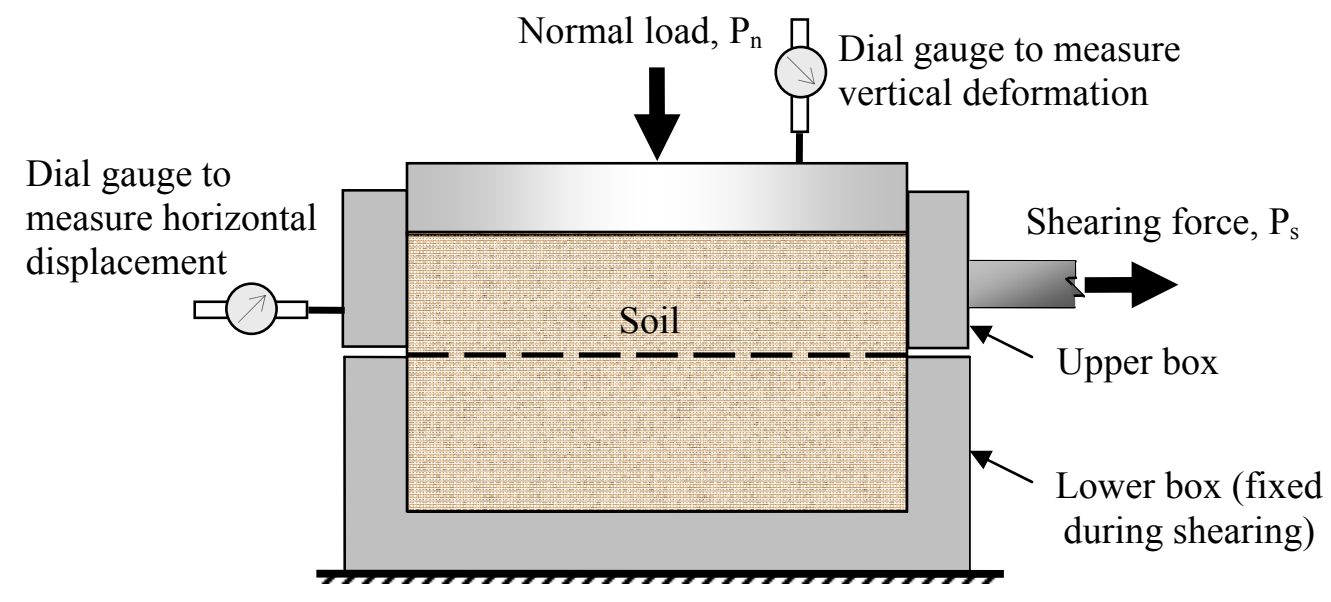

Figure 6-1 Schematic of a typical DS apparatus.

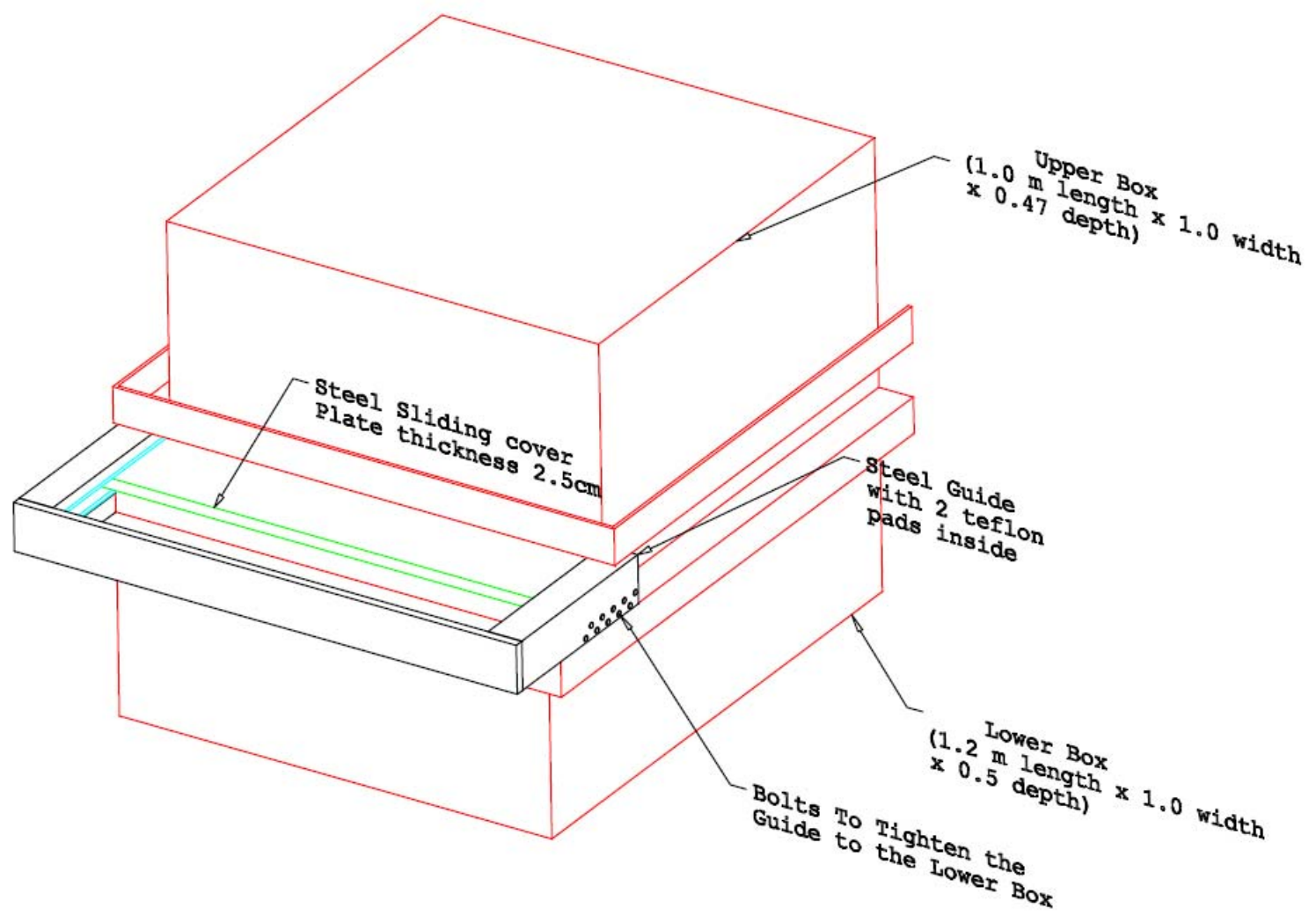

Figure 6-2 Schematic of large-scale DS box. 


\subsection{Experimental Set-up}

In the following sections, we describe the main components of the DS box along with their specifications and operational details. We also provide the details of the instrumentation of the large-scale DS box and the compaction equipment used to compact the tire shred-sand mixtures investigated. The Purdue DS box was fabricated by S.CO.R.E (Steel Construction \& Robotic Machinery EST.; www.score-steel.com).

\subsubsection{Main components of the large-scale DS box}

The main components of the DS box are indicated in Figure 6-3 and Figure 6-4 gives the components of the DS box and a brief description of their function.

Table 6-2 Main Components of the DS machine

\begin{tabular}{ll}
\hline \multicolumn{1}{c}{ Component } & \multicolumn{1}{c}{ Description } \\
\hline A: Piston & Oil is pumped from the hydraulic pack to the piston (25 \\
& mm inner diameter) to apply the desired pressure on top \\
& of the sample \\
\hline B: Pressure Gauge & The pressure gauge is used to measure the oil pressure \\
& acting in the pressure line that connects the hydraulic \\
& pack (labeled ' $P$ ' in Figure 6-3) to the piston \\
\hline C: Vertical LVDT Support & An LVDT (Omega Model No. LD600-100) is fixed at the \\
& vertical support connected to the piston to measure the \\
& vertical deformation of the sample during shearing. The \\
& maximum stroke length of the LVDT is \pm 100 mm \\
\hline D: Upper Truss & Structural member \\
\hline
\end{tabular}




\begin{tabular}{|c|c|}
\hline Component & Description \\
\hline $\begin{array}{l}\text { E: Piston Plate } \\
\text { F: Large Teflon Pad }\end{array}$ & $\begin{array}{l}\text { The oil pressure from the piston is applied to the piston plate } \\
\text { on top of the sample. A large teflon pad is placed between } \\
\text { the piston plate and the cover plate before testing. The } \\
\text { Teflon pad is greased on both of its sides to minimize the } \\
\text { friction between the cover plate and the piston plate }\end{array}$ \\
\hline G: Upper Box Cover Plate & $\begin{array}{l}\text { Load is applied on top of the sample via the upper box cover } \\
\text { plate }\end{array}$ \\
\hline \multicolumn{2}{|l|}{ H: Upper Box } \\
\hline I: Load Cell Support & $\begin{array}{l}\text { A Load cell (Omega Model No. LCWD-100K) is fixed at the } \\
\text { load support to measure the shear force acting on the shear } \\
\text { plane. Capacity: } \sim 45360 \mathrm{~kg}(100,000 \mathrm{lb})\end{array}$ \\
\hline \multicolumn{2}{|l|}{ J: Upper Truss Bolts } \\
\hline K: Copper Tip Guides & The copper tip guides prevent the tipping of the upper box \\
\hline L: Lateral LVDT Support & $\begin{array}{l}\text { An LVDT (Omega Model No. LD600-150) is fixed at the } \\
\text { lateral LVDT support to measure the lateral displacement of } \\
\text { the lower box during shearing. Maximum stroke length of the } \\
\text { LVDT is } \pm 150 \mathrm{~mm}\end{array}$ \\
\hline M: High Torque Gear Box & $\begin{array}{l}\text { The lateral movement of the lower box is enabled using the } \\
\text { high torque gearbox }\end{array}$ \\
\hline $\begin{array}{l}\text { N: Lateral Motor and } \\
\text { Variable Inline Gearbox }\end{array}$ & $\begin{array}{l}\text { The desired lateral speed of the lower box is adjusted using } \\
\text { the gear box ratio of the lateral motor }\end{array}$ \\
\hline O: Control Panel & The box is operated using the control panel \\
\hline P: Hydraulic Pack & $\begin{array}{l}\text { The oil is pumped to the piston from the hydraulic pack } \\
\text { according to the pressure value set in the control panel }\end{array}$ \\
\hline $\begin{array}{l}\text { Q: Upper Box Supports with } \\
\text { Small Teflon Pads }\end{array}$ & $\begin{array}{l}\text { The upper box rests on the upper box supports. Small teflon } \\
\text { pads are placed at the top of these supports. The small } \\
\text { Teflon pads are greased to minimize friction during } \\
\text { shearing }\end{array}$ \\
\hline
\end{tabular}




\begin{tabular}{ll}
\hline \multicolumn{1}{c}{ Component } & \multicolumn{1}{c}{ Description } \\
\hline R: Top Rail & The top rails are used to move and position the upper box \\
& cover plate centrally over the sample \\
\hline S: Pin Supports & Pins are inserted in the pin supports to connect the upper \\
& box to the cover plate \\
\hline T: Cover & A cover is used to protect the high torque gear from dirt \\
\hline U: Drain Holes & Drained and undrained testing can be performed with the \\
\hline V: Ground Supports & drain holes open or closed \\
\hline
\end{tabular}




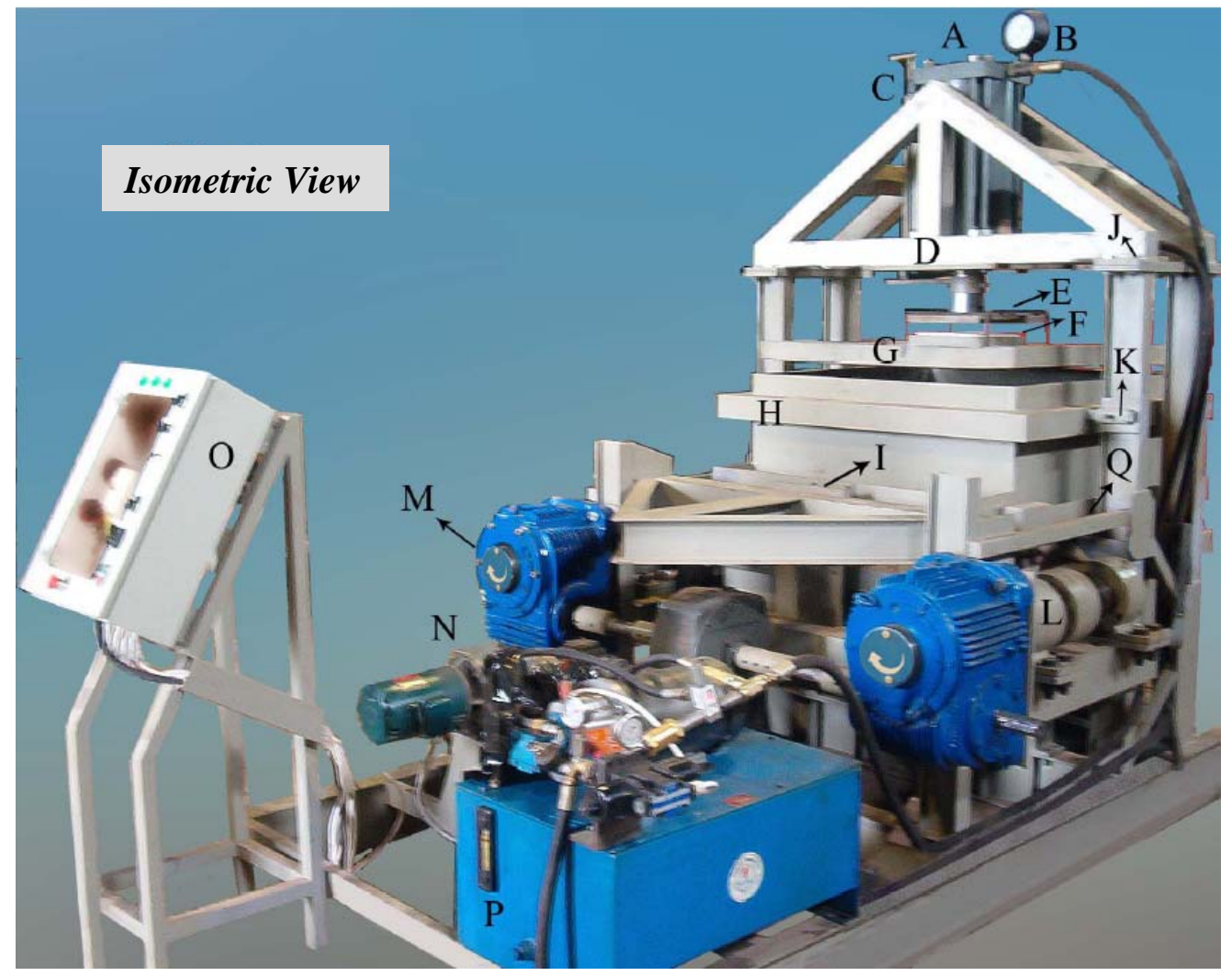

Figure 6-3 Isometric view of the DS box. 


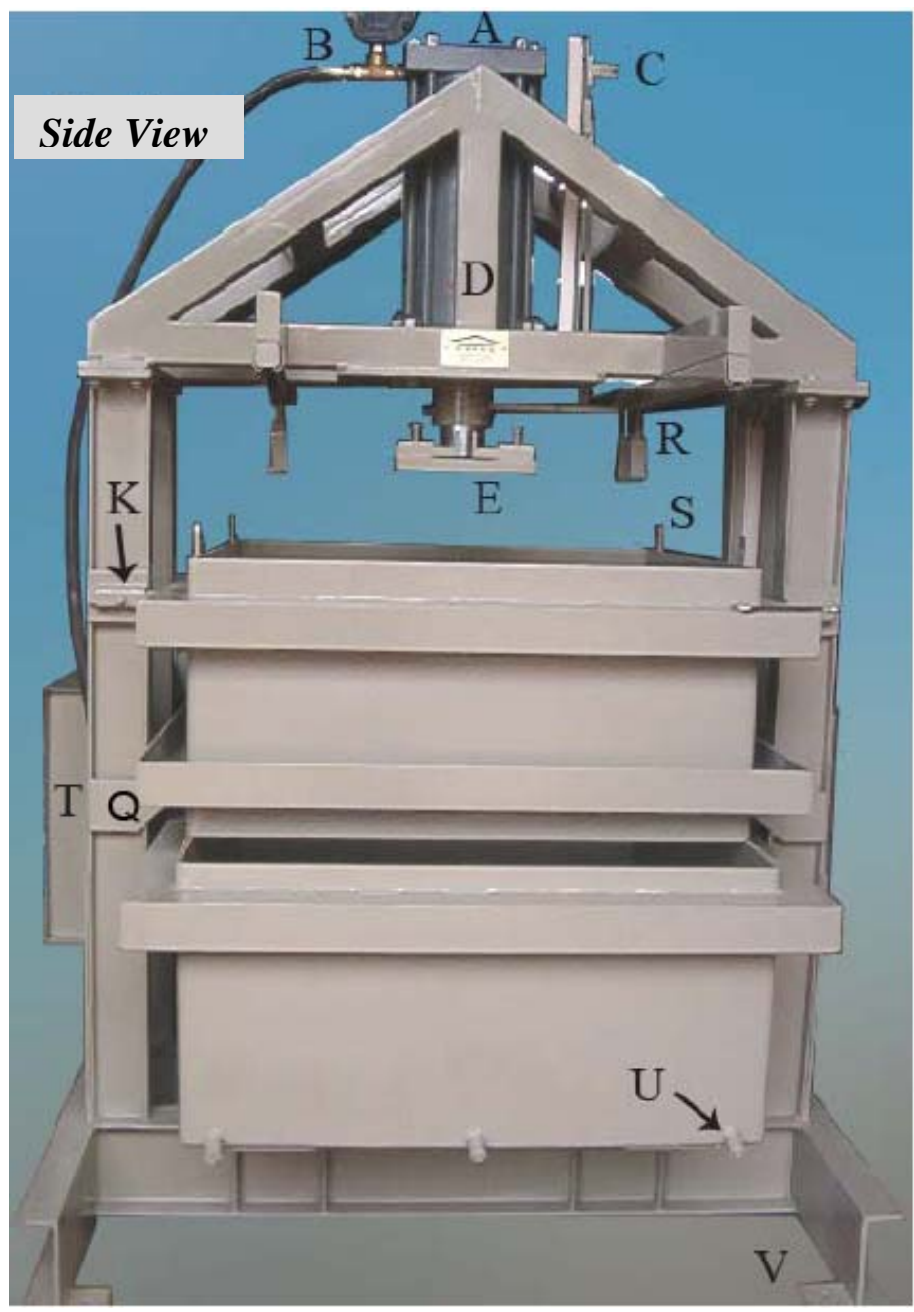

Figure 6-4 Front view of the DS box. 


\subsubsection{DS box Operation}

DS box is mainly operated by two systems:
a) Lateral system, and
b) Vertical system

The lateral system of the DS box is controlled using the buttons labeled as "D", "E", and "F", whereas the vertical system is controlled using the buttons labeled as "G", "H", and "I" shown in Figure 6-5.

The specifications of these buttons are as follows:

D: Lateral movement control

$$
\begin{aligned}
& \text { I - Lateral Motor Start (Shearing direction “Run Test”) } \\
& 0 \text { - Stop } \\
& \text { II- Lateral Motor Reverse (Return to zero position) }
\end{aligned}
$$

E: Lateral motor coil selection

I - Fast Motor

II - Slow Motor

F: Lateral motor variable speed potentiometer

G: Automatic pressure control to keep constant vertical load $0-O F F$ $I-O N$

H: Manual vertical piston movement $U p$ Down

I: Hydraulic pump

Start

Stop 
Before the start of shearing, the A, B and C buttons should be green (see Figure 6-5):
A: Power OK indicator
B: Oil level OK indicator
C: Hydraulic pump running Indicator

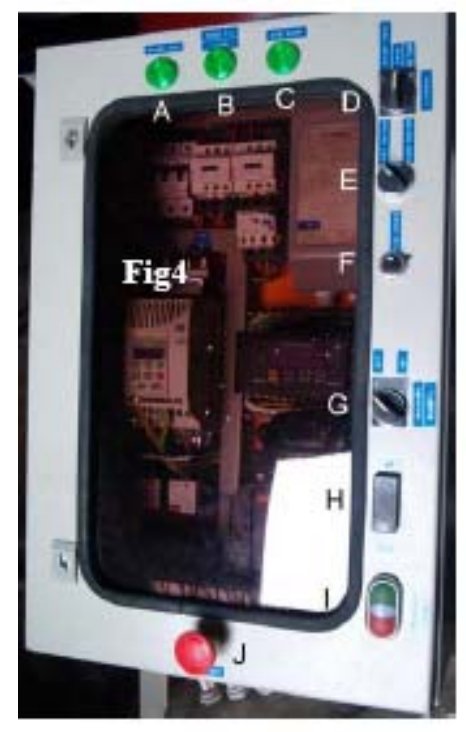

Figure 6-5 Components of control panel.

' $\mathbf{J}$ ' shown in Figure 6-5 is an emergency-stop button; pressing it will disconnect the power supply to the entire system and stop the system.

\section{Lateral System}

To ensure parallelism of movement, a double-sided driving system is used to displace the lower box at a specified rate of displacement during the shearing process. Each side of the lower box is mounted on a huge power screw which is coupled to a high torque gearbox. A double output worm gear is then coupled to both gears allowing a 
double-coiled motor and a variable ratio inline gearbox to drive the whole shearing process.

The lateral speed can be adjusted in three ways: a) selecting one of the ratios of the variable ratio gearbox by rotating its lever arm b) selecting either the fast or slow motor coil (done by turning button ' $E$ ' in the control panel), and c) fine tuning the potentiometer connected to the motor electric driver (done by turning the button ' $\mathrm{F}$ ' in the control panel).

The manufacturer (S.CO.R.E.) provided a table with the corresponding lateral speeds for various combinations of gear ratios and fast/slow motor coil. Through these adjustments, the lower box can be displaced at displacement rates in the range between $0.5 \mathrm{~mm} /$ minute and $3.5 \mathrm{~mm} /$ minute. The speed of the motor is monitored in the pulse meter located in the control panel (Figure 6-6). The rotation of the output of the high torque gearbox in the direction of the arrows shown in the high torque gear box (clockwise) indicates that the lower box is running in the shearing mode (Figure 6-7). Movement in the opposite direction means that the lower box is returning to its original position. The system has a 30 Ton lateral load capacity. 


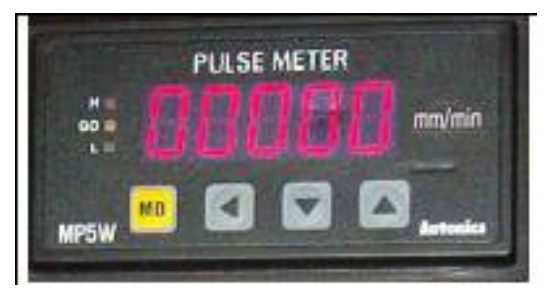

Figure 6-6 The lateral speed detector programmed to show the lateral speed of the lower box in $\mathrm{mm} /$ minute.

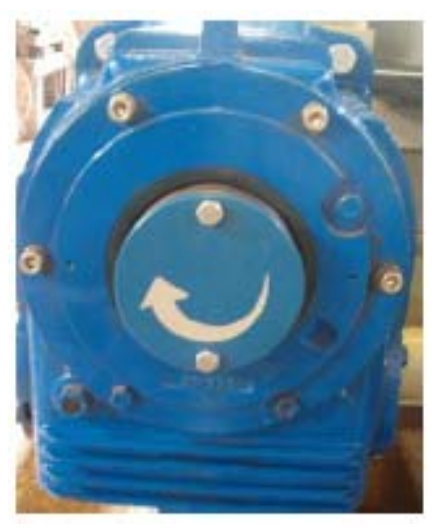

Figure 6-7 The arrow direction imprinted on the high-torque gear box indicating the shearing direction of the lower box. 


\section{Vertical System}

A hydraulic system is used to apply the confining pressure on the sample. The desired pressure reading is set in the electronic pressure switch (Model Type: HYDAC ELECTRONIC, Series EDS 1600) located in the control panel (see Figure 6-8). This electronic device can be used to monitor and control the pressure in the hydraulic system. It is equipped with a transducer that converts the pressure into an electronic signal for display and analog output. The adjustable switching points in the pressure switch can be used to set hydraulic pressure in the system. Based on the set pressure value, the hydraulic pack opens the valve and pumps oil to the piston to apply the pressure on the sample. Upper and lower limits for the confining pressure (differential pressure) should also be set in the control panel for the hydraulic system to always apply the pressure within these prescribed limits. The system is designed for a maximum vertical load of 30 Ton $(30,000 \mathrm{~kg})$. Due to friction existing along the pressure lines connecting the hydraulic pack to the piston and also within the piston, there is a pressure drop of about $448 \mathrm{kPa}$ from the hydraulic pack to the piston plate. Hence, in order to apply the correct confining pressure to the sample, $448 \mathrm{kPa}$ should be added to the piston pressure to be set in the control panel (Note that the piston pressure set in the control panel minus the pressure loss of $448 \mathrm{kPa}$ needs to be multiplied by the area of the piston to obtain the load that will be transferred to the top of the sample). 


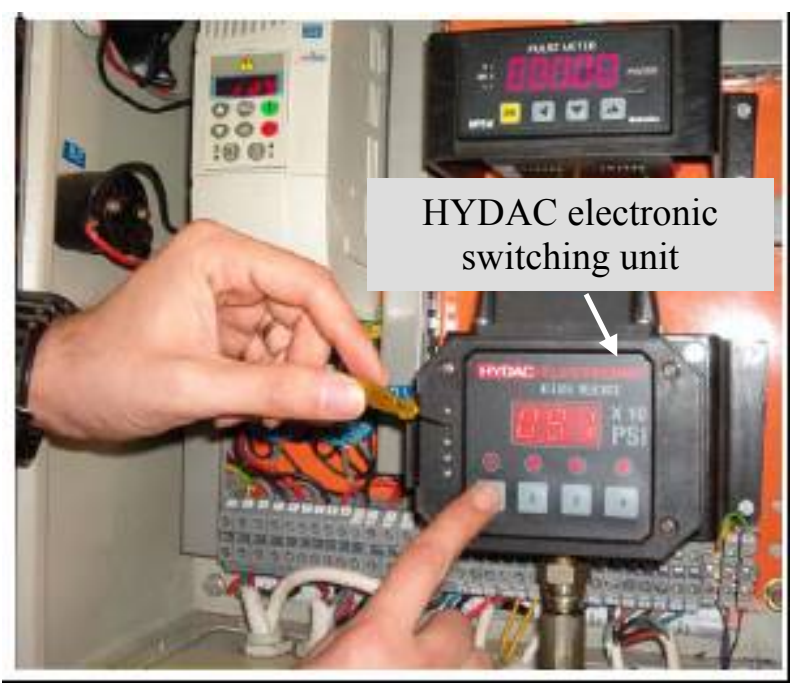

Figure 6-8 Setting the desired pressure in the hydraulic system switch located in the control panel.

\subsubsection{Instrumentation}

\section{Load cell}

A load cell (Omega Model No. LCWD-100K with a maximum capacity of $\sim 45360$ $\mathrm{kg}$ ) is positioned between the upper box and the fixed support just below the upper box. To ensure a firm contact between the load cell and the supports above and below it, the spacing between these supports can be adjusted by turning the adjustable length screws (see Figure 6-9). The load cell measures the shear load on the shear plane when the lower box is displaced laterally during shearing. 


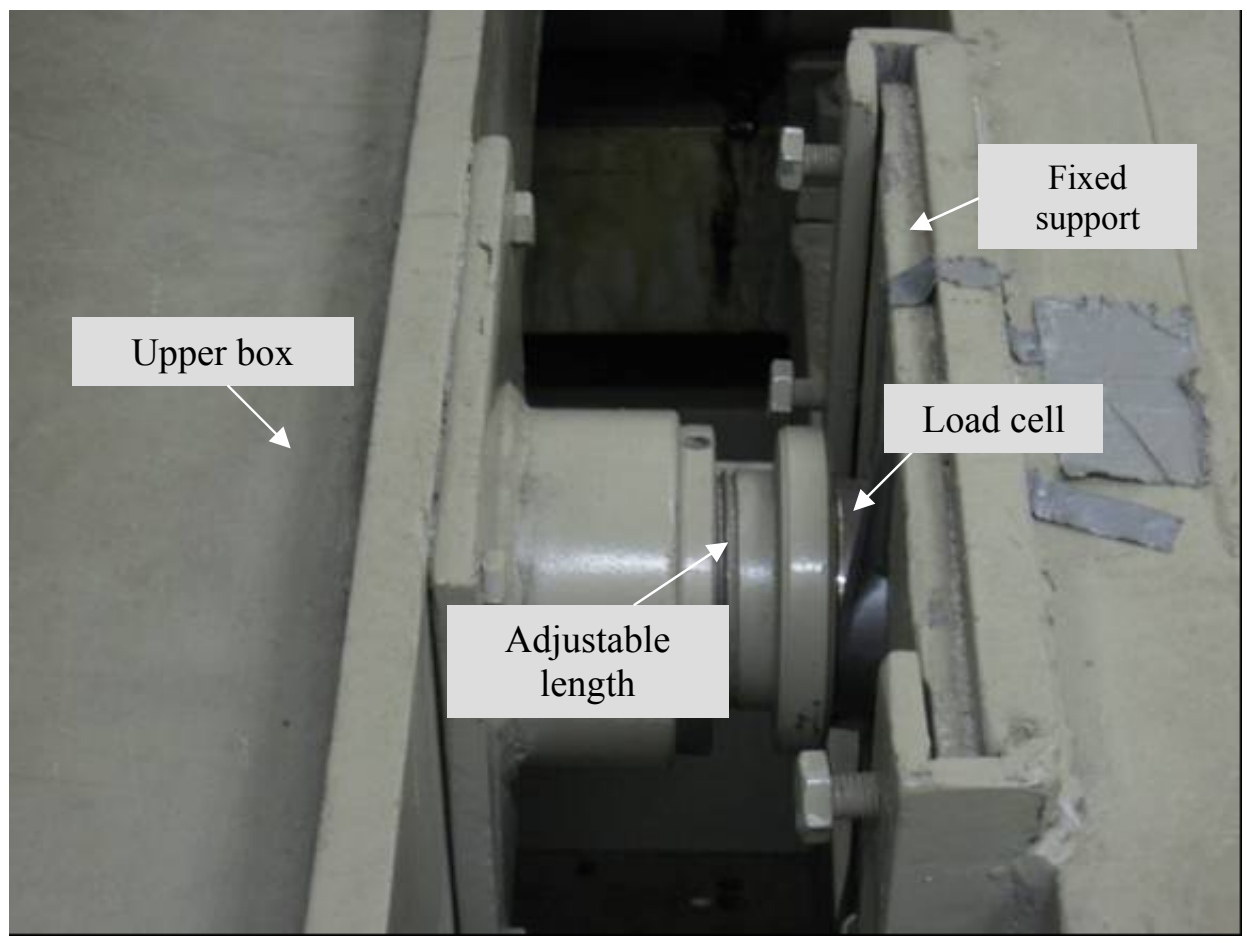

Figure 6-9 Load cell in position. 


\section{Lateral LVDT}

A lateral LVDT is fixed as shown in Figure 6-10. The tip of the LVDT is fixed at ' $\mathrm{B}$ ', and the cylindrical casing of the LVDT moves with the movable part 'A' when the lower box is displaced.

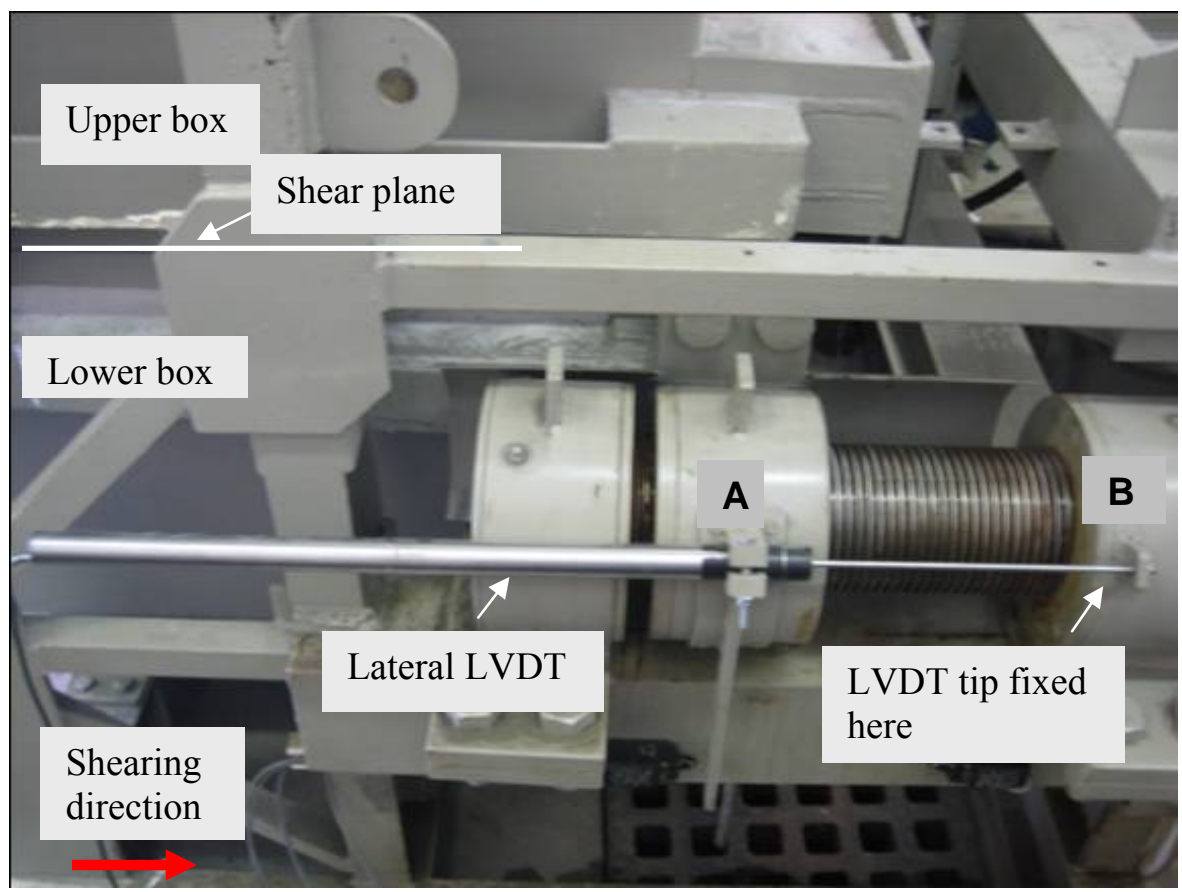

Figure 6-10 Lateral LVDT in position. 
Vertical LVDT

A vertical LVDT is fixed as shown in Figure 6-11. An extension added to the LVDT was attached to the piston. The magnetic core of the LVDT moves when the cover plate is displaced up or down due to volume change in the sample during shearing.

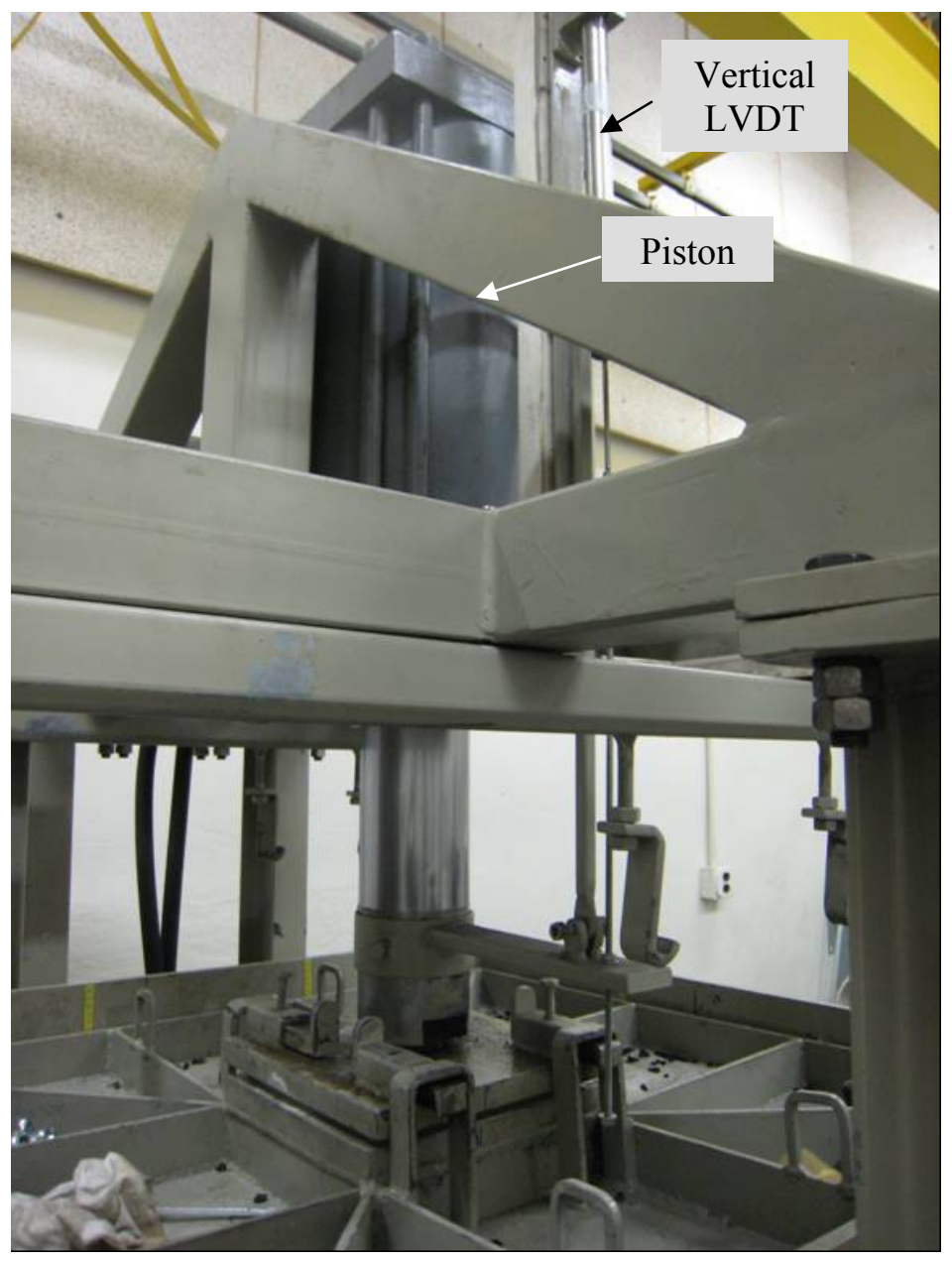

Figure 6-11 Vertical LVDT in position. 


\section{Pressure Transducer}

A pressure transducer is attached within the HYDAC electronic switching unit (see Figure 6-8). The pressure transducer converts the pressure applied in the hydraulic system into an electrical signal. The electrical signal produced by the pressure transducer has been calibrated for varying pressures in the hydraulic system using a load cell that was placed just below the piston plate for calibration purposes. The load applied on top of the sample is obtained by multiplying the measured electric signal values by the conversion factor determined through the pressure transducer calibration.

\section{Data acquisition system}

Due to the slow rate of displacement during shearing and the huge amount of data that need to be gathered collected over a long period of time, a computer-based data acquisition system was set up specifically for the DS box. The data acquisition system consists of a computer connected to a hardware device (instruNet, manufactured by OMEGA) into which the load cell, vertical LVDT, lateral LVDT, and pressure transducer are connected. A custom-designed software created using the driver provided by (OMEGA) allows the display of the measured signals (i.e. shear load, lateral displacement, vertical deformation, and the applied confining load) on the screen in terms of user-defined measurement units. Measured signals are then transferred automatically at every second to Microsoft Excel ${ }^{\circledR}$ in order to be saved and plotted as required. 


\subsubsection{Compaction Equipment}

An impact-type piston vibrator used to compact tire shred-sand mixtures in the pullout box was also used to compact samples in the direct shear box. The details of the compactor are given in section 4.5). Air filter, lubricator, and regulator were attached to the source pressure line near the direct shear apparatus.

\subsection{Experimental Procedure}

The following procedure was followed to prepare the tire shred-sand mixture samples in the DS box:

1. The walls of the DS box were thoroughly cleaned. The side walls of the box were lined with a smooth transparent sheet of paper to reduce friction (Figure 6-12).This paper sheet was attached using a painting roll to ensure that there were no air bubbles entrapped between the sheets of paper and the side walls of the box. A gap of approximately $5 \mathrm{~mm}$ was maintained between the upper and lower boxes by placing spacers above the teflon pads (the teflon pads are described in Table 6-2 and their location is shown in Figure 6-2). The Teflon pads and spacers were greased to minimize friction. 


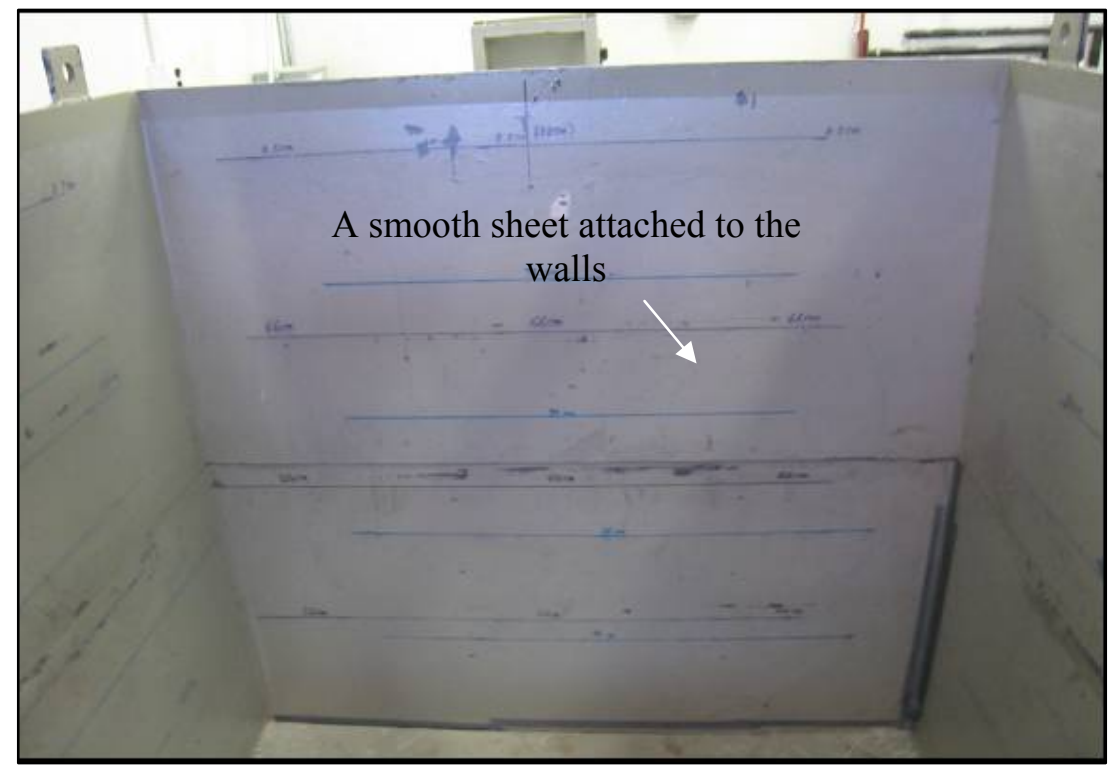

Figure 6-12 A thin smooth sheet attached to the side walls of the DS box.

2. The compactor was found to effectively compact a 0.15 -m-thick tire shred-sand layer to a density corresponding to $90 \%$ relative compaction. Hence, the tire shred-sand mixtures were compacted in six layers with layer thicknesses of $0.15 \mathrm{~m}, 0.15 \mathrm{~m}, 0.12 \mathrm{~m}$, $0.12 \mathrm{~m}, 0.16 \mathrm{~m}$, and $0.16 \mathrm{~m}$ (bottom to top). The layer thicknesses were slightly varied to ensure that the surface of the compacted third layer was not flush with the horizontal shear plane. For a given relative compaction and layer thickness, the required amount of tire shreds and sand was added in the box. For example, we know from our laboratory tests that for a tire shred-sand mixture sample at the optimum mixing ratio of 25/75 (tire shred and sand weight ratio) using tire shreds of 50 to $100 \mathrm{~mm}$ in length, $90 \%$ relative compaction corresponds to a density of $1530 \mathrm{~kg} / \mathrm{m}^{3}$. The calculations for a $0.15-\mathrm{m}$-thick layer are shown below: 
Volume of 0.15 -m-thick layer placed in the bottom box

Weight of the mixture to be added to achieve $90 \%$ relative compaction

Weight of tire shreds to be added

Weight of sand to be added
$=0.18 \mathrm{~m}^{3}$

$=275.4 \mathrm{~kg}$

$=68.9 \mathrm{~kg}$

$=206.6 \mathrm{~kg}$

The measured amounts of the material were thoroughly mixed inside the DS box to obtain a uniform mixture.

3. The surface of each layer was leveled off and uniformly compacted layer-bylayer using the compactor. During compaction, the operator firmly held the compactor while traversing it uniformly along the length and width of the box (see Figure 6-13). The side walls of the box were marked with the final heights of each layer and compaction for each layer was continued until the final target height for each layer was achieved. Segregation of tire shreds was not observed during the compaction process.

4. The surface of the final compacted layer was leveled off and the cover plate was placed centrally over the prepared sample (see Figure 6-14). A Teflon pad was greased and placed on top of the cover plate; lubrication of the teflon pad minimizes friction between the piston plate and the cover plate.

5. The desired confining pressure to be applied on the sample was set in the control panel and the piston plate was moved downwards in the automatic mode. The tire shred-sand mixture compressed due to application of the confining pressure. The confining pressure was maintained for $45-60$ minutes before start of shearing. 
6. The lower box is displaced at a constant rate equal to $1.2 \mathrm{~mm} /$ minute, and the instruNet software records and displays the shear load, confining load, lateral displacement, and vertical displacement data on the computer screen at every second during shearing. Note that, to prevent any loss of material from the lower box during shearing, a $2.5-\mathrm{cm}$-thick steel sliding plate was installed at the edge of the lower box (the sample would be unconfined at the top if the sliding plate had not been installed at the edge of the box) (see Figure 6-2).

7. The test was terminated when the lateral displacement of $\sim 170 \mathrm{~mm}$ was reached.

8. The cover plate was then removed, and the contents of the DS box were emptied. 


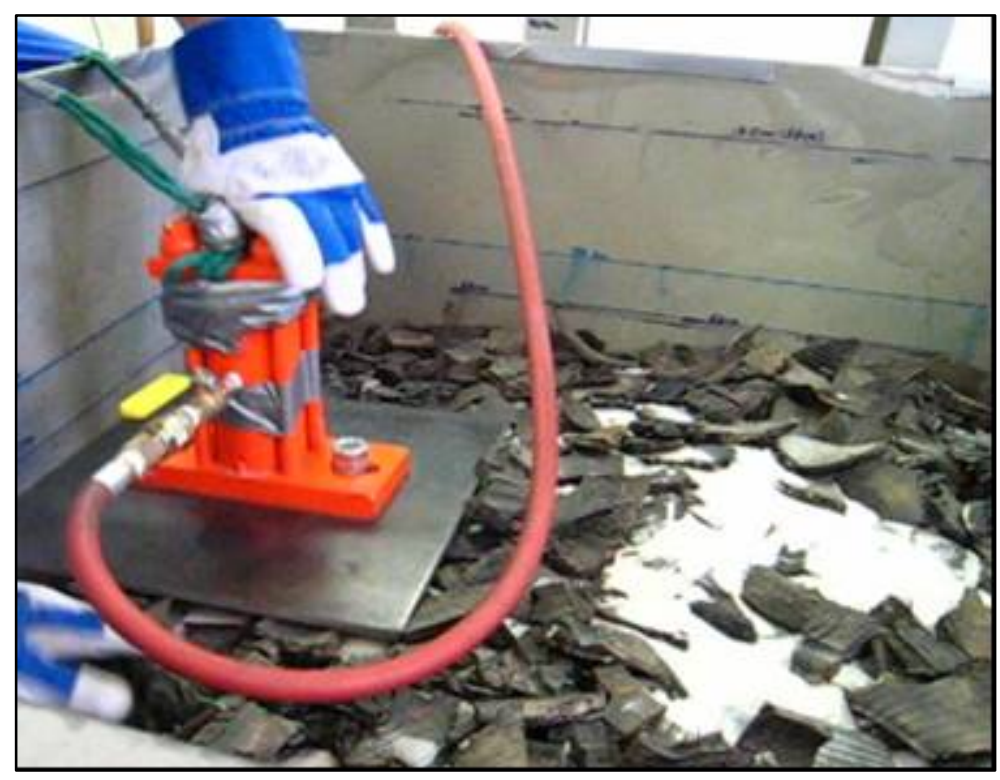

(a)

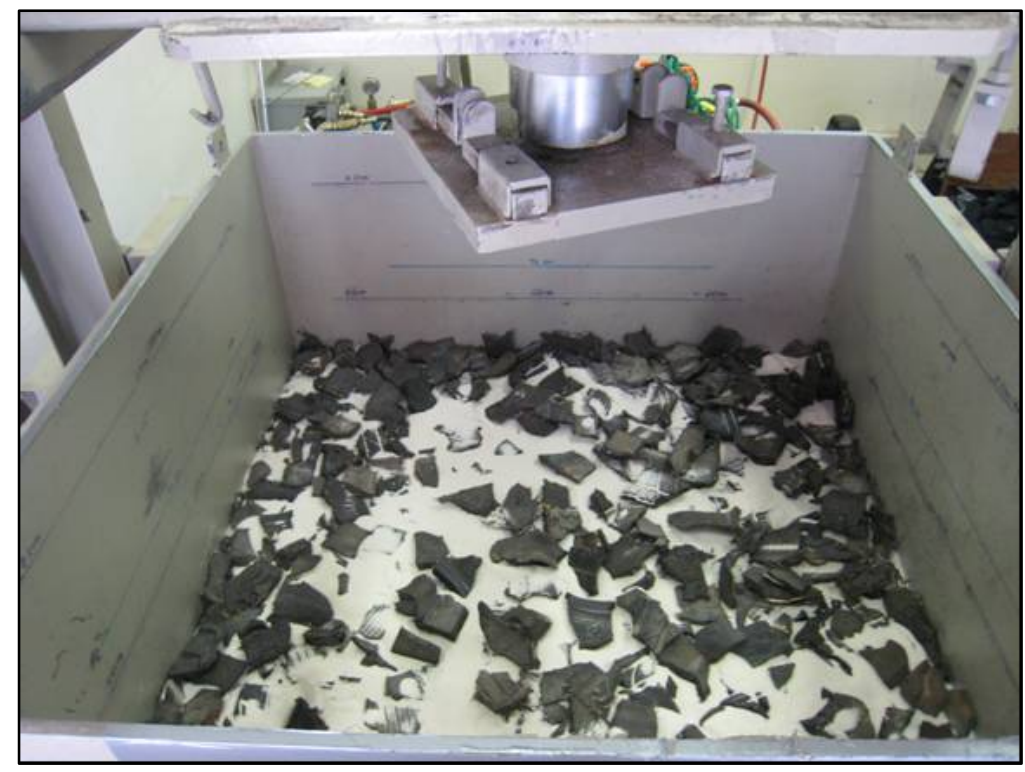

(b)

Figure 6-13 Compaction of a layer of tire shred-sand mixture: a) a layer of tire shredsand mixture being compacted using an impact-type piston compactor, and b) a compacted layer of the mixture. 


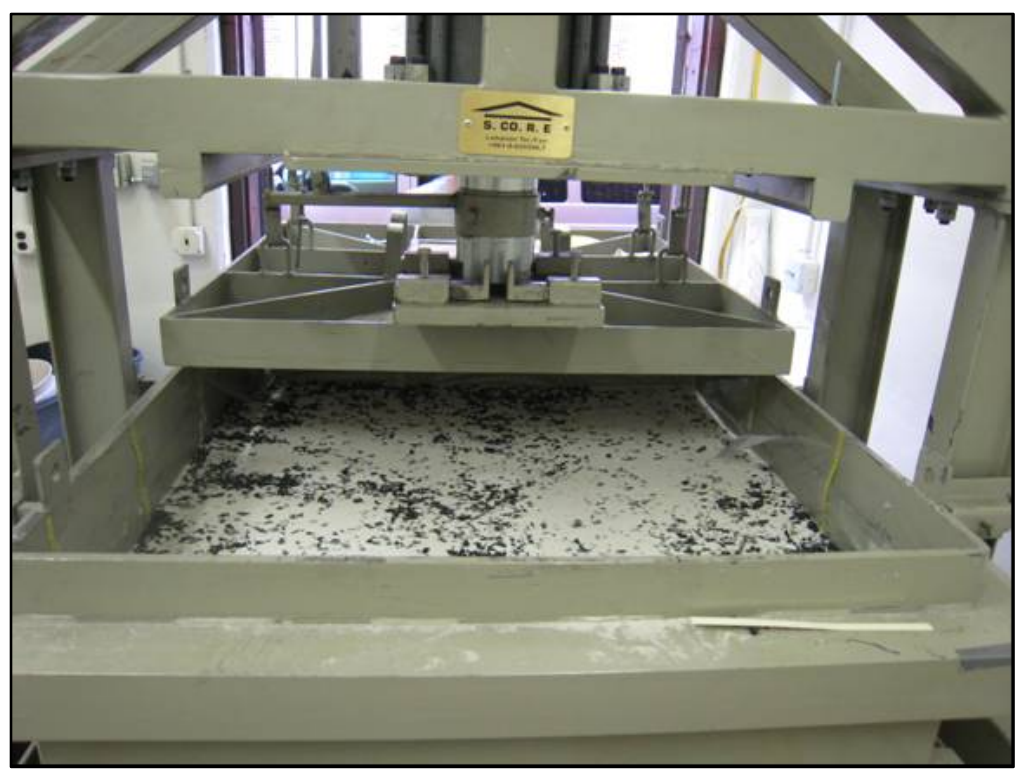

(a)

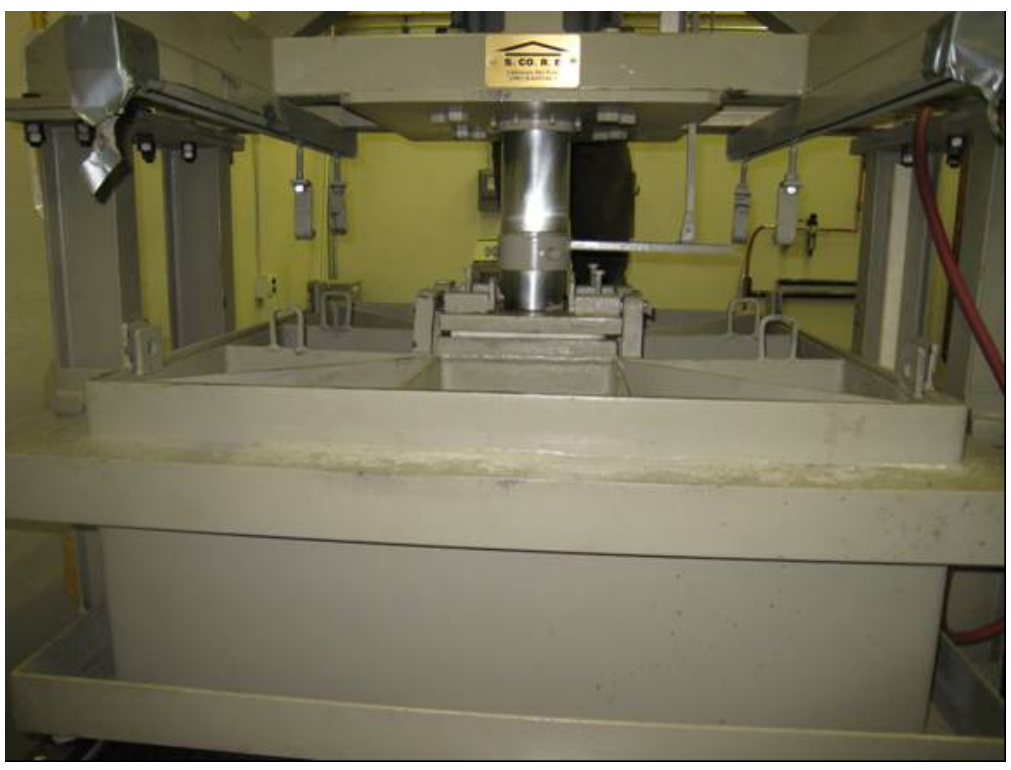

(b)

Figure 6-14 Placement of the cover plate on top of the sample: (a) rails used to position the cover plate centrally on the final compacted layer, and (b) cover plate placed in position. 


\subsection{Test Results}

Shear strength properties of the tire shred-sand mixtures considered in this study were determined using the large-scale direct shear box described in the previous section. Two tire shred sizes were considered: a) tire shreds of 50-100 $\mathrm{mm}$ in length, and b) tire chips $9.5 \mathrm{~mm}$ in nominal size. The mixtures were prepared at the optimum mixing ratio and compacted to a dry density corresponding to $90 \%$ relative compaction. The laboratory procedure to determine the optimum mixing ratios for various tire shred-sand mixtures is described in Chapter 3 of this report. Table 6-3 gives the optimum mixing ratios and the maximum dry densities of the tire shred-sand mixtures as obtained from compaction tests.

Table 6-3 Optimum mixing ratios and maximum dry densities of the tire shred-sand mixtures used in DS tests

\begin{tabular}{cccc}
\hline Size of shredded tires & $\begin{array}{c}\gamma_{\text {d,mixture with }} \text { optimum } \\
\text { mixing ratio } \\
\left(\mathrm{kN} / \mathrm{m}^{3}\right)\end{array}$ & $\begin{array}{c}\text { Optimum mixing ratio } \\
\text { of shredded tires and } \\
\text { sand }\end{array}$ & $\begin{array}{c}\text { Optimum mixing ratio } \\
\text { of shredded tires and } \\
\text { sand (by volume })\end{array}$ \\
\hline $50-100 \mathrm{~mm}$ in length & 16.6 & $25 / 75$ & $42 / 58$ \\
$9.5 \mathrm{~mm}$ in nominal size & 15.2 & $25 / 75$ & $46 / 54$ \\
\hline
\end{tabular}

Table 6-4 presents an overview of the various test conditions for the mixtures tested in the large-scale direct shear box. 
Table 6-4 Overview of test cases considered for DS tests.

\begin{tabular}{ccccc}
\hline $\begin{array}{c}\text { Size of shredded } \\
\text { tires }\end{array}$ & $\begin{array}{c}\text { Tire shred and } \\
\text { sand } \\
\text { (by weight) }\end{array}$ & $\begin{array}{c}\text { Confining } \\
\text { pressure }(\mathrm{kPa})\end{array}$ & $\begin{array}{c}\text { Dry unit weight of } \\
\text { mixture used in } \\
\text { testing }\left(\mathrm{kN} / \mathrm{m}^{3}\right)\end{array}$ & $\begin{array}{c}\text { Relative } \\
\text { compaction of } \\
\text { mixture (\%) }\end{array}$ \\
\hline \multirow{2}{*}{$50-100 \mathrm{~mm}$} & $25 / 75$ & 128 & 15.0 & 90 \\
& & 164 & 15.0 & 90 \\
$9.5 \mathrm{~mm}$ in nominal & $25 / 75$ & 112 & 15.0 & 90 \\
size & & 164.8 & 90 \\
& & 164 & 13.8 & 90 \\
\hline
\end{tabular}

6.4.1. DS tests performed on $50-100 \mathrm{~mm}$ tire shred-sand mixtures

Figure 6-15 shows the variation of the shear stress developed along the horizontal shear plane during lateral displacement of the lower box. The tire shred-sand mixture showed peak stresses at $27 \mathrm{~mm}, 37 \mathrm{~mm}$, and $40 \mathrm{~mm}$ for confining stresses of $60 \mathrm{kPa}, 128$ $\mathrm{kPa}$, and $164 \mathrm{kPa}$, respectively. 


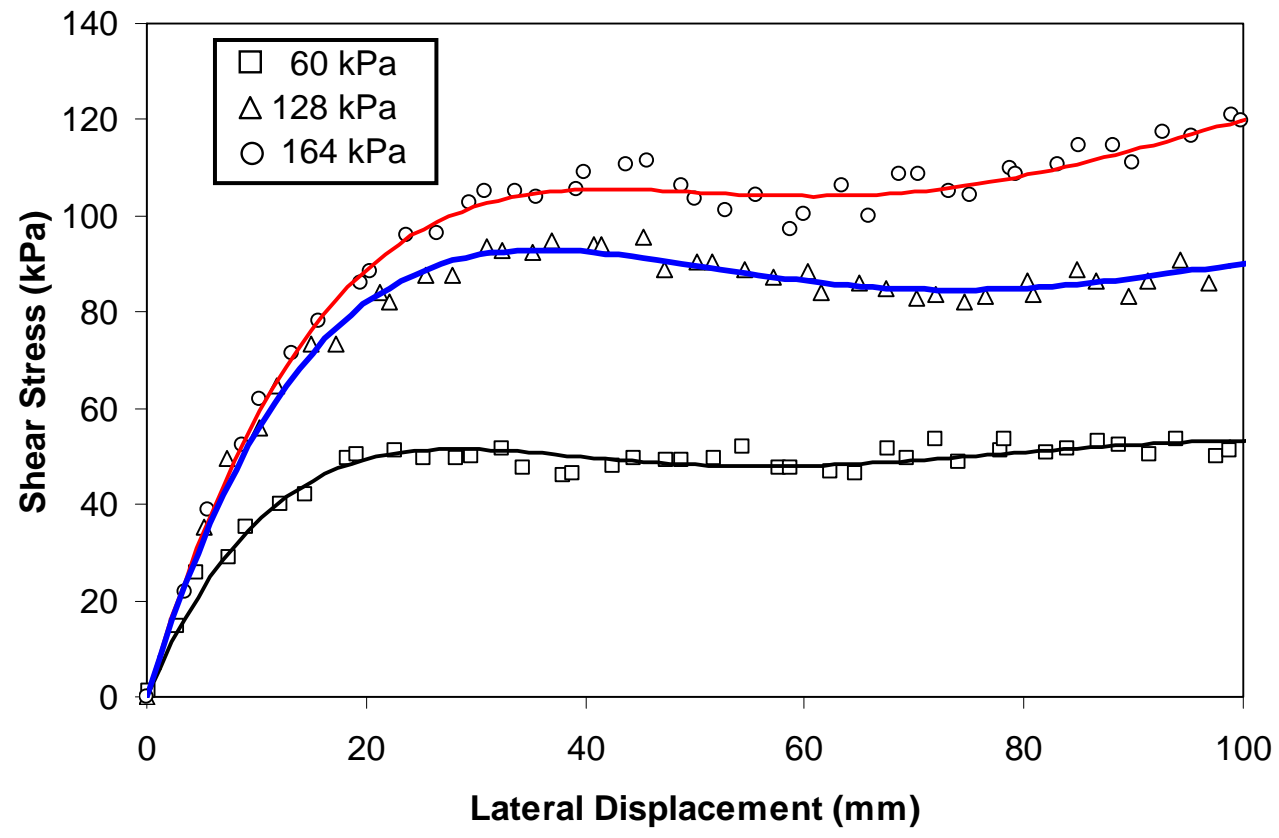

Figure 6-15 Shear stress - lateral displacement response for 50 -100 mm tire shred-sand mixtures prepared at a tire shred-sand mixing ratio of $25 \%$ by weight.

\subsubsection{DS tests performed on $9.5 \mathrm{~mm}$ tire chip-sand mixtures}

Figure 6-16 shows the variation of the shear stress developed along the horizontal shear plane during lateral displacement of the lower box. The tire chip-sand mixture did not show a distinguishable peak shear stress. 


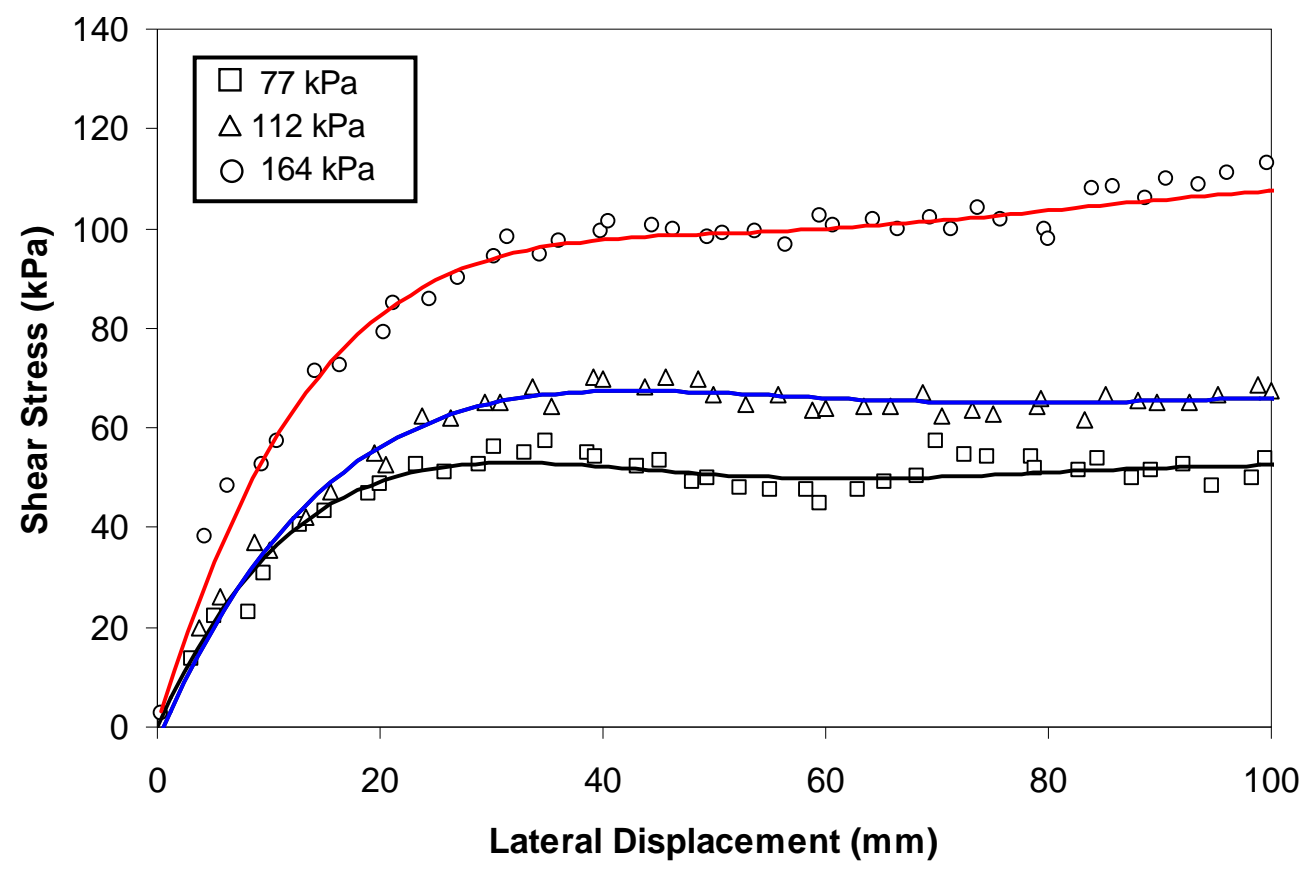

Figure 6-16 Shear stress - lateral displacement response for $9.5 \mathrm{~mm}$ tire chip-sand mixtures prepared at a tire shred-sand mixing ratio of $25 \%$ by weight.

6.4.3. Shear strength envelopes for $50-100 \mathrm{~mm}$ tire shred-sand and $9.5 \mathrm{~mm}$ tire chip-sand mixtures

For tire shred-sand mixture, a shear stress peak was observed and the strength envelope was defined based on the peak stresses. In the case of the tire chip-sand mixture, the strength envelope was based on the AASHTO (1993) criterion as no distinguishable peak shear stress was observed. According to the AASHTO T236-84, the shear stress developed at a lateral displacement of $10 \%$ of the size of the box can be considered as the shear strength of materials tested in a DS box. For the DS box size $(1 \mathrm{x} 1 \mathrm{x} 1 \mathrm{~m})$ used in this study, the shear stress developed at a lateral displacement of 100 $\mathrm{mm}$ of the lower box can thus be considered as the shear strength of the sample tested. 
Figure 6-17 shows the strength envelopes for the tire shred-sand mixture and tirechip sand mixture based on peak stress and $10 \%$ relative criterion, respectively. Table 6-5 shows the shear strength parameters for the tire shred-sand and tire-chip sand mixtures considered in the DS tests.

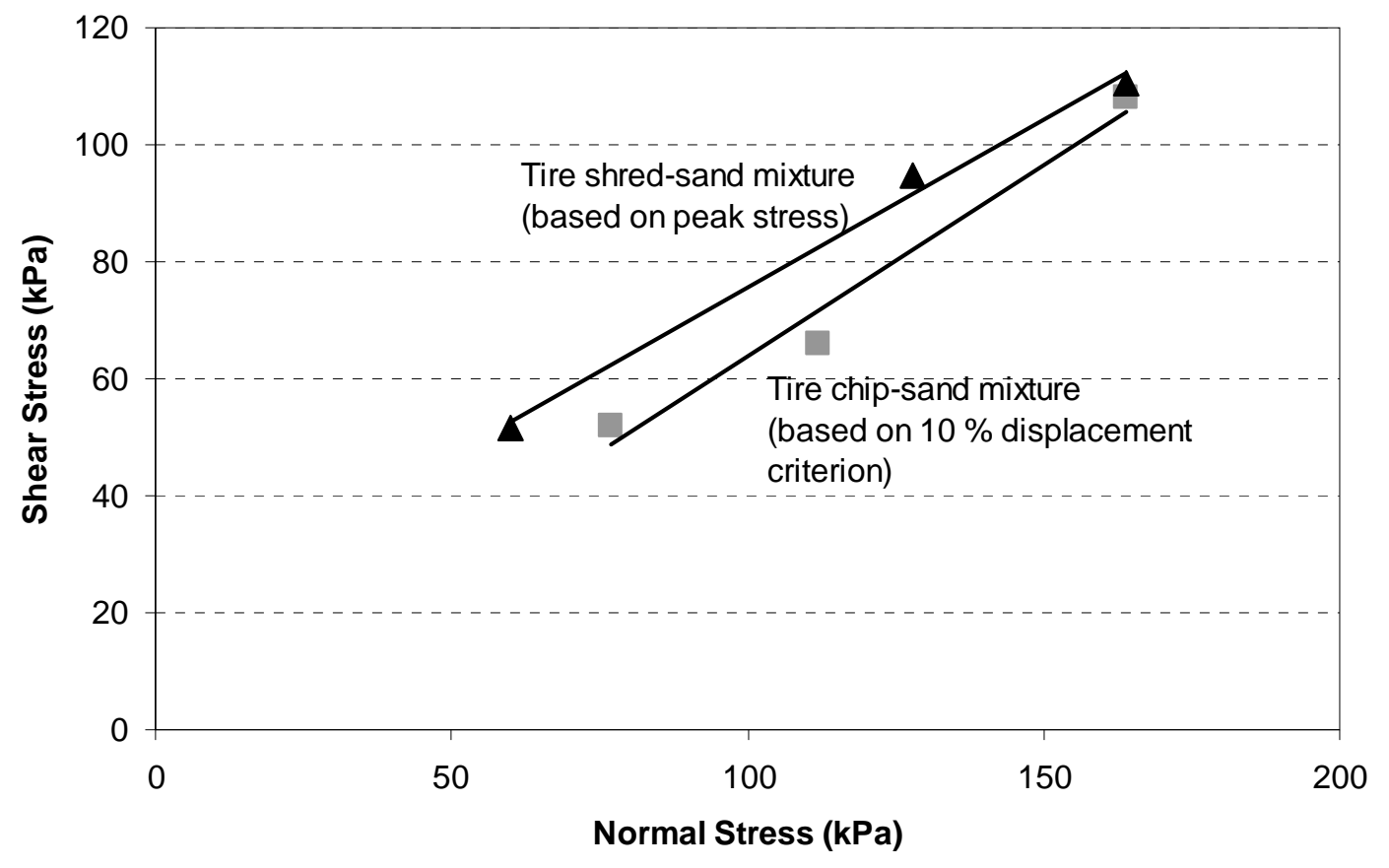

Figure 6-17 Shear strength envelopes for tire shred-sand and tire chip-sand mixtures prepared at a tire shred-sand mixing ratio of $25 \%$ by weight. 
Table 6-5 c- $\phi$ shear strength fitting parameters for the range of confining stresses considered

\begin{tabular}{cccc}
\hline Mixture & Criterion used & c (kPa) & $\phi($ deg. $)$ \\
\hline $\begin{array}{c}50-100 \text { mm tire shred-sand } \\
\text { mixtures }\end{array}$ & Peak stress & 21.8 & 29.4 \\
\hline $\begin{array}{c}9.5 \mathrm{~mm} \text { tire chip-sand } \\
\text { mixtures }\end{array}$ & $10 \%$ displacement & 0 & 36.8 \\
\hline
\end{tabular}

\subsection{Summary}

A large-scale direct shear box was specifically designed to perform shear strength tests on tire chip-sand and tire shred-sand mixtures with relatively large-size tire shreds. Large-scale direct shear tests were performed on tire shred-sand mixtures prepared at the optimum mixing ratio ( $25 \%$ by weight of tire shreds and sand). The tire chips and tire shred sizes considered in this study were $9.5 \mathrm{~mm}$ in nominal size and $50-100 \mathrm{~mm}$ in length, respectively. Shear strength envelopes for the two mixtures were established from the DS test results. Based on the peak strength values, c- $\phi$ fitting parameters of $21.8 \mathrm{kPa}$ and $29.4^{\circ}$ were obtained for the tire shred-sand mixture with tire shreds $50-100 \mathrm{~mm}$ in length. Based on the $10 \%$ relative criterion, a friction angle of $36.8^{\circ}$ was obtained for the tire chip-sand mixture with tire chips $9.5 \mathrm{~mm}$ in nominal size. 


\section{CHAPTER 7. CONCLUSIONS AND RECOMMENDATIONS}

\subsection{Findings and Conclusions}

The main objective of this study was to evaluate the feasibility of using tire shreds mixed with sand as fill material for MSE wall applications. Even though, waste tire shreds have been used in geotechnical applications in several states in the US, very limited research has been reported on tire shred-sand mixtures containing large-size tire shreds. In the present research study, a literature review and a series of laboratory tests were performed to evaluate tire shred-sand mixtures prepared at different mixing ratios with tire shreds of various sizes. Also, the performance of large-size tire shreds in tire shred-sand mixtures was evaluated using large-scale laboratory testing (pullout and direct-shear tests).

The following conclusions were drawn from this research study:

1. The isolation of tire shreds in a sand mixture is recommended to prevent exothermic reactions in tire shred fills. When sand is mixed with tire shreds, the total void ratio of the mixture decreases up to a certain mixing ratio because the voids between the tires are filled with sand. The optimum mixing ratio of a given tire shred-sand mixture is the mixing ratio at which addition of more sand to the mixture leads to an increase in the total void ratio of the mixture. The optimum mixing ratio can be decided using a series of compaction tests, as demonstrated by 
this study. The optimum mixing ratio for the mixtures considered in this study, which consist of tire shreds and poorly graded sand, ranged from $25 \%$ to $30 \%$ by weight ( $42 \%$ to $49 \%$ by volume) of tire shreds in the mixture.

2. The segregation of tire shred-sand mixtures was examined using laboratory compaction tests. It was observed that, for low tire shred contents, segregation did not occur. When the tire shred content was greater than the optimum mixing ratio, segregation of the two materials was observed.

3. The pullout behavior of geogrids and ribbed-metal strips embedded in the tire shred-sand mixtures was evaluated based on large-scale pullout tests. The tests were performed with various tire shred-sand mixtures prepared at various mixing ratios $(0,12,25$ and 100\%). The backfill materials consisted of shredded tires (9.5 $\mathrm{mm}$ in nominal size, $50-100 \mathrm{~mm}$ in length and $100-200 \mathrm{~mm}$ in length) and Ottawa sand. The pullout tests were performed for a confining pressure of $40 \mathrm{kPa}$. Based on the test results, the effects of tire shred size, and mixing ratio were evaluated: (1) the pullout capacity of geogrid and ribbed-metal strip increases with decreasing tire shred-sand ratio in the mixture for a confining pressure of 40 $\mathrm{kPa}$. The pullout force corresponding to a frontal displacement of $80 \mathrm{~mm}(10 \%$ of the embedded length of geogrid) is often taken as the pullout capacity of geogrid; while for ribbed-metal strip reinforcement (inextensible reinforcement), the pullout force corresponding to a frontal displacement of $20 \mathrm{~mm}$ or the peak pullout force if it occurs within the prescribed $20-\mathrm{mm}$ frontal displacement is 
taken as its pullout capacity, (2) the pullout resistance of geogrid placed in samples prepared at the optimum tire shred-sand mixing ratio of $25 \%$ by weight is higher for tire chip-sand mixtures than for tire shred-sand mixtures. The pullout capacity of geogrid (type-UX 1500 MSE) embedded in tire chip-sand mixtures is $30 \%$ higher than that of the tire shred (100-200 mm)-sand mixtures, (3) the pullout capacity of geogrid embedded in the sample prepared using only tire shreds is about $65-70 \%$ lower than that measured for geogrid embedded in samples prepared with sand only, (4) the size of shredded tires has a negligible effect on the pullout capacity of ribbed-metal strips, and (5) the pullout capacity of the ribbed-metal strip embedded in samples prepared with tire shreds only is about $25-30 \%$ lower than that measured for ribbed-metal strip embedded in samples prepared with sand only.

4. Large-scale DS tests were performed on tire shred-sand mixtures to obtain the shear strength envelopes. Based on the peak strength values, c- $\phi$ fitting parameters of $21.8 \mathrm{kPa}$ and $29.4^{\circ}$ were obtained for the tire shred-sand mixture with tire shreds $50-100 \mathrm{~mm}$ in length. Based on the $10 \%$ relative criterion, a friction angle of $36.8^{\circ}$ was obtained for the tire chip-sand mixture with tire chips $9.5 \mathrm{~mm}$ in nominal size. 


\subsection{Recommendations for Future Research}

Based on the work performed in this research study, the following ideas and recommendations are suggested for future research:

1. Large-scale testing is recommended since there is only limited data reported in the literature on mixtures containing large-size tire shreds. This will give useful insights into the behavior of the mixtures without any scale effects.

2. Fully-monitored (settlement plates, pressure cells, vertical and horizontal inclinometers, and internal displacement gauges on the reinforcement) demonstration projects are needed to evaluate the field performance of MSE walls and to allow costeffective designs.

3. Large-scale direct shear box tests should be performed on tire shred-sand mixtures with tire shreds of sizes available in the market. Samples prepared at various mixing ratios should be tested to evaluate the optimum size of tire shreds and tire shredsand mixing ratio to achieve maximum shear strength. The anisotropy effect (due to the preferential way in which tire shred particles align during placement and compaction) on the resulting strength of the mixtures should also be studied.

4. Pullout tests should be performed for various types of reinforcements, such as geotextiles, geostraps, and geogrids with various aperture sizes. The effect of the 
mixing ratio, tire-shred size and confining stress should be evaluated for each type of reinforcement.

5. Monitoring of the long-term performance of MSE wall structures constructed with mixtures of tire shred and sand should be encouraged; the environmental impact of the backfill material on the groundwater should be carefully evaluated in such long-term studies. 


\section{LIST OF REFERENCES}

Ahmed, I., (1993). "Laboratory study on properties of rubber-soils", Report FHWA/IN/JHRP-93/4, Indiana Department of Transportation, Purdue University, West Lafayette, Indiana.

Ahmed, I., and C.W. Lovell, (1993). "Rubber soils as lightweight geomaterials", Transportation Research Record 1422, TRB, National Research Council, Washington, D.C., pp. 61-70.

American Association of State Highway and Transportation Officials (AASHTO), (1993). "Direct shear test of soils under consolidated drained conditions," AASHTO Designation: T236-84, Part II Tests, 16th Edition, 1993.

American Association of State Highway and Transportation Officials (AASHTO), "Standard specification for high-strength low-alloy Columbium-Vanadium structural steels of structural quality," AASHTO Designation: M223M/M 223-96.

American Society for Testing and Materials, ASTM D3080-04, "Standard test method for direct shear test of soils under consolidated drained conditions", Philadelphia, PA.

American Society for Testing and Materials, ASTM D4253-00, "Standard test methods for maximum index density and unit weight of soils using a vibratory table", Philadelphia, PA.

American Society for Testing and Materials, ASTM A572/A 572M-07, "Standard specification for high-strength low-alloy Columbium-Vanadium structural steel", Philadelphia, PA.

American Society for Testing and Materials, ASTM D 6270-98, "Standard practice for use of scrap tires in civil engineering application", Philadelphia, PA.

American Society for Testing and Materials, ASTM D 698-00a, "Standard test method for laboratory compaction characteristics of soil using standard effort $(12,400 \mathrm{ft}$ $\left.\mathrm{lbf} / \mathrm{ft}^{3}\left(600 \mathrm{kN}-\mathrm{m} / \mathrm{m}^{3}\right)\right) "$, Philadelphia, PA.

American Society for Testing and Materials, ASTM D 854-02, "Standard test methods for specific gravity of soil solids by water pycnometer", Philadelphia, PA.

Bergado, D. T., S.Youwai, and A. Rittirong, (2005). "Strength and deformation of flat and cubical rubber tyre chip-sand mixtures", Geotechnique, Vol. 55, No. 8, pp. 603-606.

Bernal, A., C.W. Lovell, and R. Salgado, (1996). "Laboratory study on the use of tire shreds and rubber-sand in backfills and reinforced soil applications", FHWA/IN/JHRP96/12, Purdue University, West Lafayette, Indiana. 
Bishop, A. W., (1948). "A Large shear box for testing sands and gravels", Proceedings of the 2nd International Conference on Soil Mechanics and Foundation Engineering, Vol. 1, pp. 207-211.

Bosscher, P.J., T.B. Edil,, and N.N. Eldin, (1992). "Construction and performance of a shredded waste tire test embankment", Transportation Research Record 1345, TRB, National Research Council, Washington, D.C., pp. 44-52.

California Integrated Waste Management Board, (2001). "Waste tire marketing guide".

Chang, D. T., F. Chang, G. Yang, and C. Yan, (2000). "The influence factors study for geogrid pullout test", ASTM STP 1379, P. E. Stevenson, Ed., American Society of Testing and Materials, West Conshohocken, PA.

Collins, K.J., A.C. Jensen, and S. Albert, (1995). "A review of waste tyre utilisation in the marine environment", Chemistry and Ecology, Vol 10, pp. 205-216.

Collins, K.J., A.C. Jensen, J.J. Mallinson, V. Roenelle, and I.P. Smith, (2002). "Environmental impact assessment of a scrap tyre artificial reef", ICES Journal of Marine Science, Vol. 59, pp S243-S249.

Crane, G., R.A. Elefritz, E.L. Kay, and J.R. Laman, (1975). "Scrap tyre disposal procedures", Rubber Chemistry and Technology, Vol. 48.

Drescher, A., D. Newcomb, and T. Heimdahl, (1999). "Deformability of shredded tires", Report-1993-13, Minnesota Department of Transportation, Minneapolis, Minnesota.

Dickson, T.H., D.F. Dwyer, and D.N. Humphrey, (2001). "Prototype tire-shred embankment construction", Transportation Research Record 1755, TRB, National Research Council, Washington, D.C., pp. 160-167.

Ealding, W., (1992). "Leachable metals in scrap tires", Final Report, Virginia Department of Transportation.

Edil, T.B. and P.J. Bosscher, (1992). "Development of engineering criteria for shredded waste tires in highway applications", Final Report GT-92-9, Wisconsin Department of Transportation.

Edil, T. B., and P. J. Bosscher, (1994). "Engineering properties of tire chips and soil mixtures", Geotechnical Testing Journal, Vol. 17, No. 4, pp. 453-464.

Elias, V., J. Welsh, J. Warren, and R. Lukas, (1998). "Ground improvement technical summaries", Federal Highway Administration Report, No. FHWA-SA-98-086. 
Elias, V., and B.R. Christopher, (1997). "Mechanically stabilized earth walls and reinforced soil slopes, design, and construction guidelines", Federal Highway Administration Report, No. FHWA-SA-96-071.

Farrag, K., B. A. Yalcin, and I. Juran, (1993). "Pull-out resistance of geogrid reinforcements", Geotextiles and Geomembranes, Vol. 12, pp. 133-159.

Foose, G. J., C. H. Benson, and P. J. Bosscher, (1996). "Sand reinforced with shredded waste tires", Journal of Geotechnical Engineering, ASCE, 122(9), pp. 760-767.

Foose, G., (1993). "Shear strength of sand reinforced with shredded waste tires", MS thesis, Dept. of Civil and Environmental Engineering, University of Wisconsin, Madison.

Fox, P. J., M. Rowland, J. Scheithe, K. Davis, M. Supple, and C. Crow, (1997). "Design and evaluation of a large direct shear machine for geosynthetic clay liners", Geotechnical Testing Journal, American Society for Testing and Materials, Vol. 20, No. 3, pp. 279-288.

GeoSyntec Consultants, (1998). "Guidance manual-tire shred as operations layer material at municipal solid waste landfills", Prepared for the California Integrated Waste Management Board.

Graham, M. A., B. H. Kjartanson, and R. A. Lohnes, (2001). "Shear strength of large-size shredded scrap tires”, Transportation Research Record, Issue No. 1755, pp. 168-172.

Hall, T.J., (1990). "Reuse of shredded waste tire material for leachate collection systems at municipal solid waste landfills", Report for Iowa Department of Natural Resources Waste Management and Authority Division.

Hird, A.B., P. J. Griffiths, and R. A. Smith, (2002). "Tyre waste and resource management: A mass balance approach". Viridis Report VR2.

Holtz, R., (1989). "Treatment of problem foundations for highway embankments", National Cooperative Highway Research Program, Report No. 147, Washington D.C.

Holtz, R.D., and W. D. Kovacs, (1981). "An introduction to geotechnical engineering", Prentice-Hall, Inc., Englewood Cliffs, N.J.

HR Wallingford, (2005). "Sustainable re-use of tyres in port, coastal and river engineering: guidance for planning, implementation and maintenance", Report SR 669.

Humphrey, D.N., P.A. Dunn, and P.S. Merfeld, (2000). "Tire shred save money for Maine", TR News. Issue. 206, pp. 42-44.

Humphery, D.N., (1996). "Investigation of exothermic reaction in tire shred fill located on SR 100 in Ilwaco, Washington", Fedral Highway Administration Washington, D.C. 
Humphery, D.N., and W.P. Manion, (1992). "Properties of tire chips for lightweight fill.", Proceedings of the Conference on Grouting, Soil Improvement, and Geosynthetics, ASCE, New Orleans, Louisiana, Vol-2, pp. 1344-1355.

Humphery, D.N., T.C. Sandford, M.M. Cribbs, and W.P. Manion, (1993). "Shear strength and compressibility of tire chips for use as retaining wall backfill", Transportation Research Record 1422, Transportation Research Board, Washington, D.C.

Humphrey, D.N. and R.A. Eaton, (1993). "Tire chips as subgrade insulation", Proceedings of Recovery and Effective Reuse of Discarded Materials and By-Products for Construction of Highway Facilities. Federal Highway Administration, Denver, Colorado, pp. 555-568.

Humphrey, D.N. and T.C. Sandford, (1993). "Tire chips as lightweight subgrade fill and retaining wall backfill", Proceedings of the Symposium on Recovery and Effective Reuse of Discarded Materials and By-Products for Construction of Highway Facilities, Federal Highway Administration, Washington, DC, pp. 5-87 to 5-99.

Humphrey, D.N., T.C. Sandford, M.M. Cribbs, H. Gharegrat, and W.P. Manion, (1992). "Tire chips as lightweight backfill for retaining walls - Phase I. a study for the new england transportation consortium", Department of Civil Engineering, University of Maine, Orono, ME.

Indraratna, B., L. S. S.Wijewardena, and A. S. Balasubramanium, (1993). "Large-scale triaxial testing of greywacke rockfill", Geotechnique, 43 (1), pp. 37-51.

Kaya, A., (1992). "Potential Use of tire rubber and ebonite in asphalt", Report FHWA/IN/JHRP-92/14, Indiana Department of Transportation.

Khan, R.A., and A. Shalaby, (2002). "Performance of a road base constructed with shredded rubber tires", Proceeding of Annual Conference of the Canadian Society for Civil Engineering, Montreal, Quebec, Canada, June 5-8.

Koerner, R. M., (1998). "Design with geosynthetics", 4th edition, Prentice Hall, New Jersey.

Lade, P.V., C.D. Liggio, and J.A. Yamamuro, (1998). "Effects of non-plastic fines on minimum and maximum void ratios of sand", Geotechnical Testing Journal, ASTM, Vol. 21, No. 4, pp. 336-347.

Lawrence B.K., L.H. Chen, and D.N. Humphrey, (1998), "Use of tire chip/soil mixtures to limit frost heave and pavement damage of paved roads", Department of Civil and Environmental Engineering, University of Maine, Orono, Maine. 
Lee, J. H., R. Salgado, A. Bernal, and C. W. Lovell, (1999), "Shredded tires and rubbersand as lightweight backfill", Journal of Geotechnical and Geoenvironmental Engineering, ASCE, 125(2), pp. 132-141.

Liu, H.S., J. L. Mead, and R. G. Stacer, (2000), "Environmental effects of recycled rubber in light-fill applications", Rubber Chemistry and Technology, American Chemical Society., Vol. 73, pp.551-564.

Marachi, N. D., C. K. Chan, and H. B. Seed, (1972). "Evaluation of properties of rockfill materials", Journal of Soil Mechanics and Foundation Engineering, ASCE, SM 1, pp. 95114.

Masad, E., R. Taha, C. Ho, and T. Papagiannakis, (1996), "Engineering properties of tire/soil mixtures as a lightweight fill material", Geotechnical Testing Journal, Vol.19, No.3, pp. 297-304.

Minnesota Pollution Control Agency, (1990). "Report on the environmental study of the use of shredded waste tires for roadway sub-grade support", Waste Tire Management Unit, Site Response Section, Groundwater and Solid Waste Division.

Moo-Young, H., C. Ochola, D. Zeroka, K. Sellassie, G. Sabnis, C. Glass, and O. Thornton, (2001). "Guidance document for scrap tire utilization in embankments", Report PTI2002/08, Pennsylvania Department of Transportation.

O'Shaughnessy, V. and V.K. Garga, (2000). "Tire reinforced earthfill. Part 3: Environmental assessment", Canadian Geotechnical Journal, Vol. 37, pp 117-131.

Reddy, K.R. and A. Marella, (2001), "Properties of different size scrap tire shred: implications on using as drainage material in landfill cover systems", Seventh International Conference on Soils Waste Technology and Management, Philadelphia, PA.

Rubber Manufacturers Association, (2006), "Scrap Tire Markets in the United States", Washington DC.

Shred-tech, (2006). "Shredding operation", Retrieved January 1, 2006 from the World Wide Web: http://www.shred-tech.com.

Shukla, S.K. and Y. Jian-Hua, (2007). "Fundamentals of geosynthetic engineering", Taylor and Francis Publisher.

Tatlisoz, N., T.B. Edil, and C.H. Benson, (1998). "Interaction between reinforcing geosynthetics and soil-tire chip mixtures". Journal of Geotechnical and Geoenvironmental Engineering, Vol. 124, No. 11, pp 1109-1119, ASCE. 
Tweedie, J.J., D.N.Humphrey, and T.C.Sandford, (1998). "Full scale field trials of tire shreds as lightweight retaining wall backfill, at-rest condition", Transportation Research Board, Washington, D.C., Issue. 1619, pp.64-71.

Vashisth, P., K.W. Lee, and R.M Wright, (1998). "Assessment of water pollutants from asphalt pavement containing recycled rubber in Rhode Island, Environmental and social effects of transportation", Transportation Research Record, Nol.1626, pp.95-104.

Westerberg, B. and J. Màcsik, (2001). "Geotechnical and environmental properties of tyre shreds in civil engineering applications: Recycling and reuse of tyres", London, Thomas Telford.

Woodward, P.K., and J. Blewett, (1998). "Observations on the direct shear strength of a sand-rubber mixture for use as a lightweight fill material”, Ground Engineering, pp. 3640 .

Wu, W., C. Benda, and R. Cauley, (1997). "Triaxial determination of shear strength of tire chips", Journal of Geotechnical and Geoenvironmental Engineering, ASCE, Vol.123, No.5, pp.479-482.

Yang, S., R. A. Lohnes, and B. H. Kjartanson, (2002). "Mechanical properties of shredded tires", Geotechnical Testing Journal, Vol. 25, No .1, pp. 44-52.

Youwai, S., (2003). "Strength and deformation characteristics of reinforced rubber tire chip with and without sand mixtures and the numerical simulation of reinforced wall, $\mathrm{PhD}$ Thesis.

Youwai, S. and D.T. Bergado, (2003). "Strength and deformation characteristics of shredded rubber tire-sand mixtures", Canadian Geotechnical Journal, 40, pp. 254-264.

Zimmerman, P.S., (1997). "Compressibility, hydraulic conductivity, and soil infiltration testing of tire shreds and field testing of a shredded tire horizontal drain", M.S. Thesis, Iowa State University, Ames, Iowa.

Zevgolis, I ., (2007). "Numerical and probabilistic analysis of reinforced soil structures", $\mathrm{PhD}$ Thesis, Purdue University.

Zornberg, J. G., A. R. Cabral, and C. Viratjandr, (2004). "Behavior of tire shred-sand mixtures", Canadian Geotechnical Journal, Vol. 41, pp. 227-241. 